


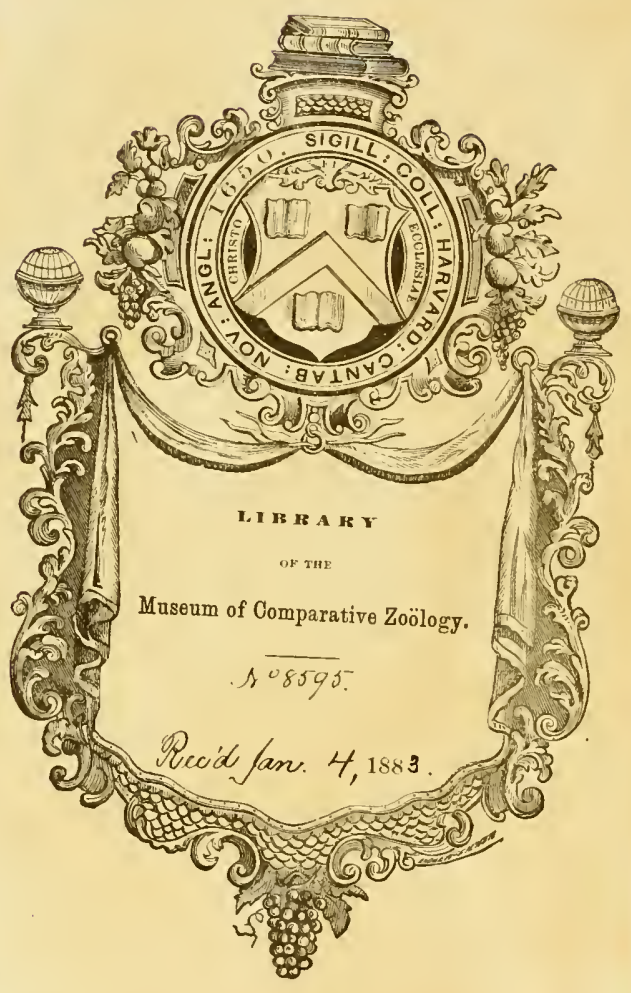




TH I:

\title{
POWERS OF THE OREATOR
}

\section{DISPLAYED IN THE CREATION:}

\author{
( $\mathbf{R}$, \\ OBSERVATIONS ON IIFE AMIDST THE VARIOUS FORUS \\ OF THE
}

HUMBLER TRIBES OF ANIMATFD NATURE:

WITII

PRACTICAI CONMENTS AND ILLUSTRATIONS.

BY

SIR JOHN GRAHAM DAIIELL, KNIGHT ANI BARONET.

IN TWO VOLUMES,

CONTAINING

YCMEROUS PLATES OF LIVINS SUBJECTS, FINEJY COLOURED.

V OLU ME I.

COMPEEHENDING SEVENTY PLATES.

$\therefore$ LON DON:

JOHN VAN VOORST, PATERNOSTER ROW.

sim M.D.CCCLI. 



\section{CONTENTS}

OF

VOLUME FIRST.

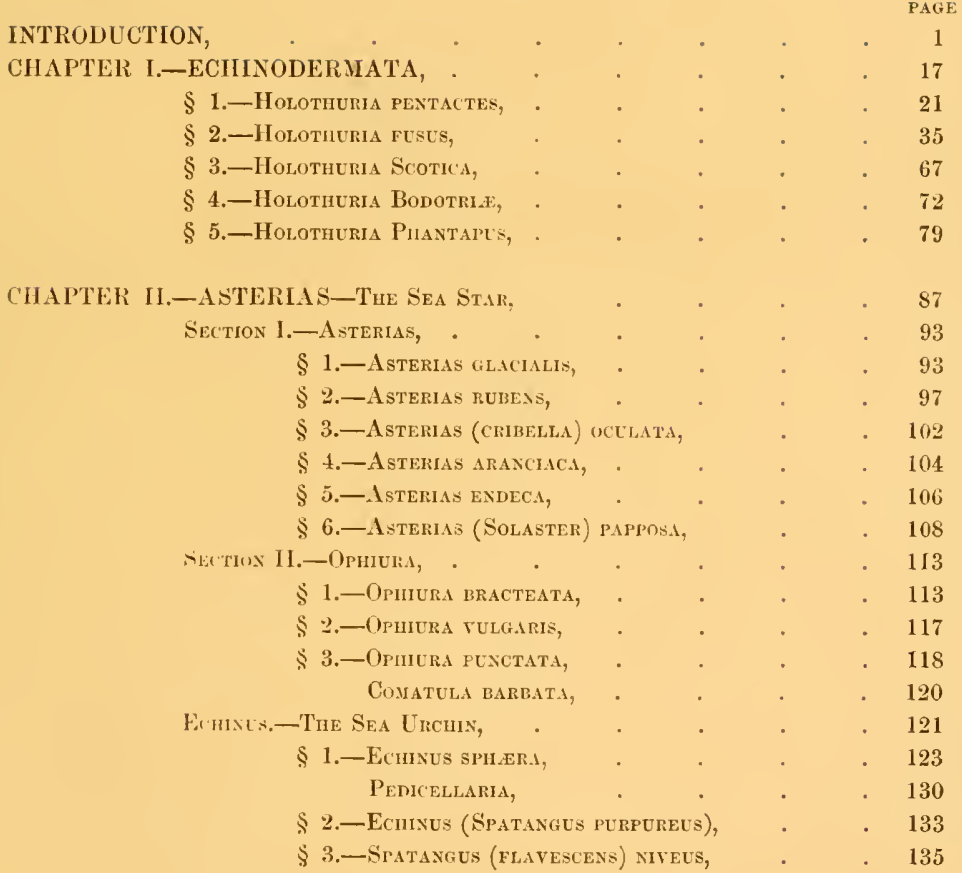


CHAPTER III.-CRUSTACEANS, . . . . . . . PAGE 139

Part I.-A.-Decapodes, Ten-limben, Short-talled, C'rabs.Brachyuri, . . . . 150

$\$$ 1.-Cancer Menas, - the Shore or Harbour Crab, 150

$\$ 2$-Cancer pagurus, - the Common (Edible) Crab, 167

\$ 3.-Cancer (Pontunus) lividus, - the Flying Crab, 178

\$ 4.-Cancer (Portunus) pusillus,-the Sand Crab, 183

\$ 5.-Cancer (PINNotheres) veterum, . . 189.

B.-Decapodes, Ten-footed Brachyuri, * 191

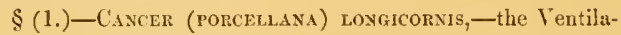
ting Crab, . . . . . 191

$\$$ (2.)-Cincer (porcellana) platycheles, - the Roughfooted Crab, . . . . 193

C.-Cancer (corystes) Cassivelaunus, . . 193

D.-1. Cancer (inachus) Dursettensis, . . 194

D.-2. Hyas ARANEU, . . . . . 195

D.-3. Cancer (hyas) coarctatus, . . . . 196

§ (4.)-Cancer phalaxgiuj, Macrapodia phalangici, 198

$\$$ (5.)-Cancen horridis, Maia lithodes,-the Priekly Crab, . . . . . 201

Part II.-A.-Decapodes, Ten-limbed, Long-talled CrustaCEANs,-Macrouri, . . . . 202

\$ 1.-Caxcer Bernilardus, - the Hermit Crab, or Soldier, 203 \$2.-Galatuea spinigera, - the Thomy Bastard Lobster, 207 B.-Decapoñes, Ten-limbed, Long-tailed Crustaceans, Macrouri,-Astacus, THE Lobster, . . 211

\$ 1.-Astacus Norvegicus,-the Norwegian Lohster, 211

\$2.-Astacus Marinus, - the Common Lobster, . 215

\$3.-Crangon, - the Shrimp, . . . 217

$\$$ 4.-Pandalus annulicornis, - the Ring-horn Shrimp, 220

CHAPTER IV.-MISCELLANEOUS CRUSTACEANS, . • . 222

\$1.-Cancerilla tubulata, . . . . . . 223

\$2.-Astaricllla, . . . . . . . 224

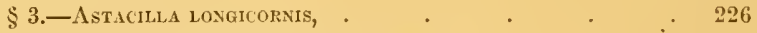

$\$$ 1.-Oniscus balthicus (IDeotea Marina), . . . 228

\$ 5.-Oxiscls (IDFoteA) ENTOMON, . . . . 229

$\$ 6 .-A$ sellus Medus.e, . . . . . 230

B.-Asellus Meduse, . . . . . 232

C.-Crclops stagnorum, . . . $\quad 232$

D.-Crclops punctatus, . . . . 233

E.-Crclops fasciatus, . . . . 234 
CHAPTER IV.-MISCELLANEOUS CRUSTACEANS.-'ontinued. PATi

\$ 7.-NYMPHON GRACILIs, . . . . . . 234

\$ 8.-Prciogonum LitToRale, - the Whale Louse, . . 236

\$ 9.-A Sellets velgaris, . . . . . 237

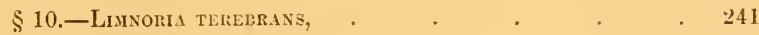

$\$ 11$. Cypris Pilosa, . . . . . . . 244 Ctrris Fortinexsis, . . . . . 245

(IIAPTER V.-PARASITES, . . . . . . 246

\$1.-Caligus curtus, . . . . . . . . . 216

\$2.-Caligus Salmonis, . . . . . . 249

§3.-Caligus, . . . . . . . . 250

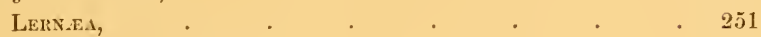

Lernata branchlalis, . . . . . . 251

\$4.-Botryllofer, . . . . . . 252

\$5.-Pegasillus hinsutus, . . . . . . 253

CIYAPTER VI-THE HYDRACINA, OR WATER SPIDER, . . 254

Cosclusion, . . . . . . . 266 

TO THE BINDER.

The Binder will place the Plates thus :-

plate I. Holothuria Pentactes, to front . . . . Page 18

b. II. Ilolothuria Pentactes, . . . . . . 20

r III. Holothuria Pentactes, laid open, . . . . 26

IV. Holothuria Pentactes, laid open, . . . . . 28

V. Holothuria Pentactes, Intestinal Organs, _ . . . 30

VI. IIolothuria Pentactes, Respiratory Organs, . . . . . 32

v VII. Holothuria Pentactes, Ovarium, . . . . 36

VIII. Holothuria Fusus, . . . . . . . 40

+ IX. Holothuria Fusus, . . . . . . 42

X. Holothuria Fusus, . . . . . . . 44

XI. Holothuria Fusus, . . . . . . 52

XII. Holothuria, . . . . . . 68

XIII. ILolothuria, . . . . . . 72

XIV. Holothuria lodotriæ, . . . . . . . 78

XV. Ilolothuria Phantapus, . . . . . . . 86

XVI. Asterias Glacialis, . . . . . . . 94

XVII. Asterias Rubens, $\quad$. $\quad$. $\quad$. $\quad$. $\quad$. $\quad . \quad 96$

XVIII. Asterias Rubens, . . . . . . . . 95

XIX. Asterias Rubens, . . . . . . 100

XX. Asterias (Cribella) Oculata, . . . . . $1(12$

XXI. Asterias Aranciaca, . . . . . . 104

XXII. Asterias Endeca, . . . . . . . 106

XXIII. Asterias Endeca. . . . . . 108

XXIV. Asterias (Solaster) Papposa, . . . . . 110

XXV. Asterias (Solaster) Papposa, under surface, . . . . 112

XXVI. Asterias (Solaster) Papposa, . . . . . 114

XXVII. Ophiura Bracteata, . . . . . . 116

XXVIII. Ophiura Vulgaris, . . . . . . . . 118

XXIX. Ophiura Punctata, . . . . . . 120

XXX. Comatula Barbata, . . . . . . 122

XXXI, Echinus, . . . . . . . 124

XXXII. Eehinus, . . . . . . . . 130

XXXIII. Spatangus, . . . . . . . . 134 
Plate XXXIV. Cancer Mænas, . . . . . Page 150

XXXV. Caneer Mænas, . . . . . . 152

XXXVI. Cancer Mrnas, . . . . . . 160

XXXVII. Cancer Mænas, . . . . . . 164

XXXVIII. Cancer Pagurus, Common Crab, . • . . 166

XXXIX. Cancer Pagurus, Common Crab, . . . . 168

XI. Cancer Pagurus, $\quad . \quad$. $\quad$. $\quad . \quad$. $\quad$. 721

XLI. Caneer Pagurus, Common Crab, . . . . 176

XLII. Cancer (Portunus) Lividus, . . . . . 178

XLIII. Cancer (Portunus) Pusillus, . . . . 182

XLIV. Cancer Inachus, . . . . . . 186

XLV. Cancer Porcellana, . . . . . $\quad 190$

XLVI. Caucer, $\quad . \quad$. $\quad$. $\quad$. $\quad . \quad$. 192

XLVII. Hyas Araneus, . . . . . . 194

XLVIII. Hyas Araneus, . . . . . . . 196

XLIX, Hyas Coarctatus, . . . . . 198

L. Cancer Phalangium, . . . . . 200

LI. Cancer Horridus, Prickly Crab, . . . . 202

LII. Cancer Horridus, Prickly Crab, . . . . 204

LIII. Cancer Bernhardus, Hermit Crab, . . . 206

LIV. Cancer Bernhardus, . . . . . . 208

LV. Galathea Spinigera, . . . . . 210

LVI. Astacus Norvegicus, . . . . . . 212

LVII. Astacus Norvegicus, . . . . . 214

LVIII. Astacus Marinus, . . . . . . 216

LIX. Astacus Marinus, . . . . . 218

LX. Crangon, the Shrimp, . . . . . 220

LXI. Pandalus Annulicornis, . . . . . 222

LXII. Miscellaneous Crustaceans, . . . . . 224

LXIII. Astacilla Longicornis, . . . . . 230

LXIV. Nymphon Gracilis, . . . . . . . 234

LXV. A sellus Vulgaris, . . . . . 236

LXVI. Caligus Curtus, . . . . . . 246

LXVII. Parasites, . . . . . . 248

LXVIII. Hydrachna, . . . . . . . 254

LXIX. Hydrachna, . . . . . . 258

LXX. Miscellaneous Crustaceans,-Supplemental, . . . 264 


\section{INTRODUCTION.}

BEFORE proceeding to discuss the subjects whereof these Volumes treat in detail, let me cursorily glance at the circumstances of this sublunary sphere appointed for the abode of mankind. My remarks are designed for the literary and illiterate, alike,-for the pions, the moralist, and the indifferent. They aspire no higher than worldly considerations of the weak, nor aim at judging of the precise injunctions or explicit declarations of the Divine Will. They originate only from contemplating the fair face of Nature.

The opinions of men unbiassed by prejudice, of those who think justly, will roll in the same chammel, and arrive at nearly the same conclusions. Sustained on a firm basis, they will rivet truth, the final purpose of all argument.

If the records of history, as delivered from remote antiquity, be not called in to support the evidence of the Dirine Author in his works, it is not from depreciating their authority, but from the facility of referring to immediate and patent proof, afforded by the wonderful objects displayed every moment before us.

In surveying the vast and magnificent frame of the Universe, the mind is absorbed by admiration. That which bears the impress of the mighty seal of Omuipotent Power, by its magnitude bewilders the reasoning faculties devoted to our lower and humbler condition. It elevates our reflections to heaven.

The origin and the source of the smallest portion of the universe orerpowers our comprehension. How little can the acutest senses, the 
profoundest judgment, the widest view, embrace? It is as nothing ; it is as less than nothing. We are capable of doing no more than surveying the edifice and adoring the Architect.

We behold the superficies only.

But all is in harmonious arrangement, evidently the offspring of a Creative Power, exercised at an epoch which has vanished in eternity: yet devised for preserving perpetual order inviolate, and renewed incessantly in remembrance by images of the original truth.

It has pleaser the Great Creator to combine the gross and brutish matter of the world with the refined ethereal principle of animal life. By their union, the grandeur of his plans is discovered, and by their presence in ourselves, like a secret inspiration, they awaken the consciousness of its excellence. Were the two elements separate, we should be incapable of pronouncing on the power, the influence, and effect of each. Their indefinable incorporation in our own persons renders us sentient beings, and capable of surveying the surrounding scenes, as well as of reverting, by retrospective conjecture, to the incidents of the Creation.

It must be, nevertheless, a most imperfect view : for, how vast a proportion of the animated world remains concealed from the inquisitive eyes of mankind ; something by distance, something by tenuity, something by interception, or by the mere imperfection of our personal organs.

A multitude of questions and doubts at once obtrude themselves on the mind, apparently reasonable as the suggestions of truth, whereof there seem no data for solution. We, the humble tenants of the earth, may presume to speculate on that which is known to the Omnipotent alone, whose intelligence we see has been directed solely to beneficial purposes.

All in the beginning is hidden,- - profound,-mysterious, - an abyss unfathomable.

When did the Creator reduce to symmetry the chaotic mass, that amidst which the earth was "without form and void,"-and darkness hung over the deep; when was it first illuminated by the glorious orbs of the firmament: at what part of its progress, what was its condition, at what epoch of time was the form of man summoned into being, and inspirited by the breath of life? 
Was the ethereal principle originally infused while the matter receiving it lay in an embryonic state, and thereby awakened to life, or was it the substance of the adult that the spirit first animated?

If conjecture may be permitted-it is but conjecture-the earth was not then in its earliest condition : it was in some advance. Man enjoyed his fullest powers and faculties : the soil yielded its produce; its fruits grew spontaneously. Man, an adult, could discharge his functions, converting what surrounded him to satisfy his own exigencies.

But, although reaping the means of subsistence, he could not know the arts. Naked and unprotected, he could only occupy his place among the other tenants of the earth, doubtless of cotemporary existence.

Unless secured by distance, he may have had to contend with some of those monsters which became extinct before the opening of the record of history, and which have been revealed to modern generations as the relics of a former worll.

The extirpation of the largest and most imposing of Nature's creatures is thus established. Many among the whole subjects of creation have ceased to exist for ages; myriads seem to have been involved in one common ruin, never to be revived again ; and numbers have perished in detail.

Neither presumption nor fact has afforded a relevant inference of more creations than one, or that the total animal workl was not framed at once, or at least so as to be co-existent. Nothing has hitherto shewn, as some maintain, that successive creations followed at different long intervals after the first; or that others arose and may yet be formed from unknown materials down to the present day.

If it does appear that the entire host of creatures occupying the universe was never recognised as cotemporary, this may be truth ; for that secret property which involves the living principle may lie dormant for ages, but when aroused shall be ushered into the world, combined with matter in sensible form and substance.

Thus many animals, whose existence no annalist has recorded, may be actually brought into notice, and supposed of later creation. The extent of modern research, especially among the waters, and amidst remote 
territories of the earth, has rendered some, which were previously unknown, familiar to the moderns.

Yet we are compelled to reject the theory of successive creations as an unsound doctrine-resulting merely from imagination-unsupported by evidence.

The cotemporary origin of mind and matter is a question infinitely more abstruse.

We camnot pretend to enquire whether after first conception of each of the vast variety of the animal frame, any or all individually received additions or improvements; to say they did not would be to limit the divine intelligence. Neither can we conjecture whether they were preceded by any model of their form.

Though rejecting the theory of some recent philosophers, that if animals laboured under inconvenience from positive deficiency of members, the plastic powers of Nature would shoot forth still one or another, or a second pair, some modification of the creative faculty was perhaps exercised. A multitude of similar organs might be actually augmented, reduced, or improved in the species, as the necessities and the benefit of the genus required.

It is true, that if an animal with numerous feet be mutilated of a portion of them, another portion will originate to supply the loss, and hence, from superficial views, the theory has arose. But it is alike true, that if many animals, entirely deficient of extemal organs, undergo mutilations, reproductive energies will restore the defective body though unfurnished with limbs.

Nothing can be more vague and imperfect than our ideas of the incidents of the creation, for all our reasoning must be bounded by the narrowest circle; therefore resolving into simple conjectures regarding a subject too intricate and obscure to be compassed by the highest faculties of mortals.

That Nature does undergo some temporary or permanent modifications is undoubted, though to what extent is unknown. If animals and vegetables were from the first adapted for special climates, and if living beings required sustentation to support life, it is beyond human compre- 
hension how the whole products of the universe could be brought to maturity at the same season, or concentrated in the same spot.

Their nature may be now infinitely modified.

If all the animated subjects of the creation were framed as now existing of perishable matter, their durability was mere transience compared with the lasting endurance of time. If resembling those wherewith the earth, the air, and the waters are now replete, can we presume them exempt from the ravages of disease, decay, and death. Therefore, the whole being liable to sudden extirpation, might have left a frightful roid, to be replenished only by a new creation.

But now did the Supreme Intelligence devise a marvellous expedient to counteract the blight, and avert desolation. Animals were empowered to reproduce themselves, to restore their own similitude in the production of progeny. By this meaus is generation transmitted through gener:tion, and at the latest moment the images of what existed at the date of their creation are offered to our view.

The regularity and simplicity wherehy the world is in this mamner carried on, forms an impressive feature of the grandeur of the whole lesign, though the minutix of such reproduction be still wrapped in mystery.

By the general laws governing the perpetuation of living beings, each is ordained to spring from two parents. But to this there are wide and extrardinary exceptions. Frequently the progeny is derived from only one, whereby it is murtured through a previous state of imperfection until ushered into the world. Sometimes a portion of the single parent separates spontaneously as a shapeless mass, which is slowly refined into symmetrical form, with the development of all the organic structure required for its exigencies, and necessary to present a perfect image of the parent.

The vegetable kingdom is multiplied through the medium of seeds, and buds, or shoots, wherein appears a striking analogy to the processes beheld in the multiplication of animals.

Fleshy buds germinate from the surface of some of the humbler creatures, either dropping off at a certain stage of their progress, or 
ripening in their site to perfection, in resemblance of the parent, and remaining as a permanent addition to the common stock.

In as far as human observation extends, almost every living being is propagated through a principle originating in the substance of the parent, whether as incorporated with its body, or preserved in a detached form. Herein is the germ sustained by a pabulum generated along with it under the same integument ; and it is nurtured until adapted for separation, by growing strength and increasing dimensions.

For the most part, both the ovum and the young are discharged from the parent ; the former to bring its contents into existence, the latter to reach that maturity essential for its well-being in an independent state.

But both the internal and the external ova of certain creatures are ripened until ready to burst the integument, when they give birth to the young while still included in the body of the parent, or affixed to it ; and the young hydra remains attached to the parent, while some still younger generate from its skin, or from that of its descendants, if early separation do not ensue.

No proper parallel ean be drawn between the fertility of some tribes, compared with the sterility of others. Thousands of ova, or a multitude of young attain nuaturity, and are produced almost at the same moment by fertile animals : in those which are less so, the progress of the ovum is slow and gradual, oceupying a long time, and if several, only a single one is produced at once, after considerable intervals.

Where confined in a transparent integument, nothing ean be more interesting to the contemplative than the progress of the embryo. At first invisible, next the merest speck, then the development of originating parts, the current of the vital fluid carrying vigour to the extremities, and the motion of the members, all as life is awakened.

The ovum of most of the larger animated tribes is invested by a hard ealcareous shell, sometimes eapable of resisting great force and pressure. In many of the smaller tribes it is readily crushed, and the contents annihilated, being contained only in a flexible skin or capsule.

Among the larger and more perfect creatures, their race is carried 
on by a single individual or few at a birth, and the ovum contains but a single foetus. Among the more perfect animals also, almost every brood of certain species consists of several young. But among the lower tribes are many, each of whose ova contain several embryos, each of these wrapped in its own integument.

If the race of some of the larger animals be perpetuated by the production of a single individual, it will appear a disproportioned multiplication that the families of some of the smaller tribes amount to a brood of perhaps twenty thousand, originating in the same litter.

It would be erroneous to conclude, however, that the number of young augments in proportion to the diminished size of the parent; such peculiarities there are no means of explaining. We must content ourselves with saying, " they belong to the race," just as certain animals are solitary, while others are gregarious, or dwell in society.

The distribution of life amidst the varied multitude of forms enjoying it, so unlike each other in shape or disposition, and existing under such an infinity of circumstances, yet all concurring to the same end, evinces Omnipotent Power diffused throughout the creation.

It is not in their origin only, in their symmetry and perfection, that they ought to be viewed. We have also to consider of organic bodies, when distorted and impaired of the parts once pertaining to them, how they can be recovered.

A shapless fragment violently reft from an entire creature, or from one about to perish irretrievably, may become perfect by subsequent development of the deficient parts.

This, which we now prize as a reproductive faculty, is in no respect under the control of the living being capable of producing its own likeness, or of its abstracted portion, but results from a vis insita, preserving the existence, and promoting the growth of living matter. It is not confined to one portion, but may extend over many ; and it may ensue even in relation to the regenerated portions more than once.

Nevertheless, the faculty gradually weakens, so that in general every successive regeneration is smaller or more imperfect than the organization preceding it ; and at length it is exhausted. 
Thus, it is probable, that a previous diffusion of elementary germs promotes the successive regenerations; that their development ensues in perfecting the new portion, rather than in the depositation of new matter from the old, to be modified into form.

The history of the Polypus, and the reproductions of the Actinia, together with those of some of the limacine tribes, have been long familiar. Several, perhaps most of the purely vermicular race, may be cut in twenty portions with impunity, and many subdivide spontaneously, while each becomes perfect by acquiring the defective organization. These facts are an impediment to ascertaining the real dimensions of the parent subjects. They render them questionable.

Regeneration downwards is obviously more readily effected than the restoration of defective parts upwards. New development speedily follows mutilation towards the lower extremity.

In the violent or spontaneous division of animals, wherein reproduction is most vigorons, it ensues both downwards from the principal portion of the original, if unequally made, and it generates from the sundered portion upwards.

The generation of eotemporary supernumerary parts may be obtained by sundering a fragment from the posterior extremity of the Amphitrite ventilalrum. A beautiful and complex branchial plume is generated upwards, while the original branchial phume continues in full vigour. Both fulfil their specific purposes. If it camnot be affirmed that a germ is newly formed by new depositation of elementary matter, it may be conjectured that all the rudiments of the regenerated portion pre-existed separation of the original animal's body.

All animated beings seem to undergo a certain metamorphosis between the date of their early origin, and their attaiument of perfection. Some are passing through it while still conneeted with the parent; in others the changes advance long afterwards.

It is not obvious whether any kind of metamorphosis enters the simple development of animals as they enlarge in natural growth, or in the regeneration of their defective parts. While in progressive adrances to perfection, metamorphosis, as present to the eye, consists in 
the suecessive evolution of new parts, and the partial or total obliteration of the old ones. Monstrosities, or rather their semblance, must be therefore generated, which are rectified in symmetry through the progress to maturity.

During this transition, some of a wonderful description suceed. An animated being springs from a known parent, to which it does not bear the slightest resemblance either in form or habits. While the latter remains stationary, immoveably affixed, or permanently adhering to the same spot, its progeny enjoys unbounded activity ; it never rests. None. of the organs it possesses are to be discovered in the parent; its food is different, or it is not known to feed ; its form, its habits, its whole mode of existence are foreign to those of the author of its being. Void of evidence of the fact, we are prone to deny their kindred. But gradual modification of all peeuliarities begins to render them less unlike, and at length the new animal is identified with the aspeet of the old.

The form of some creatures being pesfected, all the parts remain soft and compressible. The body also undergoes great reduetion of size, more conspieuous in the different organs altemately, than as affecting its whole structure. An incredible portion of the entire animal is occupied by tubes, by pouches, and cavities, which, replenished by imbibition, or absorption greatly enlarges its size. It is thus that the beautiful and active tentacula, and perhaps also the branchia, are swollen. Their contents being discharged, little remains of the admirable form but an empty skin.

It may be readily comprehended how in states, stages, and circumstances so very different, the organs of sense, sensation, and perception, must be moulded to the creature's exigeneies in each : and herein is the benignity of Omnipotence displayed. The refining animal is suffering no injury; it reaches perfection in possession of what is important for its preservation.

Nevertheless we still remain profoundly ignorant of the real number, power, and nature of the senses belonging to most of the inferior tribes, whether dwelling in air or in water. Neither can we positively affirm that 
any one sense is common to the whole, unless it be feeling, and touch, or taste, which is a kind of feeling. Observers have assigmed a variety of offices to the antennæ where they are present. Though freely employed, it is not evident that they discharge any known function which is familiar to us. The faculty of vision, the senses of hearing and smelling are still more vague and indefinite, we have little satisfactory means of ascertaining some of them. The tremor imparted to the medium of communication may readily induce erroneous conclusions. Some of the senses, also, seem entirely wanting in a multitude of the lower animals, and in numbers they are most obtuse and defective : they are apparently of least avail when the greatest acuteness might have been expected.

But such defieiencies are probably compensated by instinct, or that quality where, by a kind of natural intuition, animals without experience enjoy a reasoning faculty, enabling them to determine on utilities to themselves or their progeny.

This singular property, lowest and latest seen in the human species, is often demonstrated by the humbler tribes to an admirable extent. It is always most prominent in the pursuit of food and shelter, and in preparing for the benefit of the young, when its exercise both preedes their existence and watehes over their imbecility.

What is it that teaches the bee to found the original cell of the honey-comb, or the Amphitrite to eommenee that tube which shall afford it perpetual shelter ; the spider to construct its web ; or a thousand others to prepare for necessities or for safety.

liut there are some things which are unintelligible, and to us weak mortals seemingly inconsistent with the benignity of Providence.

Myriads of the young produced never reach any stage of maturity ; they are abandoned to their fate by the parent from the moment of birth. Thousands of animals, some the most valuable, appear to be ereated only that they may become the prey of others. A war of extermination is incessantly raging among the living world. Legions have vanished from the surface of the earth, leaving no type behind them, nor aught, unless some seattered relics, which may have lain undisturbed for thonsands of years. 
All animated matter has a tendency and a desire for self-preservation. But all living beings are liable to perish from disease or from accident.

Pestilence is borne on the winds and on the waters.

Judging from the animals themselves, they offer no sufficient data enabling us to conjecture the duration of life.

Though denied to entire genera, longevity may be granted to individuals. Among the lower orders, life is assuredly longer than usually allotted to them by mankind.

Several noted examples might be given. Of two Actiniae, one survived twenty-two years in my possession, during which time it produced above 300 young. The aspect of the other underwent an important change, for the first time, during the fifteenth and sixtenth years of its life in captivity. Neither of them could be less than thirty years old at the period of these observations. Likewise the inhabitant of a minute shell had survived nearly nine years, when it was destroyed by another animal accidentally brought to its vicinity.

Were not decay and death essential elements in the constitution of the universe, it would plainly be rendered inadequate for the reception of its multiplying inhabitants.

Thus there is a continual waste and a constant replenishment.

A suspension of the active and passive animal faculties, and of conscious existence, ensues in sleep, and especially from that kind of it denominated torpidity.

The sleep of plants bears some analogy to the insensibility betrayed by animals.

Another kind of suspended animation, protracted even for years, was discovered a considerable time ago, by a distinguished Italian naturalist : and an eminent French physiologist has recently revived the subject by a learned treatise on the species of an entire genus endowed with this remarkable property. Specimens removed from their native abode, and allowed to dry, become motionless and insensible, and so they may remain without extinction of life, until revived by humectation, after the lapse of years.

Humidity seems indispensable for demonstrations of the vital prin- 
ciple. It encourages the germination of plants, preserves and also revives many vegetable products.

A species of Tremella, of a fine yellow colour, may be found vegetating as a parasite on the ligneous parts of common furze, towards the middle of autumn, especially in damp seasons. Then it is beantiful, plump, smooth, and vigorous. But, when removed from its proper sphere, it dries and shrivels up to the smallest dimensions.

Long ago I selected many specimens. They dried and shrivelled up, and so remained during weeks and months, until humeetation restored their vigour.

In prosecuting a course of observations, I selected and laid aside some of the best and largest, besides the precerling, which, like them, beeame equally dry and shrivelled. They were preserved with much care untouched, until forty years had been allowed to elapse, when I moistened them again. Although they did not acquire their pristine size and vigour, their enlargement was such as to shew that the vital principle belonging to the mature of vegetables, still subsisted throughout that long interval.

Well authenticated narratives prove the preservation of the germinating faculty of vegetable seeds for ages.

It appears to the learned, that the frame of the larger and more important animals of the higher orlers, has been constructed after nearly the same model. Some of no mean attainments, have also argued that a continuous chain connects living nature, whereby each distinct genus passes through the slightest variation into one preceding or following it.

It may be that the discharge of the vital functions requires the presence of similar organs throughout all animals, though they cannot be recognized independently : and if ever a chain of beings was designed at the creation, it may be now interrupted by the links broken from the lapse of time.

The peculiar distribution of life amidst the multiplied forms ocenpying the universe, is a subject for profound reflection, conld it be rendered intelligible in words.

The disposition of the tribe, which is animated, seems to be modi- 
fied by its form. Hence, while one race of aninals revels in blood and slaughter, another knows only peace and trancuillity.

Some are ingenions architects from their origin. Having founded a dwelling, they never cease enlarging it for their own accommodation, wherein they employ the numerous organs incident to their form. The architectural disposition of others is exercised only for behoof of their young, when the employment of the organs peculiar to their form censing, it is resumed with an approaching brood in a succeeding year.

It is thus appointed in regular order, by the Power which dictated the laws for preserving the Creation.

No external indications are presented, wherehy the disposition of living creatures is to be at once detected. Our knowledge of it must be gathered from time and experience.

We find the natural propensities unequally bestowed, and irregularly exereised. What we believe a structure denoting refined skill, may proceed, on investigation, from natural causes, as when a tubular dwelling, fashioned by its tenant, forms the most regular cylinder, though resulting simply from the necessary revolution of the animal while adding to its dimensions.

Perhaps we incline to assign too much to the sagacity of amimals, and we are more surprised than we ought to be at some of their actions. But if reasoning is dependent on comparison, many animals certainly enjoy that fuculty to a certain extent, notwithstanding such a privilege be most unwillingly adnitted by mankind.

Whatever be the condition of a living creature, whether dwelling in the air or in the waters, or in the flesh of others; whether its organs appear defective or redundant, the power of the Creator has alapted its circumstances for its place in the creation.

Overpassing many grand, many wonderful, many sublime arrangements, which can have had no other source than the Will of Onnipotence,- that which first bade the lightnings flash and the thunders roll,nothing from the highest to the lowest-from the greatest to the least.betrays disorder, or interrupts the harmonies of the Universe.

If such conclusions be justly deduced from contemplating merely 
the exterior of the animated and inanimate world, and if all must be necessarily ascribed to manifestations of a Divine Power, how shall we appreciate the various intricate natural processes incessantly advancing within that secret laboratory, forming part of the internal system of every living being.

The purity of the atmosphere would have been of no avail without the means of reaping its benefit by respiration. What utility could the profusion of food, or the organs for taking it, have afforded without its preparation for nutrition by ligestion? A vast and complex apparatus, physical, mechanical, chemical, all in active operation, has been devised for secretion, solution, combination, and assimilation, to strengthen every corporeal frame, and aid the preservation of life.

No human invention could either contrive or adapt the multiplicity of organs, and assign their respective functions, as directed singly or united, for the advantage of animated creation.

Such are the reflections on animated existence, immediately derived from contemplating the fair face of Nature, undisguised by guile.

Let them receive a fair, just, and candid interpretation, bearing only that weight to which they are entitled, as sustained on obvious facts and reasonable inferences.

Beyond this I have no particular theories to entertain. I make no pretensions to priority of observation : I advance no claim to discovery ; nor do I urge my opinions on the varions subjects treated of in these Volumes, otherwise than with the utmost diffidence. But I could multiply and embellish the numerous facts they contain so much farther, as perhaps to render them more impressive and satisfactory.

Sedulously interrogating Nature, we shall not be disappointed of responses.

The following ingredients may be useful to those who propose to prepare corrected views of the Systema Nature.

But I wish very earnestly to guard the intelligent reader from expecting a complete history of the living subjects presented before him. This would be an undertaking far surpassing my capacity ; indeed, I be- 
lieve, exceeding the capacity of any individual, for of many it is inconceivably obseure. The drawings and descriptions must compensate numerous omissions.

The former have been an object of especial solicitude. None but living subjects, and those in the highest health and vigour are represented, independently of the best specimens attainable having been uniformly selected. Whatever influence internal anatomy may have in fixing our ultimate arrangements, external configuration is undeniably the primary guide, and the basis of our primary judgment. In truth, it can admit of no substitute.

But, in accepting it, we must beware of allowing those trivial peeuliarities whereon less experienced naturalists repose their confidence, as constituting the eharacter of animals, which should be ever distinguished by the strongest features. If systematic arrangements govern the relative position of animals, they are framed in heaven, not on eartl.

Neither should the naturalist, impatient for the lisclosures of dissection, defeat the possibility of detecting habits from permanent obliteration, by the premature destruction of his specimen,- - to sily nothing of the cruelty of such an alternative.

The diffienlty of preserving correct and suitable delineations is frequently very great, and all artists have to undergo a certain peculiar education in qualifying themselves for their task. Figures are of little avail, unless they be both good and faithful representations of the original, and taken at the most propitions moment. I can truly affirm that only the best and most satisfactory have been almitted here.

Striking inequalities must prevail in the composition of such a work as this, from eauses too obvions to require ennmeration. Hence many imperfections.

But, on all oceasions, I have anxionsly studied brevity, and, in as firr as in my power, to render the subject explicit. 



\section{CH A P TER I.}

\section{ECH I NODERMATA.}

The peculiar object of the present treatise, is to render some of the natural productions of Scotland more familar to its inhabitants, and better understood than they have been hitherto.

Enthusiasm in favour of our native soil, and of our favourite pursuits, may kindle a glow which warms us into undue partiality for certain subjects,-above their true importance in literature and their value to mankind. We may thus rate them too highly, and dwell on them too long. If so, let us appeal to the liberal for indulgence of an innocent weakness.

But, to penetrate the history of ereatures so far removed from ourselves as the humbler tribes of the ereation, is an arduous task. Until the more recent investigations of science, few have adventured on it. Such living tenants of the globe have been scarcely acknowledged as the Divine works ; many were beheld with contempt, some with abhorrence, -all were neglected.

Yet the inquisitive stuctent of Nature is not to be discouraged in his ardent thirst for knowledge. What although he has to ascend rocks and mountains, to dip into cavities of the earth, or to explore the depths of the ocean, if he is rewarded by the fruits of research. It is the perishable condition of life he has more seriously to contend with. He must find a safe and salubrious abode for his objects; he must ascertain their proper sustenance, and avert their enemies. He must replace the loss he sustains by casualties, by accident, disease, and death ; thence multiplying his observations by unwearied diligence, until the solution 
of all his problems is obtained. Still, do not these incidents exhanst the perils of disappointment. Some of the most interesting objects which have roused our curiosity prove of such rarity, that even a second specimen cannot be obtained after the first, to complete our observations ; or the continuity is lost with the lapse of time. Sometimes the services of an accomplished artist are not to be procured at the critical moment, when they would be most essential ; and at length, amidst numberless obstructions, the subject deemed so precious, perishes spite of all precaution.

Personal experience enables me to testify, that, from similar causes, the investigation of the nature of particular objects has been more than once interrupted for ten, nay for twenty years.

Aithough it be the ordinary disposition of mankind to relish a further aequaintance with what is already familiar to them in part, I shall venture here to introduce some products of a less common kind, whereof most of the learned, the curious, and inquisitive, are usually denied all knowledge.

Holomurria. - A class of animals has been constituted by later naturalists under the name of Echinodermata, which, strictly interpreted, is probably meant to infer Hedge-hog skins, or Rough skins. Herein are included three different genera whereon I propose to make a few observations-the Holothuria, Asterias and Echinus, though the name is inapplieable to any but the last, for neither of the others have any such corresponding characters; and if I be right in the etymology, I cannot compreliend how they could be associated with it.

Naturalists liave been greatly embarrassed, both in determining the real structure of the Holothuria, and in assigning to it its positive position in the Systema Natura; nor have they been more successful, in as far as I am aware, in ascertaining the habits of the race. Those apparently among the best qualified for settling such important points, by the preservation of living specimens, if ever they had them in view, have certainly contributed to their own disappointment by premature dissection : or they have been unable to obtain specimens in healthy and vigorous animation. Hence the uniform prevalence of the most indis- 


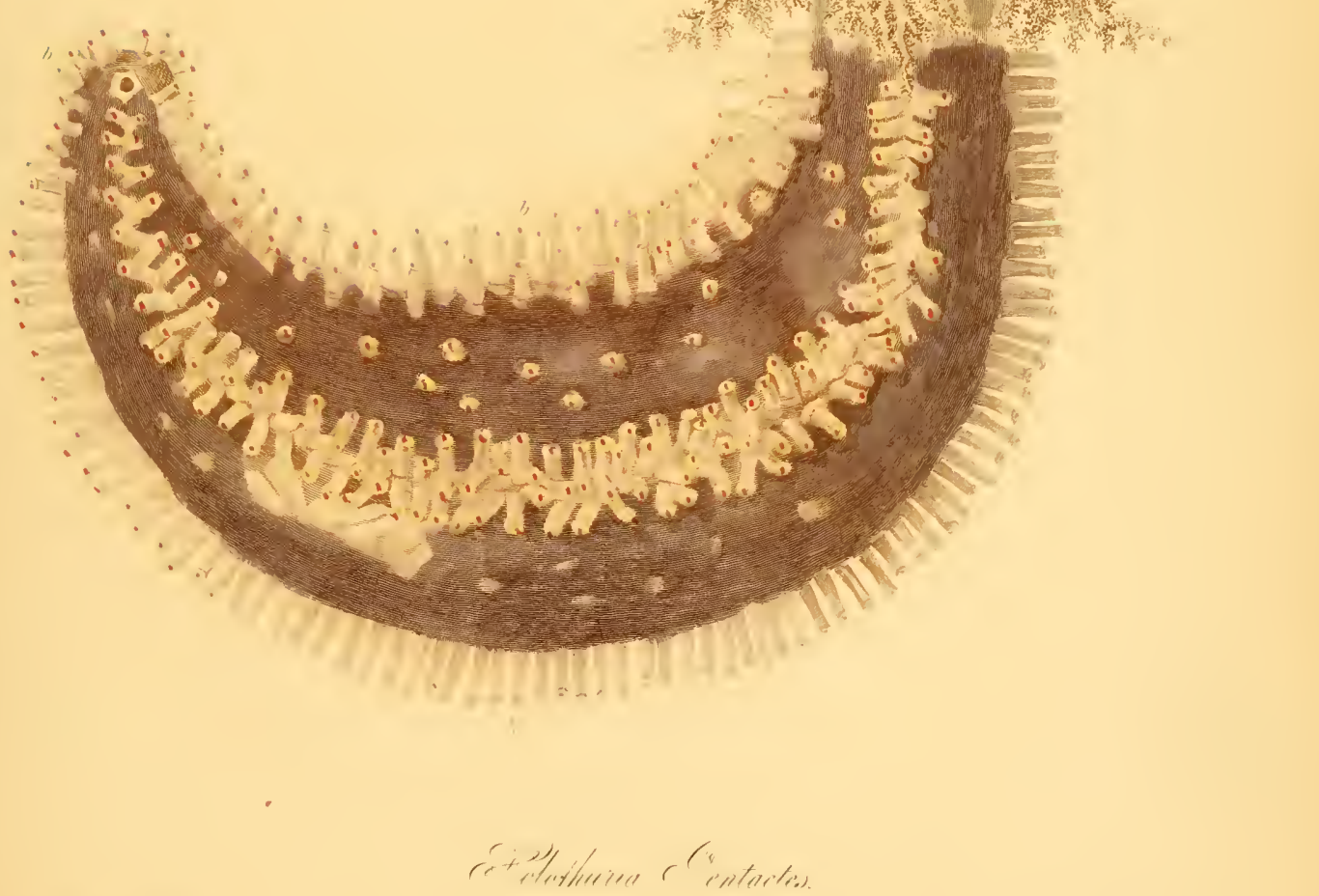

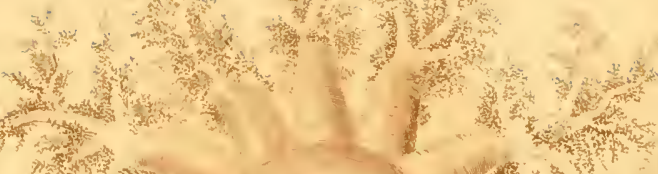

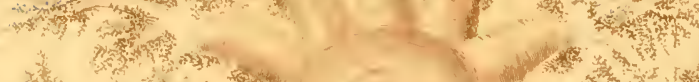

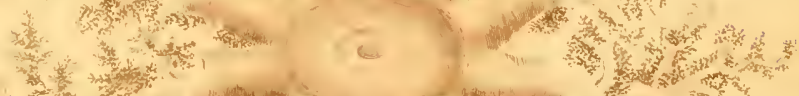

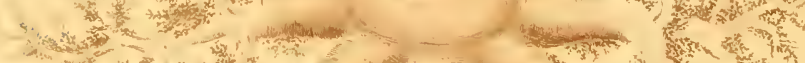
F sint

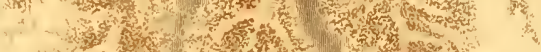

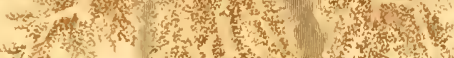

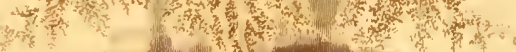



tinct description, and the most imperfect representation, from the days of Gesner in the sixteenth century, down to the present era ; for, unless in solitary examples of a few of the more learned, an uninterrupted series of errors has led the others astray. So completely has the subject been overlooked, that, although the etymology of the name Holothuria may be conjectured, I know not any author who treats of its origin or derivation."*

Besides the few auxiliaries of the sedulous student, the transient observer is certainly exposed to delusion, from the utter dissimilarity of the Holothuria in its active and passive state. No two aninals, in maturity, can be more unlike than this single creature is to itself. It is wholly a simple bag, or partially a beautiful flower, or luxuriant arboresence.

An intimate knowledge of only the external form of the Holothuria, is therefore absolutely dependent on patient preservation of living speeimens, and the opportunities which they offer to us to study them.

If these be favourable, the observer will not be slow in discovering that the characteristic Echinodermata is of the most doubtful application, and that none of the definitions hitherto proposed or adopted will distinguish the race intelligilly, because there is no common resemblance sufficiently precise among all its members. At least that resemblance is not yet explained.

In several instances also we find several different Holothurie receiving the same name from different authors, and the same Holothuria distinguished by different names from the same anthor; all tending to aggravate the perplexities, besides unnecessarily multiplying the number of species. Much of this, indeed, ensues from the difficulty of the subject. It is not an easy matter to satisfy each originating doubt by resorting to the bottom of the sea for authority. All researches there are liable to the most uncertain result.

Nevertheless, it is possible that, by the personal study of these re-

* Gesnerus, Icones Animalium, considers one species as motionless, others as differing little from plants, p. 262. 
markable animals, and by seeking frequent opportunities of observation, the learned might have both avoided their own errors, and might have corrected those of others. But doing so in their proper element was indispensable.

The following discussion shall be limited to my personal observations on a few of the tribe, which have afforded me the best opportunities. Many more indeed have come into my possession; some of them fine specimens. Yet they did not yield matter sufficient for commentary, or were perfect enough for delineation. The distinetions of those selected are so well marked that they stand far apart.

Including the whole specimens of the various species that have been obtained by me, they may be probably rated at one hundred and sixty, of different size and age, within the period of thirty years. Yet inconceivably few of that number, perhaps not a tenth or twelfth, were entire, strong, free of mutilation, and fit for continued observation. Among these was only one specimen of that I have named provisionally the Scotica, one of the Inhcerens, and seven of the Phantapus. All these and others survived their captivity; yet drawings were sometimes impracticable, and sometimes attained with the utmost difficulty of the rest.

All Holothuria dwell in the sea ; and it may be presumed that, under certain modifications, they attain greater size in deeper water. In most parts of Scotland they are extremely rare.

In their native abodes these animals seem to affix themselves very firmly below, to such substances as they can be dislodged from with great difficulty, and very seldom with impunity. As the larger are the stronger, it may be understood why so many are injured in recovery. It is only some inconvenience that induces them to quit their hold, or they become spontaneously erratic-floating away on the waters also, when they may be safely taken.

The true nature of the Holothuria cannot be discovered in its distempered state, and most of the conditions admitting its capture renders its subsequent preservation equally precarious. The wounds and lacerations endured by forcible removal of speeimens from the spot of adhesion almost invariably occasion speedy death. Even the slightest abrasion of 
I:I.

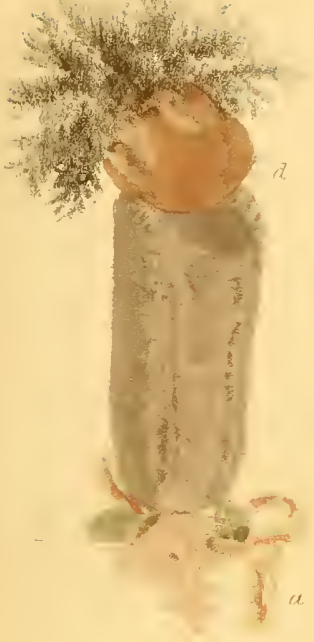

:-

$20^{2 x}$

6

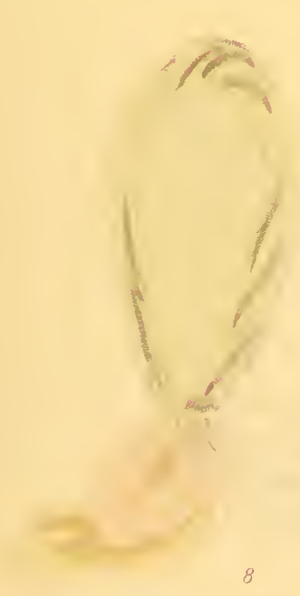

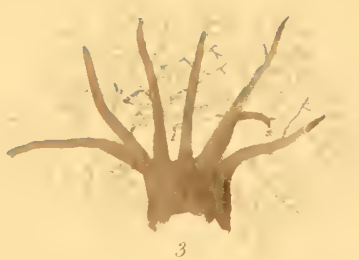

- tile

PL. II.
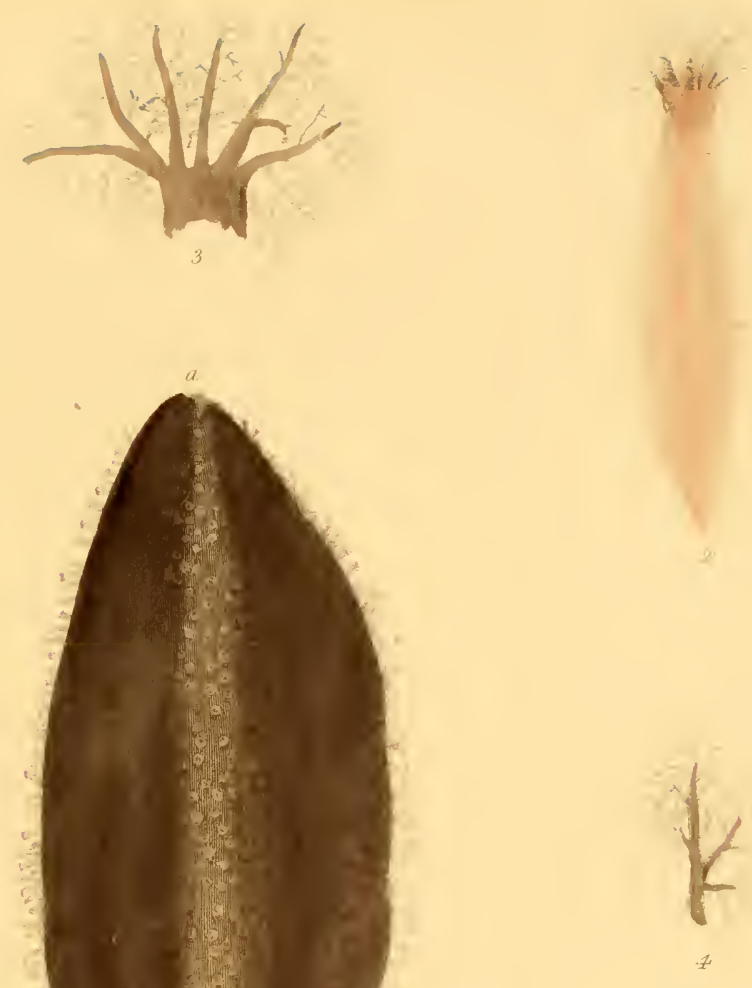

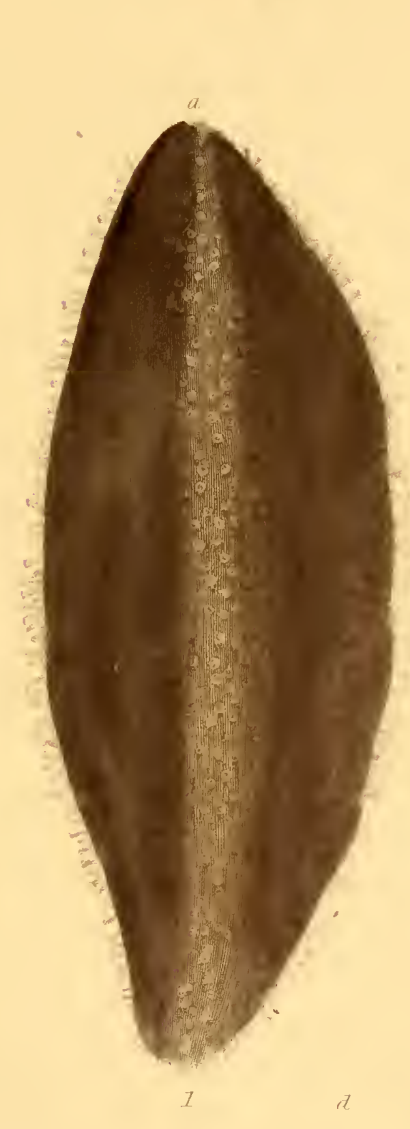



the surface has uniformly proved fatal ; and besides these accidents, which are incidental to the race, the larger Holothuria not only lose their intestinal organs, but almost always rupture their bodies whell withdrawn from the sea to an artificial dwelling.

Authors have generally confined their observations to the anatomy of the Holothuria exclusively, wherein some accomplished naturalists have gratified the curious. But very few lave adventured on an accurate description of its extemal form; nor have I heard of any one attempting to illustrate its habits. Certainly the subject is difficult, for the most distinguished foreign naturalists, even without the impediment of scarcity, complain of the extreme embarassment to which they were exposed in their progress ; and the figures devoted to the anatomical structure are actually often unintelligible.

We must, therefore, very highly prize whatever occasions admit of any accessions or elncidations of the history hitherto so obscure of this extraordinary creature.

The first step to be adopted here alike for the purpose of ascertaining the nature of the animal, and to enlist the services of other observers, is to fix its form in recollection by accurate delineation.

\section{§ 1. Holotiuuria Pentactes.-Fire Rilbed Sea Cacumber-Séa Pudding.-Plates I., II., III., IV., V., VI., VII.}

The Holothuriæ are so unlike each other, it is impossible to comprehend any number of species under a general definition. If any were devised it would be very defective, each special definition being scarcely applicable to another species than that from whence it is derived. Authors have been induced to attempt constituting several genera, but most unsuccessfully ; and their labours in fact resolve into the enumeration of species.

The exterior integument of the Iolothuria, with the tough coriaceous inner layers, constitutes a capacious bag, wherein are contained the respiratory, the intestinal organs, and the ovarium. The head is also retracted within it when at rest ; but in action it protrudes, unfolding a fine 
luxuriant flower or arborescence, constituting what are supposed tentacula. The body of most specimens assumes the form of a horse-shoe, erescent, or cucumber, and a stream of water, playing like a fountain, is forcibly discharged from the posterior extremity.

These general features of external aspect will probably enable the student to distinguish a few species of the Holothurian tribe. But of later years the progress of comparative anatomy, from the desire of ascertaining the precise position, form, and functions of every portion of the animated frame, has threatened to disturb the facilities enjoyed from simple aspect, and has beset the study with higher obstructions.

The reader must be sensible, however, that the uniform tenor of this treatise, so far from contemplating the destruction of life, encourages its cireful preservation, as the best, and indeed the only means, of discovering the nature of animals.

The Holothuria forms a genus whose exact position is one of the most doubtful in the Systema Nature. It is not in immediate approximation to any other, for some great chasm seems to intercept it from all. We cannot point out any genus, sufficiently distinguished, which either precedes or follows it.

The Holothuria pentactes is a large, strong, and vigorous creature. But the distension of the body, the alteration of its figure, together with the circumstances wherein it is found, and which attend its preservation, induce considerable ambiguity respecting its utmost natural dimensions.

The unrestrained form of this animal, at ease, and in undisturbed security, is a crescent, throughout two-thirds of its length. The anterior part, which is retractile within the body, expands into ten beautiful arborescent tentacula, bordering a broad disc, with the mouth in the centre. An exterior smooth skin is here interposed between the head and the shoulder, and the remainder of the body, decreasing from the middle downwards, terninates in an orifice, discharging the continued stream of water above alluded to.-Plate I.

Five longitudinal rows of peduncles or suckers traverse the skin of the whole body, commencing near the root of the tentacula, and terminating at the posterior orifice, through whose adhesion the animal is 
firmly rivetted to solid substances. The skin between the rows is sunooth. but of quite a different character from that on the neck, the disc, or near the tentacula. That different character of the different parts is very conspicuous.

About 100 suckers occupy the length of a row in such a specimen as represented. The five divisions may be ealled, for distinction, stripes or belts of suckers. In some specimens, five, six, or seven suckers occupy the broadest part of the belt, the number decreasing towards the extremities. The breadth of the stripe or belt, and the number of the suckers, depent on the size and age of the subject. Small specimens have only a double row of suckers in the stripe or belt ; nor are all the five complete. In one extending above thirty lines, including the head or anterior portion, they stood single or somewhat zig-zag in a row.--Plate II. fig. 2. Thus they augment with age; and in large specimens some appear straggling over the body.

The usual aspect of the Ilolothurin pentactes is represented, Plate I.. when in a state of quiescent security. When absolutely mactive, it resembles Plate II. fig. 1, reduced from the original, which extended twelve inches by four. This I concluded a full-grown subject. But I cannot define the largest dimensions attained,-certainly not under two feet, with the tentacula displayed; the body three inches thick or more.

The observer is always liable to delusion, however, in this respect. owing to the animal's susceptibility of change and extraordinary distension. Some time after the specimen, Plate I., was taken, it resembled the figure and dimensions of the heart of an ox, while floating ; next it extended a foot long by four inches in diameter, and ultimately subsided to the permanent shape and size wherein it is represented.

When the animals are detached, they generally float as long ovoids. being then turgid with water. One in that condition weighed four pounds, whereof the body might be one and a half, and water the remainder. But, the dimensions seem very mueh affeeted by circumstances, such as freedom, fixture, health, or disease, and perhaps also by the temperature of the atmosphere.

The suckers can be wholly retracted and sunk in the flesh. The 
tentacula, in a quiescent state, are retracted within the body, the skin of the upper part closing over them. Thus the animal may then appear entirely divested of external organs. When it is active, and the suckers in powerful adhesion, the tentacula, rising from the disc by a stout cylindrical stem, are beautifully displayed in circular arrangement, cach discharging its external functions separately. These exercises, as we shall see of others, are also most interesting to the spectator.

There is much difference in the quality of the skin, as above alluded to. That investing the body, from the shoulder upwards, bears the strongest resemblance to the appearance of birch bark. The surface of the disc and of the tentacula, are of this peculiar description, which adds to the heauty and singularity of the parts. The tentacula, whose actual structure is shewn in Plate II. figs. 3, 4, are luxuriantly arborescent. The hollow cylindrical stem is half an inch in diameter, and all the parts diverging from it in circular arrangement.

Each tentaculum sweeps through the water, and then curves into the central orifice of the disc, in a contracted state, as explained more minutely of the subjects illustrating the following paragraph.

The distension of these organs is obviously from the absorption of water, though by what chammels is unknown. On this point naturalists are not agreed. There can be no doubt, however, of copious absorption, which is proved both by the great dimensious of the body, and by the jet from the posterior extremity producing a vortex at the surface, while the orifice is far below. The jet is so vigorous as sometimes to spout eight or ten inches, and over the side of the vessel.

The colour of the Holothuria pentactes is various. On the whole brown predominates, lighter or darker, and diverging from different shades into mulberry or purple. Large specimens are dark as chocolate : some are wood-brown. Two small specimens, which I concluded the pentactes, with a double row of suckers in the stripes, were grey. About a fifth part of the circumference of the body is frequently much paler than the rest, which is particularly conspicuous in large specimens ; and thence do some naturalists conjecture this the belly of the mimal. One such portion, comprehending two stripes of suckers, was yellowish-brown. 
while the predominant colour above was reddish-brown. The suckers are sometimes almost white, with a central red speck in their flattened adhering extremities. The contracted tentacula of some are nearly black. Perhaps it could be ascertained only by dissection, whether the same internal parts are always lowest in position where the pale under portion, if it be such, is applied to the sustaining substance.

So many features enter the characters of what I would conceive the IIolothuria pentactes, as certainly ought to facilitate recognition of the species; yet it seems to me, although I say it with reserve, that certain discrepancies, apparently slight enough, among individuals, have prompted naturalists to constitute two or three species of one: Nor is this the only example of such an error, if it be an error, for the same has occurred of other Holothuria. The whole subject, I repeat, is difficult ; yet I fear that we create ambiguities by neglecting to shun them.

No Holothuria is recovered from the sea fit for immediate study. All are disfigured or contracted; some in one form, some in anotlier. Until relaxing into shape, adhering as a crescent, and displaying the tentacula, nothing can be known of their nature.

The skin of this species, the pentactes, is very coriaceous, hard and thick, tough, and diffeult to be penetrated when in a contracted state. It becomes as thin as paper when the animal is distended, which is very sensible in a specimen extending twelve or fifteen inches; and it is more evident in the higher and lower parts of one laid open.

A very accomplished physiologist, Mr Henry Goadby, who had devoted much attention to entomology, and the form of the invertebrate animals, visited Edinburgh in 1841, where he gave some excellent lectures in illustration of the preceding subject. At that time I happened to be occupied with the Holothuria, and as he expressed a desire to see that animal, with which he had never had the fortune to meet previously, I had the gratification of supplying him with several fine specimens of the pentactes.

Of these he made various preparations and dissections, far surpassing any that has ever been seen, both for minuteness and beauty, in shewing the form, the multiplicity, and the arrangement of the parts. 
From these I am induced to believe that the structure of this extraordinary creature, which seems to have no parallel, will probably be better understood than hitherto, for all anatomists have expressed how much it has perplexed them ; and it is evident, indeed, how very slow the progress of the history of the Holothuria has been, from the works of Bohadsch, Muller, Tiedemann, Delle Chiaie, and others.

The skilful will avail themselves much more by simple inspection of the engravings which have been executed after very fine drawings, than of any description that I could give them.

The Holothuria pentactes is a powerful animal, capable of great dilatation, and strong contraction. On laying open a large specimen, and removing the intestinal organs, Mr Goadby exposed five longitudinal muscular bands, connected by several strong tendons, which might explain its strength : Plate III., representing a preparation, here reduced by about a third under the natural size.

Some of the Holothuria die with the tentacula withdrawn, and the whole body closely contracted. But the Holothurix of this species generally die with the arborescence exposed, though not expanded. A general view of the internal parts is obtained from Plate IV., where the orifice of the mouth $a$ is found in the centre of the tentacula ; and on one side is seen a capacious transparent vessel b, the Ampulla Poliana, as named by Delle Chiaie, to which some have assigned the functions of a heart. The alimentary canal is disposed in various convolutions $c, d$, and the long ropes of a great ovarium are stretching down $e$.

On divesting the body entirely of its integument, the commencement of the oesophagus appears, leading to the intestinal canal : Plate $\mathrm{V}$., $a, b, c$. Also the general mass of intestines below, together with the delicate reticulated mesentery, the respiratory organs $d, d$, and the great cloaca $e$.

By a singular arrangement, not altogether unexampled, respiration belongs chiefly to the organisation connected with the lower part of the body of this species of the Holothuria.

A large yellow ovoidal sac or cloaca is situated near the posterior extremity of the animal, from which a continual jet is discharged by the terminal orifice. This peculiar organ is secured by numerous ligaments 


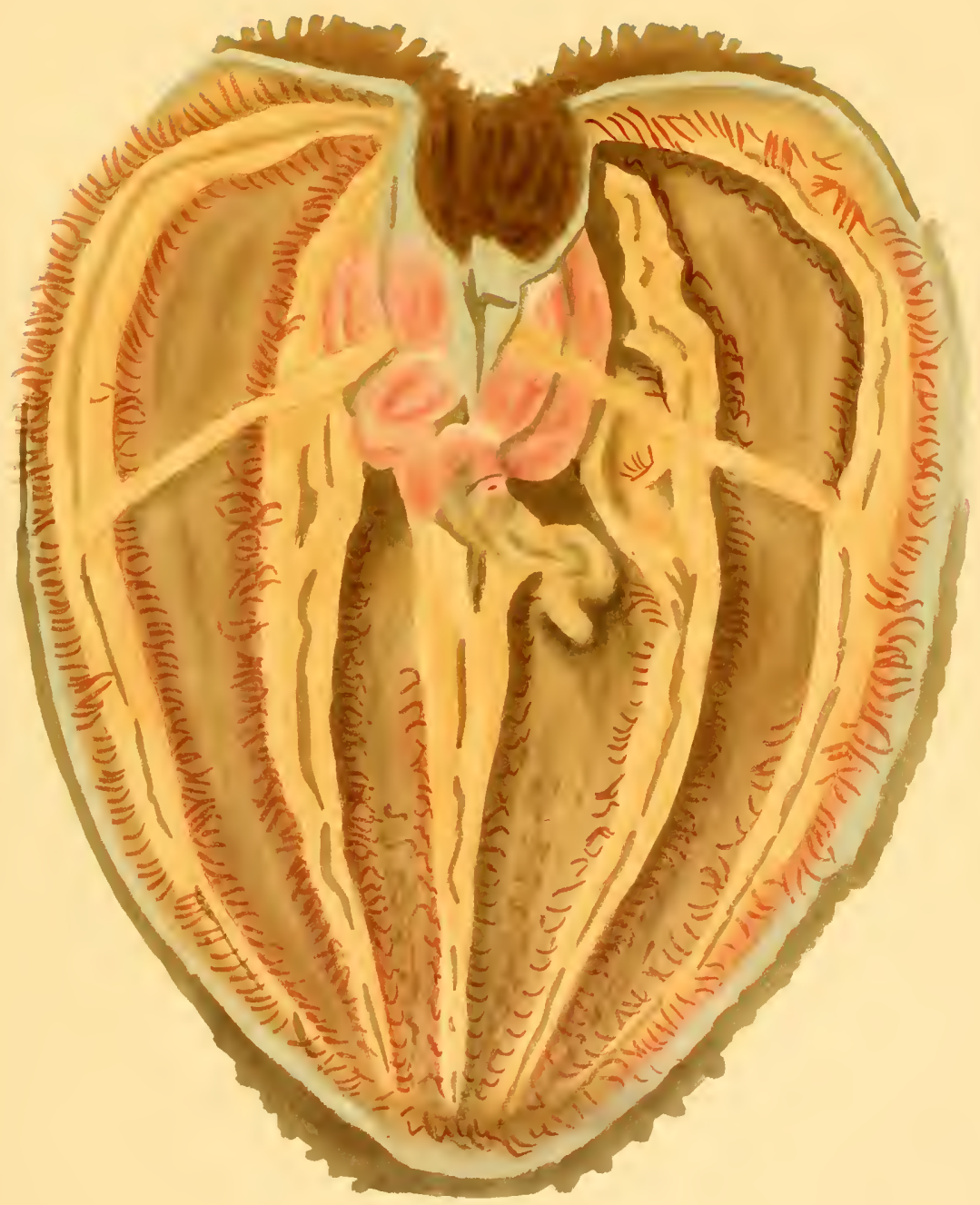

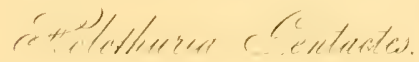

$$
\begin{aligned}
& \text { leet ifente. }
\end{aligned}
$$



to the neighbouring parietes, and it seems capable of great expansion and powerful contraction.

The respiratory apparatus is farther displayed by two large tubular trunks, extending nearly six inches from a common tube comected with the cloaca, and diverging upwards into innumerable lesser channels, with obtuse extremities; the whole also secured by tendons to the neighbouring parietes. An intestinal organ, here divided and turned back, communicates likewise to all the common tubes.

All these parts constitute what is called the respiratory tree, whereof very indistinct flaccid portions are represented in some treatises, or rather simple notices of the animal.

Thus the respiratory apparatus obviously constitutes a great portion of the internal contents of the body, where it is distended by water, whence the oxygen may be disengaged.

The exact powers by which both the physical and mechanical functions are effected in such animals merit the profound attention of the skilful physiologist.

The beautiful structure of the respiratory tree is favourably represented here, from an excellent preparation by Mr Henry Goadby, the same accomplished naturalist to whom I am indebted for the others. Plate VI.

In the living object, however, while the vital functions are advancing, this organization is more amply developed, being distended farther, and exhibiting considerable action. The side of a specimen of the Holothuria, somewhat exceeding medium size, having ruptured, part of the respiratory tree protruded from the wound. It now resembled a great assemblage of caca, if I may so speak, all anastomosing, the reciprocal junction and conmunication being quite perceptible through the diaphanous membrane, and the transparence of its contents. The whole was very turgid, sometimes becoming a little flaccid, every portion endowed with vitality, as demonstrated by their curvature, especially at the extremities. On shewing this subject to a distinguished anatomist, $\mathrm{Dr}$ Robert Knox, he immediately pronounced the protrusion part of the respiratory organs. The rupture being an inch above the terminal ori- 
fice, the animal survived under it four or five days: Plate II., fig. 5. Outline of the body $a, a, a, a$, suckers $b, b, b, b$, orifice $c$, respiratory organs protruding $d$.

These organs are obviously distended by reception of a fluid, which may be presumed the sea-water, amidst which the Holothuria dwells. But the mode of their replenishment, by what channels or absorbents, is by no means evident. Perhaps it is by alternate discharge and replenishment that the respiratory functions, those so essential towards life and salubrity, are effected. If, in passing from the tubes, there is an accumulation in the great cloaca or reservoir, the powerful muscular contraction of this organ may produce a continued jet. But while this goes on it is rational to conclude that imbibition or absorption by some other organic structure contributes the supply.

The whole is a very admirable and extraordinary apparatus, consisting of such a multitude of subordinate parts, that it is impossible to represent above two-thirds of them.

The opinions of naturalists do not correspond regarding an important portion of the animal frame, the nervous system.

Delle Chiaie, who seems to have had tenfold the number of specimens of any other observer, says the Holothuria has no nervous system, since the most diligent investigation could not discover any traces of it"that no one could be more favourably situated than himself, with thousands of living Holothurix, whereon he was occupied constantly during ten months in dissection." *

Professor Goodsir, of the University of Edinburgh, no less a distinguished anatomist, acquaints me, that he ascertained the nervous system of the Holothuria to lie in a pentagonal form around the tentacula, descending the body in five cords, so as to be connected with the rows of pedicles or suckers.

The preceding author, Delle Chiaie, enters on some explanation of the sanguiferous system.

He also speaks of the animal feeding on fragments of alga and the

* Delle Chiaie, Memorie sulla Storia e Notomia degli animali senza Vertebre, rol. i. p. 100. 


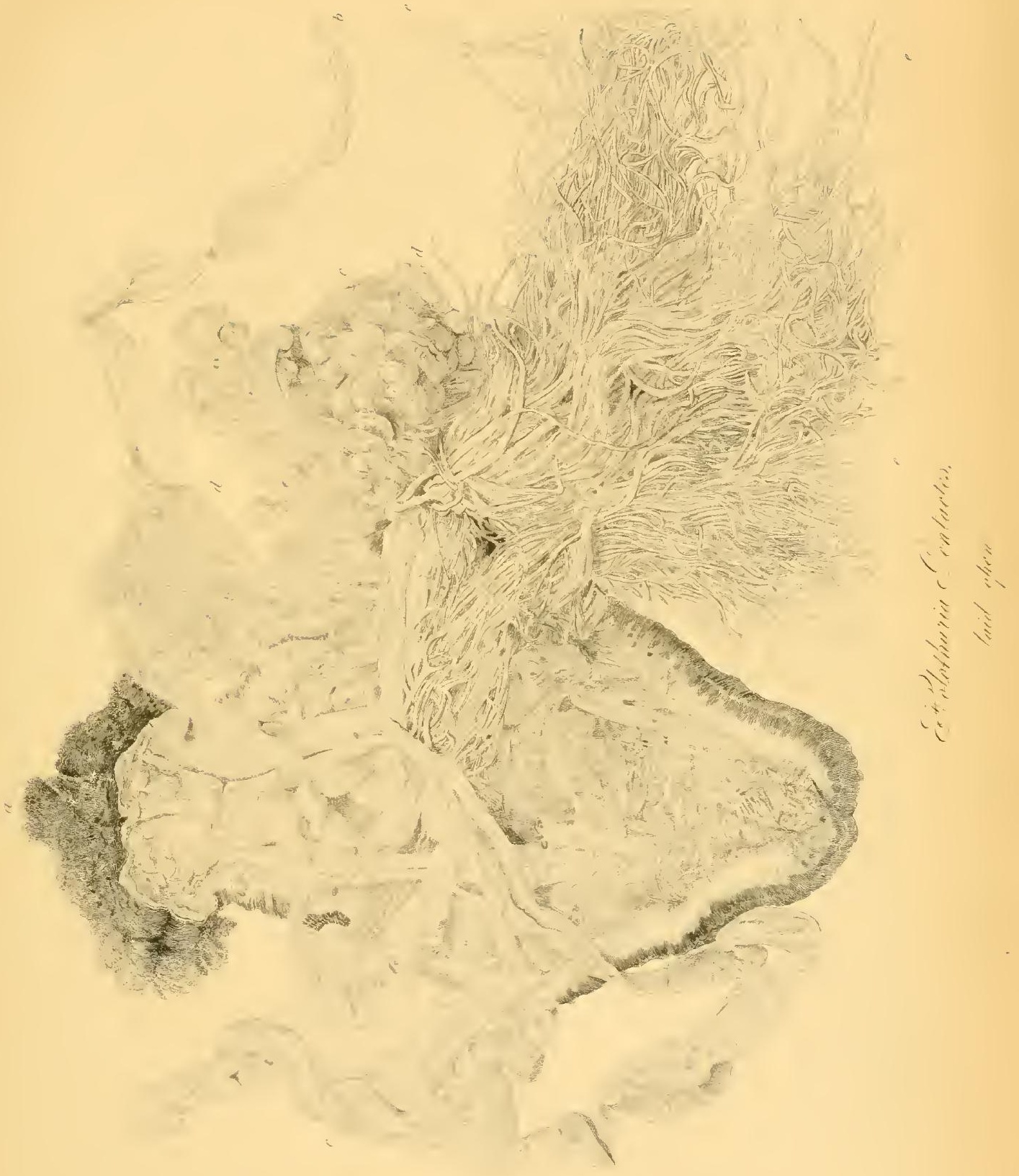



like, but I have never found any solid substance whatever in the intestines, either animal or vegetable: Nor has any specimen ever testified the least disposition to feed in my possession.

A very large specimen of the pentactes was obtained about a year ago, distended by sea-water, so as to be ten inches in length, and six in thickness, the tentacula being contracted to three-fourths of their diameter. Next day it had emptied itself; it lay motionless, extending 16 or 17 inches. The intestines occupied the whole cavity of the body, but they contained nothing except a dark thick fluid matter.

The natural form and position of the Holothuria pentactes is a crescent, so that while quiescent it does in fact bear considerable resemblance to a cucumber,-whence its name. The body remains affixed by the suckers to the side of a vessel, the head or the portion comprehending its tentacula remaining free for their evolutions, and the posterior extremity likewise disengaged for the play of the fountain.

In general liabits the Holothuria pentactes resembles the following subject, but here, the tentacula being formed by a prolongation and adaptation of the integument of the shoulder, they are not immediately connected with the intestines like the tentacula of the Holothuria fusus. All the former, that is those of the pentactes, being a continuation of the cylindrical neck, are protruded with its unfolding skin as it extends after having been withdrawn into the body when closed up.-Plate II., fig. 1. The tentacula of the fusus are immediately connected with the intestines by a peculiar receptacle, wherein the whole can be retracted. Herein, any single tentaculum, or the whole, may be retracted when the apparatus constituting the receptacle sinks within the body which closes over it.

Night appears the chief season of the enjoyment and activity of these creatures. Whatever be their contracted state through the day, they then expand themselves, and display their beautiful arborescent tentacula at the utmost dimensions. Nevertheless many remain expanded through the day, and, whether or not it be from the momentary stimulus, some seem to become more erect on the approach of light,which is certainly an exception to the general rule, for both light and 
heat appear to be extremely prejudicial. Their safety depends on coolness; and, I firmly believe, that one principal difficulty opposing their conservation is lodging them in too high a temperature. The specimen, Plate I., survived five or six weeks. None other in the lapse of nearly thirty years afforded a display of the tentacula equally luxuriant for delineation. The Holothuria being properly a nocturnal animal, I was indebted for this to Mr Daniel Whyte $\mathrm{I}^{\prime} \mathrm{C}$ Culloch, an excellent artist, whose labours generally commenced about midnight, when his subject had reached its finest condition.

The animals of this species are not nearly as stationary as those of the following, which frequently remain for months in the same spot. The small specimen, Plate II., fig. 2, was very active. It traversed its vessel freely, and curved itself in all directions while quitting a wide mouthed phial; also advancing with the tentacula in front. But others have been stationary in comparison, remaining affixed to the side of a vessel for a considerable time, just at the surface of the water, and testifying little inclination to move.

Among the numerous obstacles obstructing all observers, and which have much retarded our knowledge of this curions creature, is its extreme tendency to rupture. Such an accident, whether external or internal, is particularly incident to larger specimens; and, as already noticed, slight abrasion of the skin seems to be irremediably fatal.

It does not appear that the rupture is confined to any part of the body, though frequently ensuing in the vicinity of the terminal orifice of the great cloaca. A prolapsus then follows, whereby the intestinal organs are discharged in large proportion.

Its progress and effects may be seen at the protrusion of part of the respiratory tree, Plate II., fig. 5 ; also in the escape of some of the intestinal canal $a$; the same organs, fig. $7, b$; and of an immature ovarium among other organs, fig 8 .

Sometimes the rupture is $\mathrm{m}$ the side of the animal, not far from the middle, when portions of the ovarium, almost mature, escape. An intestinal protrusion also sometimes ensues by the mouth, with rupture of the body. 


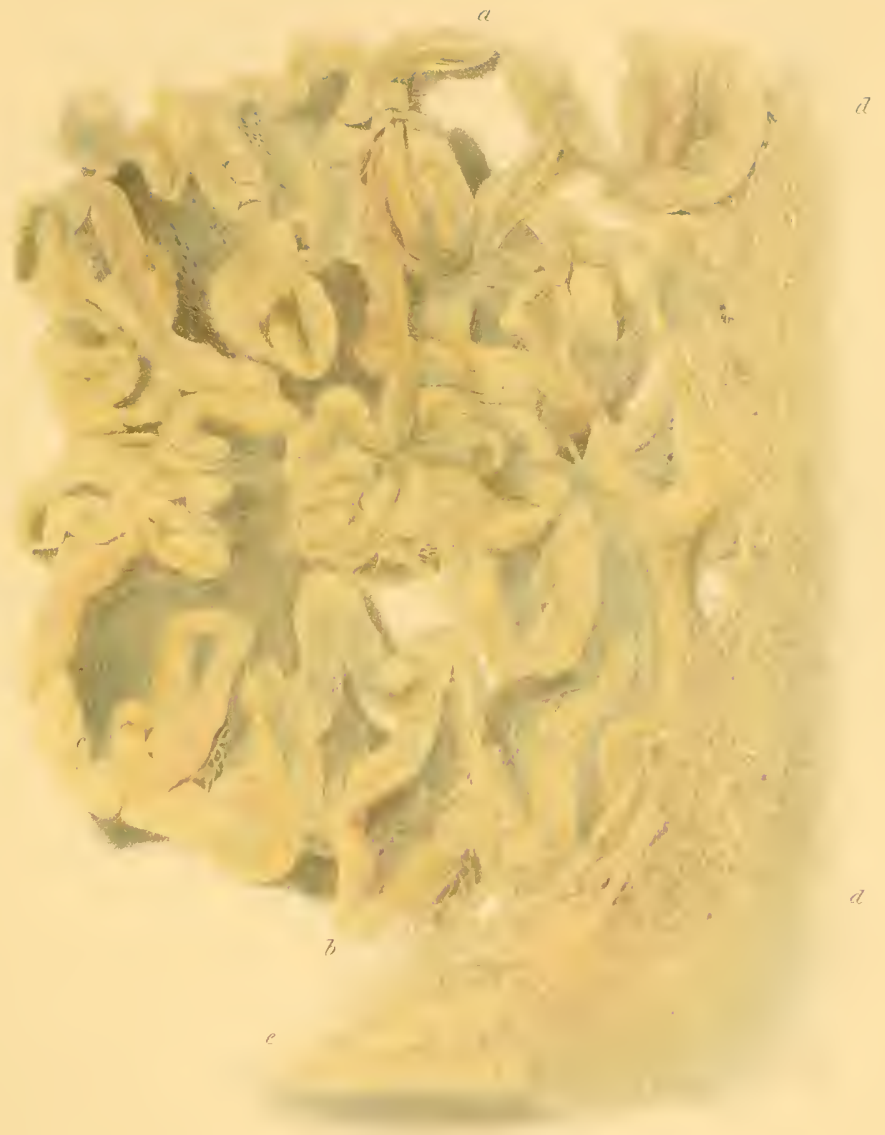

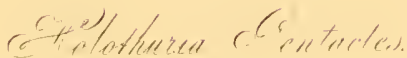

$$
\begin{aligned}
& \text { chestinat l'spins. }
\end{aligned}
$$



It is difficult to account for such ruptures where the integuments are so strong. The cuticle of certain species is very thin, generally gray or dark. But the substance next it, white, is so very hard and tough that an edged instrument can hardly pierce it, for it equals the consistence of leather. The cartilaginous parts are also extremely tough and strong.

Perhaps the ruptures are consequent on violence, seen or unseen, suffered by the subject. It is difficult to admit that such an incident could take place without violence. Mr Adams, a skilful naturalist, who lately accompanied Sir Edward Belcher during his interesting voyage in the Eastern seas, and promises to throw much light on the history of the lower animals, speaks of " a Holothuria with a soft, brown, tesselated integument, which on being touched-suddenly ejects the entire contents of its sacciform body, including the whole of the viscera and appendagesshrivels up, and immediately dies.":

The period, the occurrence, and the degree of such ruptures in confinement are uncertain. After preservation of the specimen Plate I. for about a month or little more, prolapse commenced of the intestinal organs, $\rightarrow$ an invariable prognostic of death. The water became turbid, while the specimen weakened, and the tentacula swept with feeble incurvature towards the mouth. Its adhesive faculty was gradually impaired, and having been entirely lost, it died after abont six weeks captivity.

As rupture of the body is a common concomitant on confinement, prolapse of the intestinal organs is alike frequent; and from this accidental injury, the Holothuria usually perishes. If otherwise, it dwindles down to small dimensions, and seems to die from mere inanition. The contracted body always bears little proportion to the size of the healthy living animal ; and after death, the tentacula often remain partially expanded. But the reverse is also frequent. The disparities are striking. A specimen extending, perhaps eighteen inches while in vigorous life, will lie in a saucer five or six inches wide when dead.

It is affirmed that the IIolothuria pentactes lives naturally among

* Adams' Notes of Belcher's Voyage of II. MI. S. Samarang, vol. ii. p. 495. 
beds of the Laminaria or tangle, which is not improbable, if portions of this vegetable product are devoured. But it rather appears that a more solid foundation is congenial to its nature, for the suckers, which constitute its chief security, are not well adapted for application to such flexible substances. Possibly the food is yet unknown. The animal's mouth is susceptible of great dilatation, opening almost as wide as the entire diameter of the disc.

During this remarkable expansion of the specimen, Plate I., I dropped various animal substances into the cavity, nothing vegetable being then at command. But none proved acceptable. All were found afterwards in the vessel.

With so firm a hold, and such a capacious mouth, the Holothuria, if carnivorous, would be a dangerous enemy. Its extreme timidity, however, most conspicuous on all occasions, prohibits our supposition of its acting offensively against any part of the animated creation, and hence the tentacula are probably to be chiefly protected.

Nevertheless, the nature of the food is a question of some interest. Those genera of the Echinodermata, with which it is most immediately classed, are highly carnivorous, the Asterias and Echinus. The true nature of its sustenance might affect its position in the Systema.

It is rexatious to witness the subjects of observation pining away before us, from inability to ascertain their food.

The Holothuria pentactes dwells in various parts of the Scotish seas. It is found about the mouth of the estuary of the Forth ; and in the course of years, some straggling specinens occur to the westward, it is said even as high as Newhaven, where stream tides rise seventeen or eighteen feet. If the fishermen may be credited, it is recovered from the depth of ten or twelve fathoms. But where particularly abundaut, as at Lerwick, whence many fine specimens have reached me, I have been informed that they dwell at the depth of one or two fathoms from the surface, and very near the shore.

The wonted colour of the Holothuria pentactes is different shades of brown or purple. Two, which I considered varieties, were dingy white. One of these shewed great versatility of form. This specimen lost the 


intestines, together with a profusion of vivid red ropes of the ovarium. After previous discharge, a large brush or mop, eonsisting of at least forty ropes, was found beside it on the first of May ; and subsequently, mueh more: the same speeimen was so distended, thin, and pale, that the internal ovarium was distinctly visible through the skin.

Holothuria, on arriving from a distance, are generally contracted, and the tentacula withdrawn. There is reason to believe, however, that, in a healthy eondition, these organs remain constantly expanded.

Nany are found floating like balls of various shapes, at the surface of the water.

These, on arrival, should be transferred to capacious vessels, and plaeed in the dark, remaining undisturbed, where they will affix themselves, and assume their natural curvatures.

A considerable number of this particular species reached me during several years from Shetland in safety, the distanee being computed at about 300 miles."

Two of them survived seven months. Avoiding all violence, giving plenty of room, and frequently replenishing their vessels, will certainly contribute to their preservation. But the greatest difficulty is detaching them with impunity from their natural site.

Those of smaller size are more convenient in all respects, both for observation and conservation. They are more easily managed ; for large specimens distending themselves, require very eapacious vessels, and great quantities of water.

The preeeding detail has been derived from about sixty specimens of the Holothuria pentactes.

In coneluding the subject, I may remark, that, in common with many others to which investigation is seldom devoted, we are disturbed by anomalies interrupting the ordinary course of observation. In one specimen, the Ampulla Poliana, distended by a transparent fluid,

* I cannot omit this opportunity of expressing my high obligations to Mr William Merrilees of Lerwick, to whom I an indebted for some of the most valuable subjects described and represented in these volumes. 
protruded about an inch and a quarter. Here the intestine was quite yellow, and the ovarium simple white threads, or of the faintest yellow, entirely empty.

Another, which I thought a specimen of the pentactes, never exposed the head for five months, nor did anything farther than mere tufts indistinctly appear. A representation of this animal was executed when it had been eight months in my possession, Plate XII., fig. 1. It contracted much during the five succeeding months, and some particles, as if of decomposing parts, appeared in its vessel, resembling minute white scales. At length, they lay in hundreds, none exceeding half a line in length. Under the microscope, they proved dark, oval, convex, and drilled with holes in considerable regularity, elliptical rows being within each other.-Plate XII. fig. 2 ; Scales, $a$.—One more enlarged, $b$.

Plate I.-Holothuria pentactes, the Sea Cucumber, Sea Pudding,-with the tentacula displayed, as adhering by the suckers in its natural position.

\section{Plate II.}

Fig. 1. Holothuria pentactes, quiescent; the tentacula withdrawn, and the anterior extremity closed over them. Reduced from a specimen twelve inches long.

2. Young specimen. Tentacula displayed, $a$.

3. Portion of a tentaculum, shewing the arrangement of the parts.

4. Another portion of a tentaculum.

5. A portion of the respiratory organs of a living specimen protruding from a rupture of the lower part of the body, $a, a, a, a$.

6. Ova nearly mature.

7. Holothuria pentactes losing the intestinal parts, by a rupture near the extremity of the body. Intestinal canal, $a$. Portion of the respiratory organs, $b$. Tentacula contracted, $c$. Neck, $d$.

8. Portion of the intestinal organs escaping by a rupture. Immature ropes of the ovarium, $a$. 
Plate III.-Large specimen laid open, and most of the internal organization removed-from a preparation by Mr Goadby. Reduced.

Plate IV.-Internal organization of the Holothuria pentactes, as in a preparation by $\mathrm{Mr}$ Goadby. Tentacula contracted, a. Ampulla Poliana, $b$. Intestinal canal, $c$. Portion of the ropes of the ovarium, $e$.

Pl.ITE V.-Intestinal organs exposed. Stomach everted, $a$. Intestinal canal, $b$. Mesentery, $c$. Portion of the respiratory tree, $d$. Muscular ligaments of the cloaca, $e$,-from a preparation by $\mathrm{Mr}$ Goadby.

PlaATE VI.-Respiratory organs as dissected and prepared by Mr Goadby. Orifice of the cloaca, $a$. Muscular ligaments, $b$, securing the cloaca to the parietes of the body. Obtuse extremities of the tubular organs, $c$. Ligaments securing the trunks to the parietes, $d$.

Plate VII.-Ovarium of the IIolothuria pentactes, from a dissection by Mr Goadby.

Plate XII.

Fig. 1. Small Holothuria.

2. Scales upon the skin, $a$. Scale enlarged, $b$.

\$ 2. Holothuria fusus.-The Spindle Sea Cucumber or Sweepwater. -PI.ATES VIII., IX., X., XI., XII.

On the 1Sth of November, a specimen was recovered from the north-eastern part of the Frith of Forth. It is of some consequence to date the leading incidents of natural history as done in these pages, both because intervals of time are the grand regulators of the world, and the 
result of experiments and observations become deeply affected by the seasons: also because the learned have been induced to credit the periodical migratory habits of various animals, which are, perhaps, altogether stationary, or nearly so, on the spot where they originated.

This specimen extended somewhat as a misshapen pear two inches in length, and nine lines through where thickest. It was miversally invested by a yellowish-brown shaggy coat hung loosely over it, with fragments of weeds and shells also adhering to the surface. The covering, like the coarse wool of a quadruped, relaxed into a multitude of papilla, or, more correctly speaking, suckers, alternately stretching and contracting, and ultimately affixing to the side of a glass vessel, where the specimen remained motionless for ten days. But the site proving unsuitable, together with superrening vitiation of the element, rendered removal indispensable,-which was effected by whirling the vessel rapidly round, and the animal,was liberated safely, by the suckers gradually losing their adhesion. Having affixed itself again in another vessel better adapted for such a subject, it resumed its pristine form.-Plate VIII. fig. 1.

All the Holothurix of this and the preceding paragraph when disengaged, assume a globular, ovoidal, or spherical form, under which they float amidst the waters, or are rolled on the bottom below. They are contracted to varions dimensions, and moulded into different shapes, gradually changing as they find themselves in positions of security, fig. 2 .

But there is a difference so extraordinary between the quiescent and the active animal, that the experienced only-those to whom no alteration is new, are capable of declaring their identity previous to the evolution of the parts. Who can anticipate that the purple, smooth, and apparently lifeless mass which he leaves like an egg at twilight, shall become a crescent, or a cylinder sometimes the length of his leg, ere the break of dawn, mnfolding a beantiful, huxuriant, arborescent apparatus of many branches, which tranquilly sweeps through the water? Hence is it, perhaps, that older naturalists describe such creatures, beholding them in the day, as motionless, and, although animated, differing but little from plants.

But let us pass, per saltum, from the beginning of December to the 
I. $I$.

II. III 

end of June, wherelsy we shall attain more intimate acquaintance with the true external structure of this singular being, which, concealing the most interesting features of its orginization, has hitherto appeared only in disguise.

In the natural sound and healthy condition, such a specimen as the preceding adheres in the form of a crescent to any solid substance, the borly extending about three inches and a half. The anterior extremity is quite obtuse, and the posterior tapers almost to a point, while both are somewhat raised above the centre of the animal, whether it be affixed to the side or the bottom of the vessel. When vigorous, the Holothuria is always a crescent, and always in adhesion.

This peculiar figure must he helt a leading characteristic of many species of Holothurix, and has been evidently assigned to it by the Anthor of the animal world, for the facility of discharging certain essential functions. But the rarity of perfect specinens, and the lifficulty of preserving them in vigour, have undoubtelly precluded the nutice of naturalists to so rlefinite a feature. Sometimes the curvature equals a horse-shoe, therefore exceeding the proportions of a crescent.

For the most part, absolute quiescence prevails through the day. How strange it is, that this and so many other tenants of the deep, should thus seem to slumber, - that we might almost affirm the sun hal not been created for a great multitude of the living world, as if light were uninportant to life? But as he sinks heneath the horizon, the anterior of the quiescent Holothuria swelling into still greater convexity, at length opens to protrude a beautiful complex apparatus, as a substitute adapted for the head and the hands of other creatures standing higher in the animal scale. Eight luxuriant, arborescent tentacular organs, each as long as the whole body, besides two antemulie of smaller dimensions, are unfolded in the form of a fumnel stretching beyond the shoulder. All these organs radiate from the circumference of a short osseous and cartilaginous cylinder or case, with an orifice denoting the mouth in the centre. The whole apparatus, released from concealment, is externally expanded and withdrawn at will.-Plates IX., X.

Soon, after display of this complex apparatus, the tentacula, ex- 
panded to their utmost dimensions, are observed sweeping successively through the water. One of them then curving its extremity inwards, the central orifice dilates to receive it, wherein, after its size diminishing, it is absorbed almost to the root. While thus occupied, one of the antennular organs likewise curves into the orifice, and both are evidently engaged below. Next, the arborescent tentaculum still reduced in size, returns to expand anew, and the antennula follows it. Now, another tentaculum contracts and curves to penetrate the orifice, left vacant by the former, wherein it is also speedily followed by the second antennula. Both are employed within, and their functions being discharged, both return to resume their original figure and dimensions.

Before indulging any conjectures on the real object to be accomplished by such remarkable evolutions, a general view of the parts engaged in them may be taken, by which means more skilful physiologists will be aided in determining their purpose.

What I here denominate the cylinder or case, which bearing the tentacula is extruded beyond the body, is in itself a compound organization of considerable complexity.

When the tentacula are partly contracted during quiescence of the animal, the origin of this cylinder as the whole issues from the body appears, Plate VIII., fig. 2, $c$. If the case or cylinder be entirely detached from the animal, several bony or shelly receptacles are seen around its circumference, into which the tentacula, $b$, are retracted, and the whole then withdrawn within the body, which is closed over it.

The lower part of this apparatus is united to the intestine, and here also appears the transparent vessel or Ampulla Poliana.

On narrower inspection the channels seem partly osseous, and partly cartilaginous. They are white circumferential sheaths receiving the inactive tentacula.

The central orifice is susceptible of great dilatation ; it communicates through the œsophagus with the intestine, towards one side of which, comnected with the cylinder, is the transparent vessel, Plate XI., fig. 7, a. The eight arborescent tentacula issue from the higher circumference of the case or cylinder at regular intervals, unless at one point, where 
two stand farther apart to allow the intervention of the two antennula between them, Plate IX. From the arrangement and multiplicity of parts in the tentacula, both in the earliest and latest display, and especially in maturity, they seem a vegetable product. Collectively, nothing ean be more luxuriant and beantiful.

During quiescence only the shaggy coat investing the whole body is seen; but as the Holothuria ronses itself from its passive state, and the cylinder begins to protrude, the contracted tentacula may be compared to the heads of asparagus in early vegetation. They develope very slowly and progressively into their most ample dimensions, at last displaying an indefinite number of subordinate parts, as dependent on size, on agre, or maturity. I do not know that I have ever seen those of any specimen in perfection; nor can I present the reader with an adequate delineation of them in full luxuriance, or of that interesting purple hue which is their peculiar character.

The rib or stem of the tentaculum is enrironed by branches gradually shortening as they rise upwards to the summit, and each of these branches is environed by twigs disposed after similar form and fashion, which also have their own subordinate parts. An extraordinary profusion of the whole decorates adults, wherein it may be discovered that the general outline of all is conical.

No farther distinction between the tentacula and the antennula is to be recognised than the difference of size and proportions of the individual parts of the latter, which divide into two principal limbs, each partitioning into five or six branches more bushy than those of the former, Plate XI., fig. 3, tentaculum ; fig. 4, antennula enlarged.

This Holothuria is the most timorous of creatures. It is only while in conscions security, and especially during the stillness of night, that the beautiful complex arborescent apparatus thus unfolds before the spectator. Then it becomes a wide shallow fumnel, the orifice in the centre being the mouth, towards which the incurving tentacula are always successively directed. The width of expansion depends on the capacity of the ressel, and the position of the funnel on the protrusion of the cylinder, which assumes various degrees of inclination, and appears sometimes at right 
angles to the adhering body. Though in itself rigid, this shelly organization is flexible in relation to the other parts, from the pliancy of the lower intestinal portion, from which it originates.

Each tentaculum is independent of its fellow, and each subordinate nember, branch, or twig, is free of all the rest. The funnel is constituted by the common expansion of the whole, and for this the night is chiefly chosen. But so timid is the creature, that amidst the fullest display and the most ample exercise of its arborescent organs, while sweeping through the water in obvious enjoyment of renovated invigoration, the slightest shock, or an approaching taper, though there be no eyes to behold it, interrupts the tentacular evolutions; the cylinder recedes, the branches contract, and the whole apparatus, now resembling a rich cluster of rye grass, is quickly withdrawn. In disappearing from view, the shaggy coat closes over it, withont leaving a trace of the opening whence it had issued.

Then will the animal remain in pertinaceous retreat, not only for the coming night, but for several ensuing.

It may seem extraordinary that such a large and complex organization shall be reduced so expeditiously, as to be confined within the cavity of the body undistended by its reception ; or, speaking more correctly, that each tentaculum shall be received in its shelly sheath, not exceeling six or seven lines in length, and scarcely one in diameter.

But all the arrangements of nature are perfect in themselves. They are so constructed, that neither check nor embarrassment shall impede their application and use.

We may conclude that the infinite parts of the arborescent tentaculum are tubnlar, that they are distended by a fluid in attaining their full dimensions, which is suddenly discharged to operate their reduction.

The fact is shewn in the detail of their formation, exposed by the origin or root of the respective members. While displayed, the whole quickly collapsing, are withdrawn: When returning to resume their evolution, absorption replenishing the eavities adapts them for their proper functions.

It is thus that the great Architect provides for his marvellous works. 

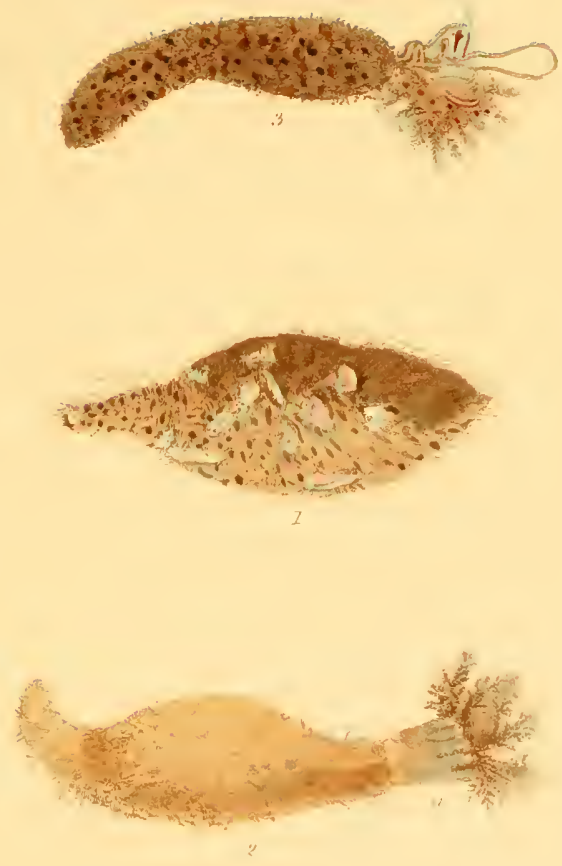

$$
\text { - Trtetionsine Tresen }
$$



In investigating the precise purpose of all this apparatus, its singular evolutions, its periodical display and concealment, we can find no solid basis whereon to rest any probable conjectures. We behold it again and again, we admire its uniformity, yet without reaching any satisfactory conclusions. We doubt whether the discharge of such functions be for an alimentary or a respiratory object, or for something else.

With rare exception, the funnel of this particular species of Holothuria never expands through the day. Evening always comes, and the night is often far advanced before the creature begins to sweep the water, and absorb the organs so employed. Now it is arouserl to action-at that same season appointed for awakening the tenants of the deep from their diurnal repose. Then it is that the green eye of fishes rolls keenly in its golden socket after their weaker prey-that the urchin, affixing its countless cables, pierces the indurated casements protecting their tender inmates-that the stellate hunter, in redoubled speed, glicles along by its extended suckers, to crush the yielding shells amidst its limbs, and devour their contents. Then, also, do the ravenous Crustacca become fiercer against each other, or overpower their common victims. It is especially during night that the Sea long worm unfolds whole yards of its unmanageable simuosities in quest of food, or for change of shelter, while its lesser fellows abandon their secret haunts, as if to recreate themselves from the tedious restraint which the presence of light has imposed upon them. Whether it be for obtaining sustenance-whether, if such be their nature, to seek a mate-whether to construct some curious edifice, whereof heaven has marle them the innate architects-or be it merely to sport amidst the waters, - night is alike the scason for excursions of enjoyment and occupation, whereas the day of the upper world is devoted to rest. Nay, so inherent is this instinetive nature, so evident this peculiarity, that the sun has scarcely passed the meridian, when certain tribes begin to betray their restlessness, and seem ready to put themselves in motion.

All these facts, combined with the singular mechanical exercise of the external arborescent organs of the Holothuria, suggest the probability of their being designed for some alimentary oflice. 
The nature of the food, however, without ocular demonstration, can only give birth to infinite conjectures. We cannot forget the extreme timidity of the animal, which seems entirely to exclude living prey. Likewise, the extreme delicacy of the tentacula apparently adapted for entrapping only the smallest and weakest creatures, if that be the mode of capture — the most defenceless and least resisting,-presuming the Holothuria to be carnivorous, of which there is no evidence. By a common law, with few exceptions, the vast preponderance of aquatic animals become each other's prey. The stronger overpower the weaker; the boldest fall the victims of artifice. So few are sustained on vegetable products exclusively, that all may be said to perish as alternate sacrifices. Many are devoured alive by enemies of such contemptible appearance, as to form but specks in relative dimensions; and some, though not courageous enough to attack the living, feed greedily on the dead. By the immutable ordinances of nature, incessant deperdition and incessant reproduction prevail, whether on the earth, or amidst the waters.

But how can the Holothuria be an animal of prey? The presence of a trifling insect seems to fill it with alarm, restraining evolution of its arborescent organs; and the contact of any extraneous, though diminutive substance, commonly leads to their entire retraction from view.

Neither experiment nor observation regarding the food of the Holothuria has proved satisfactory. The intestine is always full of a soft brown or yellowish matter, and dark pellets are sometimes found in its vessel, but under great irregularities in everything.

Amidst infinite trials to preserve the life and vigour of different specimens, I cannot affirm that any substance whatever has been acceptable. Many particles of animal and vegetable matter were occasionally brought in contact, or within reach, of the arborescent tentacula, which, having rather an adhesive than a prehensile faculty, might convey them towards the mouth. Likewise, when the weather was genial, and the whole funnel finely displayed, I have dropped some fragments of mussel gently on the tentacula. Their contact apparently excited a slight effort in these organs to seize and convey them to the orifice of the mouth; 


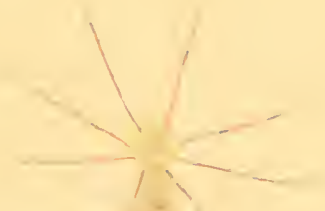

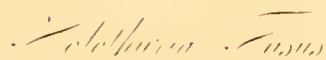



and in this way several were absorbed successively. Next evening, a larger piece was rejected, being perhaps unmanageable, for it was retained a long time among the branches. Small portions of worms dropped over the mouth in the course of other evenings were swallowed ; but of many attempts to induce any specimen to feed, few were successful ; so few, that I must rather ascribe them to accident. Fragments falling on the orifice irequently rested across the roots of the tentacula, whose evolutions, sweeping through the water, or curving into the interior, continued; and they were sometimes suddenly retracted. These experiments were carefully made with the specimen represented Plate IX. in particular, besides with others. But at length, from apprehensions of injury, though perhaps groundless, such artificial supplies were abandoned, and that animal left to shift for itself as usual. After a considerable time, when it began to pine, and became reduced, they were renewed, yet not more satisfactorily; and very seldom could it be said to have fed. Nevertheless dark pellets, apparently frecal, were seen in the vessel, as if consequent on the supplies.

Concerning this subject, which is so important in aiding the researches of the naturalist, we should remember, that the choice of many animals, whether carnivorous or phytovorous, is most fastidious. Some rather perish than receive that of which others are insatiable, for nature has determined it to be unsuitable in respect to them. Perhaps the whole carnivorous Mollusea and Vermes prefer the flesh of such aquatic animals as have the least resemblance to themselves. Other tribes, such as the Crustacea and Echini, devour whaterer they can master. The former are perfect cannibals-making no nice selections, and feerling even on shelly substances. Numerous varieties of every kind, however, were offered to the Holothuria, without my being able to ascertain that which might be adapted for its sustenance.

It cannot be supposed that a large compact fleshy animal attains the ample dimensions and weight of the Holothuria, without an adequate supply of food. The quantum of animal matter in a Holothuria, may be equivalent to what is in a rat or a weasel : or, indeed, the largest species inhabiting the Scotish seas may be compared to a small 
cat among quadrupeds. More of the tenants of the sanie waters are perhaps rather under it than above it. Thus, such creatures must have suffieient subsistence, of whatever kind it may be, and however obtained.

A leamed author indeed, already quoted, the Professor Delle Chiaie, to whose minute anatomy of the Holothuria science is deeply indebted, seems to conelude, that the aliment of these animals is ehiefly vegetable and miseellaneous subtanees, in saying, "Le Oloturie eibansi di figli, di coralline, di alghe, di arena e di altre immondezze di mare."* But such would be rather indigestible ingredients, whence it is not improbable that heterogeneous matter of the kind, instead of being the subject of ehoice, may be intermingled with or adhering to animal substances, and swallowed along with them : Nor is so great an exception to general rules admissible without farther evidence. No naturalists of ny aequaintance, among the few having had opportunities of dissecting this animal, found any definite remains in its intestines; and whatever I may have myself observed, might be rather referred to the residue of substanees purely animal, than to vegetable or zoophytical produets.

The food of the Holothuria seems still problematical.

Nevertheless, the tentacular evolutions are too remarkable-too peculitr' a feature-and altogether unexampled, in as far as I know, among living beings, not to excite great euriosity regarding their specific purposes. The incurvature of these organs ensues alternately, not successively, in regular order following the first in action: but the same tentaculum is never observed to descend twice into the orifice of the mouth: one or two of the circular series always intervenes. However, one of the antennulæ uniformly descends after a tentaculum is down, and the other frequently replaces this tentaeulum when withdrawn. Sometimes both antennulæ remain a short time below, after the tentaculum has returned: and their office there evidently occupies them much longer than that of the tentaeulum, which always rises speedily to resume its full dimensions from the contracted state. With this alternate or suceessive exercise the animal continues engaged whole hours, after a manner both to the entertainment and admiration of the spectator.

* Delle Chiaie, Descrizione Zoologica ed Anatomica de Alcuni Specie di Oloturia, $§ 8$. 


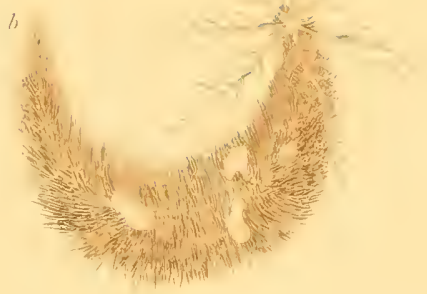

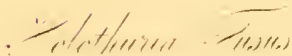



Future observers may discover the genuine functions of these organs which are at present very doubtful. All the authors whose words I have in recollection, except the Neapolitan professor, assign a tentacular office, or what is equivalent to feeling in the larger animals, as their nature, while he conjoins something respiratory along with it.*. To this, however, as will afterwards appear, there are certain relevant ubjections. Nevertheless, the opimion of so learned and industrious a naturalist merits high consideration.

During quiescence of the Holothuria, the tentacula occupy the narrow circumferential channels of the cylinder, which is retracted within the cavity of the borly. Their display is extremely irregular, and is often so transient that it may seem quite capricious-nor essential to the necessities of the animal. A specimen obtained in June, floated as if turgid with water. The tentacula sometimes protrnded like a purple plume, along with some part of the cylinder. But they were never seen completely expanded until the subsequent March, that is, for nine months. This specimen afterwards displayed them occasionally during the whole day in full vigour,-an incident which occurs very rarely. Another specimen procured in December, was not observed to display the tentacula before the end of March. These two specimens sometimes assumed the form of a horse-shoe, when the two ends, from the great curvature of the body, came alnost in contact.

The destruction of any resisting prey is irreconcileable with the extraordinary timidity of this creature. It is firmly rivetted to the spot of its selection by numerous suckers, which, in the present instance, constitute the shaggy coat investing it. An adhesive faculty also attaches shells or fuci to the whole body, when coming in contact. All this is spontaneous, but sooner than quit its hold by violence, the Holothuria will submit to the severest injuries, even to absolute destruetion. Thence may be understood the difficulty of obtaining specimens entire. Were it bold and carnivorous, the same powerful adhesion might enable

* Delle Chiaie's Observations were made on a species different from mine. After describing the internal respiratory organs connected with the intestinal canal, he says, "the tentacula are also the medium of the respiration of these admirable beings," $\$ 4$. 
the Holothuria to seize and retain animals larger than itself, and possibly render them its prey.

Attempting to solve the question of aliment, has led me into this prolix detail, for the purpose of shewing of what importance it would be to naturalists studying the properties of living beings, which, indeed, is the best foundation of zoology. Though some creatures survive incredibly long without visible sustenance, perhaps secreting an invisible pabulum from the circumambient fluid, all nature opposes the permanence of life without nutrition; thus, however gradual the decline, it prevails at last.

The body of this species of Holothuria is totally covered by flexible, extensile papillæ, alike instrumental in adhesion, and in aiding progression. It is by their means that an artificial shelter can be framed occasionally of the fragments of shells and fuci. Doubts have originated whether others, such as the Holothuria inherens, do not occupy a tube with a close extremity. But I have seen nothing to indicate that any of the tribe are so protected. Most specimens are bare, though the fusus is always disposed to attach fragments within reach of the papilla or suckers to the body.

During quiescence, or while floating, the skin resembles shagreen, the suckers being scarcely, if at all, prominent. When somewhat prolonged, the whole body is invested by a woollen-like coat, and when, exercising their proper functions, they extend abont three lines, with the extremity applied as an enlarged disc to some solid adjacent surface, Plate XI. fig. 2.

The number of these organs is great, but it has not been ascertained that those of this species are distributed in any regular arrangement; they overspread the whole skin. In certain species of Holothuriæ they are disposed in definite rows, or longitudinal bands, specifically characteristic. On gross computation the suckers of this specimen, Plate IX., exceeded two thousand. When disengaged they are very flexible, moving freely around, and each has an independent action. When occupied in fixture, it appears, from the most accurate microscopic observation practicable, that this is a simple application of the extremity some- 
what enlarged in trumpet shape ; and that the intermediate portion is a muricate or tuberculate cylinder. Possibly subordinate organization might be discovered in the flattened disc ; but the opportunities of bringing any part of the organ whatever under the microscope are so rare, as to prove a great obstacle to inspection. Were there any question of their solidity, they might be supposed absorbents, for the peculiar organization employed in this function is not obvious,-it goes on however to a great extent. Sometimes the flattened dise seemed reddish during observation, and conjectures were entertained of the motion of globules or a fluid in the eylindrical part. But the illusions concomitant on artificial aid are so ready to disturb the truth, that the naturalist distrusting himself cannot repeat his observations too carefully, or too often, before arriving at definite conclusions. The microscope demands many precautions. Besides the numerous suckers anchoring the subject to the sides of its vessel, many free and disengaged stretch around in various directions, as if in search of other objects. Several days frequently elapse before weaker specimens affix themselves, therefore some exertion seems requisite.

The animal being secured by adhesion of the suckers, its position is seldom changed afterwards. Curvature of the crescent may augment or diminish while adhering; and adhesion ceasing, progression may ensue. For a long time I was much perplexed as to the mode wherein this was accomplished. I could not form an opinion regarding the advance of the one or the other extremity. From certain indications, and especially from the inadequacy of the arborescent apparatus to encounter resistance, I rather concluded that it must be the opposite extremity; and this fact was apparently corroborated by the timidity of the animal, and its singular care to protect the tentacula. But I was mistaken : the Holothuria, as most natural to believe, advances head foremost,-and with the arborescence displayed. Commencing progression, the suckers in front are relaxed, while those free behind are brought forward and secured ; the former fix again, and the latter being loosened, the body is advanced. Thus are steps effected, and the transition of the Holothuria 
from place to place effected. The tentacula being always first rather affords confirmation of the faculty indicated by their name.

During entire months a specimen will remain stationary and void of all activity, unless in the evolution of these organs, and even this will be restrained, as already said, by the presence of any other animated being.

In common with other tenants of the deep, the Holothuria betrays its nocturnal habits with the decline of day. Only once in the course of two years that the specimen of Plate IX. survived, were the tentacula unfolded during the day; nor did I ever see it in progression the whole of that time. However, all are not alike timid. A small specimen both disregarded the presence of part of an amphitrite in the same vessel, and remained completely displayed a whole day. Originally it lay a montl dormant in an ovoidal form. After three months it evinced particular boldness, by allowing the vessel to be gently raised and swung in the hand, without retracting its organs. A specimen of considerable size, obtained on the sixth of June, never displayed its arborescent apparatus completely before the tenth of Narch subsequent, when it formed a fine funnel, of a crimson colour, two inches wide, and an inch and a half deep. This animal was very pale, little darker than yellowish grey; somewhat larger than the specimen Plate IX., therefore the branches were hardly full grown. It became grayer, and the tentacula coloured between lake and crimson. At length they came to be constantly displayed, though from the excessive timidity of the animal, the slightest shock occasioned their disappearance.

Thus, some slight variation is seen in the habits of the Holothuria, preserved under observation, just as betrayed among the domestic animals familiar to us. They are timid or they are bold. The common nature of a genus is somewhat diversified in its species: and great discrepancies shewn by individuals, denote the difference of temperament gradually leading to a separation.

But there is little interest to be found in such descriptive remarks. Naturalists have indulged in scarcely any other of the Holothuria. I say 
there is little interesting here compared with some very remarkable physiological anomalies presenter by this animal.

The aspect of the specimen, Plate VIII. fig. 1,-its resemblance to an elongated pear, with a villous coating when first procured, will be recollected. Between a fortuight and three weeks from its acquisition, the tentacular apparatus, imperfectly expanded, protruded for the first time along with the cylinder, from the upper part of the body. Next day a large proportion of the intestine, descending from it, came forth also; and the animal having crawled up the side of the vessel, allowed most of the investing shelly fragments to fall off. No external symptoms of suffering were demonstrated; yet it was reasonable to apprehend that these, and some other marks of weakness, were the prelude of decay : and this apprehension was aggravated by the separation of all the orgaus protruded from the body, on enptying the vessel for replenishment. Still, the Holothuria seemed no more affected now than hefore. Assuming an oblique position, it rose on the side up to the ver: edge of the water. But, instead of ascending higher, it remained affixed immoveably to the glass, for the water is never quitted by this species.

Following the history of the detiched organs:-the tentacula rose from the extruded mass like crimson tufts, and the whole testified signs of vitality for several days. When remover to another vessel, death and decomposition ensued, as might have been expected.

But a premonition of no slight utility was afforded here, evincing the liability of even the most practised naturalist to error. Muller, whose name is justly enrolled with those of the highest order, deluded by certain fallacies, on beholding the upper portion of such a mass, determined it to be a perfect animal, which he distinguished as the IIolothuria penicillus. Repeated opportunity and patient investigation can alone discover the truth amiclst ambiguities. The Iolothuria penicillus, to which a place was long assigned as a distinct species, must be therefore now expunged from the Systema Nature.

So many extraordinary instances of complete renovation of defective organs had been witnessed in the course of years, and of such as were endowed with all the faculties of those they replaced, that, after 
brief survivance of this specimen unaltered, I began to entertain expectations that Nature had something in preparation here. Such, indeed, would be a wonderful effort : yet, during subsistence of the vital principle, her energies are incessant and inexhanstible.

Mutilation had occurred on the fourth of December. From the fourteenth of that month, the body remained stationary, rather lower than the surface of the water, only extending itself on replenishment of the vessel-a precaution never to be neglected in any circumstances. Even then every foreign substance, on reaching the villous coating, was retained as firmly as before.

On the twenty-fifth of February, or eleven weeks subsequent to the date of mutilation, reproduction had made advances,--short, transparent, regenerated tentacula were displayed; but very bare in comparison with their precursors and the luxuriance of maturity, for they had only a few lateral twigs.-All were speedily withdrawn. Nevertheless, enough was discovered to prove that the subject had not sustained any essential injury, from the violent disruption of so large and important an organic mass.

In the course of time some rermiculi had found harbour in the vessel, and about the animal itself, which might be injured by their decay. Their presence might also restrain the display of the regenerating parts. By artificially vitiating the water with slight putrescence, all these noxious visitors were induced to forsake their haunts, and, rising to the surface, could be readily removed.

On the 27 th of the month, the new tentacula were fully exhibited, when they consisted of eight, the proper complement, besides the two antemulæ, all rising from a short white regenerated cylinder. Each tentaculum extended about nine lines, or three quarters of an inch, and was provided with 16 or 18 subordinate twigs : the whole quite colourless, but distinctly seen while slowly withdrawn, Plate X. In another week they exceeded an inch. During the subsequent fortnight their progress was still more rapid, as they could not have been inscribed in a circle of less than three inches diameter. Their structure had become more complex, they were discovered waving in their element, and they were tinged 
the faintest red. Fifteen weeks having elapsed from the date of mutilation, the regenerated portion had not only recovered its most important organs, but all these were discharging the wonted natural functions, sweeping the water, then curving into the mouth, which dilated for their reception, and contracting as they withdrew.

Thus did increment gradually advance. The ramifications, augmenting both in size and number, were stained with lake coloured patehes, especially at the angles, and on the thirteenth of June, when, having attained nearly their ultimate dimensions, the funnel which they formed oceupied a cirele of about five inches in diameter, Plate IX.

In this manner was the whole of such a singular, beautiful, and complicated fabric reproduced from its very origin, while a fortunate concurrence of circumstances permitted uninterrupted observation of its progress.

Though the parts exposed externally were so conspicuous, and so interesting, they enlarged still farther; but I cannot affirm that theyerer attained the dimensions of a full grown specimen, or the colour proper to the subject or the species. The arborescence was neither so luxuriant nor so dark. After eighteen months' increment the hue was only deepening. That of the largest specimens probably tends either to red, or to some combination wherein red is predoninant.

Perhaps in its native state, in its orginal abode, and with ample congenial sustenance, reproduction might have advanced quicker, and with deeper colours. On the other hand, the ligher temperature of an apartment than of the sea ought to promote more speedy organic evolution. Let it be remembered also, that naseent organization is always paler, and that the elements of the animal creation are hidden in transparency. Whatever be the colour peculiar to the embryonic stages, the young Holothuria is perfectly white some time after exchsion from the egro.

The specimen Plate XI., fig. 1, was of the palest grey, the tentacula quite transparent, and as long as the body. The same is seen of others, -one much smaller, for example, which, when they were retracted, might be compared to a large grain of corn. The tentacula of each were 
quite as long as the body, and the same evolutions exhibited by them as in the adult. In minute specimens the eylinder is perfectly white. Indeed, so far as I can judge, white is the colour of the nascent Holothuria, and some never darken. Certainly intensity of colour is not a definite characteristic of an infinity of marine animals, whence natnralists must beware of denying identity from the discrepancy of specimens in this respect. But it is undoubted that the arborescent organization multiplies with the size and age of the specimens, or in proportion to the period of its own subsistence. Hence their true luxuriance, beauty, and symmetry have never been hitherto diselosed by the hand of art.

The loss and regeneration of such an assemblage of important parts, those whereon the sustenance and safety of the animal apparently depend, affords an ample field for the profoundest meditation. That beings so humble are yet so privileged; that those inferior works of creation, as they are designed by the ignorant arrogance of mankind, should be enabled to bear privations with impunity which would be inevitable death to the strongest tenants of the earth, might argue their superiority among the special favourites of Nature.

The history of this individual, so prolific of interesting incidents, received various corroborations of the genuine nature of the Holothuria, from other examples witnessed in different specimens, which shall be postponed for the present, that the narrative may not be interrupted. Such corroborations will be the more valued, considering the rarity of these products, and the extreme diffieulty of obtaining them entire.

Looking back to May 15 th, just about six months after the capture of the specimen, for we had advanced above a year beyond that incident, it hiad altered its form together with its position in the vessel. The obtuse anterior, now elose, adithered to the side, while the sharper posterior extrenity, somewhat lower, projected towards the center of the vessel. From the shortness of the curvature below, together with the unequal height of the two extremities, the whole bore some general resenblance to a bird's fountain.

During the night a greenish albuminous mass, consisting of at least 5000 eggs, had been discharged by the Holothuria, and now lay under the 
1

${ }_{0}^{3}=$

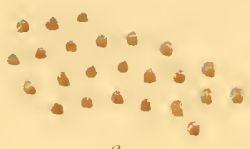
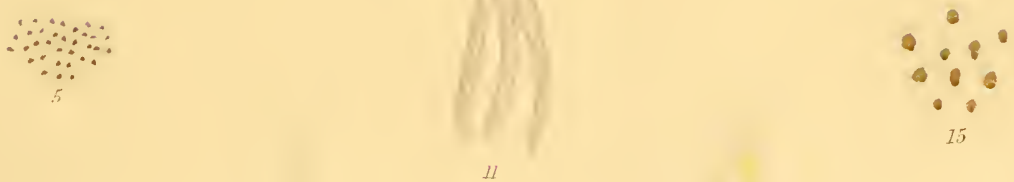

$$
20
$$
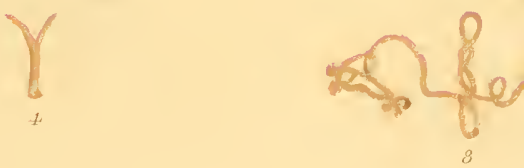

creature. All were spherical, the fifth or sixth of a line in diameter, of an olive colour, and containing a dark speck in the centre.-Plate XI. fig. 5., portion of spawn slightly enlarged; fig. 6, more enlarged. When first observed, the ova seemed to be discharged from the acute or posterior extremity of the animal, where the oviduct might have been supposed to terminate. But it is not in that place, it is nearer the root of the protruded tentacula; nor do the ova thus escape.

They then rose with such foree as to reach the surface of the water, two or three inches above that orifice ; and in falling, accumulated below on the bottom of the vessel, around the curvature of the body. Some were apparently absorbed in the orifice when they fell down, and thence a secoud projection or apparent discharge ensued.

However, on weighing all the concomitint circumstances, I was induced to conclude, that the apparent absorption was only a recoptionan accidental one from the position, and the course of the organs and the ova.

We have already spoke of the stream ejected by the IIolothurin pentactes, which may be of long continuance, from the absorbing and discharging faculty : also of the probability, that the respiratory organs are benefited by this process. Many aquatic animals, and among them the Holothuria, give ocular demonstration of it, by the formation of a vortex in their element. For this some are provided with extermal, some with internal organs. But the observer must beware of delusion, by the mere revolution of buoyant particles on a consiclerable surface, which often ensures, particularly in open shallow vessels, from invisible currents of air, alternations of temperature, and the like.

A gentle vortex was sensible in the vessel of this Holothuria, on the evening which preceded its spawning. In the next place, more forcible resumption of the jet having disturbed the falling or the fallen ova, conducted them upwards by its force, and then some of them fell back accidentally into the orifice, from which the water was discharged.

Although the greater portion of the spawn formed a mass consisting of ova imbedded in gelatinous matter, many floated separately among the water. This happens frequently, either from their being free 
originally, or detached subsequently. Four months after the present copious spawning, eighty or ninety ova, pure white to the naked eye, though exposing a dark central nucleus, were found, principally on a leaf with which the parent had invested itself. They were imbedded in a transparent gelatinous substance, whence all were detached on changing the water, and floated with nearly the same specific gravity.

Notwithstanding every precaution to preserve it on both occasions, none of the spawn proved fertile, which is to be the more regretted, as the early history of the Holothuria, and particularly the progressive evolution of the original organization, is yet unexplained.

Regarding the latter, there are probably some equivalent data, indicating the uniform process which may guide the first evolution of the tentacula, and that attending their regeneration. All the parts are successively developed. This specimen had undergone an extraordinary mutilation, which was not fatal. The renovating organs were much advanced in May of the second year of its custody, which had then continued about eighteen months: and in the course of the succeeding months, when nearly in its greatest vigour, about twenty-four lateral branches sprung from each stem of the tentacula, the higher being merely twigs; the others abbreviated in proportion to their distance from the cylinder. The second on the stem of some was longer than the first or lowest. Towards the latter part of June, flitting crimson patches occasionally stained the whole arborescent apparatus; and in the earlier days of July, the reddish colour was more predominant than previously.

From the first of September the size of the animal diminished. Though displayed on the 8 th, and sometimes subsequently, the branches manifested less vigorous action. Their scope was confined. Yet distension of the body to almost its natural size, attended renewal of the water on the 13 th ; the antennulæe were in feeble operation; also the cylinder protruded feebly, with the tentacula reduced to a tuft, as if too weak for evolution; and the whole apparatus was soon withdrawn. But the body became distended and pellucid as before, without displaying the organs. 
Next morning, the body, much reduced, hung perpendicularly down the side of the vessel, while the cylinder protruded along with some intestinal portion; and this prolapsus gradually augmented. Yet the branches were still partially unfolded in the feeblest exercise.-Plate VIII. fig. 3.

In the evening the whole organic mass separated from the body, and fell into a watch-glass which had been introduced to receive it.

When extricated from its convolutions, the intestine proved to be just five inches long by a line in diameter, nearly equal throughout, but enlarging slightly from the cylinder. Now, the hard or shelly portion was discovered to consist of the union of a circle of hollow thattish pieces. The Ampulla Poliana, Plate XI. fig. 7, hung from below. Such organs without the ovarium, commonly appear somewhat as Plate XI. fig. $\delta$, which shews the intestinal parts separated from another specimen. The separate arborescent apparatus of one is seen, Plate XII. fig. 3 : and the shelly sheath, $a, b$; Ampulla Poliana, $c$; and intestine (of another), fig. 4. Here the dark belt denotes the lower part of the tentacula. Only a portion of the cylinder, with its tentacular sheaths, was preserved.

The tufts formed by the contracted tentacula still testified a tendency to their ordinary functions, spite of separation from the body.

Next day the sac or integument which had contained all the interior, adhered shightly to the side; on the subsequent morning, it lay at the bottom of the vessel. A yellow bunch of filaments, constituting the attenuated or immature oxarium, protruded from the anterior extrenity. It resembled a mass of coarse threads, some of them folded double ; and this also separated with a brown intestinal portion. Remarkable enough to observe, the animal, under so great a mutilation, yet shifted its place, but weakening more, and shortening to an inch, it was transferred to spirit of wine, wherein it scarcely contracted farther with the extinction of life.

This specimen survived exactly twenty-two months under observation. Had it remained in its native abode, or had it been even in a vigorous condition at the date of the latter, the second intestinal privation, there is much probability that the important organs then lost would 
have been regenerated. We know that these were the second set which had been generated in the sac, the first having separated within a month of the original acquisition of the animal.

New and most interesting illustrations of the reproductive process advancing in living adult animals, are afforded by the preceding narrative. They shew, not merely that a ereature of considerable size, and complex organization, may survive the loss of many important parts, whereon exclnsively the vital functions might be supposed dependent, and that during a long interval, without perishing, but that these will be regenerated entire. Nay, that a second loss, apparently of equal extent and importance, may ensue, yet leaving us to presume, that it also will be repaired.

Nevertheless, that such mutilation results from some natural process or condition ineident to the animal, is void of all probability, for it must be rather ascribed to accidental causes, or consequent on something beyond the course of those physiologieal arrangements regulating the ordinary existence of living beings. Perhaps, like rupture of the sac of the Holothuria pentactes, it follows exposure to a certain degree of constraint or violence unknown.

There are eertain animals, it is true, which lose and regain important parts, becanse those originally developed in their system may be of insufficient strength or permanence to accompany them throughout life ; or, as seen in the larger tribes, they may be lost and regained periodically, the new serving to discharge the functions of the old. Likewise the organs of certain creatures, few in the begimning, multiply continually by new evolution during a long portion, if not the whole of their life. By a singular natural process also, propagation of the race may be carried on simply by a fragment separating from the body of the parent, wherein the organs are for a time latent, and then visibly dereloped for essential purposes, as well as proving resemblance to the animal when entire. These, and other similar peculiarities, open to the view of the admiring naturalist additional sources of wonder at the arrangements which may affect individnal form without affecting life. But that divulsion, rending the very intestines with a great complex organic mass from the body of 
the Holothuria seems of quite a different character, - at least as far as hitherto proved by observation.

It is evident, however, that the reproductive energies with which this curious animal is endowed are of the most powerful kind.

The preceding facts, diligently noted on their occurrence, were confirmed by other examples throughout a course of years. Therefore, notwithstanding the detail, perhaps too prolix, alrealy given, I shall add a few illustrations relative to the various features distinguishing the nature of this species of the Holothuria. They must be considered only as detached remarks, collected from irregular opportunities of observation, not as discussion from a connected narrative.

The Holothuria fusus dwells in the northern seas, about Orkney and Shetland, also in the estuary of the Forth, where it occurs occasionally, though very rarely, as far up as opposite to the city of Edinburgh, and lives in different places down to the open ocean. It is probably more abundant in certain districts, for Nature seems to have appointed a particular region as more congenial to each different tribe of her animated products. If so, why should a creature be rare whose progeny may amount to 5000 in a single season? Those reaching me, indeer, were recovered only by chance; but, if memory serves, I learned in Narch 1838, from a skilful naturalist, Professor Goodsir, that during a violent storm on the first of the same month, numbers were cast ashore at Anstruther Easter, in the county of Fife.

Five specimens were at that time in my possession.

The colour of the Holothuria obtained, in as far as I could discorer from deep water or the open sea, is white, and thence of every shade to dark grey; the arborescent apparatus then seems to be dark crimson. The animals are besides sometimes of a straw-yellow colour.

The body in good specimens is three inches or little more in length, and in these the tentacula in full display extend as much, being quite as long as the body. Specimens seldom occur of larger size. But this may be from the persons employed in their pursuits of the fishery failing to resort to places the most favourable for increment. Such speci- 
mens will prove the source of many entertaining, instructive, and interesting observations.

There is extraordinary difficulty in determining the difference of species of an animal appearing in such disproportion as the extension and contraction of the tumid and empty Holothuria. The identity of the species may be most readily mistaken : also there may be varieties which require to be seen under the most favourable conditions.

From various circumstances, I feel little surprised that the species of the Holothuria are multiplied infinitely beyond the truth. If I myself be not mistaken in regard to species, I must conjecture that the Holothuria fusus extends a foot in length when full grown. The body of a specimen, nearly white, extended eight inches by about fifteen lines in diameter. It was almost cylindrical throughout, with very obtuse extremities. It assumed a curvature at the bottom of a jar. The tentacula, of a reddish colour, were never completely displayed : a gangrene consumed the skin of the lower extremity, and the animal died in five weeks.

Another specimen taken considerably eastward of the Isle of May, was of dingy brown, and five inches long in its contracted state. It survived but a short time, and died without evolution of the organs. Many specimens are dark grey. Could the fishermen be credited, the dimensions of specimens occurring to them, have exceeded the proportions here assigned by me. But independently of their propensity to exaggeration, farther than the Sea Pudding previously described, the Holothuria seems utterly unknown to them, both by name and appearance. I never met with one who knew the existence of such an animal, far less the variable and perfect form which it assumes.

I was unable to determine the species of the two last named, from not having obtained a sufficient view of either. Reflecting on the first, however, since the date of occurrence, I think it may have possibly been the long species described in the next paragraph.

I have been alike perplexed by others of ample dimensions, though never unfolded so much as to shew their actual formation.

The Holothuria fusus readily covers itself with whatever flexible or 
inflexible extraneous matter comes within contact, of which it cannot be easily divested. One remained thus, so completely clothed, during two months, as to prevent discovery of its real shape. Nevertheless, the wonted evolntions, and the greater extension of the posterior extremity ensued towards evening.

I repeat, that it does not appear that the loss of the arborescent apparatus, together with the ovarium and intestinal organs wholly, if that truly takes place, or partially, which is frequent, and their regeneration though essential to the continuance of life, are to be deemed a natural process.

A specimen of the same size, but lighter colour than that whose history has been given in detail, was procured on January 14. It occasionally assumed such a curvature, like a horse-shoe, that the extremities met. From the clearness of the body, and the constant concealment of the arborescence, I conjectured that the usual mutilation had deprived the animal of its parts. It was so, though not recently ; when the arborescence was first seen, on the last of March, or eleven weeks from the period of acquisition, it seemed to be full grown. The cylinder also, when protruded, was observed of full size, and perfectly white. The animal being much distended, July 29 , and having lost its adhesion, was transferred to a different vessel replenished with recent sea-water. Here it affixed itself next evening to the side, with the head lianging perpendicularly downwards. The arborescent and intestinal organs then beginning to escape, were discharged the following morning; and portions of an inmature ovarium a day or two after, when the animal had fallen to the bottom, where it died.-Plate XI. fig. 8 .

A specimen obtained in April, had assumed a globular form, rolling over the bottom of the glass,-nor was it unlike an alcyonic mass. In a week it affixed, being somewhat elongated ; and in a fortnight, it had assumed its proper crescent-shape, of about equal dimensions to the principal figure described, Plate IX. Its position was shifted daily, yet the precise mode of progression could not be ascertained. As usual with this species, it attained its full size about ten in the evening. In five weeks the arborescent apparatus, along with the ovarium, protruded like 
a mop from the anterior, and, added to this, in a few hours the whole intestinal aggregate, gradually discharged, lay free on the bottom of the vessel. Here the tentacula and antennula, much contracted as usual on separation from the body, continued some time imperfectly exercising their ordinary functions.

Meanwhile, the shaggy sac or integumentary body itself, deprived of all this important organization, remained adhering to the glass as before privation, but, for a day, comparatively quite flattened. However, adhesion was firm ; and the partial recovery of its pristine rotundity and natural figure, with the lapse of two more days, showed that turgescence did not depend on the absorption of water, to be effected by means of the lost organs.

No external indications of reproduction were betrayed for seven weeks; nor, by illuminating the sac as much as practicable in such an opaque substance, could any renovated interanea be discovered. To obviate the injury of angmenting temperature in an apartment, the specimen was exposed during an hour or two to the cool nocturnal air.

Owing to my absence, and certain unavoidable circumstances for a month preceding the middle of Angust, this specimen was entirely neglected : it had lost its adhesive quality, was greatly contracted, and rolled as an ovoid below. Replenishment of the vessel revived it in six hours.

From the end of August it became whiter and whiter, and towards the middle of September, a dark internal substance announced regeneration there.

At last, in four months from the date of mutilation, recovery of the essential organs, whereof the animal was then deprived, now appeared, by the display of new tentacula and antennula, exereising those evolutions peculiar to their nature.

The length of the cylinder did not exceed a line in the first week of October, while the tentacula and antennula were scarcely more than visible from extreme transparency. One of the former had acquired twelve twigs on the fifteenth, some of these without subordinate parts. 
A fortnight later they had extended half an inch, and some had fourteen twigs. Thus the evolution of each part is successive.

As the dark internal substance apparently angmented a month before this latter period, it wight be from the early regeneration of the arborescence, though imperceptible to human observation.

The creature declined from the first of November. It shrunk extraordinarily, at length remaining but an inch in extent, and a quarter of an inch thick. The intestines protruded by a rupture in the side; and it died on the eleventh-having survived just about seven months.

To me it seems doubtful whether any individual of the Inlothurin fusus, young or old, large or small, is exempt from snch mutilation, which is so common as to be apparently incident to all. The body then seems an empty sac : yet, by some elements of organization still preserverl, rather than to be ascribed to new depositation, it becomes turgid from absorption of the circumambient fluid, the same as when entire. Perhaps the absorbents, still unknown, may be connected with the respiratory organs, which are certainly retained. I have never olserved them discharged along with the interanea. The precise quantum of organizattion lost on such occasions merits farther investigation. It may comprehend some important parts which are readily overlooked.

The position and functions of the respiratory organs are more favourably exposed in the subject of the prececting paragraph, the Holothuria pentactes.

Professor Delle Chiaie remarks, that some of his Holothuria survived the loss of the intestinal canal fifteen clays, not a few hours only; as had been advanced by Bohadsch. It is uncertain whether either of these anthors had seen the fusus ; probably not. The latter, Bohadsch, says he was "struck dumb with astonishment on finding the intestinal canal full of sand, discharged from the posterior extremity of one" he had carried home from the shore. He had concluded that the purpose of this mutilation was for the intestine to carry out the ovarimm along with it. But he seems to have changed his opinion; and he obviously mistakes the ovarium for intestinal cxca. Bohadsch considers it almost 
unexampled in Nature, that " each animal of three others should have remained several hours alive after losing the intestines."*

The fact is, that the destruction or indemnity of the specimen may depend on the mode whereby the parts are evacuated. If this ensues by the anterior extremity of the Holothuria fusus, regeneration commonly replaces them ; but if by the posterior extremity, the animal invariably perishes. Probably the respiratory organs are irrecorerably injured, for the rupture whereby the intestines escape is truly in the vicinity of the great cloaca, with which they are so intimately connected. Even a slight protrusion here is always a mortal symptom.

The fact now related perhaps determines the nature of what is called Trepang, or Beche de Mer, so perplexing to naturalists, which is carried from the Southern Ocean especially to China, as a delicacy for the luxurious.

But the species must be different from that which is under our consideration, and may be more akin to the Holothuria pentactes. $f$

Propagation.-The Holothuria fusus is a very prolific animal. Its ample ovarium consists of many ropes of ova, these being discharged, as already said, amidst an albuminous matter. The ropes terminate in ob-

* Bohadsch, De quibusdam Animalibus Marinis, § 6, pp. 88, 89, Dresdce, 1761, in 410. + "On a reef of rocks near the island Raiatea, is a huge, unshapely, black, or brown slug, here called biche, from six to seven inches long, and five to six broad. It is caught in vast quantities, and not only regarded as a great delicacy by the natives, but, being cured, has become a valuable article of commerce to the China market, whither it is carried from many insular coasts of the Pacific by American ships. One of these disgusting masses of morbid matter, endued with sensation, was taken into our boat. Being wounded, the dying animal protruded all its entrails by the tail end, and learing the apparent body a mere thick skin. We have seen a number of lads fill three canoes in two hours with these sea snails." -Tyerman and Bennet's Voyages and Travels in the South Sea Islands, 1821-29; vol. i. p. 541 ; vol. ii. p. 256.

Mr Beale speaks of the Beche de Mer, or worm of the sea, found at Oahoo, one of the Sandwich Islands, being considered a great delicacy, though " almost as tough as caoutchouc."-Natural History of the Sperm Whale, p. 261.

The reader may also consult Mr Frederick Dobell Bennet's Narrative of a Whaling Voyage round the Globe, 1833-36, vol. i. p. 175, where he identifies the IIolothuria with the Trepang, esteemed a delicacy by the luxurious. 
tuse extremities; some are folded double; and in a great number, if not in all, the ova are arranged in more than a single row, Plate XI., fig. 9 : end of a rope, enlarged, fig. 10 : extremity of ropes, enlarged, fig. 11.

When preparing to shew a naturalist of my acquaintance such objects, he assured me that no one had ever seen the ovum of a Holothuria. Certainly very little is said of it.

In all instances, excepting two, the ova have been green of different shades, or yellowish. The ovarium tended to purple in one, it was red in the other. When protruding by an accidental rupture, it resembles a mop or brush.

The specimen Plate VIII., fig. 2, lost the whole arborescent apparatus within two or three days of its capture. Nevertheless it seemed still plump and full of spawn. In ten days a large ovarium, composed of numerous ropes, protruded like a brush, the ova irregnlarly distributed in one, two, or three rows, all of a greenish-yellow. Probably the ropes are in reality long and folded, they have some appearance of being tubular, which may be deceptive. In the course of extent they are of unequal diameter. The ova are minute, spherical, or slightly ovoidal, consisting of a nucleus within albuminous matter. A few have occurred of a yellow colour ; but green, greenish, or greenish-yellow, is the common hue, Plate XI., figs. 5, 6. 12, 13, 14, 15. Their natural aspect appears in fig. 12.

Spawning has ensued in February, March, April, May, and June, when many thousand ova have been produced by single individuals.

But to my great concern, spite of the most careful treatment, none have ever proved fertile. On no occasion having been from large specimens, I was almost induced to conjecture that the Holothuria must be of a certain age before the spawn is prolific,-a fact not likely. I confess. but which is to be ascertained only by future observation.

It would be very interesting to behold the development of the young from the ovum, and to follow the progressive evolution of the parts. But I have not been so favoured. It is by the merest chance that smaller specimens can fall into the hands of the observer. From 
these, however, we may collect, that the early external organs are very few, which is confirmed by the slow and gradual evolution of regenerated parts, to replace the loss of adults in a more perfect state.

A vigorous young Holothnria is represented two months after its capture, Plate XI. fig. 1 . It lost the arborescent apparatus, and died after having been the subject of observation during six months. Eight years previously, a minute milk-white specimen occurred, about four lines long, by one in thickness, the tentacula extending a line at the utmost, distinctly visible by the naked eye,- the whole resembling a maggot, Plate XI. figs. 16, 17. Of the species of that particular specimen, however, I speak with some diffidence, owing to the difficulty of getting a satisfactory view. At the same time, its genus was evident. The curvature of the body, the display of the tentacula at night, their introduction into the mouth, where stripped and whence withdrawn, besides the firm adhesion, were all the same as in adults.

Another specimen, little if any larger, with ten tentacula as long as the body, exhibited the same evolutions as those of adults; absorbing a tentaculum in the mouth, along with one of the antennulæ, as above describerl. Of the identity of this specimen with the fusus I entertained no doubt.

One still smaller than any of the preceeding, of such irregular shape that I incline to think it of another species, survired some months, in 18:31. It never extended above an eighth of an inch, having few snckers, some of them munaturally large ; the whole body perfectly white. This also was inaccessible.

In general these smaller specimens are much bolder than the adults ; but their early nature is conspicuously shewn by similar habits. They enclure greater intensity of light, and remain displayed while their vessels are moved. The arborescence of all is pale or colourless, while that of adults is grey or crimson, which seems entirely dependent on age.

The present, and indeed all the Scotish Holothuria, are free of any uffensive odour, such as ascribed to the race by some authors, probably from inspecting or dissecting decaying specimens.*

\footnotetext{
* Bosc, Ilistoire Naturelle Des Vers, t. ii. pp. 147-151. Paris, 1827.
} 
None are converted to use.

In that artificial condition-one so different from the natural state wherein these auimals are preserved, few predominant features are to be discovered.

Such animals have no opportunity of shewing whether they have any care of their young; nor how they may go in quest of food, or of even testifying their proper selection of the meagre variety presented to them. Neither can we say low they protect themselves from those ravenous animals, of which, like others, they unquestionably become the prey. They are evidently dissatisfied with substances around them, as unsuitable for their permanent establishment. Discrimination is clearly exercised, first, in choosing those places not liable to disturbance for an abode ; secondly, in selecting a position adapted for the sweep of their arborescence, and for the free jet of the fountain from within. Soliclity in the one case, unobstructed space in the other, must be determined for the spot of adhesion.

Perhaps the natural and most favourable abode of the Iolothuria fusus is in deep water. Whether it may attain large dimensions in that which is shallow seems doubtful, although I have heard of specimens found in the shallowest. Few naturalists, if any, seem to have had many of the species, nor do any appear to have preserved them permanently. To judge by the figures of all Holothurix that I have ever seen represented, the specinens must have been injured, dead, or dying, greatly enfeebled, or verging to decay,-i more convincing illustration of the difficulties attending the study of the animal than can be offered by any argument. Figure and fixture are the true indications of a healthy condition. They cannot be mistaken. Every race of the animal creation is peculiarly distinguished by position, attitude, and motion.

In some places this species may be very abundant, in others rare, and naturalists have certainly fornd it so. There can be no doubt that some animals are actually rare, that their rarity becomes constantly greater and greater, and that it has terminated in extirpation. Yet, a creature of our days, from which the progeny of a single season may amount to five thousand, should not be rare. Most animals are very unequally dis- 
tributed. Scarcity and abumdance are frequently unmeaning comparatives. Unpropitious circumstances, ravenous and inveterate enemies, repress multiplication and diminish numbers. The excessive timidity of the Holothuria indieates the liability of its exterual organs to injury, while precluding all presumption of its subsistence by the eapture of living prey.

No animal will more readily escape observation amidst miscellaneous marine eollections. When free of adhesion, it contracts infinitely without regularly assuming any determinate form : and afterwards floats as a sphere, or an ovoid, or rolls over the bottom of its vessel. Very few fishermen seem aware of the existence of such a ereature. None of those which I have carried to them, were recognised as having been previously seen, and when bronght to me by themselves, it has been always in ignoranee of their presence among other substanees. While endeavouring to obtain speeimens, by describing the subject of the preeeding paragraph to some of them, one present observed that it might be the same as a substance he had found, which "he had pierced with a knife, to discover whether it was alive!" At length, some of the younger fishermen, finding it their personal interest to extricate the Holothuria from among the rubbish brought up by nets and dredges, they have enabled me to conduct my enquiries witl greater facility.

The diffieulty and improbability of detaeling this animal entire, while unseen, from its firm adhesion at the bottom of the sea, and by the rude apparatus employed, must be self-erident. Hence it is that naturalists must be indelted chiefly to aceirlent for perfect speeimens.

\section{Plate ViII.}

Fig. 1. Holothuria fusus. The Spindle Sea Cucumber or Sweep-WVater.

2. Another specimen, with the arborescence partially protruding.

3. The specimen, fig. I, in a dying state. The tentacular apparatus and intestines escaping.

Plate IX.-The specimen, Plate VIII. fig. 1, having regenerated the tentacula, $a$. 
PLate X.-The same, in an earlier stage of regeneration. Tentacula, $a$. Posterior orifice, $b$.

Plate XI.

FIG. 1. Young Holothuria fusus.

2. Sucker enlarged.

3. Tentaculum.

4. Antennula enlarged.

5. Spawn of the specimen, Plate IX., slightly enlarged.

6. The same more enlarged.

7. Lower extremity of the cylinder or case bearing the tentacula; Ampulla Poliana bclow.

8. Cylinder, tentacula, and intestinal organization. after having been discharged.

9. Extremity of a rope of an ovarium.

10. The same enlarged.

11. Extremity of the ropes of an ovarium enlarged.

12. Ova.

13. Ova enlarged.

14. Ova enlarged.

15. Ova enlarged.

16. Minute Holothuria.

17. The same in its natural and peculiar attitude.

Plate XII.

Frg. 3. Arborescent apparatus. Shelly sheaths receiving the tentacula, $\alpha$. Ampuilla Poliana below.

4. Intestinal organ lost along with the tentacula, which latter are not represented here. Their sheaths and bases, $\alpha, b$; Ampullo Poliana, c.

\section{§ 3. Holotimuria Scotica.-Plates XII., XIII.}

From what has been already said, it is indisputable, that the history of the Holothuria is very imperfectly understood, that it is clouded by obscurities even at the present day: Neither can we refrain from presuming that these have chiefly arose from omitting to bring such specimens as might be procured under immediate observation. 
The surprising mutilations incidental to some of the race may utterly mislead one naturalist desirons of comparing his own remarks with the narrative of another, or with the figures presented to his view by preceding authors: Nor is it from external appearance alone that he shall be exposed to error, for, on careful dissection, he may be disappointed of finding those internal organs known to distinguish his subject from all its fellows,-they have been lost by one of those extraordinary processes, uatural or umatural, above described, to be regenerated with the lapse of time, provided the survivance of the animal should be sufficient to admit of it.

Therefore it is essential that due attention be invariably paid to perfection, vigour, and the most favourable conditions of existence, and that nothing slould be overlooked in representation.

I have repeatedly failed in my attempts to identify various species of the Holothuria falling into my possession, with those described by other authors, though the difference was apparently inconsiderable. Without presuming any inaccuracy on their part, I would rather tax unyself with some oversight, and supply my deficiencies by correct delineations, along with descriptions, which might be the best means of attaining the truth. Wanting such auxiliaries, which are truly substitutes for real specimens, most of the subjects of natural history of rare occurrence, or, in fact, that may not be daily before us, must prove unintelligible.

There are numerous sources of embarrassment, nor do all originate from the different views of different naturalists. I have failed to identify certain subjects of rare occurrence with those familiar to me, either from defective organization, or supervening injuries and decay. I eould not pronounce them the same, though personally satisfied that they were not distinct. At the same time, such subjects were dead, and disfigured for the most part, for equal embarrassment is seldom experienced with living specimens of sufficient dimensions.

On the 27th of February, a specimen of the Holothuria reacher me, which had been recently fished up from the sea. It was contracted to abont five inches in lengtl, rather slender in proportion, and totally 


covered with suckers void of evident arrangement. The surface wats entirely of a dingy white colour, with a few brown patches irregularly interspersed.

On the whole, this subject, except in its proportions, bore considerable resemblance to the Holothuria fusus. But, unable to identify it either with that or with any of the rest which I have seen, I propose to name it, provisionally, Holothuria Scotica, as indicative, at least, of the country of its nativity.-Plate XII. fig. 5.

In two days the creature had expanded ten inches in length. ly about one where thickest,-the body being round, and tapering slightly towards the extremities; yet it did not adhere, though feebly discharging a stream from the posterior orifice. In nine days, however, some of the suckers were in adhesion, afterwards they were discovered to be in five rows, as in other nine days the animal had established itself firmly in its vessel.

This is the usual course followed by all Holothurie, on original recovery from the sea.

The specimen seemed to be gaining strength along with the advance of the season ; and it began to display some of the habits of the fusus. such as appeared from the curvature of the body in its position, together with greater elongation while the day declined.

After having preserved this specimen half a year, under constant observation, without protrusion of the tentacular organs, I concluded that they had been lost before it came into my possession.

Nevertheless, the skin now growing purer, thinner, and more diaphanous, which was promoted by the specimen being kept continually in the dark, symptoms of intermal reproduction were exposed within.

Near the anterior extremity, an internal darkish portion, much contrasting with the external whiteness, denoted progressive regeneration.

It shewed that the animal had actually lost the arborescent apparatus, with the appendages.

During the season of redintegration, we have seen that almost complete quiescence prevails. 
I watched this creature incessantly: yet, no less than ten months elapsed, before I was gratified with a sight of the renovating organs.

The Holothuria was taken in the end of February. In the end of December it extended to dimensions I had never anticipated ; and it assumed a form, position, and attitudes sneh as I had never seen in the Holothuria fusus or in any others.

The length of this speeimen equalled at least eighteen inches : and, some time afterwards, it testified an inclination to cast a knot of the body.-Plate XII. fig. 6 .

In the month of January of the year following acquisition of the animal, its tentacula remained transiently protruded while exposed to the light.

This Holothuria was affixed like a horse shoe to the side of a capacious vessel; the lower half of the animal adopting such curvature that one part always comprehends the posterior extremity, eonsequently the orifice; and now the specimen had been so vigorous during the night that its jet was discharged over the side of the vessel.

Some animals are incredibly shy ; their timidity never diminishes; they shun the presence of light, and even the erossing of a shadow may be the signal for disappearanee. Although the tentacular apparatus protruded several times, I could never obtain a complete view-one such as was desirable and satisfaetory of the component parts. Nor until five weeks later could the sketch Plate XIII. be exeented, which brings the history of the subjeet to about seven months and a fortnight from the date of acquisition.

The sketch was obtained under much inconvenience; and although I believe it correct as to the number and quality of the tentacula, I could have anxiously wished a drawing of them, from observation, during permanent expansion. But to procure anything better proved impossible.

At one time, I acknowledge, I thought the tentacula more than eight, that they amounted to ten, besides the two antennule. However, on endeavouring to dissect the parts, after the animal died, I was unable to find above eight shelly receptacles, wherein they might be retracted. 
Comparing the appearance of this Holothuria with the fusus, it extended eighteen inches in length by scarcely an inch in thickness, which, from all $I$ have seen, would be disproportionate in the other. The fumnel was above two inches deep, and the part immediately under it contracted to a very small diameter. Five double rows of suckers run down the whole length of the body, the intermediate skin between one double row and the double row adjacent being smooth, and the distance separating the double row from that next it exceeding the distance separating each single row of the pair from its fellow.

The dimensions and the luxuriance of the tentacula continned angmenting. They acquired a deep purple colour, but remained always smaller in comparison to those of the Holothurin fusus, probably requiring longer time to grow. Their functions seemed to be the sime.

In the next place, the creature began to decline; and in sixteen months from the first, its length contracted to three inches and a half. I thought the excessive heat of the weather at the time most pernicious.

Though occasionally reviving, it never recovered its proper size and vigour; and at last assuming the resemblance of a worm half a foot long, and under half an inch thick, it died in nineteen months from the date of its original acquisition.

The skin proved extremely tough and coriaceous; and several small ropes of an inmature ovarium were found in the borly on dissection.

For some time I was disposed to view this amimal as an overgrown specimen of the IIolothuria fusus, especially before the parts were sufficiently developed. But between the two, we find several prominent distinctions. First, the disparity of size and proportions ; next, in longitudinal double rows of suckers down the body, whereas those of the fusus are distributed promiscuonsly over the whole surface, and thence much more numerous, comparatively. The difference in the proportions of each, would render the flexures seen in the one impracticable by the other.

No important difference distinguished the halbits of the two.

In the course of a number of years, I have had three younger 
specimens of what I consider the same species. None were vigorous, however, their survivance was very short, nor did any of them display the tentacula ; those of the largest were evidently scarlet. These animals extended two, four, and five inches respectively, tapering very gradually from near the anterior to the posterior extrenity. All were white, and each was characterized by five double rows of suckers, quite distinct. Had they been vigorous, they would have appeared of larger dimensions.

From inability to identify the subject of these brief observations with any known species; and speaking at all times with much reserve of the characters of a single specimen, unless perfect in every respect, I propose to name it provisionally, Holothuria Scotica: Meanwhile, awaiting the commentaries of some more fortunate naturalist.

\section{Plate XII.}

Fig. 5. Holothuria Scotica contracted.

6. The same extended in a remarkable flexure.

Plate XIII.-Holothuria Scotica extended, and as adhering to the side of a spacious glass jar. The advancing tentacula protrude, and the suckers may be seen in double rows.

\section{§ 4. Holothuria Bodotrie-Holothuria Ecrus.-Plate XIV.}

The first perplexity involving the naturalist on occurrence of small animals, is whether they are young or adults : and this especially among the tribes which are known to undergo important changes with advancing age. Never having seen the subject of this paragraph under any aspect but such as represented, I camnot identify it with the species of Holothuria already clescribed.*

* Since this was originally written, which is a number of years ago, I observe the Holothuria Cenus in the valuable work of Professor Edward Forbes on the Echinodermata. 
I. $I$.

I'L. . IIII.
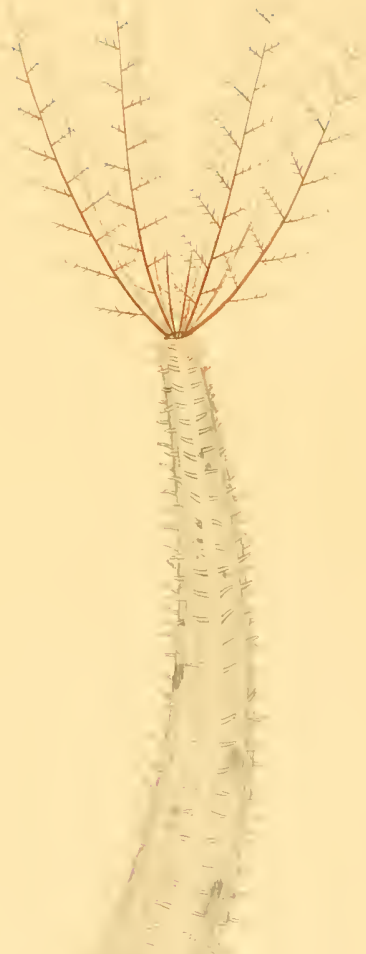

It is of more irregular shape than the preceding species; rather cylindrical on the whole, the largest extending two inches by about three lines, or scarcely as much, in thickness. Numerous extensile peduncles or suckers are scattered over the body without definite arrangement, though sometimes apparently in five or six irregular rows. All are of uniform colour, pure, or dingy white, and yellowish-brown.Plate XIV., fig. 1.

The anterior extremity, closed during quiescence, opens for the protrusion of an arborescent apparatus, consisting of eight tentacula, and two antennule, thus corresponding with the same number of these organs in the Iolothuria fusus, Plate XIV., fig. 2. The office of the organs themselves also seems to be of the same nature, figs. 3, 4, 5. But neither tentacula nor antennula are equally luxuriant as those of that species; and the tentaculum, consisting of a stout stem, with branches proportionally shortening upwards, set alternately, having few subdivisions or subordinate parts, is inferior to that of the pentactes likewise, figs. $6,7,8$.

The tentacula of some extend towards six lines, the antennula alout half as much, fig. 9, enlarged; tentacula and antemnula. The stem of the tentaculum is peculiarly organized, being distinguished by minute prominences disposed in spiral lines.

Little discrepancy prevails in this animal's habits, and those of the Holothuriæ previously described. It sometimes remains long quiescent, and at others is very active, traversing its vessel freely with the tentaculn displayed in front. While quiescent the whole arborescent apparatus is retracted within the body. As this apparatus is formed by a prolongation of the skin, its structure is different from that of the corresponding parts of the fusus and pentactes.

Moderate temperature, together with frequent renovation of their element, seems congenial to every species of the whole tribe. During fine weather the tentacula are readily displayed, and often remain so during much of the day. Some keep them always expanded, allowing their vessel to be exposed to the light without contracting or retreating.

They rise to the surface to escape the impurity of the water.

The prevailing colour is perhaps affected by their site; I remarked 
that specimens procured in 1833 were pure white, whereas most of those obtained in 1841 were yellowish-brown. The animal dwells in the astuary of the Forth, from the island of Inchkeith down to the Mar Bank, fifty or sixty miles farther distant.

Although this animal is distinguished by few peculiarities, perhaps from my failing to investigate its nature sufficiently, it exhibits one of the most remarkable kind, in the spontaneous subdivision of the body into two or even a greater number of parts. Neither does this violent effort, as it might appear, prove fatal to the specimen, for the defective organs are regenerated complete in each of the portions, renovating them to entire animals.

So singular a process being incident to all, it becomes difficult to fix the ultimate dimensions to be acquired by individnals.

Of two specimens, one large and the other small, obtained from the Mar Bank, one solved the problem, so long obscure, as to the mode of progression, by traversing the inner circumference of a vessel four inches wide within two hours, having the tentacula displayed in front as it advanced. Both were active. While at rest they adhered by their peduncles or suckers to the glass, near the surface of the water.

The larger exceeded the smaller by a third part. On June 28 th it ruptured asunder into nearly equal halves, as appearing figs. 10, 11, and remaining so during an indispensable absence, until my return on August second; they appeared on the 29th as in figs. 12, 13. On August second I found the smaller had also ruptured in halves, which now appeared as in figs. 14, 15 .

After the lapse of three or four weeks I witnessed, with considerable surprise, the regeneration of a complete arborescent funnel in each posterior half of the two specimens. But the animals were now so shy that it was diflicult to obtain a view either of these or of the original tentacula of the anterior portions. Nevertheless the regenerations were ascertained to be very short and very white.

All four parts of the two Holothuriæ moved about in the vessel. The tentacula of the whole four were displayed on the 30th of Angnst, but their impatience of light had not abated. 
In a week, fig. 10, the anterior portion of the Holothuria, sundered again near the middle; so that, what originally constituted one entire animal, now consisted of three parts. Afterwards, another portion sundered from one of the five parts at that time in the vessel; but from which I could not determine. If from the smaller Holothuria, each animal had subdivided into three. All continued shifting their places : some of them occasionally displaying the tentacula, until May 27, of the following year, when, on renewing the sea-water, this arborescent apparatus was displayed by the whole six.

A small grey mass was detached from one of them in August. One or other specimen had thus subdivided four times. But on November 19 , or seventeen months after they had come into my possession, only one portion of the whole survived.

The subdivision of these animals does not appear to result either from constraint or from injury. If a natural process, however, it is a very singular mode of multiplication,-for there is no doubt that each fragment becomes a perfect animal ; nay, there is nothing to shew that the creature undergoing such a disruption, suffers very much from it.

I cannot discover that any precise rule governs the time of division, or regulates the number of parts.

Both the animals and the parts present a singular, and sometimes a very uncouth appearance.

A specimen two inches long, recovered on July 21, divided into two halves nearly equal on the 25th.-Plate XIV. figs. 16, 17. In the night of the 29 th, the posterior half, fig. 17 , subdivided, whereby the entire Holothuria was now in three parts. These parts, which were delineated on August 5, being fig. 18, the upper half of fig. 17 ; fig. 19, being the under half of fig. 17 ; and fig. 20 the same as fig. 16 , now seen at the later date of August 5, that period comprehending a week, and the animal now somewhat more extended.

A specimen, fig. 4, obtained on August 3, was delineated August 5 ; also, a fragment procured on August 3, delineated August 5, fig. 21.

Another specimen of a dark colour, obtained on August 3, though delineation was omitted, presented some peculiarities. It proved rather 
slender, extending about an inch and a half, including the tentacula, and rather under the eighth of an inch thick.

In a few days, this specimen appeared at its full stretch on the side of the vessel. The middle became gradually smaller and smaller, and quite smooth, so that the figure of the animal resembled a long sandglass. In the aftermoon of the day when this was observed, it had smmdered into two halves of nearly equal dimensions, each about half an inch long, and when noticed, about four lines apart. The division seemed to be natural, not the result of constraint, nor attended with suffering. But in respect to the fusus, there is much presumption of mutilation following violence, though unobserved.

The fact presumed, receives confirmation by attending to the course of the process.

Of five specimens obtained on August 11, four were dingy white, tending to brownish, and one pure white. Next evening, two of the former were much extended cylindrically, the one two inches and a quarter, the other exhibiting a contraction in the middle, two inches and a half. In expectation of division, I watched it some time, but unsuccessfully, for this did not then take place. However, it ensued in the night. Another had divided also, and a third was observed next morning uncler the process of division.

In this third subject, the two halves were about five lines apart, thongh still connected by a small greenish thread or ligament, apparently tubular, which I conjectured might be the intestinal canal. The ligament had subsisted above twelve hours. After its rupture, the parts became somewhat approximated, just as if they had mutually strained themselves to be free. The process is represented in its advance on August 13, fig. 22.

The tentacula of four of the five specimens having been displayed immediately preceding the ruptures undergone, it cannot be supposed that the animals were then suffering, as on the slightest constraint, these organs are instantly contracted, or entirely withdrawn.

The upper portion of a divided specimen, fig. 15, as on July 19, is. again represented as on August 5, by fig. 19. It had remained station- 
ary, much curved, four days, on September 19, with some intestinal part protruding, fig. 23. Next morning it had sundered. Abont a month later one of its portions had subdivided, so that now the entire specimen had multiplied into six or seven known portions, besides some whose progress had not been followed.

Portions of the original animal subdivided by a similar process, independently of their size. The parts recede so far from each other, and the connecting line becomes so much attenuated, that it moves, on moving the vessel. 'Two parts of this kind, neither of them two lines in length, were half an inch asunder, the connecting ligament so much above the surface of the glass sustaining the parts, that a small instrument could be introduced under it, as it waved with any motion, fig. 24 .

The portions thus separating, are sometimes exceedingly minute,not above half a line long. On first beholding then, I was inducer to conjecture that they might be nascent Holothuria of a different species, from what was truly the adult parent.-Fig. 25.

Condensing the substance of these and other observations, it appears that the spontaneous division above described ensues thus:-The specimen remains stationary during some time, on the side of its vessel, when each extremity broadens and flattens beyond its usual dimensions. This flattening occupies a considerable portion of the body, but diminishes, from the broadest part anterior and posterior, towards the mildle of the animal, so that by gradually augmenting to a central point, it renders the subject somewhat like a common sand-glass. In this manner eich extremity, that at one end of a cylinder, for comprarison, and that at the other end of the cylinder is slightly enlarged towards the broadest part, suppose a fourth of the whole, whence it diminishes to the central point, the narrowest part or neck of the sand-glass, where the rupture will take place. At length a slender hair-like ligament connects the parts, which ruptures as these mutually withdraw, and leaves the original animal in equal halves, or consisting of a greater and lesser portion.

The duration of the process is very irregular, and apparently dependent on circumstances, not only unknown, but beyond any rational conjecture. Neither does it seem influenced by size or season, or by any 
obvious condition. Separation frequently ensues in the night, without previous indication. In one specimen it was observed advancing during four days, and then accomplished.

The animal seems literally rent asunder by separation of the parts ; and the intestinal organs, occupying a large portion of the cavity of the body, are undoubtedly also rent asunder. The wounded portion closes speedily over them. If this be not the case, a wonderful internal reproduction ensues, as the external reproduction of the arborescent apparatus is perfected.

Whatever be the colour of the original animal, though of the darkest hue, the renovated tentacula are of the purest white. Thence it may be conjectured that fig. 3 was only a fragment.

Though specimens have survived seven, nine, or even above twelve months, in my possession, nothing has indicated any other mode of multiplication. It is very embarrassing when first observed, and until the naturalist sees how it is accomplished. I am not aware of its extent or its limits. It is often sudden-often unexpected. Five specimens having been committed to a vessel, on the eleventh of August, their number had doubled on the nineteenth, and it had augmented to fourteen on the twenty-seventh. But it must be remembered that, at first, the accessions are only in number, not in perfection ; for the generation or evolution of the defective organs, depends on the lapse of time.

The food of the animal is yet undiscovered. Specimens generally remain affixed to the side of their vessels, without shifting their place, where they at length pine away.

The species is not rare. Many individuals have afforded the substance of the preceding observations.

PLATE XIV.-Holothuria Bodotria-Forth Holothuria.-Holothuria EEcnus, Professor Edward Forbes.

Fig. 1. Specimen quiescent.

2. White specimen, active.

3. Brown specimen. 
i. 1 .
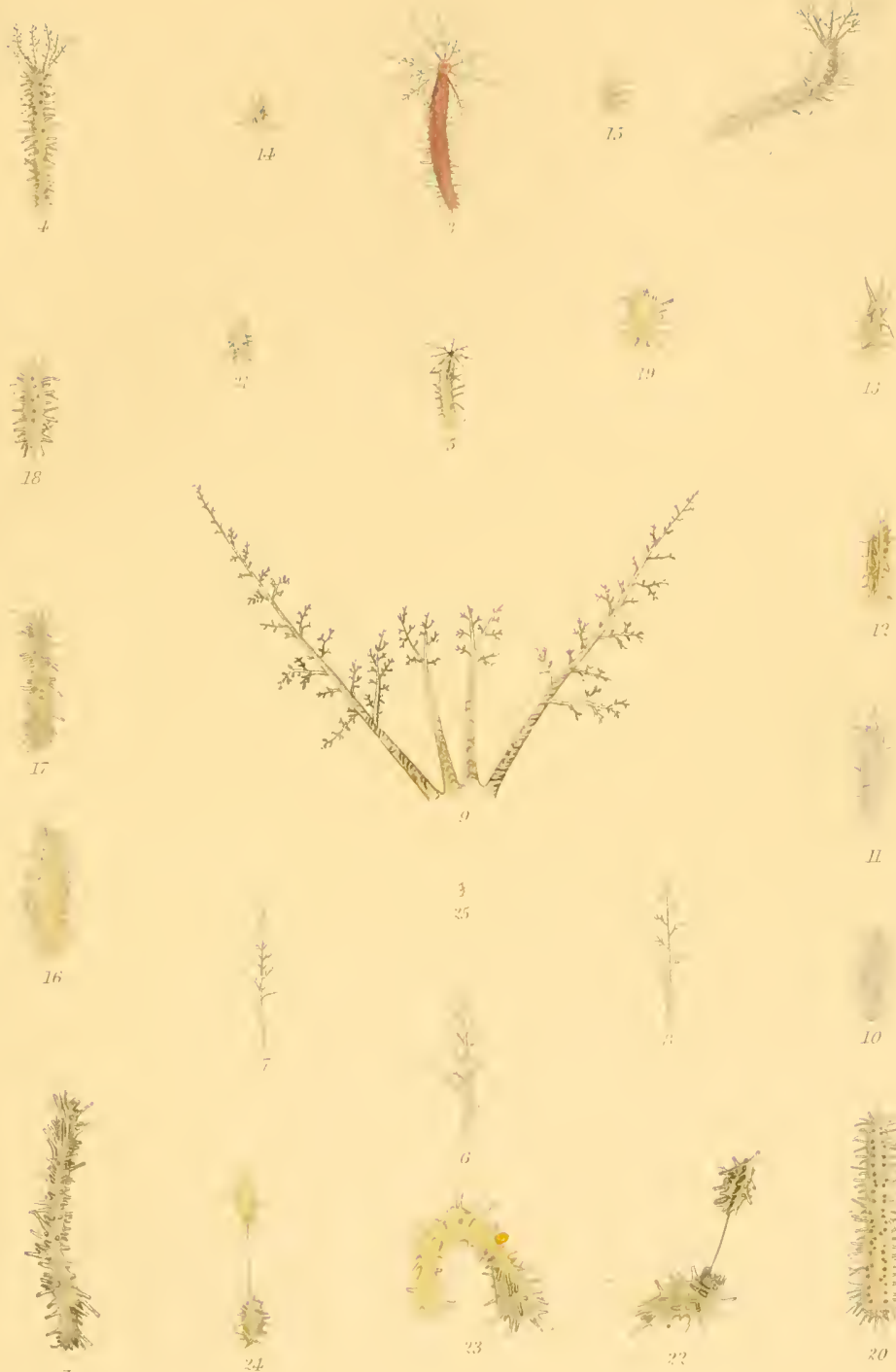

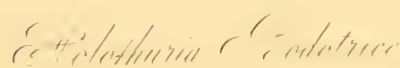



Plate XIV.

FIG. 4. White specimen.

5. White specinen.

6. Tentaculum.

7. Tentaculum.

8. Tentaculun.

9. Tentacula and antennulæ enlarged, shewing their structure and comparative dimensions.

10. One of two portions produced by the spontaneous division of fig. 2-June 28.

11. The other of the two portions of fig. 2-June 28 .

12. Fig. 10, represented two months later-August 29.

13. Fig. 11, represented two months later-A ugust 29.

14. Half of a divided specimen as it appeared August 29.

15. The other half of the same specimen-August 29.

16. Upper half of a specimen, which divided July 25, as it appeared July 29.

17. Under half of the same specimen, which divided July 25, as appearing July 29.

18. Upper half of fig. 17, after its own subdivision, as seen on August 5 .

19. Under half of fig. 17, after its own subdivision, as seen on August 5.

20. Fig. 16, there represented as on July 29, seen here a week later, as on August 5.

21. Fragment as seen on August 5.

22. Specimen in the fact of subdivision, where the two parts separating are still connected by a slender ligament-August 13 .

23. Specimen whereof an intestinal portion seemed protruding-September 19.

24. Specimen whereof the division was protracted during four days.

25. Minute fragment.

\section{$\S$ 5. Holothuria Phantapus.-Plate XV.}

If the appearance of all the species of the Holothuria be singular, this may be truly described as the most remarkable of the whole : I know not any familiar object to which it may be compared. 
It also exhibits a considerable difference both in the form and iu the general distribution of the parts from the rest, which, were there others to follow, would sanction its position at the head of one subdivision of the tribe. But, in the present state of knowledge, such a measure, as before observed, would only resolve into the distribution of species, not the institution of genera.

The peculiarity of aspect here partly ensues from the different arrangement of the parts. The suckers of the Holothurix are usually dispersed throughout the total extent of the body, either promiscuously over the whole, or arranged in definite rows or sets, enabling the specimen to adopt a certain position, in merely stretching along any substance, or adhering to it in the shape of a crescent or a cucumber. The suckers of the Phantapus occupy the sides and the middle of a quadrangular compartment on the lower surface : those of the middle extending in a row of two lines to the ends of the quadrangle; the others extending in a double or triple row of suckers in a line just within the four sides of the quadrangle. The whole compartment equals about a third of the length of the specimen.

As the animal adheres by the five rows of suckers occupying a portion of the under surface, the two extremities are much elevated above the plane of position. Plate XV.

Thus very little resemblance will be found between the form and position of the Holothurin Phantapus and others of its genus.

Some authors are dissatisfied with the name of suckers usually applied to the organs now referred to, desirous that they should be always characterised as feet. No doubt they may be sometimes employed as anxiliaries in progression, but their conmon and permanent office is to secure the body of the animal by their adhesion to some solid substance. They are occupied more as suckers than feet. I never saw the Phanta$p u s$ during progression, which is probably somewhat different from that of the other species.

This animal extends about seven inches from the tip of the tentacula to the posterior extremity, when completely displayed.

When contracted, and the arborescence concealed, it is considerably 
shorter. The anterior part is obtuse, convex, and upright ; the middle is about an inch and three quarters thick, tapering down to the extremity, from whence a jet is discharged at will.

The rectangular compartment belongs to the thickest portion ; it may occupy two inches in length, by one and a half in breadth.

As the anterior opens, the neek, of a beantiful orange, speckled with dark brown points, protrudes nearly an inch. A dise, flattened or slightly concave, crowns it, which is bordered by ten luxuriant tentacula, with the mouth, very dilatable, in the centre. The stems of the tentacula are rather short, and all the principal parts of the arborescence are surrounded by those which are subordinate. Several filaments, also rather short and slender, are dispersed irregularly on the neek.

The skin of the animal seems contracted in fine irregular corrugations, with somewhat a scaly aspect, thick and hard, and, when cut, resisting, like the bark of a tree, with exception of that of the compartment which is smooth and soft. A very thin dark cpidermis peels ofl in rags if the surface be injured. The surface below it is white.

The external aspect of the IIolothuria Phantapus is so peculiar-so unlike that of any other species, or of any other creature-it cannot be mistaken.

After various disappointments of a living entire specimen, repeated for no less than twenty years, one was obtained which had been recovered from the deep-sea fishing on the 14th of May. It reached me tloating, and much contracted, in a wide-monthed phial, admitting its reception.

Now it exhibited few signs of life, but extending slightly on the water being changed, and on transference to a vessel sufficiently capacious.

The suckers were nevertheless in firm adhesion on the fourth or fiftlı day following.

The whole of these organs were in action-those down the centre, as well as those bordering the four sides of the quadrangular compartment.

The animal was still contracted, but this having taken place within a week, encouraged me with the hope of its survivance. 
In another week it extended, as I computed, six inches, following the curves; and at length the arborescent apparatus was protruded from the anterior extremity in such perfection, as to admit of satisfactory delineation.

Though not quite so luxuriant as that of the Holothuria pentactes, perhaps from the specimen being weaker, considerable resemblance might be traced between them: ten fine tentacula bordered the circnlar disc, which were composed of a stem rather stont in proportion, together with parts to be compared to numerous boughs and branches. Of these the subordinate were set around the prineipal parts, and such were tufts when imperfectly developed. The disc resembled a shallow sancer, with the mouth expanding in the centre.

The apparatus crowned the neck of the animal, now protruding along with it, the whole having been previonsly retracted into the cavity. The colour of all the parts was speckled dark-brown or reddish-orange, producing a very agreeable contrast with the sombre hue of the body:

Erolutions similar to those seen in the Holothuria fusus were displayed by the contraction of the tentacula, their insertion into the mouth, and withdrawal from it.

But the difficulty of preserving this species is not inferior to the obstructions opposing the safety of any of the others. The suckers lost the power of adhesion, thongh the arborescence continued in display, and the animal lay chiefly on its side. The body next rupturing under the neck, a bunch of above fifty slender ovarian ropes, abont an inch long, protruded, together with a portion of yellow intestines.

The curring of the tentacula continued spite of their incrensing weakness, and the animal died in about three weeks after its original acquisition. The Jellow neck remained protruded, nor were the tentacula entirely withdrawn.

IThile this specimen still survived, another of larger dimensions reiched me, which did no more than extend slightly, having suffered some injury previous to its arrival.

One of the largest specimens occurring was about four inches and a half long in its contracted state, and somewhat under two inches 
through where thickest. The body was hard to the touch, resisting and elastic, all except the quadrangular compartment, which is always of at different natme, the skin being thick and soft. The remainder, especially towards the extremities, was dry and corrugated, cutting like old fir bark. When laid open, six strong muscular bands run down the whole length. I did not remark that any one had been divider, so as to reduce that number. A large ovarium was exposed, consisting of numerous long ropes, with small distinct ova of orpiment orange colour, apparently not far from maturity. The contracted tentacula were reddish. A blackish, thick, and very offensive fluid partly occupied the eavity of the anterior portion.

Muller remarks the difficulty of dissecting these animals, which probably has been very seldom attempted, more from want of opportunity; perhaps, than want of inclination.

In the course of twenty-one years, I have been able to obtain only six specimens, whereof nome other than that represented was in a condition fit for delineation: Nor would this have been effected without the most cautious treatment of the animal, and the patient services of a skilful artist, Mr John Hew Johnson.

I have not been so fortunate as to meet with any other figure having the arborescence displayed, though several may be seen without it. I must therefore conclude it to be an unusual incident, and that living and vigorous specimens occur very rarely.

\section{Pl.ATE XV. Ilolothuria plantapus.}

Besides the species of Holothuriæ above described, more have occurred to me in the course of researches, extending for at least thirty years. But the subjects were either greatly mutilated, in a feeble or dying state - many actually dead, and in decay, so that, on the whole, neither size, nor figure, nor the true nature of the animals could be determined, or their real appearance delineated satisfactorily.

I have been sometimes much perplexed regarding the identity of specimens, such as whether what I judged the Holothuria fusus, when of 
large size, but dead or disfigured, was truly of the same species as my smaller subjects, which I knew to be genuine.

One specimen, though much contracted, I was led by its yellow colour to identify with the Holothuriu elegans of Muller; but it was never sufficiently developed. Another I thought certainly the inharens of the same anthor.

It must be allowed that the most connected, copions, and satisfactory illustrations have been afforded by the Holothuria fusus.

Yet much still remains to be gained from it, as well as from all the rest, by future observers.

Rather than embark in discussion regarding injured and imperfect subjects, I prefer restricting myself to a smaller number and variety of those entire. Therefore I have gone no farther than offering my remarks on the Holothuria Pentactes, Fusus, Bodotrice (Ocnus), and Phantapus-truly very few to be compared with thirty years' research. But their dwelling constantly under water, and chiefly in places fir apart, independently of their powerful fixture to solid substances below, aggravates the difficulty of acquisition, consequently of specimens fit for use.

The Holothuria, however, proves an animal sufficiently hardy, and with due precaution may survive years in captivity under favourable circumstances. There it will display many of its singular properties. Perhaps it is the rude treatment received at the hands of the captors that is so destructive to all the race.

This creature is evidently local, certain districts and regions favouring its multiplication. Most probably in various parts of the Scotish seas species may be in greater variety, and subjects may be more numerous, than indicated here.

The Holothuria is an animal seldom converted to the use of mankind. Indeed, most subjects of greatest curiosity to the learned seem to be the least prized by their fellow-men.

Some Holothurix, being large and fleshy species, are said to serve as food to the poorer classess of Naples; and, if this tribe be truly the trepang of the Eastern Seas, it is highly valued by the luxurious of some remote territories nearer its native abode. 
I say nothing definite, however, of such foreign products, consiclering it enough to deal with those which are more familiar.

Naturalists apparently entertain very vague opinions on the true nature of the Holothuria, and of its proper position in the Systoma Nature. But in fact it has been seen very rarely by any of the learned devoting themselves to the study of the lower tribes, nor do I firmly believe ever in perfection. It may be questioned whether a specimen was before Limmens. Muller certainly had several, and of these, such as they were, he has preserved figures, but all must have been more or less injured or contracted. I do not think any one could be completely developed, and displaying its external organs. M. de Blainville, whose observations prove him a naturalist of distinguished quality, may have had several. Yet none could be in full vigour from his own account. Professor Delle Chiaie unduubtedly had these creatures in great profusion. Had they been entire, and vigorous, and treated suitably, how could they have been considered different when actually the same ; or identified for the same when actually different. The figures presented shew that none were living. Among the most modem naturalists, however, Professor Edward Forbes had opportunities of inspecting different species while alive. I could specify only one or two other authors, belonging either to the continent of Europe or to Great Britain, of whom I can say the same.

The facts hitherto obtained in the history of the IIolothuria, afford but few conclusions regarding its nature, compared with the tedious detail of the preceding pages. Nevertheless, some will be found of such interest, and so well established, as to encourage the farther research of the curious.

I.-The Holothuria does not appear to be allied to any other genus of animals. It is neither preceded nor followed by any one in immediate approximation: Nor does any relation subsist, as some naturalists advance, between the Holothuria, Actinia, and Ascidia. Both the latter seem to be far removed, and all are distinctly separated from each other.

II.-The extemal integument is a capacious sac, containing the viscera, the respiratory apparatus, and the ovarium, wherein also the 
part corresponding in position with the head of other animals, and all the tentacular organization or arborescence may be withdrawn, and, atter an indefinite period of concealment, again displayed at will.

III.-The arborescence is always retracted during alarm, nor erer displayed unless under a sense of security.

IV.-The Holothuria pentactes, fusus, and phantapus, propagate by ova, and probably most of the others, the ovarium consisting of the ova disposed in long ropes, single or folded double, and in vast profusion.

V.-The Holnthuria Bodotrice multiplies by spontaneous division of the body, and subdivision of the sundered parts.

VI.-Some of the Holothurix, as the fusus, are sulject to lose the tentacula, cylinder and ovarium, together with a large proportion of the intestines, by spontaneous extrusion, the whole of which will be reproduced through time and favourable circumstances.

VII-Most of the tribe, if not the whole, and especially the pentactes, are liable to rupture of different parts of the body in confinement, the rupture always proving fatal if near the posterior extremity.

VIII.-All the Scotish Holothuria dwell under the surface of the sea in the natural state, and firmly affixed for the most part to solir substances.

IX.-The Holothuria is apparently a nocturnal animal, the full derelopment of its organs, and the discharge of its more important functions, being chiefly during the night.

$\mathrm{X}$.-Little is known regarding the general habits of the Holothuria in its native state. All seem of extreme timidity, disposed to shun the light, and remain quiescent during the day. The pentactes generally rises near the surface of the water, the fusus is content to remain below. Both adopt a crescent shape, which is also the nature of the Holothuria Scotica. The Holothuria Bodotria or Ocnus does not affect any particular position, and often remains very long affixed to the same spot.

Perusal of the first part of the Professor Delle Chiaie's Instituzioni di Anatomiae Fisiologia Comparata, Napoli, 1836, and of Professor Edward Forhes' Treatise on the Echinodernata, 1841, will much facilitate the student's knowledge of these remarkable animals. 


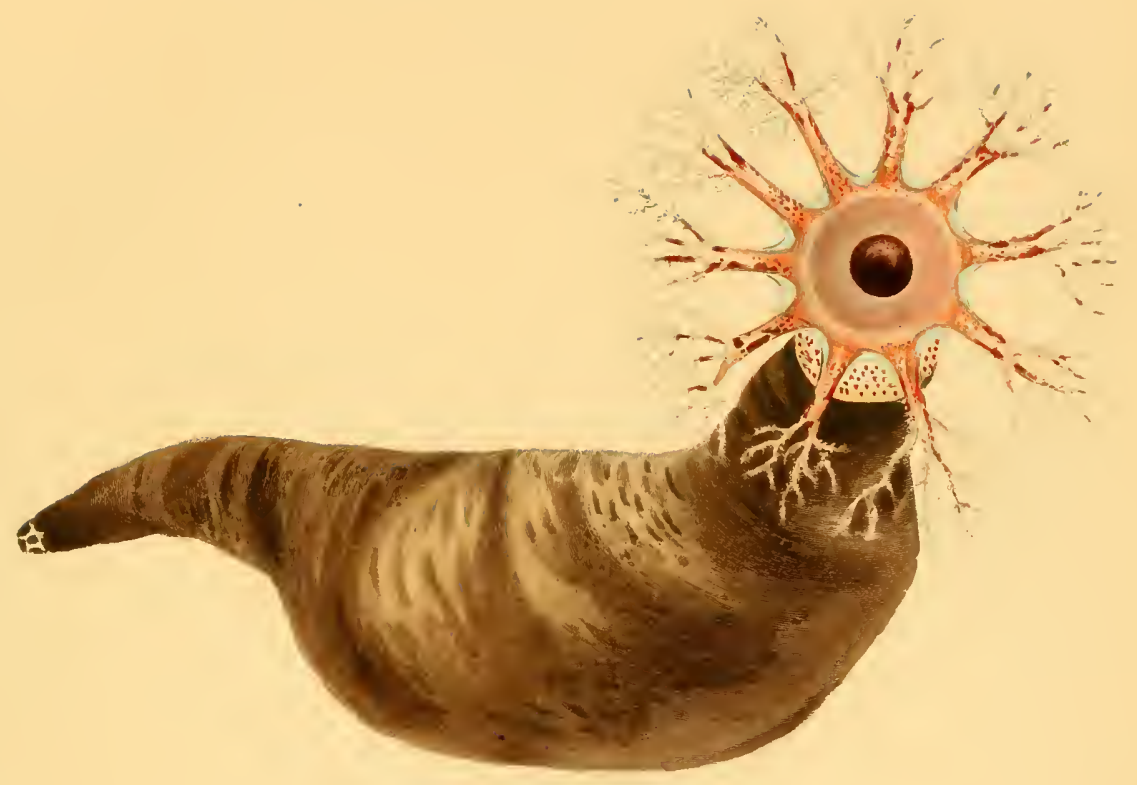

$r+4+1, r$ 



\section{H A P T E R I I.}

\section{ASTERIAS-THE SEA STAR.}

VARIOUS authors having devoted considerable attention to the history of the tribe comprehended under this name, or known as Stellevides, I propose to limit the present chapter to a few general observations on certain species, which there is seldom much difficulty in obtaining.

Though the whole were included by earlier naturalists in a single genus, known as the Asterias or Sea Star, a name sufficiently expressive, later observers have founded several subdivisions, partly derived from mere external aspect, partly from organic structure. Perhaps their arrangements are susceptible of simplification, therefore of improvement : for too little notice has been paid to vigorous living specinıens kept for permanent study, that they might be rendered authority.

To the superficial observer, a common resemblance pervades this numerous tribe; in several arms radiating from a central dise, in crawling backward and forward, from side to side, or around in all directions indifferently, and in adhering to the substances whereon they rest.

All inhabit the sea; nor does any animal bearing the slightest resemblance to the Star-fish, dwell in the fresh-waters distributed thronghout the globe.

On closer inspection of the specimens of the tribe when brought under view, so much difference, so great a variety in their organization, together with certain peculiarities in habits, may be discovered, as to sanction their subdivision for the facility of giving intelligible description, and for recognition.

They present a smooth and uniform surface, or they are penetrated 
by innumerable tubes and orifices. Some are universally or partially covered with tufts, warts, scales, or spines. $A$ kind of protecting mail seems to prepare a number for resistance, while rugosities or asperities yield to slightest pressure. Long and unmanageable rays, though subject to inevitable mutilation, entangle a certain division among foreign substances, at the same time that the strong, clumsy, thick and short :ippendages of another appear to defy violence.

Amidst the great diversity distinguishing the external parts of the star-fish, the use of a few may be explained ; but regarding the real purpose to which the majority shall be converted, maturalists are still profoundly ignorant: Nay, in some the external structure and appearance are altogether unintelligible. It is continually changing during inspection, so that what forms the permanent, the principal, or the accessory, can be scarcely ascertained. We behold a coriaceous, squamous, entire, or porous integument, with innumerable shelly internal bones or joints, besides rows of feet or suckers below.

Equally singular are the external and internal formation of the tribe. Every comparative anatomist has found it so, as may be seen in the works of Momro, Tiedemann, Delle Chiaie, and others.

These animals are provided with numerous extensile suckers, somewhat of a cartilaginous natıre, for the most part occupying a channel in the under surface of each of the rays, and performing the office of feet nore obviously than attaching the body to the plane of position. By their meaus specimens secure themselves to solid substances, or pass along from place to place. As the suckers in front affix, those behind are relaxed from their hold, so as to allow progression. Though much exceeding the specific gravity of the water, star-fish of various kinds have a swift gliding motion, as if nearly buoyant. By means of absorption, the bulk of these creatures is considerably increased, and its specific gravity diminished. But their hold is generally lost on privation of the circumambient fluid, although some may be seen adhering to rocks on recess of the tide, from inequalities retaining humidity. If the vessels in our cabinets containing specimens be emptied, they soon fill from the sides to the bottom. Thus, without violence, which is always attended 
with danger, or productive of injury, the animals are brought under the readiest controul, merely by privation of water.

In the natural state, Star-fish are disposed to crawl into fissures for protection as the tide ebbs, underneath stones, or into shells. When deprived of their natural element, they are helpless.

No race of the animal creation is more numerously and more extensively distributed: they swarm throughout the Scotish seas in great variety, and in multitudes incredible. Spite of the incessant persecution they undergo, of the perpetual war of extermination which is waged against them, their legions remain undiminisherl.

Where such myriads ean obtain subsistence is unaccountable. But although voracious, they are promiscuous feeders,-highly carnivorous, and capable of enduring long abstinenee. Perhaps most animal substances are acceptable, and possibly some vegetable substances are also devoured. None of the naked marine Termes are qualified for offering any effectual resistance; the progress of the smaller bivalve testacea being easily arrested, they are involved by the arms of their rapacious assailants, and, if fragile, crushed in the grasp ; or if larger and stronger, they may be swallowed alive. All dead animals, if soft enough, are likewise rendered a prey. The mouth in the under surface dilates widely, and, in proportion as the stomach is filled, the convexity of the baek becomes elevated.

The fishermen of some districts entertain an inveterate antipathy to the Star-fish, which is rooted in the belief of their being most destructire to oysters in particular. They find them, they say, in the very fuct, actually within the shells, devouring the eontents. But this seems an unfounded prejudice, leading to indiscriminate vengeance against the imaginary offenders. The ancients indeed have recorded the destruction, by this feeble enemy, of the largest inhabitants of shells apparently impenetrable, and from them the modern opinions have likely originated. Nevertheless their truth is yet problematical. Nor is it evident how the alleged warfare can be carried on, or how the larger bivalves can be either reached or extracted. By attending to the nature of the two races of animals we shall perhaps deem such a fact the more and more improbable. 
Though the fishermen assert they have seen the enemy in that fact, they are by no means either close or accurate observers. If they have found the Star-fish in such a position, that such an attack might be presumed, probably the weakness of the inhabitant allowed the shell to gape, whereby it became a prey. When discovered there most likely it is from seeking shelter, for the Star-fish always courts a retreat, and readily takes up its abode in any empty shell. During the colder season many occur in those that have evidently long lost their tenants.

The antipathy of the fishermen, however, is inveterate, they are always ready to slay, nor is any class of people more inured to slaughter.

I have not heard it suggested that the Star-fish possesses any kind of solvent, compelling the bivalves to sunder. Neither can its hostility be very deadly to the larger univalves, from the distance which they are enabled to retreat within their portable dwellings.

It is not the rays of the Star-fish that their prey may dread so much as seizure in the mouth.

The Star-fish sometimes shows an eversion of the stomach as it maly be concluded, or of some membrane resembling it. Whether this may be the means of affecting their prey merits investigation.

Their general habits are to force the shells of smaller bivalves asunder, and to devour the contents, as well as to consume the substance of ordinary fishes entire. In as far as I am yet aware their destruction of oysters is destitute of evidence.

I am unacquainted with their natural enemies. They are said to be found occasionally in the stomach of some of the larger and more rapacious tenants of the deep; and, cannibal like, as we shall see, certain species do not spare each other.

Many are very strong and vigorous in the sea, and most of them sufficiently hardy to be objects of interest for the cabinet of the practical naturalist. Some, perhaps a number, may be easily preserved, and with due precaution they will survive long. If perishing speedily, it seems rather from the injury received previonsly at the hands of their rude captors.

Several species feed copiously, and grow rapilly : and they attain 
dimensions which seem extraordinary. A physician, whom I accounted a most intelligent naturalist, assured me that he had seen one in the northem seas of Scotland extending nearly a yard between the opposite extremities. Admitting that conjectural measurements are delusive, this must have been a very large specimen. I was told of another in a different quarter of the country which, after two years survivance, equalled the size of " a dimmer plate."

The largest species I have har an opportunity of obtaining were the Solaster papposa, Asterias rubens, Asterias glacialis, and Asterias endeca.

The number of organs is not quite uniform in these animals. Some whose complement is nine rays may be seen with six, as the endeca; and with eleven, twelve, thirteen, or fourteen, as the papposa. Among many of the glacialis and oculatu, and multitudes of various Ophiure, none have occurred to me with any deficiency of five rays, unless from accidental and temporary mutilation, or with redundances. Five constitute their complement. It seems to me that the greatest irregularities are found in those species where the rays are most numerous.

All are cold, rigid, rough, and disagreeable to the touch; and they themselves are very impatient of heat, whence it is necessary to keep them cool. Frequent renovation of their element is indispensable.

In confinement, as well as in the sea, Star-fish are subject to frightful mutilations. Not only are they subject to lose portions, or even entire rays, but the whole animal literally falls to pieces. Nay, after a day of correct and satisfactory obserration, the following morning will sometimes present nothing but a quantity of white granulations in the vessel which had contained a perfect and beautiful specimen. 'This kind of decomposition is perhaps a casualty incidental to the whole : I know of none exempt from it.

But, as if in compensation, Nature has endowed these creatures with surprising reproductive energies. All the lost organs are replaced by others! and although some authors have denied that a complete specimen may be formed from a single ray, this is a fact which certainly does ensue. But whether some insensible fragment of the disc must have necessarily remained, I cannot presume to specify. 
Many of the animals which have been beautifully symmetrical when entire, appear strangely distorted on absolute privation of some of their perfect organs, and the irregular evolution of others.

The aspect of individuals often alters very much, either superficially, or in the distribution of the colours. Some undergo a great external change with age. The whole tribe seems to abound in varieties, insoinuch that it is difficult to reconcile the observations and descriptions of different naturalists. Perhaps the enumeration of species exceeds the truth of Nature.

The surface of the Star-fish presents many interesting, curious, and beautiful patterns for initation in the arts, and in great variety. Sometimes a singular arrangement of points and orifices-sometimes a profusion of organs in the semblance of luxuriant flowers.

As the skin is penetrated by imnumerable orifices, through which certain processes rise at the will of the animal, the surface is subject to continual alteration. Of two specimens of the Solaster, one may be the brightest scarlet, studded with many white spots, and the other of the darkest crimson, wholly of uniform colour. Of another species, individuals may appear yellow, purple, or red, speckled white.

An important branch in the history of these creatures-the mode of their perpetuation,-was long involved in mystery. 'The reproductive energies of the tribe, the frequent and ready recovery of lost parts, were well known to almost every one acquainted with the animal, or accustomed to see it entire and mutilated. But the way in which they bred could be told by none. This is a subject which seems to be involved in greater obscurity in general, than any other in the history of living beings.

In regard to those dwelling in the waters, our ignorance may originate from two sources ; first, the produce of the female parent, whatever it is, may float away at first and disappear ; secondly, it may be developed into forms, which, bearing no resemblance, are never recognized as kindred.

In so far as I have observed, a quantity of roe is generated, chiefly in spring, and advances to maturity in summer, which is differently disposed in these animals, according to their different form. 
Thus, the position of the ovarimu, or rather of the ovaria, for all have more than one, is determined by the species.

In the Asterias glacialis and rubens, they occupy a large portion of the five rays, each ovariun of the latter growing to a great size : those of Asterias aranciaca belong to the origin of the rays next the disc, and are of quite difterent formation. The roe of the Solaster papposa is found in the margin of the dise, of different arrangement from that of the others. The roe of some Uphiure occupies five external sacs, each interposed between the roots of two rays, and shew, by their swelling, the progressive advances of their contents.

The ova of the Asterias glacialis and rubens seem to be discharged from the end of May throughout Jume. On dissecting numbers of each. in the beginning of July, the rays of many were entirely vacant of spawn. But, in one large specimen of the former, a lobe of clear spawn, an inch long, was found ; and in others, very small portions, which, early in the season would have been considered originating lobes in both.

The lays are now distended by water.

The embryo animal, originally circular, is gradually moulded into form, when liberated from the capsule: the limbs are successively developed from the margin, the whole meanwhile presenting an irregular distorted aspect until attaining symmetry.

The young animals seldom oceur at large in a very early stage. When they do so they are preserved without difficulty.

The Star-fish evidently live many years. Some are extremely common, others are of great rarity.

The history of the Star-fish may be divided into two sectionsI. The Asterias-II. The Ophiura.

\section{Section I.-§ 1. Asterias Glaclalis.-Northern Sea-star, Cross-fish.- Plate XVI.}

This animal seems to be generally and numeronsly dispersed throughout the northem regions. It is abundant in the Scotish seas, insomuch that description is hardly essential, for none other is the subject of incidental reference. 
The Asterias glacialis is provided with long rays, which issue from the parts around the mouth, for there is no definite central disc, properly so called, whence they could originate, although the body is thick and compact. The back is somewhat elevated ; the under surfice flattened, with the dilatable mouth in the middle. Thus, there being no central body, as in the Ophiura, the rays may be said rather to fork from each other than to issue from a centre. These are stout and taper, convex above and flattened beneath, terminating by several slender suckers at the extremity, besides which there is a channel in the under surface, with rows of suckers, more numerous, stronger, and of larger dimensions, serving as feet, both in progression and for fixture.

The Northern Sea-star is among the largest, the most powerfil, and ravenous of its kind, expanding completely twelve inches between the tips of the opposite rays. But, the actual dimensions, and the wonted appearance of such animals, are much affected by temperature of the atmosphere, repletion with food, and especially by the presence of spawn.

The colour is extremely variable, dependent on the specimen, and sometimes on age. It is usually purple or greyish : in an early state it is white. I have seen cream-coloured specimens expanding towards three inches.

The richest purple adorns some specimens. Purple seems the natural colour of the species. A specimen, so pale as to be almost white, having been committed to recent sea-water, became speedily of a purple hue.

When inactive, the animal is greatly contracted, cronching closely in some cavity, as if for concealment, or occupying an angle, apparently quite helpless and incapable of resistance. When roused by heat or hunger, it advances as if half-swimming, with incredible quickness, such as could not be ascribed to its nature without ocular demonstration. The body is much relaxed, the rays extended, and the numerous suckers in action. It never swims, however, nor does it spontaneonsly quit the water, though seen as left behind by recess of the tide.

No creature is more rapacions. Its prey is devoured alive, whenever it can be overpowered. Let a moderate-sized mussel be presented, it is straightway covered by the body of the Star. fish, while the rays closing around it, the animal sustains itself on them as on feet, contracting still 


$$
x^{*}
$$



more by investing the prey; which is wholly absorbed, on the mouth dilating for its reception. The mussel, though sometimes rejected for fish in preference, is usually acceptable. Under protracted abstinence, even the fuci are not refused. If the portion of food be too large for the mouth, the stomach, or a transparent interual membrane, protrudes and applies to it, apparently absorbing the juices. The testacea, whether univalves or bivalves, become a ready prey. The Turbo and the Pholas fall victims alike. A specimen, not content with seizing a sunall mussel introdued into its vessel, hastened to involve another. As the prey is brought under the mouth, it is hemmed in by the limbs on all sides, crushed asunder, or swallowed entire. If chancing to escapc, it is only from superior strength. Small fishes, small Fehini, and even somle of its own genus are all among the sacrifices to the merciless voracity of the Asterias glacialis.

The colour and size are variable : the adult in perfection is of a finc purple of various inteusity, according to the specinen. That represented, Plate XVI., of half the natural dimensions, expanded completely twelve inches between the opposite extremities of the tentacula. But the young animal is white, and regenerating organs of the old are originally colourless, both in accordance with the laws usually regulating the aspect of early productions.

A small specimen, which might have been circumscribed by a circle of three lines diameter in the end of September, traversed the side of it: vessel vivaciously, and swam supine, fig. 2. Another small specimen, expanding eight lines, and which was a line thick, appeared perfectly white on February 20, and very pale grey a month later, fig. 3. At this period, the tubercles disposed over the rays in longitudinal rows, were well exposed under the microscope, fig. 4. The animal was vigorous, and fed on mussel. But I felt perplexed as to its identity with the species. In three more weeks, I thought the slightest tinge of purple perceptible, and the fact was decided ten days later, when its expansion equalled fifteen lines, or an inch and a quarter. Though hardly to be preserved, owing to the heat of the weather about June 20 , its increment had still advanced, and the colour had become dark purple on July 11. Being two inches in expansion, it was delineated, fig. $\overline{.}$ 
After surviving six or seven months, this specimen perished accidentally.

During the season of propagation, the rays of the Asterias glacialis are distended by a great ovarium. This, perhaps, may be considered as divided into five parts, one occupying each ray; each part, consisting of two triangular lobes of unequal size in every ray, with subordinate parts, also triangular, and resembling clusters of currants or grapes. Tuwards the end of May they are seen to be an accumulation of speckled capsules, which bursting, discharge a quantity of molecules, like dust, falling to the bottom of the vessel.-Fig. 6 .

The capsules farthest advanced belong to the larger portion of the roe, that towards the body of the animal which seems the first to originate. A solid nucleus within an integument is discovered in each of the molecules discharged from the capsule. The spawn is long of attaining maturity ; the lobes represented, fig. 6 , being only in progress in the end of April. A month, or perhaps two, had still to elapse before the discharge of the ova,-Fig. 7.

This species is extremely subject to mutilation of the rays. It is constantly found with one or more in progress of reproduction. Mutilation does not seem incidental to age, size, or season. But to shun repetition, I shall reserve a few observations on the subject for the following paragraph.

I am ignorant whether specimens, originally white, invariably change their colour, having witnessed its permanence in some of considerable size, as previously said.

\section{Plate XVI.}

Fir. 1. Asterias glacialis-The Northern Sea-star, adult.

2. Young specimen.

3. Young specimen, originally white.

4. Ray of fig. 3, enlarged.

5. Fig. 3 represented four months later than previously, being now purple.

6. Lobes of spawn.

7. Ova enlarged. 


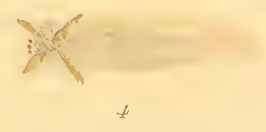

\%
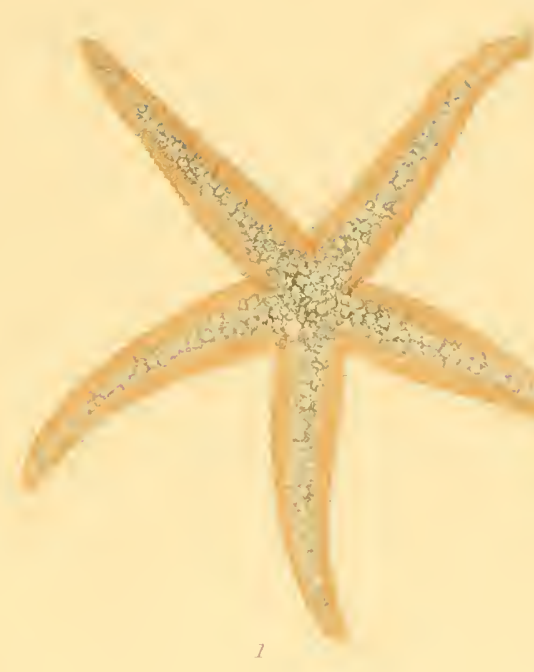

क
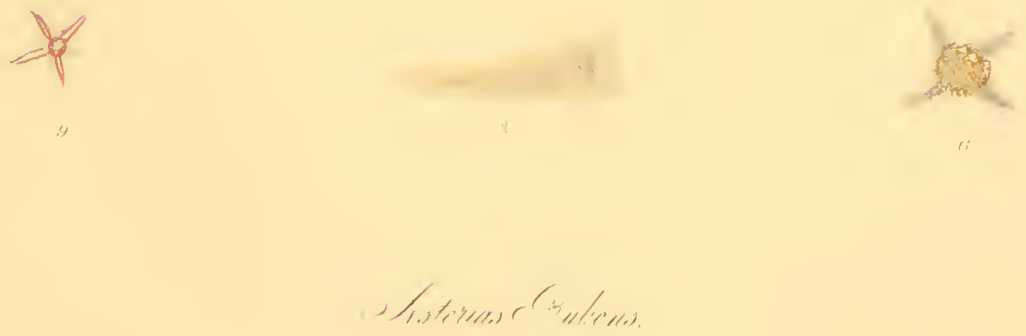



\section{§ 3. Asterias Rubens-Reddish-yellow Sea-star.-Plates XVII., XVIII., XIX.}

There is no race of animals wherein the difference and variety of colour is more noted than the Star-fish, and in none greater than in this and the preceding species. Hence the almost insuperable difficulty of discrimination; nor could I ever decide positively to which of the two Plate XVII. fig. 1 belongs. Presuming them different, I inclined to identify it with the Rubens. I am convinced, however, that two or more have been concentrated as only one; while a single species in different hands is multiplied into more than one. Perhaps the colour is so variable, that observers unable to satisfy themselves of identity, have too readily presumed on difference : all, as already explained of other animals.-Nature seems sportive in the detail of some of her works, while prominent leading principles, often unobserved by mankind, are left to determine her purpose.

The difference of aspect is most conspicuously shown by the subject under discussion.

In as far as I have been able to observe, the Asterias rubens identically resembles the Asterias glacialis in general formation, as well as in the number and proportion of the organs, and in habits. It attains the largest size that I have seen of the Scotish Star-fish, some having been found in the month of June expanding thirteen inches between the opposite extremities of the rays ; and one obtained in April, expanded no less than fifteen inches.

The natural or converted colour, if it be not original, seems some shade of yellow of various intensity above, and either pale yellow or white below.

But specimens, of which I could scarcely doubt the identity, have been very different-so different indeed, that representations after colour are scarcely authority. Thus the specimen, Plate XVII. fig. 1, was of a dull indefinite brownish-grey, while that of Plate XVIII. fig. 1, was a fine vivid yellow. Plate XIX. fig. 1, seen on a reduced scale, was yellow, but not equally fine as the preceding. I have never observed any large 
specimen of vivid yellow. In some of medium size, an intermixture of brown predominates over the yellow.

The whole surface is generally spotted white, in longitudinal rows from the centre of the body down to the extremities. By the microscope, the spots are discovered to be so many tufts, composed of spinous processes; and being protruded at will, they cannot but greatly affect the appearance of the animal, and the more according to its predominant hue. Both this and the former have rows of peculiar low processes down each margin of the five rays ; and each ray in both seems to have four rows of suckers in full-grown specimens; if only two, as usual in Star-fish, their arrangement is deceptive. The extremity of the rays have several longer and more slender tentacular organs.

A vast ovarium ocenpies the rays of the Asterias rubens in May and June, composed of lobes of a triangular figure, terminating in cones of capsules, each capsule as large as small shot. The general figure of the subordinate parts corresponds with that of the lobe.

In April the roe is not so far advanced as to distend the lobes. It resembles clusters of grapes. The surface of the capsules approaching maturity, appears mottled from the internal molecules; which fall to the bottom of the vessel in numbers incredible, as the capsules burst. A darker nucleus is exposed under the microscope by each. If these be the elements of the Star-fish, our surprise at their multitudes may cease. -Plate XVII. fig. 2.

But infinite embarrassment opposes discovery of the actual development of the embryo. Whatever success may have attended the researches of other naturalists, I have been constantly disappointed of following its progress uninterruptedly ; whence I am led to conjecture that the spawn or produce is borne away from the prodnct, and is preserved from corruption by the abundance of the circumambient fluid.

The young Asterias rubens, as it may be presumed from form and colour, is sometimes found in a very early stage, from which it appears that the development of the ovum is as an irregnlar, expanding, central, shapless portion, whence the rays are gradually issuing. But they are of indefinite form, originating successively, and refining with time. 


$$
\text { * }
$$



I speak with diffidence; but possibly the progress is beheld as represented, Plate XVII. fig. 2 ; Plate XIX. figs. 2, 3, 4, 5, 6,-the first representing the molecules or ova, and the last the young of perfect form.

All these, it will be observed, appear to be advancing to perfection. But, not having seen their origin, I am ready to give them as a general illustration of the progressive improvement, without insisting that they were necessarily the young of the Asterias rubens.

They occurred at different times, though the intervals were not great compared with the irregularities constantly embarrassing the history of such marine productions.

The ova are seen Plate XVII. fig. 2. The animal, Plate XIX. fig. 2, evidently had recently quitted the ovum. It was little above half a line in diameter, irregularly tending to a circular form ; of variable shape, of soft homogeneous aspect : endowed with slow progression and slight adhesion. Some short suckers projected from the circumference, but no indication of rays. This subject occurred on April 29, and was delineated on May 2, enlarged. The form of another specimen, under a line in diameter, delineated May 16, was much improved, for the incipient form could be distinctly determined ; fig. 3, upper surface ; fig. 4, under surface, both enlarged. Above a dozen were found among miscellaneous collections, on May 26, which, still in an early stage, had attained higher perfection. They are represented as of the natural size, fig. 5 ; one enlarged, fig. 6 .

The roe had been previously discharged from several of the Asterias rubens and several of the Asterias glacialis, all dissected on the 11 th of July.

Many marine products are totally lost in earlier age, if separating from the parent, and multitudes destroyed by sudden decay; thence it can be principally from accident, if any are preserved on quitting the ovum.

This species, the rubens, like the preceding, is extremely subject to mutilation of the rays. Of the complement many have four, three, two, and some only one. But, the reproductive energies being powerful, 
many are disfigured by monstrosities in the irregular evolution, both in size and number of the renorating parts.

On the tenth of June, a single ray was found, which had either separated from an entire specimen, or was the residue of one having lost the other parts. It shewed no symptoms of reproduction at the time; but, on the fifteenth, the rudiments of four additional rays were indicated by four papillar prominences, projecting the sixteenth of an inch from the broader end. Next evening, one of these had attained nearly double the size : the others were less adranced, but a small orifice, the mouth, was forming in the centre. The whole ray now extended about thirteen lines.

Another specimen having fallen to pieces from the extreme heat of the season, rendered me apprehensive that this would share the same fate; nevertheless it escaped. Reproduction advanced vigorously, and in two or three days longer, it appeared as in Plate XVII. fig. 3, upper surface; fig. 4 , under surface. Some smaller specimens were now perishing by the heat.

This regenerating animal haring begun to feed on June 29 and 30, it dwelt for hours over a portion of mussel. In a month from the commencement, the new organs appeared as in fig. 5 . But, on the 15th of July, the original ray fell to pieces, learing the disc, fig. 6, surrounded by the four generating organs. This was a singular incident, especially as the animal became symmetrical, and fecl soon afterwards. Nothing disproportionate, or offensive to the eye, remained by priration of the unwieldy ray, and in ten days, or on July 25 , the specimen, such as it remained, was quite rigorous. But, while still enlarging, it perished subsequent to August 15, at which time no indications promised reproduction of the fifth or defective ray.

Mutilation is not incident either to size or age. It takes place, and is succeeded by reproduction, alike in old and in young specimens. It may be called total or partial. Sereral specimens haring been collected towards the middle of July, one consisted of only two rays, each two inches and a half in length, issuing from opposite sides of the disc. Wishing to ascertain some facts in reproduction, I endeavoured to pre- 

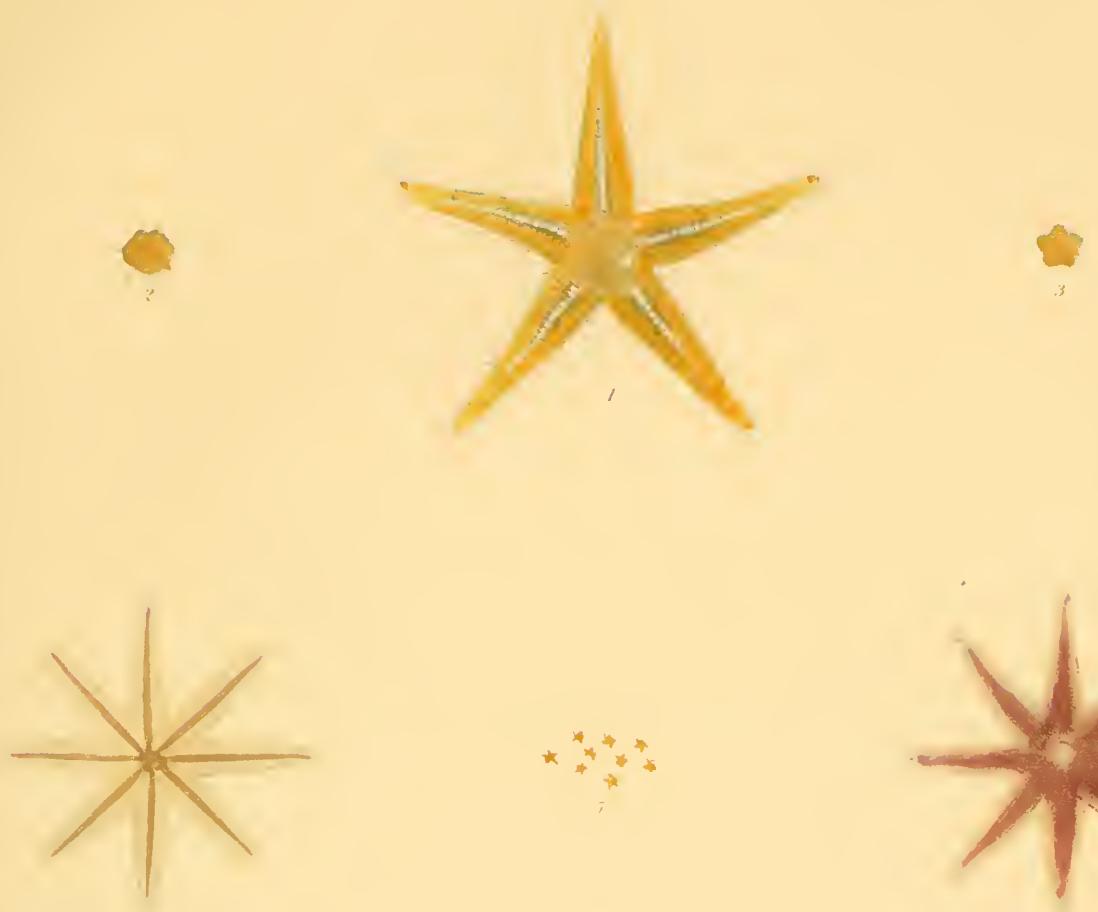

$$
t_{-4}^{4}+
$$

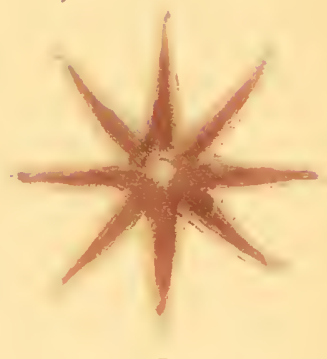

4
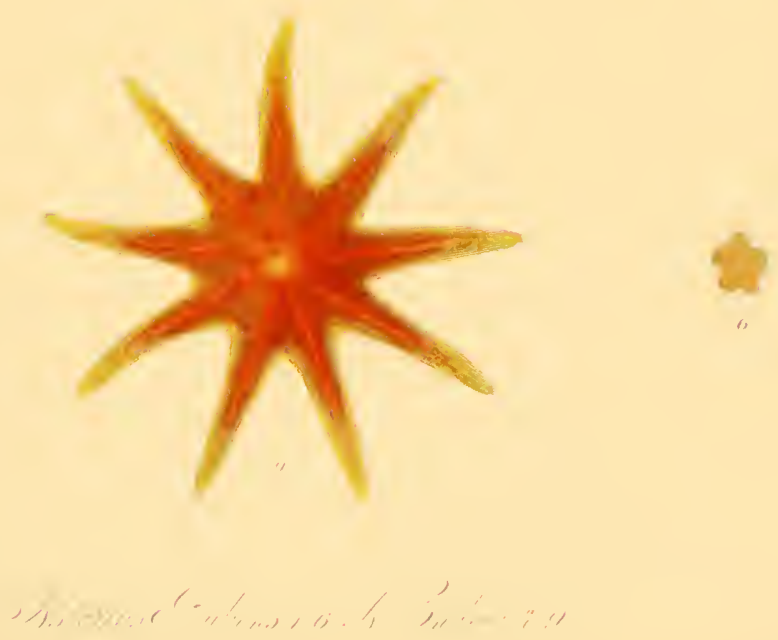

serve this specimen as it was healthy. But in three days both rays separated, leaving the disc entirely free of appendages. All went to decay in a few days longer.

A fifth ray may be added to four still subsisting to make up the complement, or four may generate where only one remains. $\Lambda$ single ray, fig. 7 , withont incipient reproduction, appeared on July 30 , as fig. 8 , when four had made considerable advance, as in the former specimen. The fifth ray of a small specimen, defective, was advancing in the end of December. Fig. 9.

Many obscurities in the history of these two, the glacialis and rubens, whether the same or different, require elncidation. $\Lambda$ t present, I incline to conclude that the same facts apply alike to both. $\Lambda$ specimen, expanding twelve inches between the tips of the opposite rays, which were of large size, being an inch and a half thick at the root, was entirely of gallstone yellow. Having lain during the night in the open air among sea-water, this external colour seemed to be altogether removed when the specimen was washer in fresh water next morning. The surface of the rays became nearly dull red lilac purple, which might have led the observer to identify it at once as the Asterias glacialis.

The peculiar organization of the skin, the varions pores by which it is penetrated, and the subsidiary parts presented to view, and withdrawn at will, merit farther investigation, for enabling us to account for external appearances.

From the aversion of the fishermen, both to the larger and smaller genera of Star-fish, they were wont to rend them asunder. But on discovering their purpose to be defeated by the reproductive energies of their victims, they are now cast ashore, and left to perish.

\section{Plate XVI.}

Fig. 1. Asterias glacialis, the Northern Sea Star or Cross-fish, half size.

2. Young specimen.

3. Young specimen, originally white.

4. Ray of fig. 3 enlarged. 


\section{Plate XVI.-continued.}

FIr. 5. Fig. 3 four months later than the preceding delineation, now converted to purple.

6. Lobes of the Ovarium in May.

7. Ova, enlarged.

\section{Plate XVII.}

F1G. 1. Asterias rubens.

2. Ova, enlarged.

3. Ray of a mutilated specimen, upper surface, 10th June.

4. The same, under surface.

5. Fig. 3 as on July 15.

6. The same, as on July 25.

7. Ray of a mutilated specimen, upper surface as on July 12.

8. The same, as on July 30 .

9. Small specimen regenerating the fiftl ray.

\section{Plate XVIII.}

Fig. 1. Asterias rubens.

2. Appearance of the skin, enlarged.

\section{Pthate XIX.}

FIG. 1. Asterias rubens.

2. Young in an early stage.

3. Young farther advanced, upper surface.

4. Under surface.

5. Group of young in greater perfection.

6. One of the group enlarged.

Figs. 2, 3, 4, 6, enlarged.

\section{§ 3. Asterias (Cribelia) oculatia.-Plate XX.}

This animal is readily recognised. It is provided with five rays, expanding four inches or more between the opposite tips, though seldom occurring as large. The rays are of a different character from those of the preceding species, being stout, round, comparatively short, and taper- 
I. 1.

P'L.XI

I. 1.
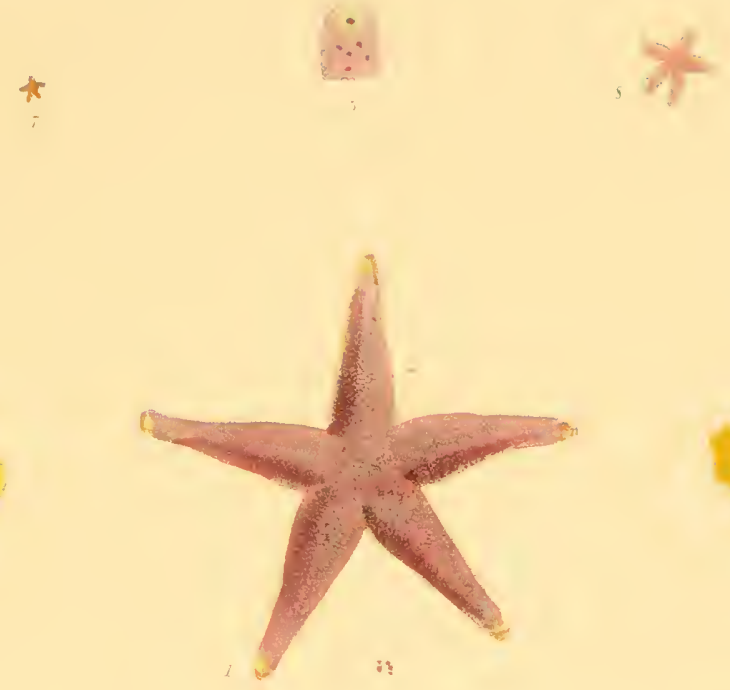

종
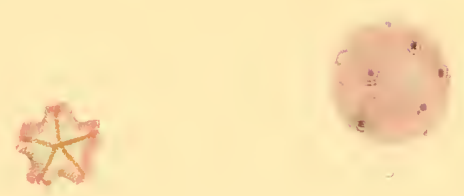

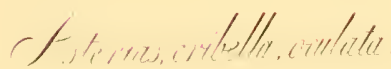



ing slightly from the origin. The whole surface is of a fine purple colour above, the extremity of the rays yellowish, the under surface tending to that colour also. Plate XX., fig. 1. A narrow channel here rumning along each ray contains the suckers, fig. 2. The skiu appears punctured to the naked eye. Under the mieroscope it seems covered with a kind of very low tufts or knobs, hardly prominent, rather in circular arrangement, interspersed with circular orifices, fig. 3 .

A small hard substance, searcely prominent above the skin, and generally of a whitish colour, appears towards the edge of the dise of the star-fish of many species. The use of this, called the Madreporiform tuberele, is yet uudiseovered. In the present subject it is very small, but the peenliarity of its structure is exposed by the microseope, fig. 4 .

In many of the star-fish also a solid round speck appears at the extremity of each ray, fig. 5 , which seems to be composed of several subordinate specks, fig. 6 . It is red in the Asterias orulatu, and is seated amidst a few tentacula, extending farther. Some authors consider such speeks the eyes of the animal ; but it does not appear that satisfactory reasons support their opinion, nor ean it be shown why the speck may not be a gland instead of an eye.

This animal feeds on the mussel, but not readily: Probably also on the Lepas. Many rejeet food entirely.

In its earlier stages, the Asterias oculata seems to be of a cirenlar form, followed by development of the rays. Of two minnte specimens occuring in the month of July, one was nearly circular, fig. 7 ; originating rays, with some suckers, distinguished the other, fig. 8. After a minnte deep reddish orange speeimen had been two months in my possession, I found it an eighth of an inch in diameter, with five short obtuse rays, fig. 9. A small orange specimen, with five stout rays, fed readily on mussel, dwelling long over its prey, fig. 10 .

I advance my opinion of the identity of such small amimals as belonging to the speeies with reserve, beeause their history was not followed from its earliest origin.

The young of the star-fish bears no resemblance to the adult. All its organs are suceessively developed into form. 
A considerable difference prevails in the intensity of colour in the adult, though always purple. The extremities are generally reddish or yellowish, and the under surface dingy yellow. Great diversity of appearance prevails among all the race.

This species may be sometimes found sheltering itself under rocks and stones, on recess of the tide. Its adhesion is slight, owing to the smallness of the suckers.

\section{Plate XX.}

FIG. 1. Asterias (Cribella) oculata.

2. Centre of the under surface, and avenues of the suckers.

3. Portion of the skin, enlarged.

4. Madreporiform organ, enlarged.

5. Ocular specks or glands, enlarged.

6. Subordinate specks, composing the same, enlarged.

7. Young Asterias in a very early stage, enlarged.

8. Another.

9. Young Asterias, natural size.

10. Young Asterias, natural size.

\section{§ 4. Asterias aranciaca.-Plate XXI.}

Authors doubt whether the name of this species is Aranciaca or Aurantiaca. It is of little consequence. The difference of names often results from ignorance of previous orthography. The variety we find in the sumames of people is very great, because many called on to subscribe documents of old were not so skilful either in chirography or orthography, as to bestow the proper appellation on themselves.

The Asterias aranciaca extends six inches between the tips of the opposite rays, which are five in number, terminating obtusely with a few tentacular filaments. The rays are bordered by numerous setaceous spines, thickly set, of which the largest are next the body. The upper margin of the rays is also bordered by a row of beads, the largest being next the body, and diminishing towards the extremities, where they are very 

small. They are of an oval shape, and being prominent and conspicuous, give the form of the animal a finished appearance :-Plate XXI., fig. 1. A double row of suckers runs along the under surface of each ray. Fig. 2.

The skin is of peculiar formation, consisting of numerous rosettes and circular orifices, in regular arrangement, very ormamental.-Fig. 3.

The upper surface is universally of light brownish colour, with a reddish tinge. A stellate arrangement of red specks occupies the centre.

I could not discover the wonted ocular or glandular speck at the extremity of the ray by the microscrope, fig. 4 . The border seems to decompose by losing the beads, fig. 5 .

In the end of April a large specimen occurred, containing a quantity of advancing spawn, situated in the origin or root of the rays.

This is also of very peculiar formation. It consists of a number of ovarian ropes of moniliform aspect, which will be best understood from its representation :-Fig. 6, portion natural size; fig. 7, enlarged; fig. 8, ovarian ropes magnified.

This animal is not common.

I understand that, in the opinion of certain naturalists, its name is derived from a mucous matter, which, they say, exudes from the body, and overspreads the surface like a spider's web.

\section{Plate XXI.}

FIG. 1. Asterias aranciaca.

2. The same, under surface.

3. Portion of the skin, enlarged.

4. Extremity of a ray, enlarged.

5. Marginal beads.

6. Ovarian ropes.

7. The same, enlarged.

8. Portion of the same, magnified. 


\section{§5. Asterias Endeca-Ninc-rayed Star-fish.-Plates XIX. figs. T, 8, 9-XXII.-XXIII.}

The species described in the preceding paragraphs are all provided with five rays, which, as before said, are commonly uniform, without deficiency or redundance. Those of the Star-fish described in the present paragraph are not alike uniform in number, being eight in the specimen, Plate XIX. fig. 7 ; nine, the full complement, in fig. 9 ; and nine in the specimens Plates XXII. and XXIII. The animal has also occurred with ten. This is one of the larger and more beautiful of the Star-fish inhabiting the Scotish seas, expanding eiglit inches between the opposite tips of the rays. The usual complement of these, I say, is nine. They diminish regularly from the root to the extremity. Two rows of suckers occupy their under surface.

The texture of the skin is rongh, and its formation and appearance are very peculiar. Not less raried is the colour, specimens being seen from pale yellow, or brilliant orange, to fine purple. Some of the former are speckled white, or a white line runs down the middle of the surface of the rays. There is no uniformity of colour whatever to guide the observer.

But the structure of the surface, whereby, perhaps, the colour is entirely modified, is neither explicable nor intelligible. It is of remarkable complexity.

The skin or integument being porous, and the animal having the faculty of elevating some singular parts of its organization above the surface, through the pores, as well as of withdrawing them, the appearance must necessarily depend on the mode wherein this faculty is exercised. I see no other means of accounting for its changeable aspect.

The specimen Plate XXIII. fig. 1, expanded seven inches, and was of a fine delicate purple above,-the uuder surface of a dingy straw yellow. A number of projecting minute white tufts, interspersed with short cylindrical tubes, studded the upper surface,- the skin being thin and flexible. The colour was no less modified by the proportional projection of the tufts. When they were depressed it was much darker, when they were elevated much lighter. A portion enlarged is represented fig. 2. 


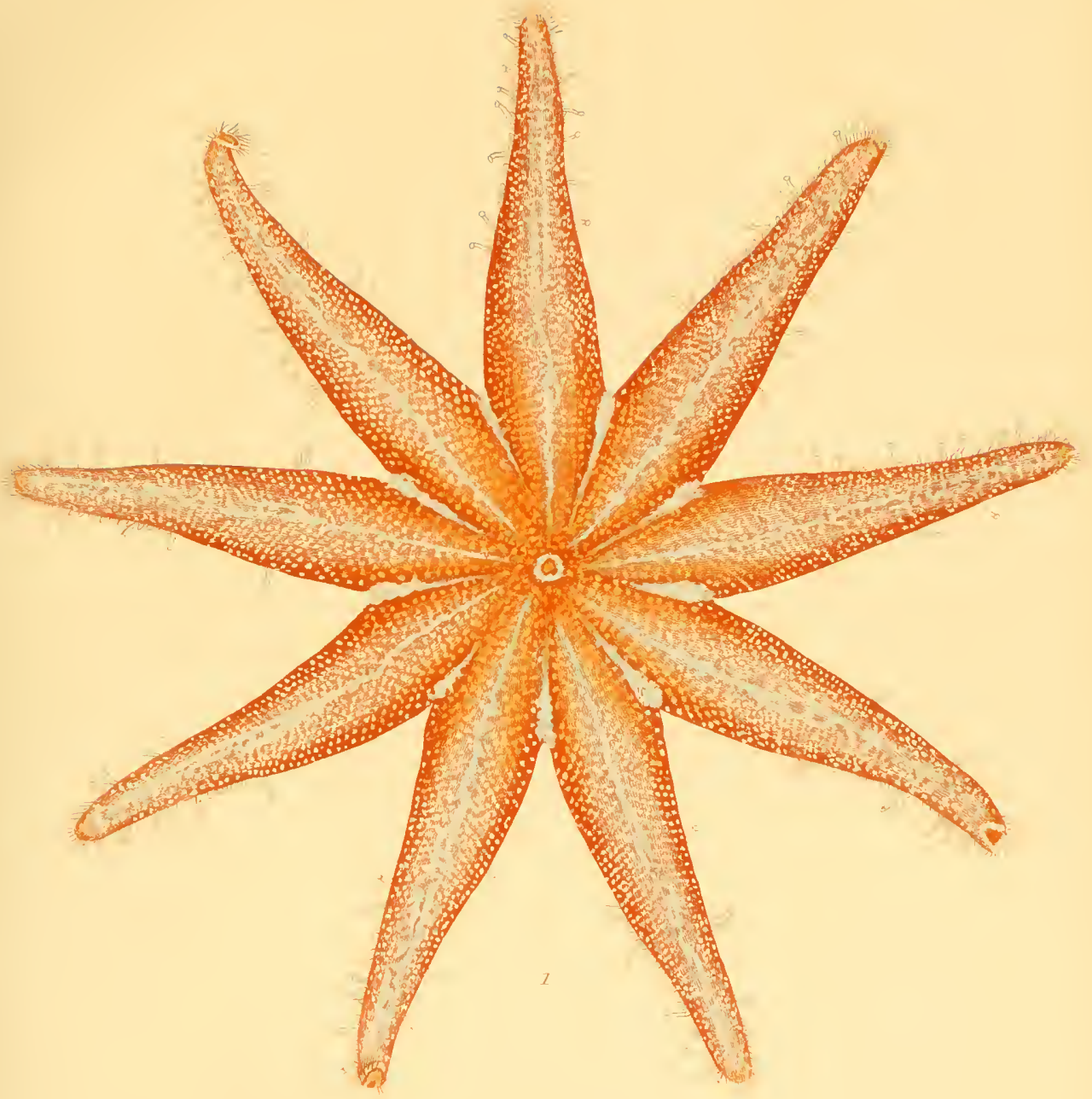

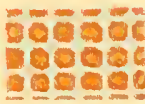

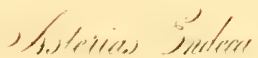



Under the microscope the outline of the tufts tended to cylindrical : and each was apparently composed of fourteen or sixteen cylinders, which are not smooth. The short cylindrical tubes appeared to be soft and fleshy. In some places they were interspersed irregularly with the tufts, and in other places, one tube stood regularly amidst four tufts. The madreporiform tubercle, was situated amidst four tnfts. An enlarged view of it is presented by fig. 4 , where other tufts are also seen; and a portion magnified is shewn fig. 5 .

Here the ocular speck at the extremity of the ray is dark reddishbrown. It is neither compact nor uniform under the higher microscopical powers, but apparently more solid towards the middle, while parts of the circumference cousist of minute specks, fig. 3 .

On March 27. I found forty or fifty ova floating near the surface of the water of a ressel containing a specimen of between seven or eight inches diameter, which had been a week in my possession. These ova were of a fine reddish-orange colonr, solid and consistent, nearly globular, but some beginning to relax in form. On transferring the specimen to another vessel, a few more ova were produced, and here thirty or forty others escaped on the following day :-Fig. 6, ova ; fig. 7, group enlarged.

Some had a slight depression in the centre, like an orange, and the figure of others tended to oroidal. All seemed fresh, smooth, and they were of vivid colour.

Selecting a number, I consigned them to five different vessels. But I was disappointed of the progeny, as none proved prolific.

This animal sometimes feeds readily. When doing so mussel is consumed ; however, many refuse food entirely. A fine specimen, expanding just about two inches, of beantiful reddish-orange colonr above, and yellowish below, fed readily on the common lepas when detached from its site. The Star-fish, involving the prey among its limbs, extracted the contents of the shell.-Plate XIX., figs. 7, 8.

The Asterias endeca has not been common in any place that I have visited; nor has it survived long in confinement.

The specimen, Plate XXII., was originally very weak, but from 
careful treatment, and particularly from being kept cool, it became sufficiently vigorous, and proved a fine example of the form of its kind. Star-fish are generally extremely impatient of heat. Many perish, apparently from nothing but the temperature of our apartments exceeding that of the sea.

These animals usually ascend the sides of the vessels devoted to their preservation. They quit their hold, if enfeebled, lie reversed below, and die.

\section{Plate XIX.}

Fia. 7. Asterias endeca, with eight rays, upper surface.

8. Under surface.

9. Another specimen, with nine rays, reduced.

\section{Plate XXII.}

FIG. 1. Asterias endeca, expanding eiglit inches.

2. Compartment of the skin, enlarged.

\section{Plate XXIII.}

FiG. 1. Asterias endeca, purple specimen expanding above seven inches.

2. Compartment of the skin, enlarged.

3. Ocular speck, enlarged.

4. Madreporiform tubercle amilst fonr tufts, with two at some distance, enlarged.

5. Portion of the same, magnified.

6. Ova near the size of nature.

7. Group of the same, enlarged.

\section{§ 6. Asterias (Solaster) Paprosa.-Plates XXIV., XXV., XXVI.}

Turs is one of the larger, the more singular, and, at the same time, one of the most beautiful of the genus dwelling in the Scotish seas. But, compared with those already described, its appearance is so remarkable, and it is so unlike them in all its features, that many less skilful might refuse to admit its kindred to the tribe. The formation of the 


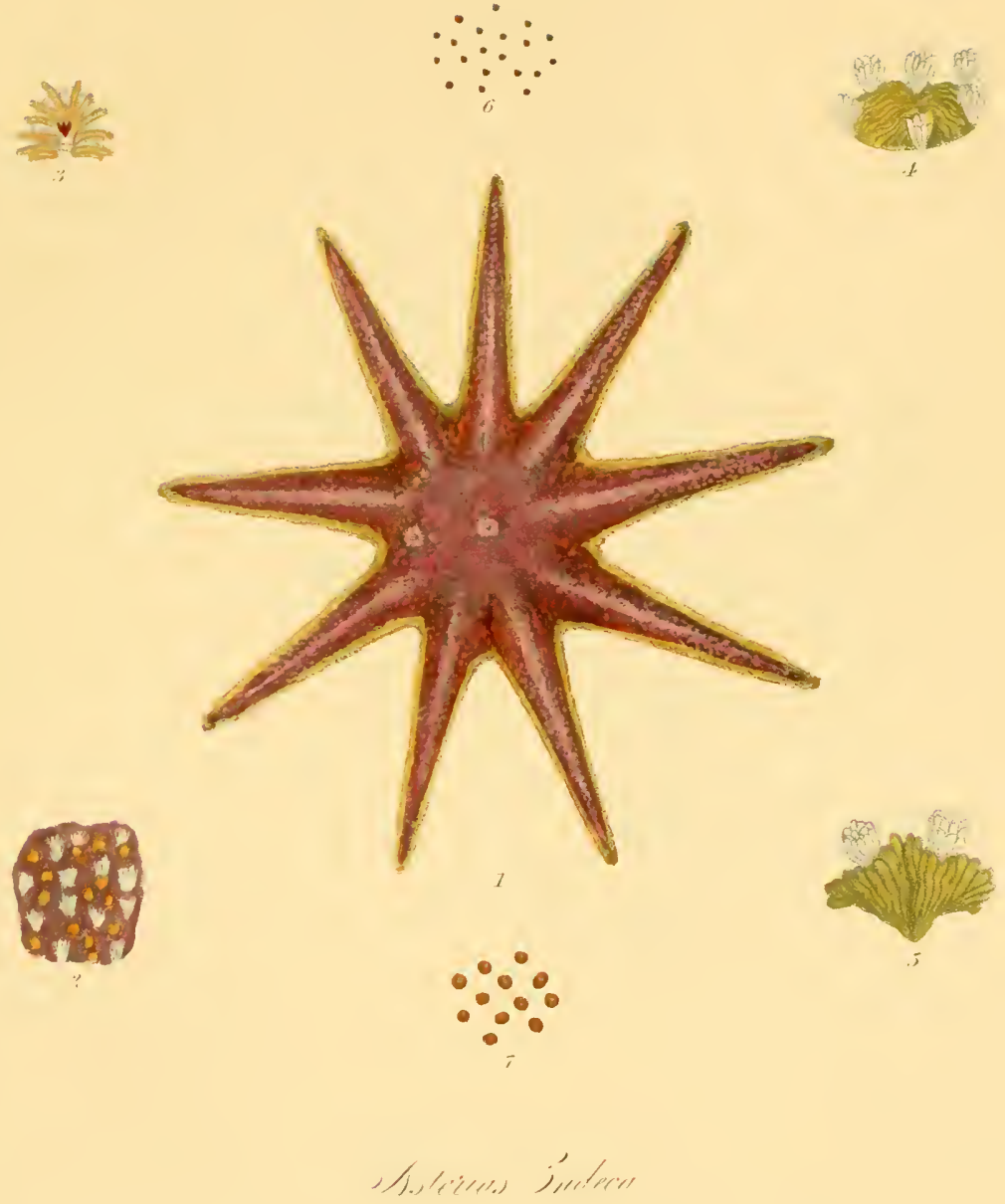



animal is indeed extraordinary ; the number, complexity, diversity, and peculiarity of its parts are such as to render it vain attempting to specify them in detail ; neither could the form be rendered more explicit, nor its nature be better understood, than by the representations given here, aided by brief description. Nothing short of actual inspection of the living subject ean satisfy the admiring and inquisitive contemplator of the marvellous works of the Creator.

Here the breadth of the disc is proportionally greater, and its form more characteristic than in any of the preceding species. Thus the rays are shorter; nor does the general aspect of the whole animal bear mueh conformity with that of the others. Everything denotes a tendency to transition.-Plate XXIV., fig. 1.

Specimens are of circular shape, and provided with from eleven to fourteen rays. Among many obtained at different times, the majority had thirteen, which seems about the proper complement.

Larger specimens expand from eight to ten inches between the tips of the opposite rays. The whole upper surfice is covered with tufts like the short bristles of a small hair pencil, advancing in regular lines along the sides of the rays. Another kind of pure white tufts stands across the rays, erect, like the teeth of a comb.-Plate XXIV. fig. 2 : Portion of the skin of a different specimen, enlarged. The whole under surface, especially towards the centre, is of very remarkable structure. One part is sufficiently obrious, being the wonted chamel, with a double row of suckers traversing each ray; and eight or ten suckers, proportionally longer, more flexible and active at the end of the rays, rather appearing, by their stretching and searching around, to discharge a tentacular office. Their strueture is also somewhat different, whence stricter attention luestowed on them might discover whether they have truly any peculiar province. The npper surface of the animal is wholly red; sometimes very fine scarlet, spotted white, from the presence of numerous suljordinate organs.-Plate XXIV. fig. 1. Besides a profusion of tufts, infinite low small white prominences arise among them from the skin. In addition to all these are many whitish or yellowish tubular orifices, perceptible by the microscope, also on the surface of the disc. 
The tufts now alluded to, whether red or yellowish, are of singular conformation. They consist of not fewer than fifteen blades, rising from a common neck uniting them, which is seemingly a prolongation from the animal's skin, fig. 4 . There are specimens wherein the tufts lean over the madreporiform tubercle, itself a small striated, indurated, flattened spot, white, or of the palest yellow, fig. 5 .

A common stcker is represented, fig. 6 ; and one of tentacular nature, fig. 7 .

The under surface of the animal is white ; it has no resemblance to the upper surface.-Plate XXV.

The ocular or glandular speck at the extremity of the rays of the Asterias papposn is red or brown. In a small lively specimen, subjected to the microscope, what appeared single and red to the naked eye was discovered to consist of about twenty very minute specks, rivid red, dispersed over a pale ground. The specks are generally circular; but while most of them are so in one ray of a specimen, those in the rest may be rudely triangular. Neither are the red specks disposed in regular order. In distribution they may be compared to similar black specks, supposed ocular, occurring in the Planaria and Vermes, fig. S. In a large dingy red specimen the specks, under a powerful magnifier, resembled an obtuse conic frustum, of vermillion intensity of colour, with a lighter depressed rather than elevated speckling, fig. 9. Another was nearly of similar form ; a third projected as a spherical segment.

This subject is extremely obscure, but I do not yet see any relevant ground for believing that such specks in the extremity of the rays of the Star-fish are the organs of vision.

Under farourable circumstances this species feeds voraciously on mussel. But, from previous injury, perhaps; specimens have proved always of difficult preservation, nor, unless with rare exceptions, are they in a condition to feed. Some, however, are very active, and feed readily. If supplied with a cleft mussel shell the everted stomach protrudes, apparently to absorb the contents. Without this fuculty food would be often inaccessible.

Three specimens had been committed to the same vessel as Plate 


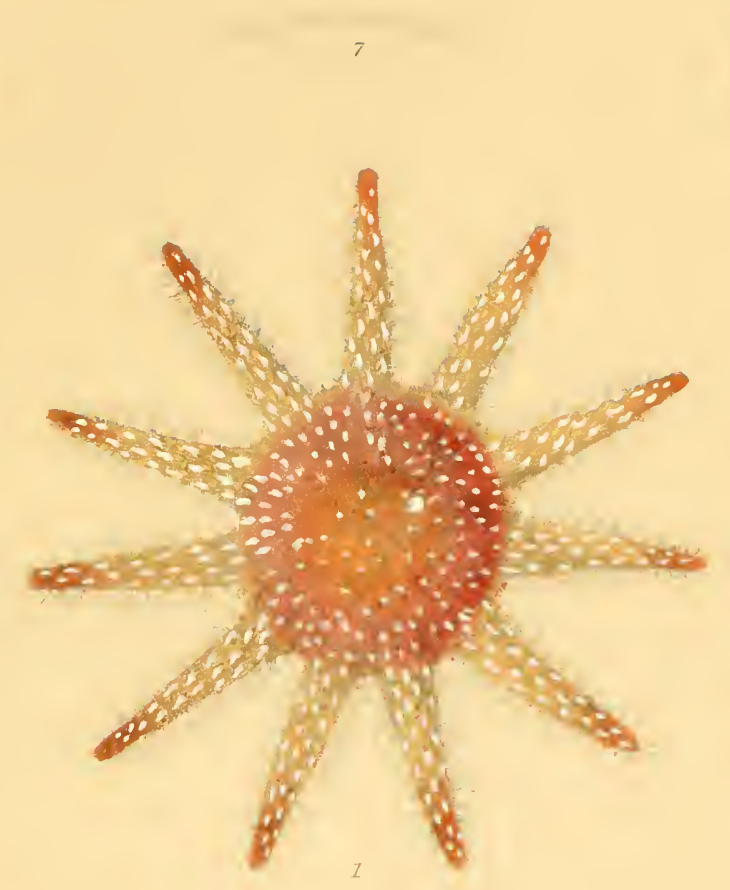

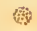 \\ w \\ s. \\ 8}

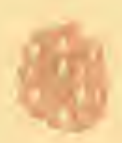

3

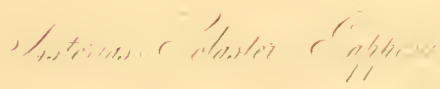



XXIV. fig. 1. About a fortnight afterwards I was surprised to detect this specimen in the fact of devouring one of its smaller companions. Part of the victim still hung from the mouth of its enemy. Not a fragment was visible next morning, and in the evening some half digested natter appeared.

Thus was a new feature in the history of the species betrayed,-one of which I had not entertained the least suspicion. Neither had I felt any apprehensions regarding the safety of varions subjects in the same vessel under a conrse of observation. The same rapacious animal now specified had previously consumed part of the common green fucts vegetating near the shore, which was rejected at night; and next day it fed copiously on mussel.

Before the specimen above mentioned was devoured another small one in the vessel had disappeared, which, though improbable, I supposed to have crawled over the side. However, a fortnight after the preceding fact, finding the same assailant attempting to satisfy its cannibal appetite still on its thrid companion, considerably larger than the ostensible victim, I could no longer doubt the fact. Thus it is impossible to presume on the indemnity of any specimens from the strength and voracity of their neighbours. The fishermen believe that this animal devours the Asterias glacialis.

The dimensions of these creatures are much affected, angmented, and reduced by the temperature of the atmosphere. From their nocturnal habits also, specimens are developed more amply towards night than throngh the day. Their safety demands that the temperature of the place where they are kept shall be very moderate. To the tonch they feel cold, and rough and disagreeable like a piece of shagreen.

Adults of this species have nsually thirteen rays, which, as well as other members, are developed originally, for they receive no additions with age. A very minute specimen, under the eighth of an inch in diameter, had fourteen. The conformation, or rather the proportions of the animal are slightly modified in time.

Perhaps the number of suckers in a row may be augmented with age by new evolutions, but the rows, being two, belonging to each ray, 
remain always the same. These rows are separated by a kind of rib in large specimens. The sucker bears a narrow resemblance to the proboscis of an elephant, being very contractile, flexible, somewhat cartilaginous, and of annulated appearance, besides enlarging at the extremity, fig. 6. As above said, eight or ten long, flexible, rather muricate organs, at the end of each ray, seem of different structure, having no enlargement, and their functions being apparently more tentacular, fig. 7 .

On emptying and inverting the ressel containing these animals, the suckers gradnally relaxing their hold, allow them to drop off.

All are very tenacious of life, insomuch that the suckers of one portion continued adhering while the remainder was in actual decay.

The ovarium of the Asterias papposa is unlike that of any of the species above described. It consists of two clusters of capsules at the root of each of the rays, thus corresponding somewhat with the ovarian lobes of the Gilacialis and Rubens. They are slightly attached to the skin of the specimen; and are nearly of the dimensions represented, Plate XXVI. figs. 1, 2,3, though scarcely as large, for one of them might be covered by a hollow hemisphere eight or nine lines in diameter.

Portions of the cluster seem forked, fig. 4, enlarged ; and parts are brauched, which is perhaps the true character of the ovarium :-Fig. 5, enlarged.

It may be thence understood that the ovarinm is, on the whole, composed of a number of irregular capsules, fig. 6, enlarged; wherein are contained an indefinite quantity of spherical and ovoidal ova, many of which are expelled from it after each other, fig. 7. One just quitting the capsule appears at the summit of fig. 6 . This capsule was an eighth of an inch long. The ova, generally spherical, are of a fine reddishorange colour, with a darker red speck or nucleus.

I set nuch of the roe and many of the ova apart in suitable vessels, yet $I$ was disappointed of their proving prolific.

The ovaria are advancing, and of a beautiful orange colour, from April until July. But specimens have had no ovarium early in the latter month, though in some they were fine and vivid, apparently approaching maturity. 


$$
\text { * }
$$



The Asterias, or Solaster papposa, is named Kelle, or Te Kelle, or Star-fish, by the Scotish fishermen.

It is not rare.

\section{Plate XXIV.}

FIG. 1. Asterias (Solaster) papposa, reduced. Back.

2. Portion of the skin, enlarged.

3. Portion of the skin of another specimen, enlarged.

4. Tuft enlarged.

5. Tuft overhanging the madreporiform tubercle, enlarged.

6. Sucker enlarged.

7. Tentacular organ at the extremity of a ray, enlarged.

S. Ocular or glandular specks at the end of the rays, enlarged.

9. Speck of the specimen referred to, fig. 3.

Plate XXV. Asterias (Solaster) papposa, under surface.

\section{PLATE XXVI.}

F1G. 1. Asterias (Solaster) papposa, cluster of capsules.

2. Another.

3. Another.

4. Portion enlarged.

5. Branch of capsules with ova, enlarged.

6. Capsule; ovum eseaping at the summit, enlarged.

7. Ova enlarged.

8. Young Asterias, upper surface.

9. The same, under surface.

10. Another, farther advaneed, under surface.

\section{SeCtion II.-\$ 1. Ophiura bracteata.-Plate-mail Star-fish.- Plate XXVII.}

As many of the parts and the properties of the preceding animals disappear in the following specimens, a new division is constituted 
for their reception, under the name of Ophiura. Possibly this is designed to infer a resemblance between the curving and twining of the rays, or of motions similar to those of the serpent.

Such a subdivision is not inconvenient; for although we are not to forget that the Ophiwe is still a Star-fish, it is sanctioned by some prominent distinctions from the others.

The Ophiure are eharacterised by a central disc, with five long slender rays issuing from the circumference immediately, or from the margin of the upper or under surface, in general somewhat within the circumference; but in several their origin approaches the orifice of the montl.

The dise is circular or sub-angular, the month generally pentagonal in the under surface, and very dilatable. Five serrated angular prolongations of the surface below are direeted inwards, as if towards the centre, as in the bracteata. Its upper surface is nearly smooth in some, and in others clothed with very minute seales or spines. But its chief variety is in colour, and in the distribution of colours.

Instead of the wonted suckers specially serving for the motion and adhesion of the Asterias, the rays of the Opliura consist of segments, and are provided with an infinity of singular spinons processes along each side, together with their accessory parts, which are different in every species of the animal.

The rays are also covered by scales, in great variety of form, arrangement, and distribution, according to the species.

These organs are extremely liable to mutilation, from their length and slenderness, and because they are so easily entangled with any foreign substance. But the reproductive faculties seem less energetic here than in the animals of the first section.

Probably the form of the Ophinice undergoes a considerable modification with age. I have had many small specimens, which I was for some time induced to consider the type of different species; yet after more mature deliberation, I abandoned my intention of representing them here, as their more prominent distinetive features might be obliterated with advances to perfection.

The vigour and the dimensions of this creature depend much on the 

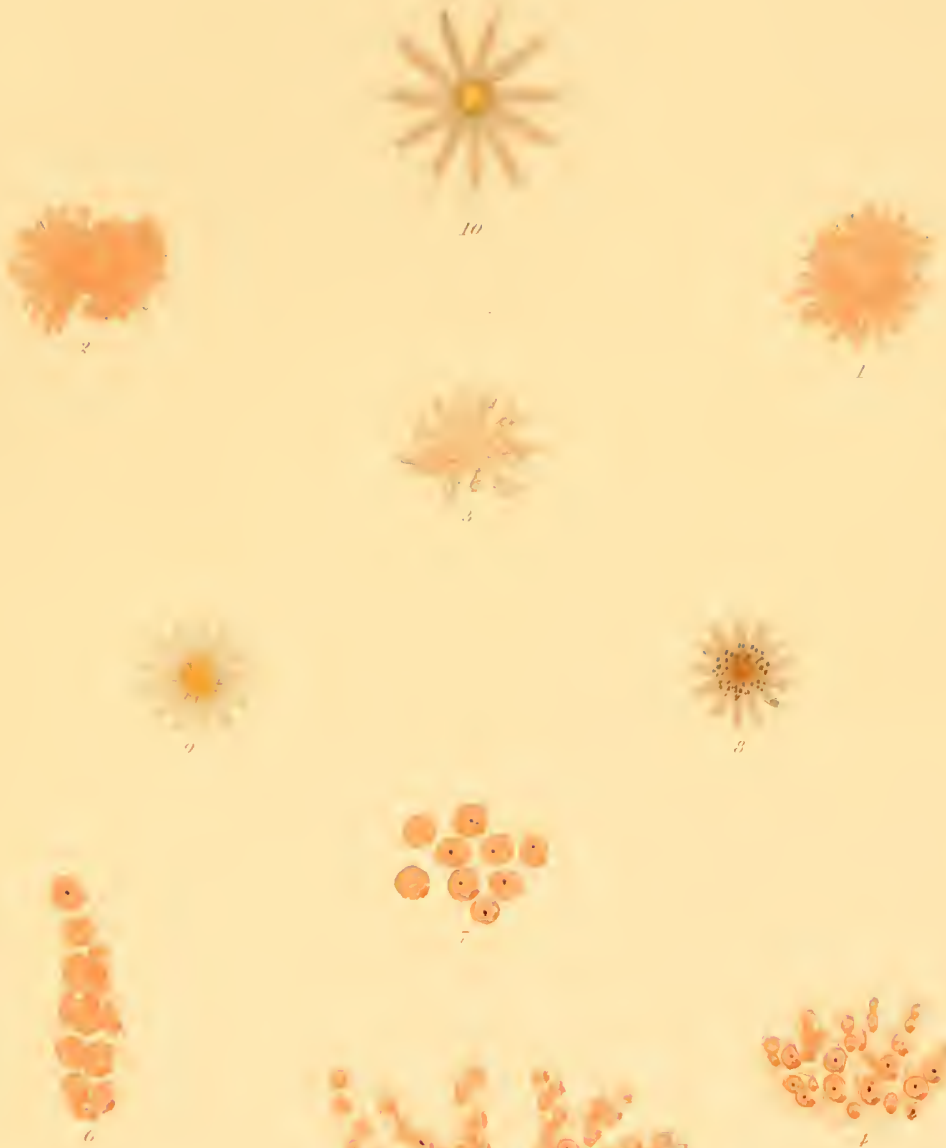

$$
e_{-}^{\infty} \cdot{ }^{-} \cdot
$$

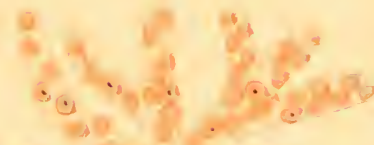

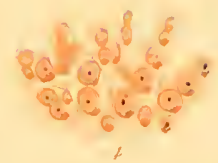

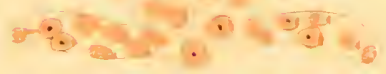

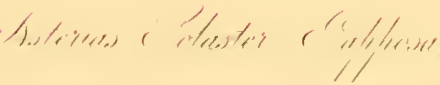



places where it dwells, and the facility of obtaining sustenance. Some live in deep water, multitudes on the oyster beds, and some amidst sand nearer to the shore.

On the whole, they are extremely numerons, and from the vast multitudes continually destroyed, their race seems to be incxhaustible.

$\S 1$. The disc of the Ophiura bracteata is circular, flattened, about an inch in diameter, and covered with varied and singular scales. Five rays, expanding seven or eight inches between the extremities, issue from the circumference above, and rather within the margin. These rays are long, slender, and imbricated, or covered with lozenge-shaped scales down the middle above, and two side pieces of a different form. The ray is further divided into segments, with three spinous processes on the sides.

Close and attentive inspection is necessary for ascertaining the structure of the parts.

Here there are no rows of suckers, properly so called, serving for adhesion, and for motion, as in the species of the preceding section.

The Ophinu Uractcatu feeds voracionsly on mussel, which it receives in preference to oyster, and then the clisc rises like a cushion from its ordinary flatness, in proportion as the prey is consumed. I have not observed any specimen attempt to swallow the shell, though the mouth be susceptible of considerable dilatation, and the capacity of the stomach sufficient for such as were offered. But whenever a part of the flesh of the mussel is within reach, the extremity of a ray twining around, it is carried to the mouth, and greedily devoured.

Sometimes a disagreeable odour exhales from these animals after feeding.

However ravenous at times, days occasionally intervene without the consumption of any food.

Mutilation of the rays is particularly incident to this species, whence many distorted, disfigured, and unshapely subjects come within cognizance of the naturalist. It constantly occurs with those in confinement, perhaps from our ignorance of suitable treatment in food, or in temperature. Nevertheless specimens survive some time, proving active, feeding readily; also shewing themselves very tenacious of life. 
Mutilation is inevitably concomitant on impurity of the water. But without any obvious cause, we witness it continually, and to the most destructive extent. Piece by piece falls off the rays, until nothing but the disc remains, yet the animal still lives. After a specimen had been preserved some time, only a very short fragment of the rays continued entire; yet the subject fed greedily, nor was motion utterly extinct even when the disc was partly decomposed.

Perpetuation of the race is carried on by ova, as with the rest. Early in April the disc is seen remarkably full, plump, and round in the margin; the intermediate space between the rays being occupied by spawn. On separating a portion of the under surface, which is very thin, and rather slightly crustaceous, the spawn, of vivid red, is found adhering to it. The colour is so bright, that the under surface of the disc is sensibly affected, and the space between the rays which it occupies becomes ruddy. Ovoidal capsules, confusedly huddled together, compose the spawn :-Plate XXVII. fig. 8, where a cluster is seen as attached to the skin, enlarged. Single capsules, more enlarged, whence some of the ova have escaped, fig. 9. The capsular integument is so refined, that the internal contents are exposed, the whole quite red.

Specimens expanding six inches have been replete with spawn; and as late as October so plump and full, that the disc resembled a cushionwith the spawn also of beautiful orange-yellow, nearly mature. When of such quality, they are not common.

\section{Plate XXVII.}

Fig. 1. Ophiura bracteata. Mail Star-fish.

2. Another specimen, young.

3. Portion of a ray of fig. 5, enlarged.

t. Dise of a specimen, enlarged.

5. Under surface of a specimen.

6. Portion of a ray of fig. 5 , under surface, enlarged.

7. Ova.

8. Cluster of eapsules, enlarged.

9. Single capsules, more enlarged. 


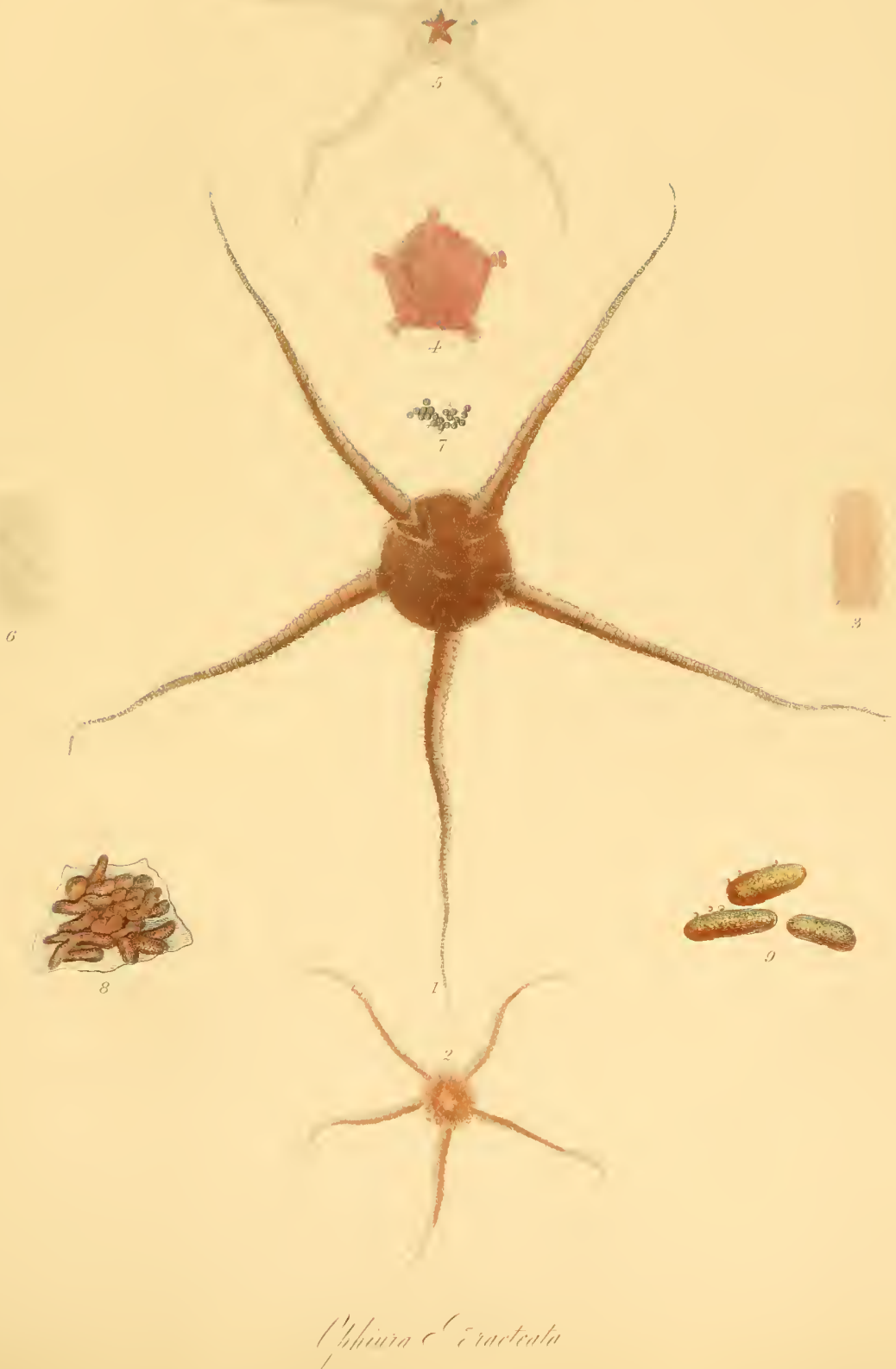





\section{§ 2. Ophiura vulgaris.-Plate XXVIII.}

THIS is the most common, and its varieties the most numerous, of any that $I$ have seen, insomuch, that it is somewhat perplexing to say what shall be assumed as the type of the species.

The profusion and the distribution of colours in every different proportion, distinguishes it among the rest, for yellow, blue, green, red, may be interspersed in a single specimen :-Plate XXVIII. fig. 1. Three lines in length-being a portion of the five rays of one specimen, were of uniform yellow from their origin, when the interspersion of other colours commenced.

The finest specimens, which are found in the northerm seas of Scotland, expand six inches between the tips of the opposite rays.

The proportion of the dise to the whole dimensious of the animal is small ; but the form and appearance not only undergo great modification in attaining the adult state, but during the season of propagation these are still more conspicuous.

Early in the season ovoids begin to swell from the margin of the disc between the rays. Advancing gradually throngh March and April, they become so much enlarged in May and June, that the rays interposed between them seem reduced in size, and as if grown more slender.

The ovoids, when mature, are full of a number of thin brownish or yellowish foliaceous lobes, composed of a vast multitude of ova.

The rays of this species are particularly subject to mutilation.

They are clothed by sets of hard and soft processes, adapted to various purposes.

\section{Plate XXVIII.}

FIG. 1. Ophiura vulgaris.

2. Section of a ray, enlarged.

3. Section of a ray.

4. Cartilaginous organ of the ray.

5 . Spinous organ of the ray.

6. Disc of a prolifie specimen, surface.

7. The same, under surface.

8. Disc of a specimen, enlarged.

9. Foliaceous lobe, from an ovoid, enlarged. 


\section{§ 3. Ophiura Punctata.-Plate XXIX.}

I feel some hesitation in the application of the name of this species, which is the largest of the Ophiurre belonging to the Scotish seas.

The finest specimens expand eight inches, or somewhat more, between the tips of the opposite rays:-Plate XXIX. fig. 1.

The disc exceeds an inch in diameter, with a waving circumference, the whole surface resembling a cushion entirely covered by microscopic granules. The rays long, and taper, are invested by transverse elliptical scales, with produced extremities, denoting so many segments. Each segment is bordered by a cluster or set of smooth obtuse spines, with a dark centre. The cartilaginous organ is covered with prominences.

When the under surface is viewed, the form of the disc and divergence of the rays are well exposed.

\section{Plite XXIX.}

FiG. 1. Opliura punctate?

2. Section of a ray, enlarged.

3. Dise, under surface.

4. Spinous and cartilaginous organ, enlarged, $a, b$.

5. Portion of the surface of another specimen, enlarged.

Miscellaneous Obscrations.-The preceding examples will afford a competent general idea of the nature of the Asterias and Ophiura, in as far as relates to the more prominent features of their structure and history. Content with this at present, I shall abstain from entering on minutia, in the expectation of some future opportmity of illustrating the subject in detail.

Several facts, especially regarding the Opliur'a, require much elucidation. The number of these animals is excessive, both of species and varieties; lut fallacies have certainly exaggerated them.

The form of many secms transient, and assuredly undergoes varions modifications, in advancing to perfection. Their precise changes are yet problematical; but while remaining so, the observer is exposed to the hazard of introducing duplicates, or spurious species, into the genus. 


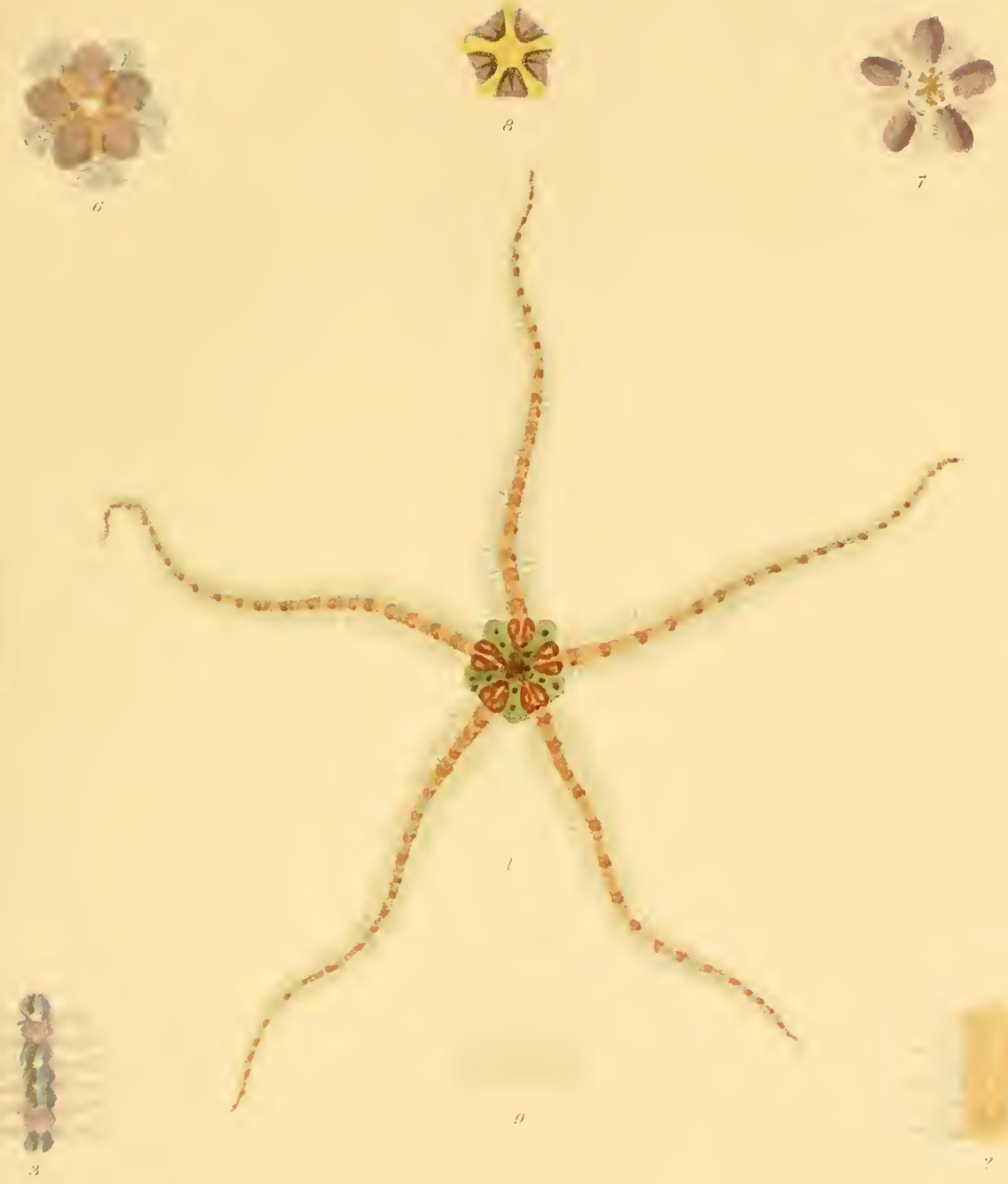

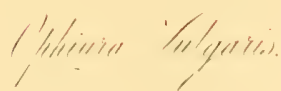



These considerations restrain me from offering a number of fine and correct figmres, as illustrative of the truth, so long as I an uncertain whether just conclusions are deduced from the originals.

The doubts of early and adult age in new subjects, let me repeat, is always a point of diffieult solution, thongh the identity or not of species is discovered from specimens in maturity.

Aseertaining the real alterations of parts and aspect, as modified by age, exacts extraordinary attention, time, and opportunity ; also requiring the permanent preservation of living specimens.

Besides the scanty illustrations of Plate XXVII. fig. 4 ; XXVILI. figs. $6,7,8$, much remains to be shemn of the dise in shape and colour; also of the formation of the rays, Plate XXVII. figs. 3, 6 ; XXVIII. figs. 2, 3 ; XXIX. figs. 2, 3 ; and of the appendages of the rays, Plate XXVIII. figs. 4,5 ; XXIX. fig. 4.

Let the preceding remarks be riewed only as a very brief and imperfect sketch of what belongs to the subject, in farther prosecution of which practical naturalists will find sources of unceasing entertainment.

Regarding the propagation of the Asterins or Cribelle oculate, by MI. Sars, an abstract may be seen in the Ammals and Magazine of Natural History, v. xiv. p. 233, the only part of the works of that leamed author which I have had an opportnnity of consulting. 


\section{Comatula barbata.-Plate XXX.}

THE animal described in this paragraph is nearly allied to the Starfish, especially to those of that genus last named, the Ophiura. Nevertheless some parts of its history being unintelligible as such, and its peculiarities being so strong and decided, a distinct genus has been instituted to receive it.

Individually, the Comatula, which bears a general resemblance to the Star-fish, consists of a small circular, flattish disc, scarcely two lines in diameter, whence issue ten disproportionately long pinnate rays, expanding about five inches between the opposite extended extremities.

The whole surface is from tile-red to crimson colour :-Plate XXX. fig. 1 .

One surface of the disc is provided with ten or twelve slender organs, each terminated by a claw, which, from their action and use, may be described as claspers. They serve to affix the animal to foreign substances, as seen fig. 2, where they are represented as adhering to an Ascidia. These organs are variegated red and white; but their figure and appearance are best discovered by the microscope, fig. 3. The form of the opposite surface tends to that of a hemispherical segment, which in one specimen was obscurely partitioned into triangular compartments. Also there is an orifice, probably the mouth, in the centre. Farther, in another compartment, is a nipple, with an orifice, said to be the vent, projecting in variable shape and aspect, fig. 4 . It does not appear in every specimen.

A double row of minute suckers, visible with microscopic aid, clothes the under surface of the ray, and that of the claspers.

The Comatula remains during whole days adhering pertinaciously to the same spot. In swimming, it is with a singular motion-somewhat undulatory of the rays, on which occasion the claspers are always below.

Extraordinary mutilation is incident to this creature. It is alike liable, as the Ophiura, to fall to pieces. Indeed, this is the way wherein all seem to perish. Part after part drops off, until only the naked disc remains, the water being slightly tinged by the decay. 

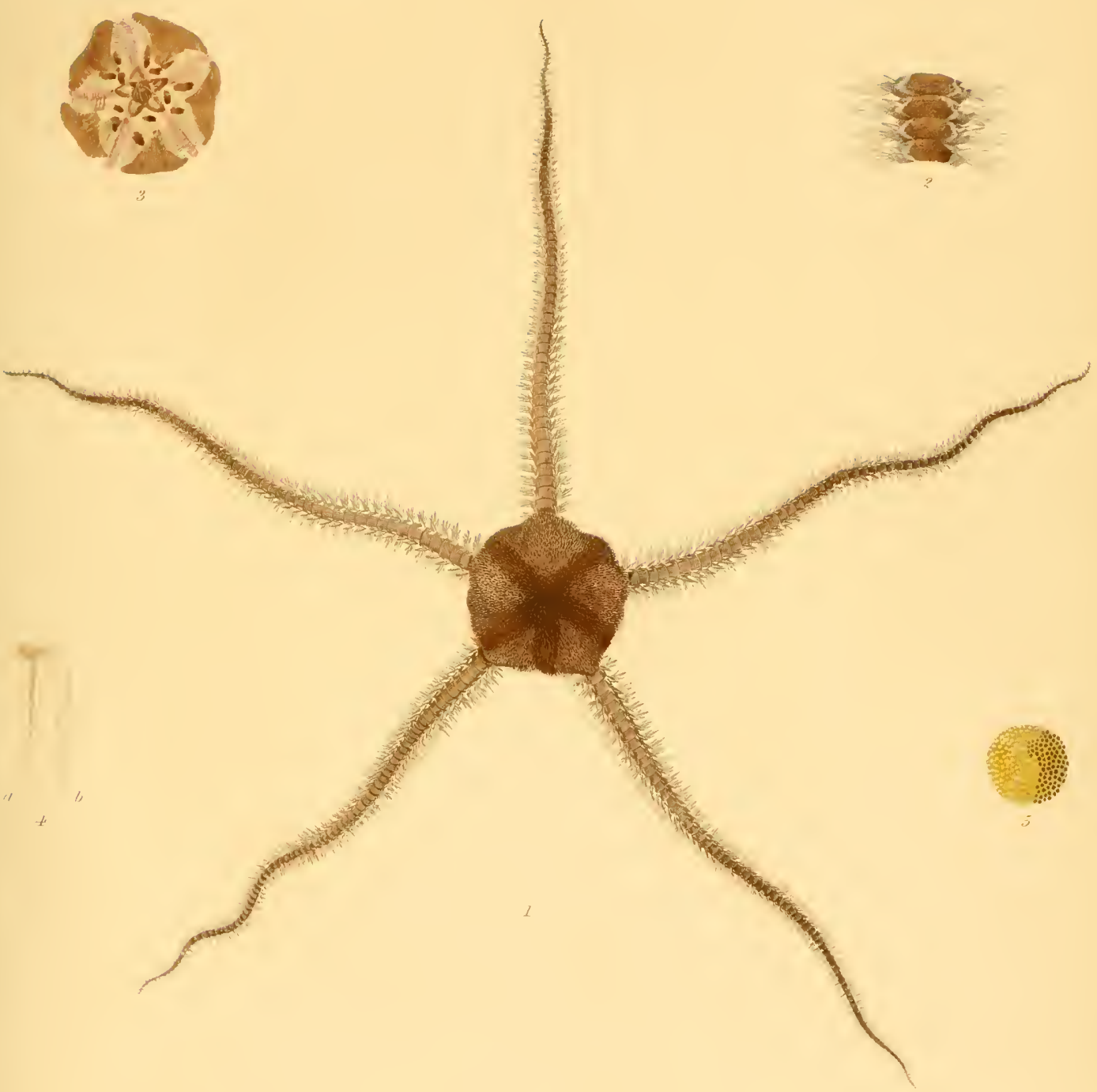

No specimen has fed on any animal substance offered to it.

I have been indebted to Dr. Duguid, whose name is very familiar to naturalists, for a number of fine Comatulæ from Orkney, where they are not equally rare as in most other parts of Scotland. Some of them survived seven weeks.

\section{Plate XXX.}

Fig. 1. Comatula barbata.

2. Prehensile organization, enlarged.

3 . Clasper and claw, enlarged.

4. Nipple, as rising from the disc.

\section{Ecminus, tile Sea Urcinn.-Plates XXXXI., XXXII., XXXIII.}

In the absence of facts sufficiently numerous and important for explaining the history of the lower animals, I shall substitute the accurate representation of certain species not difficult to be obtained, for I consider it of some consequence that the reader may himself verify the truth of what is described. Nothing has suffered equal neglect, not so much from inclination or oversight, perhaps, as from actual inability to accomplish that which was required. But, wherever practicable, this most useful branch of illustration should never be omitted. It will serve for the solution of many doubts, the correction of fallacies, and the repletion of inconvenient chasms.

I am led to these remarks from finding the valuable observations of reputable authors on the Echinus, either entirely void of the necessary illustrations, or so deficient of resemblance to nature, that to recognize them is impossible. I wish I could restrict the notice of such imperfections to the Echinus only. But it is to be regretted that they extend to the other subjects of the present section, especially the Holothuria and the Stellerides, or Sea Stars.

If such manifest imperfections be concomitant on endeavouring to give the external aspect, which should be the easiest attained, how shall 
we confide in attempts to shew and describe what is so much more difficult, abstruse, and remote, as the internal organization?

In our anxiety for the promotion of science, howerer, heightened by zeal for the perfection of art, let us be careful of reproaching individuals who may have laudably done all in their power for the embellishment of both.

Every one in the pursuit of knowledge will find himself opposed by serious if not invincible obstacles.

I know well, by experience, the general insufficiency of artists; the rarity of superior qualifications among them ; but the naturalist himself is not to be content with inferior specimens, those selected ought to be brought to their finest condition, and the most favourable position chosen, that they may be viewed to the greatest advantage; whence we shall learn to prize that delineation which proves a constant and faithful guide to the truth of nature.

All this confirms the great expediency of careful education in the more delicate branches of the graphic art, whereof the most interesting application is to reproduce in impressive images the works of the Creator.

It might blunt the edge of criticism were it calmly considered on how many conditions the naturalist is dependent for exhibiting the true quality of his studies. The specimen and all its parts being the best to be obtained, equal perfection must reign in the numerous departments throngh which its resemblance shall pass previons to preparation for the inspection of the public.

Dispensing meantime with farther ligression, and aroiding questions of identity, a few general observations may be offered regarding the more ordinary species of Echinus, such as are accessible to most observers. Whatever qualities the scientific shall discover in rarities, the same interest cannot be found in their description by the inhabitants of these kingdoms, who may never see them, as in the productions of their native shores. 
I. I.

PL...TT.
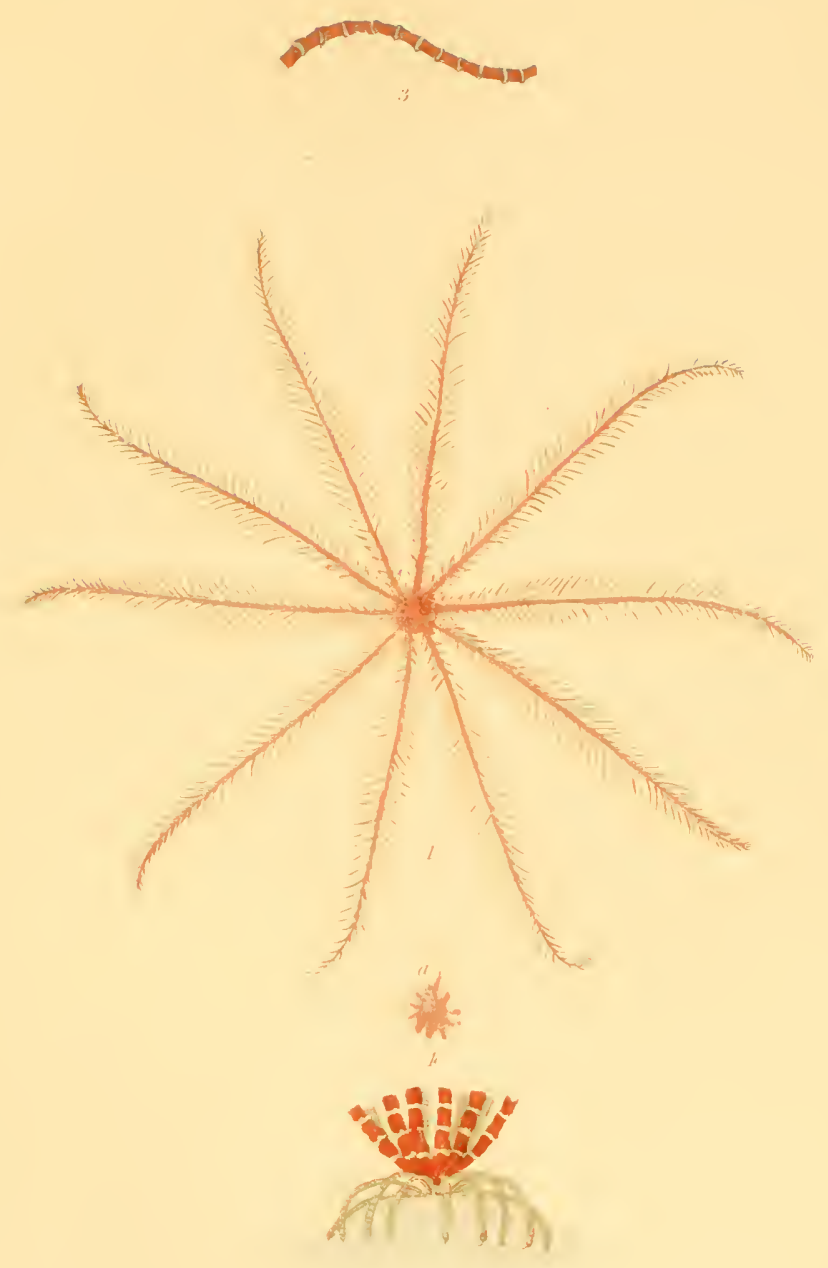

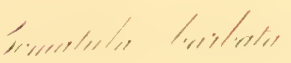





\section{§ 1. Echinus SPIL.era.-Plates XXXI., XXXII., figs. 1-11.}

While alive this animal is at least five inches and a half in diameter, computing from the opposite extremities of the spines, all the parts being in vigorous, regular, and symmetrical order.

It may be then circumseribed by about three-fourths of a sphere. Some are more nearly globular, from the greater equality of the vertical and transverse axis, while, from greater inequality, specinens appear distorted. But, for the most part, all individuals of the race are surprisingly symmetrical.

This creature, as is well known, consists of an external shell, confining the intestinal parts, wholly invested by an infinity of hard, sharp, moveable spines, resembling those of the terrestrial hedgehog;, whence it: name is derived.

Numerous flexible cords or suckers protrude from among the spines, about double their length or more, which extend until reaching some solid sulsstance. The extremity of each then flattens, broakens, and applying firmly, they assist the sulject in traversing its prison.-Plate XXXI. fig. $1, a, a$.

To understand the nature of all this, we must view the naked shell to find a double set of organs, as above, the spines and suckers.

A multitude of low spherical segments project from its surface, of all different dimensions. These sustain the basis of the spines, which play on them somewhat as a ball and socket. This part may be therefore riewed as corresponding to the articulation of the bones of other animals.

Next, the substance of the whole shell is penetrated by a multitude of minute pores, disposed in rows and compartments, for protrusion of the long flexible cords, which are so many suckers, from within. These are properly the instruments of progression.

Let us suppose a specimen at rest. All the suckers are retracted within or close on the shell, and the spines motionless. A few of the suckers now protrude; they search around for a solid foundation, others follow them; at length many are employed, and the animal is fixed securely in its site. But to change it, those behind are relaxed, while the contraction 
of others in front brings formarl the shell ; the hind suckers are again affixed, after which those before relix, and thus the step is taken.

The suckers are therefore the instruments of progression, wherein they are but feebly aided by the spines, although these may be of some ntility, being abont an inch long, and, besides any other functions, affording a formidable means of defence.

The Echinus advances in its course uninterruptedly with wonderful expedition, yet never quitting the water, and sometimes remaining long elose minder the surface.

The power of the suckers seems dependent on the presence of the ciremmambient fluid, a fact of some utility to be known, for on emptying the vessel of sen-water, all the suckers detach themselves successively, and free the specimens, adhering within, without violence.

Though discoursing familiarly of the interspersion of the numberless organs, all are arranged in the most beantiful and symmetrical order, which, to be duly appreciatel, must be beheld not only in the living animal, but in its remains, after life has fled.

How many examples do not we daily discover of the will of the Great Architect of the Universe, being alone capable of such effects! What other evidence of nameless power would mankind require than the existence of such marvellous works, to be continually recognised by the exercise of their own personal faculties? It is not on one object only, but on an endless series that their admiration can be bestowed. They are always renewed, never exhansted, while every subject, in its wondrous structure and use, seems to surpass that which has preceded it.

Let us contemplate the appearance and employment of the principal organs of the Eehinus. Contrary to the ordinary arrangements of nat ure, the mouth is situated in the under surface, always in ready contact with the plane of position. Here a depression of the shell marks a well guarded orifice as its site, from which projeets the acuminated union of five strong teeth, united as a cluster, to form a sharp extremity in one point. The intestines, within, wind up to the rertex, from which the ovaria discharge their contents.

If a specimen fished up from the sea be cast into a vessel of water, 


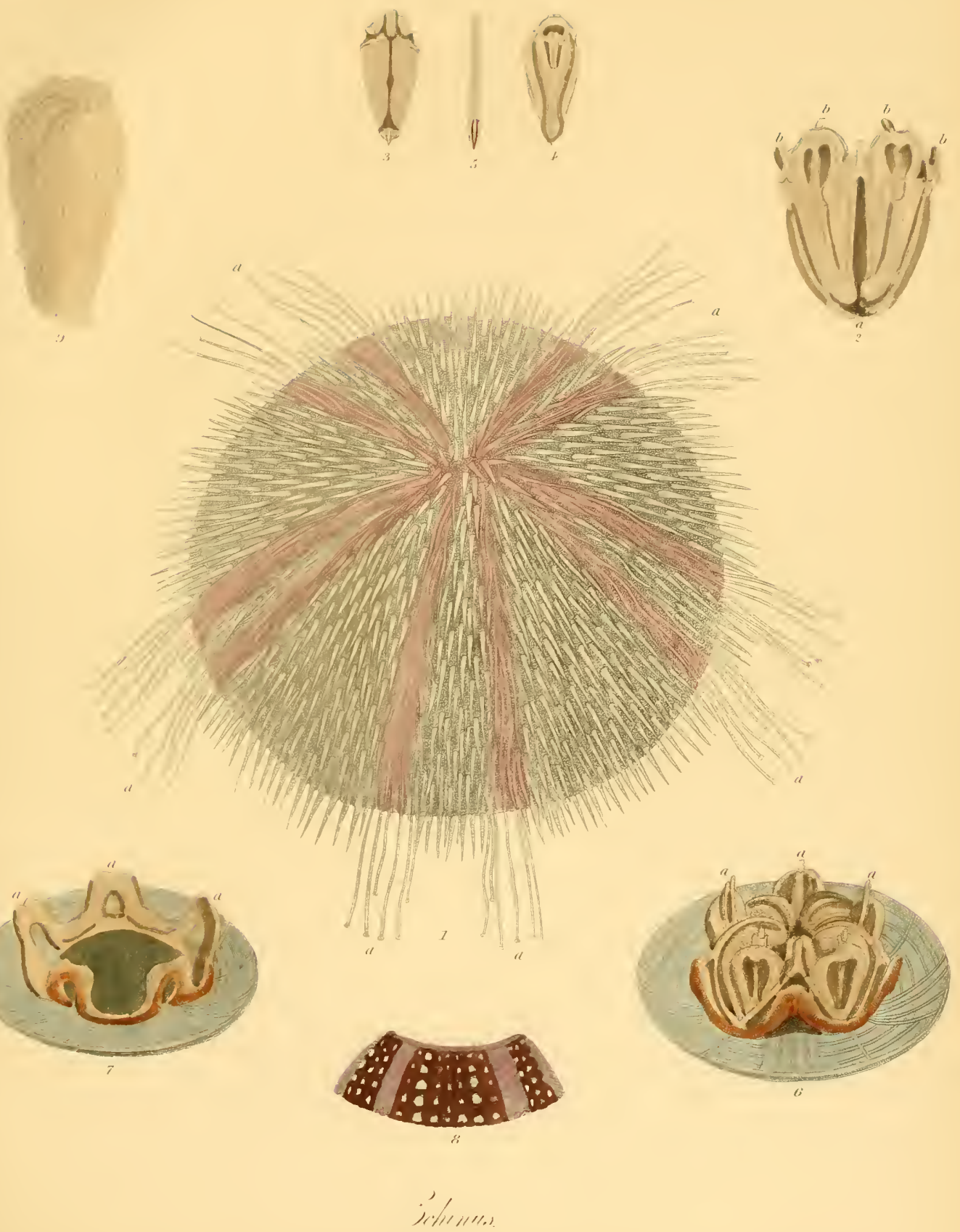


it generally lies motionless on the base or the vertex, according as it falls on either. But some of the spines very soon begin to move, and these are followed by the suckers. Evident exertion is employed to gain a suitable position for the subject traversing its prison. If a portion of food be now dropped into the vessel, the Echinus speedily becomes sensible of its presence. Should the creature be above, the suckers extend, and its descent commences immediately, as it hastens to the repast.

It is one of the most voracious and promiscuons feeders, always ready to eat, nor is any animal better qualified for the destruction of others with inpunity to itself. The strength of the teeth is marrellous, and, as if to prove anxilitures, the principal power for the capture of prey seems to reside in the sucker's near the moutl.

But the most singular and complicated part of the dental apparatus is contained within. It is scarcely to be described, and can be inspecterl only by sawing off a segment of the under part of the shell, which I have called the base. Then it is discovered to consist of so many parts, operating by such complex movements, that I should despair of explaining the province and effects of almost the whole. The five eutters, compounded as a large inverted cone, projecting below with its vertex as a point beyond the level of the shell, destroy the harlest substances. -Plate XXXI. fig. 2, a. The pointed cutter, fig. 5, is lodged within two hollow prisms, figs. 3,4 , as in a case. On inspecting the inside of the sundered segment, a vertical ring, consisting of five staples, is seen considerably elevated above the inner surface of the shell, surrouncling the orifice of the mouth, into which staples various ligaments secure the base of the inverted cone, fig. $7, a, u, a$. The whole apparatus is represented along with a section around the month, fig. $6, a, a, a$, being the upper ends of the teeth, in situ within the Echinus, and as in fig. 2, b, b, l, l.

But I repeat, that nothing short of actual inspection can convey an explanation of the operation of the various parts, and their action. The structure of the month of this animal offers a remarkable instance of natural mechanism.

These creatures often devour pure shelly matter, as appears from the numerous pellets discharged. The fishermen believe that they like- 
wise devour the Asterias glacialis. But they seem to labour nuder no apprehension of their committing ravages among the oysters, or other bivalves.

Though the office of the spines be not very prominently shewn, they are of some use in prehension or seizure. They can conrey a whole load of provender along with the auimals contained in their shells, or employ a vegetable cloke to serve as an ample covering.-A specimen was taken in July, when it persisted in rejecting food for some time. At length, being supplied with an entire mussel in the shell, it soon appeared bearing this as a burden on its back. Next it was seen with a long worm which chanced to be in the vessel, similarly secured, the long extremities hanging over the sides; or it would cover itself, either wholly or partially, with a portion of one of the littoral green fuci like a mantle. In accomplishing all this the spines are the active instruments.

The animal can travel on its back by means of the spines and suckers, and then the month appears in front. But this is an unnatural position, though fixture and relaxation of these organs ensues, as preriously described.

It is the nature of this creature to carry every thing, whether nseful or useless, on its back.

The Sea Urchin just referred to fed copionsly afterwards. It was delineated when a yenr in my possession, and still in progress of growth. -Plate XXXII. fig. 1, seen from below.

The spines are decidnons, which is a singular feature in the history of the animal, because reproduction seems concomitant on their loss. Many were now begimning to fall from the prececling specimen, and many more followed them, so that in the first week of August rery few remained. The tubercular spherical segments whereon they are sustained theu continue bare.

The precise matnre of neither, howerer, is sufficiently understood. Some embarrassing facts accompany all the changes.

The preceding Echinns did not seem to be disterapered under its losses; it fed readily and profusely. Numerons low tubercles were exposed to view in the month of August. But many new spines, some of them 
very minute, were now issuing from others, and continued still arlvancing.

In such a case as the present the multitude of parts is so great that the observer is confounded in attempting to watch the progress of any portion of them.

The specimen survived until May of the succeeding year, or twentytwo months in whole.

Another specimen, somewhat smaller, taken in January, fed plentifully at intervals. In a month it seemed to be easting the spines. Many shorter than their fellows were interspersed among tlose remaining. But in two months almost the whole of those originally investing the specimen had fallen.

Meantime new ones were advancing. When totally divested of spines in another month, the subject still fed realily. There the extent of the sucker's equalled the diameter of the shell.

From many specimens perishing, the loss of the spines either induces or indicates disease. It may be nevertheless a natural process, or consequent on some external injury.

It appears, however, that a great, if not a total loss, and regeneration of the spines, naturally ensues towards the end of the year, or cluring the months immediately succeeding.

About that time much irregularity is seen among them. Many are infinitely smaller than others, whether from the earlier or later origin of one portion of them; and many Echini are recovered from the sea whose entire coating is both shorter and thinner than at other periods. There are some wherein the disparity among the spines themselves is extraordinary.

It is only when divested of the whole of its superficial covering that the shell can be distinctly seen, or that the form, proportions, and arrangement of all its parts, are exposed to the view of the beholder in much and interesting variety.

When divested of the spines the shell bears some resemblance to an orange. The surface is divided into five larger and five smaller compartments. It is covered by au epidermis, either of uniform or variegated colours, whereon much of its beauty depends. Sometimes the spines are 
pure white, and the epidermis crimsun red, or a stellate tigure arises from the contrast; so that we seem to contemplate entirely a different animal. Also the suckers are white, grey, or reddish. But they are commonly faint, or nearly colourless. The whole animal and its parts are likewise found pure white, lout nothing more than mere varieties seem to be thus indicated. The animal usually darkens with age.

The bare shell exposes five larger and five smaller longitudinal compartments, studded with tubercles of various dimensions, whereon the spines were borne. Interspersed between these compartments, which all broaden in the middle, and contract towards the ends, exactly like the divisions of an orange, are interposed numerous lines or stripes of pores, for transmission of the suckers. Thus a portion is solid, and a portion porons.

Now the orifice for the dental apparatus is seen below, and that which opens above at the vertex of the shell becomes alike conspicuous. Both are pentangular, the former being about an inch wide, and the latter about half an inch, in a shell of three inches diameter.

The thickness of such a shell is about the sixteenth of an inch.

Like the planked hull of a vessel, the solid portions are wholly built up as it were of smaller pieces, of peculiar form, their size regulated by the dimensions of the shell. The length of each is abont trice its breadth ; three sides are rectilinear, the fourth angular. These are compartments rather in appearance than reality. The principal large compartments are composed of several smaller compartments.

It is extremely difficult to understand what takes place among the parts as the shell is enlarged. All undergo such a change as is proportioned to the dimensions of the specimen. The pieces of the compartments forming the solid portion are much extended in length and breadth ; the size of the clental apparatus increases; the pores in the substance of the shell, and the upper and lower orifices, are all greatly widened.

These changes are seen best by comparing several Echini, large and small.

Both the higher and the lower orifices form pentagonal external depressions in the surface of the shell. The latter is chiefly comnected with the mouth. Above, the upper orifice is surrounded internally by the ovarium, which sometimes rises in five clumsy conical portions from 
the shell, and sometimes by the ova consolidated in a ring, as a massy circular wall around the orifice. These parts are composed wholly of spherical ova.-Plate XXXI., fig. 9 ; Plate XXXII. fig. 5, ova. This ovarium is frequently far advanced in the month of April.

The Echinus, if uninjured, is not of difficult preservation. It is a bold, fierce, and voracious animal, the inveterate enemy of whatever it can overeome, and greedily devouring all that comes in its way,-even what seems secure from assault:-nothing has any chance of escape. I have never witnessed such an insatiable, such a universal appetite. Fish, flesh, zoophytes, algx, and fuei, are all aceepted, and a hearty meal can be made of pure shell. It is not to be doubted, as the larger testacea are readily devoured, others with their helpless inmates become easy victims.

An Echinus of moderate size having seized a small living crab the victim seemed to be paralysed by simple contact, nor did it offer any resistance to its ferocions foe. Another Echinus, about fifteen lines in diameter, fastened its extended suckers on a small lobster, a galnthea. But the latter, directing one of its claws with sufficient dexterity, eut the suckers asunder, and freed itself from the assailant's deadly grasp.

The Echinus seems to have a natural propensity to destroy. Those not a quarter of an inch in diameter will tear leares in fragments.

In some warmer climates, where certain species retreat occasionally from deeper water, persons frequenting the shore are liable to severe injuries of their feet from the spines. Examples are said to be known of limbs being thus lost.

The Echinus is reputed to have been eonverted to food by the ancients, but this practice can be scarcely said to have descended, unless very partially, to modern times.

I have heard nevertheless that the animal was formerly brought to the Edinburgh market for the sake of the roe, which was employed for culinary purposes.

We know that one species has been denominated Echinus cdulis, which indicates that it has been truly consumed as food, and some naturalists identify it with the subject of the present paragraph. Mr Waring, in his entertaining Letters from Malta and Sicily in 1834, 
speaks of "some beautiful echini or" sea-eggs, with long green and purple spines", in St Mark's bay, on the coast of the former island. "These rea-eggs are eaten by poorer persons, but I have not courage to taste them,"-p. 139.

Ourvi, the Natural Historian of the Adriatic Sea, says, he endeavoured to persuade the Venetian fishermen that they might profit by converting a species of urchin called Molo to food, being abundant, and of large size. Some of them complied, but this fishery was soon abandoned, from want of patronage, and from insufficient prices to reward their industry; Olivi, Zoologia Adriatica, p. 73, Bassano 1792, in 4 to.

Nothing but the roe was ever supposed to be adapted for food; and this possibly still continues on certain parts of the coast of Italy.

Pedicellarin.-Plate XXXII. figs. 6, 7, 8, 9, 10, 11.-The attention of naturalists has been long directed to a peculiar animated orgamization incorporated with the Echinus, of which no satisfactory explanation is yet given. At first Miiller, otherwise so competent a judge, determined this to be an independent animal product, sui yeneris, established as a parasite on the Echinus, of which there might be various species, and he constituted a new genus for its reception, under the nane Pedicellaria. But this is a very obscure and doubtful srbject, which, with all the appearance of easy solution, seems more and more involved in difficulty, notwithstanding the study of subsequent naturalists, so that at the present day it remains almost equally mysterious as originally.

Numerous short hairs, with a peculiar summit or extremity, are interspersed amidst the spines of the Echinus, and apparently implanted on the epidermis of the shell, or, it may be, immediately on the shell itself, for these facts are not yet ascertained. These, the Pedicellaria, are void of any resemblance, in form, substance, or action, to the spines or suckers. They are of two different species, or at least of two different aspects, but whether merely different stages in the growth of the same 

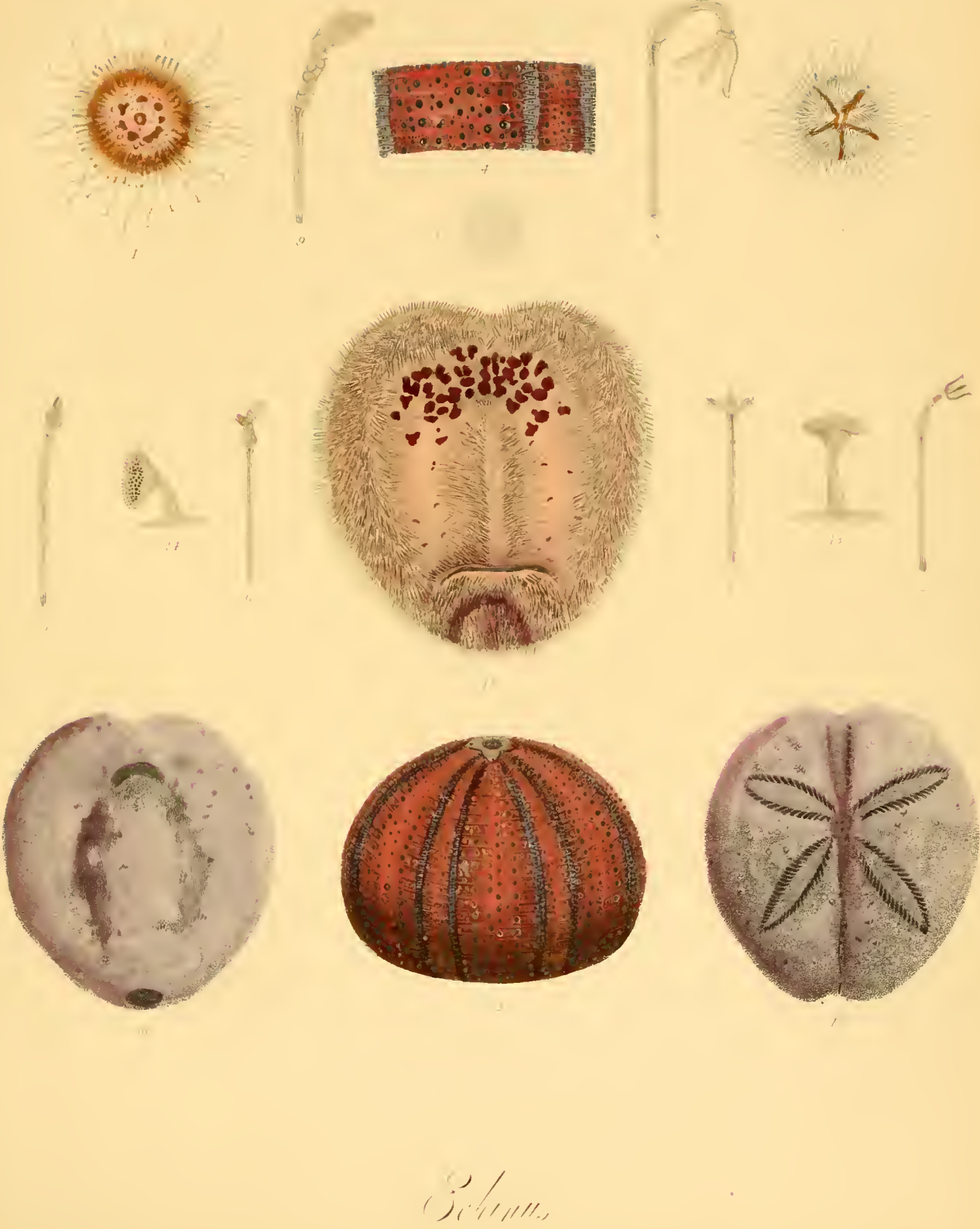

object may not mislead the observer, would require investigation. Under one view, the hair is crowned by a globular formation, of solid appearance. Under the other, the summit is partitioned into three divisions or members, resembling leaves opening and closing, like so many forceps, to clasp and retain minute fragments between them. From this summit, being trifid in one species, it is denominated Pedicellaria tridens by Müller. The hair or stalk seems cylindrical, and sometimes as if occupied by a channel or internal substance in a vacuity.

The length of the longest stalk is about ten or twelve times the diameter of the expanding leaves. Here, these leares or arms of the forceps, are variously shaped, as may be seen on inspecting the figures; and they are often very active.

From the examination of many, this portion is found of different conformation in various specimens. Thus:-

1. The head is very short, as if imperfectly developed.

2. The head, when closed, is large, and resembles a minute pomegranate; but when opening completely, the arms of the forceps of some specimens seem to terminate in a long claw.

3. The head resembles that of a duck. It is very long when closed, with three arms like the mandibles of that animal, which are apparently serrate. When employed actively, all the arms unfold with singular motion, and stand almost at right angles to the stalk.

Pedicellaria cover the Echinus in thonsands. They are of varions dimensions in large specimens, some half an inch long. If rising from the fine red epidermis when present, their motion is well exposed, as resembling the inflection of the suckers, - bending from side to side, the head describing nearly a circle by the turning of the stalk, - the whole in great activity. But there is no essential difference between the figure and the motion of the Pedicellaripe on the larger and on the smaller Echini. The stem is certainly hollow, and it may be that the lower part affixed to the epidermis or to the shell is rigid. The Pedicellaria are dispersed everywhere among the spines, also on the bare portion which surrounds the mouth of the living animal. They are not alike numerous in all specimens.-Plate XXXII. figs. 6, 7, 8, 9 10, 11. 
Multitudes of Pedicellarix drop from the Echinus on vitiation of the water, or on the animal's decay. When transferred to a suitable situation, they have been in motion for above a fortnight. The head also separates from the stalk, and remains in considerable action, while the rest disappears.

On the whole, and especially from the size of the Pedicellaria being in some respect proportioned to that of the Echinus, I feel rather disposed to hold them integral parts of the creature's organization than separate and independent parasites.

In representing the Echinus, authors have been commonly content with shewing only the shell, and some have exhibited the entire animal with the spines in the greatest disorder, which proves that the specimen had been distempered or dead, for nothing can be more regular during a healthy existence. I doubt whether the secondary spines, adverted to in description, are anything but perhaps younger spines in progress, unless ordinary spines regenerating.

\section{Plate XXXI.}

Fic. 1. Echinus sphcera (Egg urchin, Professur Forbes), in motion; a, suckers.

2. Dental apparatus.

3. Single, tooth front.

4. Interior of the tooth.

5. Cutting bone of the single tooth.

6 . Inner surface of the shell of a specimen, with the upper part of the dental apparatus, $a, a, a$.

7. Inner surface of the segment of a shell without the dental apparatus. shewing the staples to which it is secured, $a, a, a$.

s. Portion of the exterior surface of a shell.

9. Cone of roe.

\section{Plate XXXII.}

F1G. 1. Echinus spherera, young specimen, under surface.

2. Specimen with a red stellate form on the upper surface.

3. Entire shell of an adult specimen.

t. Portion of the surface of a shell.

5. Ova.

6, $7,8,9,10,11$. Pedicellariæ, enlarged. 
§ 2. Echinds (Spatangus purpureus).-Plate XXXII. figs. 12, 13, 14, $15,16$.

Another kind of Echinus, very different in external conformation, in habits and appearance, from the preceding, is denominated Spatagu. or Spatangus, a name of uncertain etymology, but said to be derived from the Greek language, whereof I do not observe any satisfactory interpretation.

It is a species, also, much less familiar to naturalists. In an Itinerary by John Ray the naturalist, describing a Tour in Great Britain during the year 1662, he says, he found on the sea shore, near Llandwyn, "a pretty shell, covered with prickles or bristles, which the Welch call $\mathbf{M e r}$ maid's Heads."-Lankester (Dr Edwin), Memorials of Jolın Ray, p. 169.

The same name is bestowed by the Scotish fishermen, who likewise call it the Man's face, and Monkey's face.

This creature is not nearly as common as the preceding, but its form has attracted the notice of so many observers, that perhaps little of general import remains to be said on the subject. In as far as I can learn, it belongs to deeper water, aud often dwells permanently buried in the sand, from which it is for the most part dug up accidentally, in prosecuting the varions departments of the fisheries.

Probably it is the largest of any Scotish animal invested by a shell, setting aside the crustaceous race.

Among others, I received two of ample size, and very heavy, in the month of October, a period when I expected they might be easily preserved.

These creatures rudely resemble a flattened heart, one side being convex, the other a flat surface.

Each of the two measured five inches in length, by half as much in thickness, and four inches in breadth, therefore having attained the complete dimensions of full grown animals. The mouth, a transverse opening, is near the upper end of the flat side, the vent in the lower extremity, Plate XXXII. fig. 12, reduced. But the proportions and rela- 
tive position of the parts, are better exposed when the shell is stripped of the numerous spines and bristles by which, like the preceding species, it is almost totally covered.-Convex surface, fig. 15 ; flattened surface, fig. 16.

About fifty suckers, issuing from pores of the shell, are scattered, without any definite arrangement, over the other parts, chiefly towards the mouth. They are void of resemblance to those either of the Echinus, or any other animal with which I am acquainted. Each is a crimson Hower or flattened disc, expanding an eighth of an inch, supported by a stem a quarter of an inch high. The margin of the flower is beset by a border of cylindrical prolongations.-Plate XXXII. figs. 13, 14.

Both the animals thus obtained seemed to be casting their spines, whereof the older, extending nine or ten lines, were dingy yellow; the new ones very short. Those of a small specimen, one under an inch in diameter, were of the same character on the first of March.

At this time another Spatcungus purpurens was invested by a thick coating of the shortest spines.

From the occurrence of more, of similar description, the spines are probably renovated about the commencement of the year.

As previously signified, I am no stranger to what is said of primury and secondary spines on the same animal. But, without entering further on the subject, the real source of the discrepance between them, must be sought, perhaps, in the progress of age, or of reproduction.

Undoubtedly spines of different character may invest different parts of the same specimen, as is seen of nails, homs, hair, and feathers. Very minute tubercles, on different parts of the Spatangus, may bear, either peculiar spines, or those in progress.

When the shell is quite divested of its covering, a stellate figure of five rays appears on the convex side, four of which are formed by a double row of pores, the fifth being merely a hollow or depression. Four apertures, said to be the ovarian pores, and sometimes a greater number, occupy the middle of this stellate figure.

The month is situated amidst a less definite stellate form, in the opposite or flattened side of the shell. The figure of a long shield, com- 

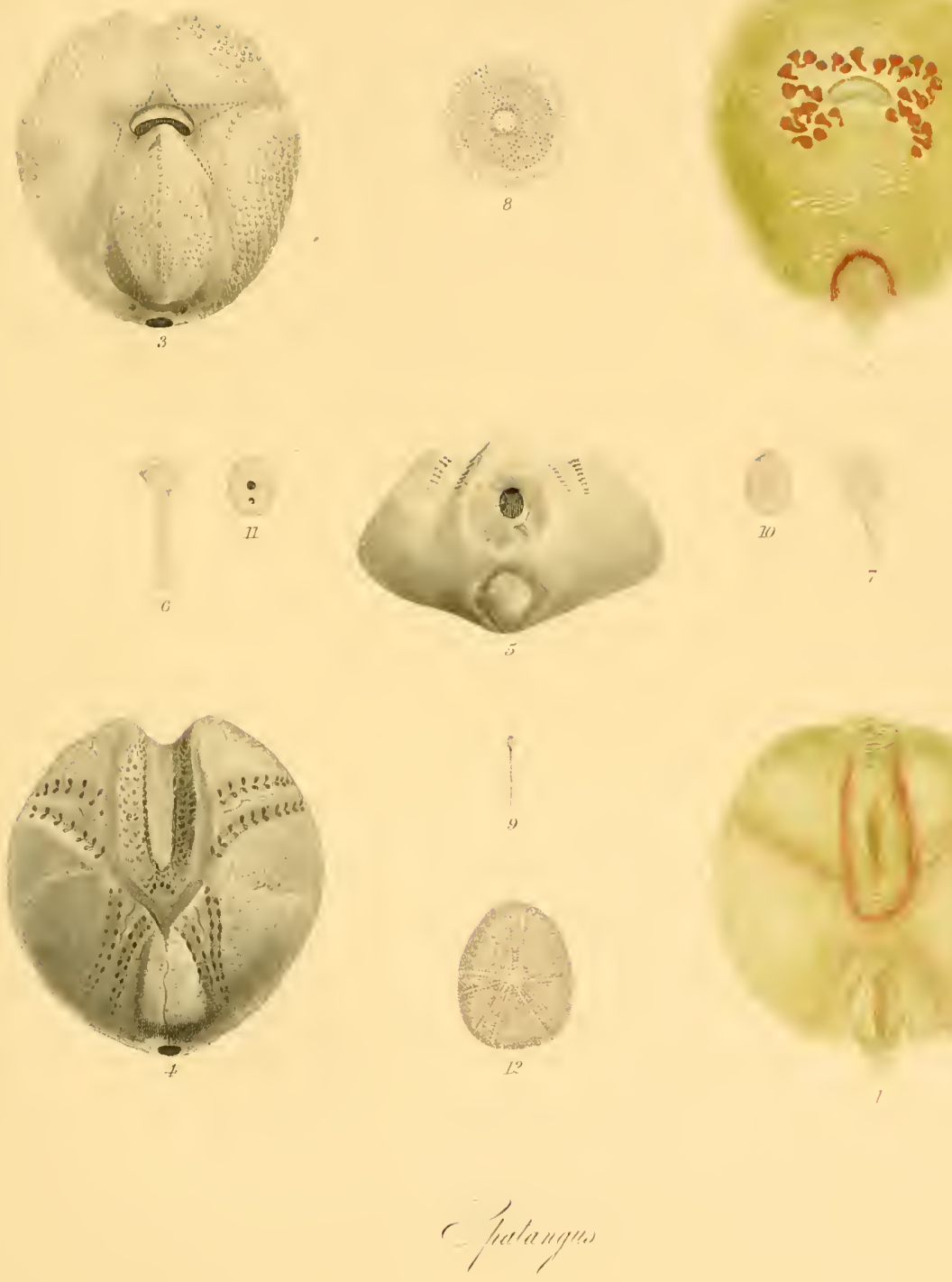

posed entirely of spines, extends from the mouth down to a transverse elliptical arrangement, the shelly portion, constituting the ellipse, being quite smooth. This transverse arrangement sometimes resembles a deep cleft in the shell, but here there is none.

Much difference in the perfection and number of the pores, and of the various superficial figures and appearance, distinguishes different shells.

The substance of all is very brittle, thin, and light, compared with their dimensions.

This animal is usually sunk amirlst the sand, of which it swallows an extraordinary quantity, so that its weight becomes surprising and unnatural. Comminuted shells, of various species, are mixed with the sand, but their inmates do not appear to have been rendered prey. No specimen has fed on any substance offered to it in captivity.

Professor Delle Clinie gives dissections of this subject.

\section{Plate XXXII.}

Fig. 12. Spatangus purpureus, reduced, under surface.

13, 14. Suckers enlarged.

15. Shell divested of the spines, shewing the stellate figure on the convex or upper side.

16. Shell divested of the spines, shewing the site and fissure of the mouth, under surface.

§3. Spatangus (Flavescens),-niveus.-Plate XXXIII. figs. 1, 2, 3, 4, $5,6,7,8,9$.

This is a fine and delicate looking animal, somewhat heart-shaped like the preceding, but thicker in proportion, and the parts more prominent or rounded.

The largest specimens falling into my possession, extended two inches and a half in length. Others were about an inch and a half, nearly two inches broad, and one in thickness. Such dimensions are to be understood as of animals invested with the white or yellow spines, wherewith they are totally covered. 
Of these, three or four different kinds are sufficiently definite. 1. Such as are long, slender, and slightly incurved. 2. Those of broad paddle-shape, with a short neck. 3. Spines of a narrow paddle-shape, with a long neck.

The upper surface of the finest white specimens of this Echinus, is distinguished by three purple rings, but not alike conspicnous in all.

The mouth, like that of the preceding animal, the Spatangus purpureus, opens in the under surface, amidst a purple star, consisting of forty or fifty suckers, as obvious in the best specimens, but less distinct in others. The rent is in the extremity.

Unlike the Syatangus purpurens, the lower part of the animal is thicker than the higher, and its general aspect somewhat different.

All the specimens, that is between twenty and thirty, which I have seen, were either white or sulphur-yellow.

The suckers of this species are beautiful floriform objects. Their flattened head or disc, composed of numerous papillæ, environed by a circular margin, is borne on a flexible stalk.-Plate XXXIII. figs. 6,7 , enlarged; magnified, fig. 8 . The colour varies from crimson to lighter red.

The shell of the Spatangus fluvescens is wonderfully thin and brittle. It seems insufficient for any resistance; actually crumbling almost to dust anong the fingers of any one attempting to cleanse it of the spines.

This creature burrows in the sand at varions depths, somewhat abore low water-mark; but it seems rather a scarce production.

On one occasion, while specimens were undergoing manipulation, a slender cartilaginous looking organ extended about two inches from among the spines of une. It terminated in an expanding star of about fifteen purplish, short, slender, unequal pointed filaments, remaining in considerable action ; but I was unable to satisfy nyself in any namer reggarding its real structure or use.

\section{PuATE XXXIII.}

Fur. 1. Spatangus flavescens.

2. Under surface.

3. Shell divested of the spines, under surface, shewing the position and form of the mouth and shield. 


\section{Plate XXXIII.}

Fic. 4. Shell divested of the spines, upper surface.

5. Under portion of the shell divested of the spines.

6, 7. Suckers enlarged.

8. Disc of the sucker, magnified.

9. Paddle-shaped spines.

10. Echinus pusillus (Echinocyamus), shell, back after nature.

11. Front.

12. Surface of fig. 10, enlarged.

It is rather from compliance with the usage of modern naturalists, than from conviction of its utility, that I have introduced the subject of the present section under the name and character of Echinodermatn.

Possibly, my researches being limited, I have viewed such an arraugement on too confined a scale to allow its full scope and effect : yet there appears little reason to expect either its general adoption, or its stability.

Nothing could be productive of greater convenience, indeed, than the permanent concentration in groups, or families, of the innumerable animated beings dispersed tliroughout the universe.

But the union must be founded on features pointed out by Nature, distrusting those the arbitrary choice of mankind.

Though Nature does not always speak in intelligible language,-intelligible at least to our humble capacities, while disgnised by metaphor, redundance, or defect,-let us persevere in patient investigation, awaiting explanations, sometimes reluctantly given.

To sanction the formation of groups or families, the relation of animals should be seen in prominent features, readily and unequivocally exposed, even to grosser sense. Here, the majority of observers will be better satisfied with finding sufficient external distinctions, than being remitted to a search for such mysteries as dissection may reveal.

TVe cannot confidently affirm that those definite conditions, constituting a separate group, subsist in the preceding species; that some pro- 
minent common attributes pervade the whole, or that there is a conmon resemblance among them.

Externally, there is scarcely enough to establish affinity.

The Holothuria seldom shews its real form, and scarcely betrays any portion of its gennine nature. The aspect of the Asterias does not bear it the most remote resemblance ; and alike distant is that of the Echinus. Did we descend to some others, usually included in the group, some might say it was in quest of discrepancies.

Agaiu,-where is there any correspondence in the organic structure of the others, with the beautiful arborescence of the Holothuria? where the curious tufts, or tubuli, or the madreporiform tubercles of the Asterias or Oplizura? Can any parallel be shewn with the extraordinary reproductions of the former, so profoundly illustrative of Nature's surprising energies to restore that perfection appointed for the works of the Omnipotent.

Nevertheless, something may be discovered to compensate all this ; something to prove that kindred which is slowly disclosed to the scientific student, and such as some anatomists think they have found.

Many sacrifices must be made for concentration, for order, and brevity.

A nameless charm attends regularity ; of itself, it facilitates labour, and leads to the easier diffusion of knowledge.

Our acquaintance with the group, we must also admit, is as yet only in progress. Many additional and interesting facts evidently remain for its further embellishment. 


\section{CH A P'TER III.}

\section{CRUST A CEANS.}

Ir is the common infirmity of Naturalists, and indeed of all systematic authors attempting general classification, to comprehend every subject within its bounds, which shall be sanctioned even by implication.

Hence, unless for judgment and discrimination, a miscellaneous mass accumulates, which, along with pertinent matter, includes much which might be assigned to another more convenient position.

It is now that subdivision resting on analogy becomes essential, so that, with the immoderate multiplication of genera, and the unreasonable separation of kindred species, those products of reciprocal resemblance yet exhibiting sensible distinctions, may be approximated.

But the arrangements must be adjusted according to the facts ol.. tained from repeated correct observation in the wide expanded field of Nature.

The cultivators of science having multiplied of recent years, and each being prone to take a different view from his fellow labourers, it is the principal office of the experienced practical observer to preserve an accurate and veracious record of such facts as may have fallen under notice in his own department.

The precisc mode of study is scarcely to be prescribed; it must be regulated by discretion, recollecting, however, that the more prominent features of animals are the better guides, that examples should be distinct and numerous, so that illustrations may be readily found among 
them. Farther, that the closer the elements of discussion are concentrated, their purport will be more convincing.

The Crustaceans form an inmense class among the animals invested by a firm, resisting, integumentary eovering, of a certain quality, which, mostly dwelling in the waters, are extensively distributed throughout the globe. They are distinguished by the greatest variety of appearance, disparity of size, modification of form, and peculiarity of habits, whence many doubts are entertained whether some are properly enrolled here, or should be discarded to other places.

As yet, they are but imperfectly known. Few have been watched in their living state, and scarcely any preserved, as the subject of care, for permanent observation. Thus, unless with rare exceptions, they have seldom fallen within the sphere of the physiologist: and at this moment, the most interesting points in the history of many, are as little understood as they were in the days of Aristotle.

The Crustacea are never represented alive, in the exercise of their natural functions, or as embellished by their natural colours ; because it is believed that they are less exposed to alteration by deatl.

Of later years, the mere classification of multitudes of these creatures, and recording their synonyms, seem to have been chiefly contemplated by modern authors, which is of considerable utility.

But this is not enough for the inquisitive, who demand information of their nature.

With infinite deference to those naturalists of superior attainments. who may have embarked in similar enquiries; and with an anxious desire to avoid interference with their peculiar pursuits, I venture to offer a few results from personal observation.

Comprehending a multitude of living creatures, externally void of any common resemblance, under the name of Crustacean, seems entirely a modern contrivance, derived from the nature of their integuments. Their flesh is very seanty; and instead of the skin usually protecting animals, they are invested, wholly or partially, by a shelly covering.

The nature of this covering leads to several singular physical consequences. Being inflexible, it does not enlarge with the life of the 
subjeet of various species. But to admit of progressive inerement, it is frequently renovated, and especially during earlier age. While it sulsists in perfection, the subject does not grow, for apparently the only period of inerement is restricted to preparation for its exuviation, or ensting of the integument. Whenee the importanee of this physical alternative is obvious. The precise period of the commencement and cessation of its oceurrence are alike unknown. Undoubtedly it commences soon, and terminates when the full dimensions are attained ; for, in the light that we consider its purpose, there is no further use for the change.

The shells of living Crustaceans are of various eolours, green, red, or yellow. When east, they dry, and the colour fades. The more vivid are consequently converted to another hue, prineipally redclish. The same tendency is often exhibited by some still investing the living subjeet; also white patehes become green on suceessive exuviations.

Those young animals which are originally pure white, are darkened by supervening patelies; and possibly the whole integuments are ultimately converted to the colour usually distinguishing their speeies. But the only Crustacean I have seen white in the early stages, is the Canerr payurus, or Common Crab.

Many naturalists have riewed the animals, or most of those included in this section, as nearly akin to insects. Some are terrestrial, others are aequatic. Only the latter are considered here.

The shell is composed of numerous parts, of which one, the prineipal, investing the intestinal organs, is ealled the carapace. Naturalists compare the parts of the borly to segments, whereof they enumerate twenty-one composing the Common Crab. The parts are connected by a kind of cartilage, which are liberated by its continued maceration, when their former articulation may be examined in detail. Tarious remarkable pieces will be then found among them.

Though composed of so many portions, the whole integument generally separates entire on exuviation.

This process is not confined to Crustaceans alone. The integuments of numerous other amimals, especially those belonging to the Inseet, the Ophidian and Batrachian tribes, are also east and renovated. But the 
student can so arrange his course of observation, that the Crustaceans are in a manner brought under such control, that its occurrence may be anticipated within given intervals.

The Crustaceans are provided with a number of limbs, whereon their subdivision into genera is principally founded. Two of these, in some genera, terminate in strong claws, each with a forceps, employed as organs of offenee or defence, and as auxiliaries in feeding.

The Decapodes, or those with ten limbs, are, of all Crustaceans, the most familiar to us, and on which most of our information regarding the whole race is founded. Some are of personal use to mankind. The characteristics of the majority of the others are not equally well known ; nor have they received as much notice.

In general, the motions of the Crustaceans is walking or running: few of them are framed for swimming, to which the structure of the body, the subordinate parts, and its gravity, are adverse. Nevertheless, some can spring with great force through the water, and a few can sustain themselves permanently amidst it. They harbour chiefly among rocks and stones, or among sand, more rarely dwelling among vegetable matter. But the Asellus and Limnoria seem to have no other habitation.

The senses of many Crustaceans are very obtuse, especially sight and smelling. They are quite sensible of light, of shade, or obscuration. They seem to distinguish the approach and the presence of persons to whom they are accustomed, especially if receiving food at their hands. But whether they have any distinct and correct vision of particular forms, is ruestionable. For a long time I was inclined to rest this doubt on believing that some integument or covering of the eyes separated on exuriation, which I am now satisfied was erroneous.

Their sense of smelling is certainly very obtuse. It is only when in their vicinity that they are aware of the presence of food. Even then the seareh after it is wavering and indirect. The eyes are neither turned towards its place, nor does the animal advance for its seizure. It appears to be aroused by nothing short of actual contact of foreign substances with the forceps, where feeling seems principally to reside. 
From the extraordinary natural disparity of size between the two claws of some species, it would appear doubtful whether they discharge precisely the same functions as where both are more nearly of equal strength and dimensions.

The Crustaceans generally are carnivorous-testifying the same disposition which distinguishes other carnivorous animals. They are ficrce, cruel, and rapacions, devouring alive such creatures as they can overpower, nor even sparing their own species. The vorncity of many is excessive, only ceasing to feed from repletion. Their choice is almost indifferent, provided animal matter can be obtained. This, although half or entirely putrid, is not rejected. Some marine regetables are consumed in periods of famine.

These creatures are very patient of abstinence. After one copious: meal, another within two days is seldom relished.

A few genera confine themselves to terrestrial vegetable productsto macerating wood or leaves exclusively. I have not observed that they were as fierce as the rest.

The food of many is unknown. Such as survived a consilerable time with me in that predicament were returned to their native abodes, on finding that I could not ascertain what it ought to consist of.

Some of the Crustaceans are of a most contentious nature. They are terrible enemies to each other, and the deadly foes of animals weaker than themselves. Hunger renders them bold and ravenous; and werc they proportionally courageous, which is far from the case, the assanlt of a few of the stronger species on people accidentally sumk in the sea might prevent them from ever rising again.

But they themselves have many inveterate enemies, as if to balance their insatiable rapacity. Those of the sea, approaching the land, are exposed to a kind of universal persecution ; indeed, some particular species might be included in the list, too large a one, of persecuted animals.

The most fatal ravages on the Crustaceans are committed by the Actinia, which might be accounted a very insignificant enemy. Securely rivetted to the same spot, while numerous stragglers are roused 
from their retreats by the flowing tide, its tentacula, treacherously spread abroad, are always ready to seize the unwary victims, with irresistible power, on simple contact. They crowd around their prey, while the wide expanding orifice of the mouth gradually receives it yet alive. Many of the victims seem completely paralysed; nor ever by the slightest struggle attempting to free themselves, even where they seem capable of doing so. Besides such destruction in detail, others are engulphed by fishes in the sea, whose capacious jaws are ever prepared to swallow the largest and most formidable.

Spite of their apparent strength and activity, the most vigorous of the Crustacea are liable to perish from the slightest impurity of their element. Hence, in confinement, all require umremitting care.

It is important for the naturalist to discover the perils which menace the subjects of observation and experiment. Whether inhabitants of the sea, of fountains, lakes, or streams, constant humidity is indispensable; though not alike essential, for the terrestrial species. Although some inhabiting the sea may quit their abode with impunity, on recess of the tide, they must not be far distant on its return ; they would inevitably perish. In confinement, the rapacious kinds ought to have the water changed soon after feeding, and not long subsequently a second time. Digestion is very rapid among these creatures, and sometimes fragments of animal matter remaining nnconsumed escape notice, which would speedily contaminate the element. Transferring the subject to a different vessel within six or eight hours is the safest expedient, and replenishment of this within twelve or sixteen more. Frequent examination is indispensable.

But specimens often die suddenly without an obvious cause, whence, if several be together, the naturalist must be careful of the survivors in confinement.

On this head it slould be observed, that, for the most part, the for("eps of the claws of living subjects are open, as if always ready to seize, and the tail, or posterior portion, is closed upon the neighbouring parts, as if kept in its position by some exertion. This is more evident among several of the Murrouri, the long-tailed or Lobster class. The reverse is 
usually concomitant on death; the claws are close, and the tail unfolded. Thus, we may conjecture from its representation, what has been the state of the subject when delineated. There are other indications, but unfortunately very seldom denoting animation. They almost invariably prove it extinct. Nay, certain authors of no mean repute have pointed out the most suitable modes of destruction !

I do not affirm, however, that the preceding rule is infallible ; that there are no exceptions. I lave even seen in two specimens of the same species, the Portumus lividus, dying in the same ressel, the claws of one closed, of the other open.

Animals being preserved in museums under the semblance of their natural position, have afforded most of the figures published of the different species, which will account for the perpetuation of imperfections. Their genuine representation, however, can be obtained only from vigorous living specimens.

To prevent sudden injury from the vitiated element, if a shell, or other substance somewhat elevated above the water, be kept in the vessel, an isolated specimen may find a temporary retreat on it in safety.

It is necessary, besides, to be very eautious regarding the disposition of the different individuals, or the different species associated together. As some wage perpetual war both against each other and against stranger species, they would defent the issue of any experiment. If twelve or twenty specimens of the Cancer manas be committed to the same vessel, their numbers daily diminish ; all are killed and devoured by their fellows, until one alone remains victor. Dead or alive they are equally acceptable as food. Therefore, as we shall see, it is prudent, in conducting our observations, to gorge the subjects abundantly, whereby they are disarmed.

But, man is the grand destroyer of all living nature. No animated tenant of the earth or of the waters is safe from his wanton cruelty, whether exercised for pleasure or profit.

Some of the larger Crustacea, as crabs and lobsters, are eagerly sought after as food, by the inhabitants of Great Britain and other countries; and, for that purpose, a considerable traffic is carried on in both 
fisheries, as a branch of individual industry, and, for the ends of commerce, are conducted on a considerable seale in places where such animals are most numerous.

Great numbers are imported for the Loudon market from the coast of Norway; and some of the Testern Isles of Scotland are said to yield 60,000 anmually. Those alone are considered marketable where the shell extends eight inches, and.they are then sold by the captors to the agents for the fisheries or the market, at $3 \frac{1}{2} d$. each.

None but rocky coasts are frequented by lobsters; which are also the resort of all kinds of crabs, in greater numbers, but of less value. The fishery of the latter is carried on ererywhere, on a small seale, throughout the coast, chiefly by those residing in the vicinity of their haunts. The same may be said of the fishery of shrimps and prawns, which abound on wet sandy beaches, wherein they burrow during the recess of the tide.

Amidst great abundance of crabs, only the claws are reserved for food, the body being thrown away.

Some seafaring persons devote themselves entirely to this kind of fishery during the season: and I have been assured, that a small boat at Newhaven has taken seventy dozen in a day in May or June. The females, full of roe, are not spared, which proves a great and needless sacrifice of the brood; nor are the younger crabs an object of any reserve.

Scarcity, abundance, or the hazard of exterminating the race, are never taken into account, nor any thing but how to secure the greatest number possible.

It would be well if all fisheries were brought under special regulations, which, in such cases as the present, might be attained by prohibiting the sale of subjects under certain dimensions.

None but the Cancer payurus and the Astacus marimus-the Common Crab and Lobster, and on a smaller scale Shrimps, are subjects of interest in Scotland. Others, such as the Cancer manas, -the Shore or Harbour Crab, are an ordinary article of food in some countries, but not here. Tast numbers of these, according to Oliri, are captured in the Adriatic, packed in barrels, and exported. They are taken when in different states and stages ; first, on casting the shell while the body is soft ; 
next, when the roe is in an early stage, and then by ordinary fishery, when attracted by bait. Of the first kind, Olivi computes that 86,000 pounds weight are taken ; of the second, 12,320,000 pounds ; and of the third, 2,660,000 pounds. The quantity must appear incredible, but the size of the species probably exceeds that of those of Britain.-Zoologia Adriatica, pp. 53-55. This author calculates the gross quantity as worth half a million of Venetian money.

Olivi speaks likewise of the wonderful number of other species, of which I shall say nothing, being ignorant whether we have any of them in Scotland.

Some genera are as peaceable, tranquil, and inactive, as others are the reverse. They select the clefts of the rocks, or retreat under stones, which appear to be occupied as a permanent abode until hunger calls them from it. All prefer concealment; they always desire cover, whence, for smaller specimens, it is beneficial to introduce the single valve of some large shell into their vessels, under which they will crawl and enjoy a long repose.

From the inactive habits of several species, many specimens are overgrown with marine vegetables; their surface serves as a nidus for zoophytes, or numerous shells adhere to it. I have seen the carapace of one totally invested by a sponge ; not a particle free.

When the profusion of parasites is great, the subjccts evidently suffer under it and perhaps they perish.

Exposed to so many sources of destruction, it is surprising how any remain, but the excessive fecundity of the tribe, in general, contributes to their preservation.

Were the progeny of a single female common crab spared but for two seasons of maturity, their multitude would probably satisfy the demands of 10,000 people.

I am not aware that any of the Crustaceans are androgynous, thongh perhaps credited formerly. In many, especially among the Decapodes, the difference of two sexes is well defined, and in some it may be recognized, by very simple rules, from the formation of the shell. The breast-plate, thorax, or apron of the female of the common crat, is a broad triangular portion 
of the shell, susceptible of great elevation, and of being folded entirely back : that of the male is very narrow, but susceptible of a similar position. Here are displayed the admirable provisions of Nature. The aprons of both are folded back in the mutual embrace. Under that of the female are now seen two circular orifices, through which the roe, ripening within, escapes to attain maturity without. As it diffuses in vast abundance, the apron of the female is gradually and proportionately elevated while covering the encreasing mass of ova. Sometimes it rises so high as to stand vertically or at right angles to the under surface of the shell, if reversed, and then the ova of the common crab are in teus of thousands.

Here the roe remains in permanent adhesion to the shell; no part of it is deposited on foreign substances to be hatched, as is the case with many animals-insects iu particular-to which crabs have been compared, as if allied. The whole continues attached to the body of the parent, until by supervening maturity, the foetus bursts the egg or enpsule to escape,- the tie seems to be then clissolved for ever.

Should I not be mistaken, the ova of the whole tribe of Crustacea adhere externally to the lower part of the thorax or abdomen of the females. In a few which naturalists include here, they are clischarged through long tubes with the advancing embryo in an envelope.

I have not been able to ascertain that the young of any species of the Crustaceans are ushered into life under the precise form of the parent. Many undergo a great metamorphosis. In those best known, a much farther development succeeds, as they issue forth, for indiscriminate distribution amidst their boundless element, they readily escape the view of the naturalist.

The change of some is perhaps inconsiderable, and chiefly limited to the acquisition of additional limbs. Several species of animals now incorporated with this comprehensive tribe are less distinguished by such peculiarities. But the young and the adults of others could not be possibly identified as of the same species, unless bred before the observer's eyes.

The preserration of living subjects, together with unwearied study, can alone lead to the solution of points so embarrassing. But here we are opposed by the erratic habits of many. Possibly a very small pro- 
portion of the brood is reserved for the adult state, the obstacles are so numerous to its attainment. Could we preserve them, very few would suffice for all our wants : they would elucidate all our doubts.

None but living subjects occupy a place in these volumes. Independently of my invincible repugnance to injure or destroy, it is self-evident that destruction immediately counteracts the object proposed, namely, what animated beings shall do. If we hope to render our aequaintance with them useful, they are to be always beheld in the most vigorous condition. We cannot otherwise discover their form unimpaired, their motions unembarrassed, the quality of their food, their mode of perpetuation, and their peeuliar habits.

It is an absolute error, believing that, with the loss of life, such animals as are sheltered by a hard integument, undergo no alteration.

The preferable method of comnterbalancing the evils inseparable from destruction, is obtaining multiplied correct delineation of the whole animal frame, and of many of its eomplicated parts. Thus may the organic structure be explained and understood.

This, however, may seem a very wide prospect ;- - of distant completion, and demanding the work of various hands, as guided by various prineiples.

The habits of the Crustaceans are extremely diversified, aceording to the different genera, comprising such a comprehensive class of animals. Some are all life and activity; others ean be scareely seen to move. Some sulssist on living animals. Burying their external organs in the flesh, it is not known that they ever abandon the position once assumed.

Perhaps as animals of prey many of the Crustaceans are solitary, for very few such are known to hunt in eoncert. But several dwell in numerous societies. Also some are said to be gregarious : and, although not in Seotland, that they aecumulate in quantities compared to hillocks in other countries. Possibly this may be in the cold season.

Notwithstanding their delicate nature, perhaps the life of a few individuals escaping the pursuit of enemies and the war of extermination is long.

It is one peenliarity of certain species, that they simulate death, lying 
motionless, contracted, and supine, until the dread of danger is dispelled, their natural posture and functions are resumed. Here are recognised decisive features of insects.

Although we characterise the Crustaceans in general as invested by a hard shell, this is not strictly true of every species. The integument of some is rather horny or coriaceous, eapable of slight resistance in its place, and yielding easily to pressure when separated. Perhaps it gradually degenerates into an integumentary skin.

For practical illustration of the general form and nature of the Crustacean tribes treated of in this work, the subject may be conveniently subdivided into three portions, comprehending-

I. Cancer, the Crab.

II. Astacus, the Lobster.

III. Miscellaneous subjects, some of them approaching both, or resembling neither, nor alike familiar or sufficiently understood.

\section{PART I.}

A.-DECAPODES, TEN-LIMBED, SHORT-TAILED CRABS,-BRACHYLTI.

\section{\$ 1. CANCER nexas-The Shore or Harbour Crab.-Plates XXXIV., XXXV., XXXVI., XXXVII.}

A small green Crab, running actively over the rocks and sands during recess of the tide, cannot have escaped the notice of those frequenting the sea-shore.

This is the subject of the present paragraph ; and as it is one equally convenient for experiment and observation, especially from its size and abundance, we shall view it at greater length than many other species require.

Though usually green, it is seen under varions aspects, whether entire or mutilated. The green is uniform, or interrupted ; of various shades and intensity, sometimes variegated in such a manner, that the shell seems green and black. But plain and nniform green must be considered the usual and more natural colour. 
T. I.

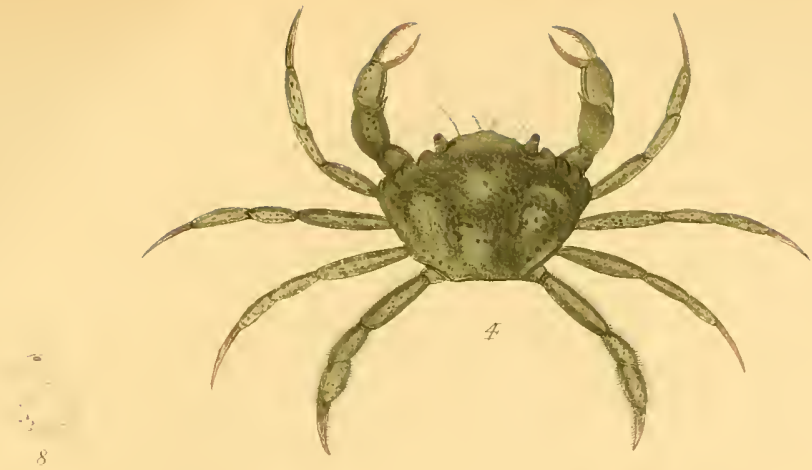

PI. FIII:
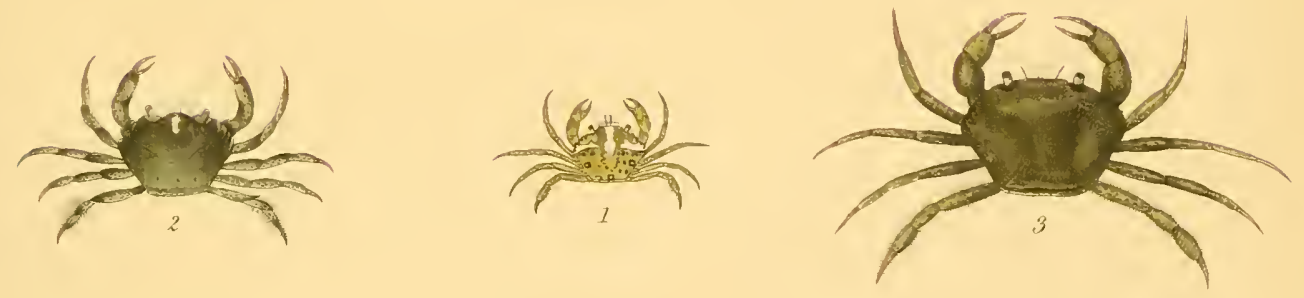

- tob : 80

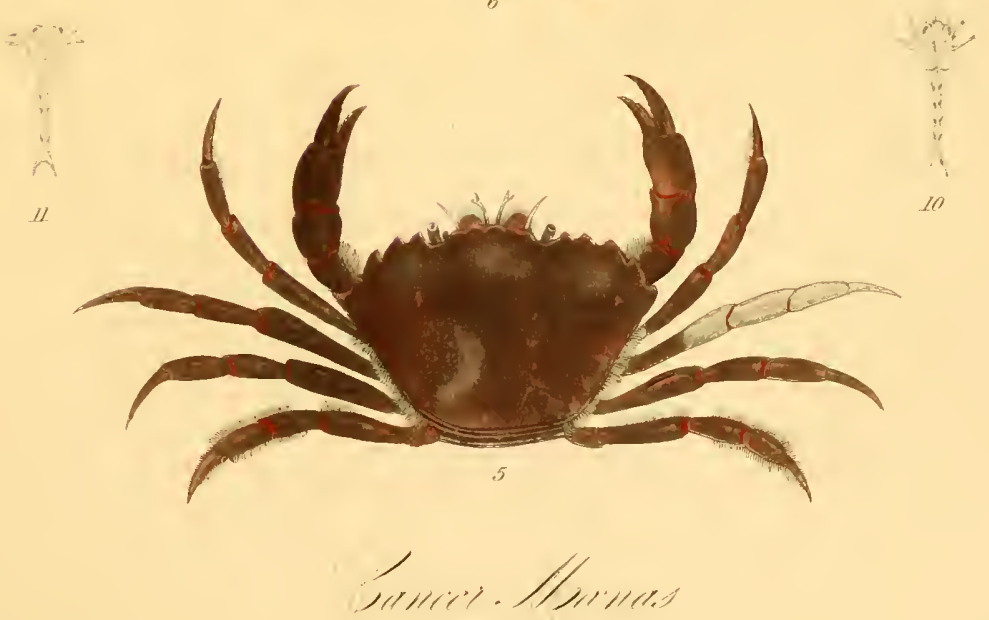



It seldom, if ever, attains any considerable dimensions, as the body, shell, or carapace of those apparently full grown in this country, may be inscribed in a broad oval outline of about three inches by two. Hundreds are found of all inferior sizes. The shell is slightly convex, the sides and anterior edge curving, but interrupted by notches, the posterior margin almost in a straight line.

In front are two eyes, on peduncles of the shell, and four tentacular organs near the edge, two of them like stout bristles, exterior, and two shorter, nearer the region of the month, which is below, forked, and in constant motion. The eyes on perluncles rise from a socket in the edge of the shell, outside the longer antenna, each folding down for insertion to right and left in its respective socket. They are most prominent during life.

Two broad, thin, maxillary organs below, exercise a horizontal action, like scissors, or the blades of two knives, as the animal feeds.

The Cancer mernas is provided with ten limbs, being two claws and eight legs. In all the tribe the claws are differently formed, being larger and stronger than the legs. They have several important parts to perform ; first, in holding the food, tearing it asunder, and carrying it to the mouth. They are likewise the organs of defence, and the instruments of offence. The limbs, disposed in pairs, are adapted for running, and resemble each other, only those of the lind pair are fringed, and slightly flattened. Many other Crustaceans have a greater number of limbs, besides some apparently imperfect or abortive, and a kind of auxiliary finny organ to aid their movements.

The claws, however, are the main and most important organs, armed with forceps, whose office may be compared to the hands of mankind, and the paws of other animals. They possess remarkable strength, in proportion to their dimensions.

The Crustacean class is often compared to Insects, with which it was formerly conjoined ; and many analogies, at least in form, will be allowed to subsist between them. But characters equally distinctive, are deficient. For example, I have seen no indication, in any species, of the same intelligence that seems to be possessed by Insects. Neither is it 
by those in their ultimate and most perfect form that this is evidenced, for it appears in an early stage, and long preceding the ultimate state. The common cabbage caterpillar secures itself by a cord for preservation during the season of inactivity, there to await its proximate clange to the chrysalis, and one more remote, to the butterfly. The bee stores its cells with provision of one kind for itself, and another for its young; the spider spins the web, wherein its prey is captured ; and the ant constructs sulterranean galleries to favour its predatory habits.

Nothing to be compared to any such artifices, is found among any of the Crustaceans that I have seen.

Like so many insects, they are distinguished by segmentine divisions of the body, whereof Dr Milne Edwards, in his comprehensive work, enumerates twenty-one,--that is, inclications equivalent to twenty-one.

Practically viewed by the less learned, the principal divisions are not rated at more than two in the crab, that is the main shell, back, or carapace, and the thorax bearing the limbs, attached to it, which two may be rent asunder, the latter separating entire.

As I to not purpose entering on the anatomical details of the structure of these animals, for which other naturalists are infinitely better qualified, as shewn in the work just referred to, I shall confine myself to different topies chiefly receiving very little notice, comparatively.

The ordinary external colour of the Cancer menas is green, which is sometimes variegated by an intermixture of white, seldom permanent throughout life, the latter being gradually obliterated; and some are entirely reddish, especially with advancing age.

The specimen, Plate XXXIV. fig. 1, was green and white, the former greatly predominating. The specimen, Plate XXXV. fig. 1, was almost white, with red eyes; and the specimen, fig. 2 , of the same Plate, had the back red, patches on the claws and limbs, and the rest white.

The specimen, Plate XXXIII. figs. 1, 2, preserved its proper colour very long; but at length the white was obscured, and a tendency of the whole to red ensued.

Certain interesting facts relative to the derivation of colour, in either plain or variegated crabs, are of difficult explauation. 
V. I

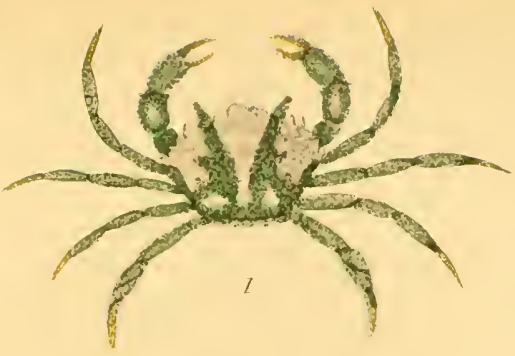

PL. TXTY
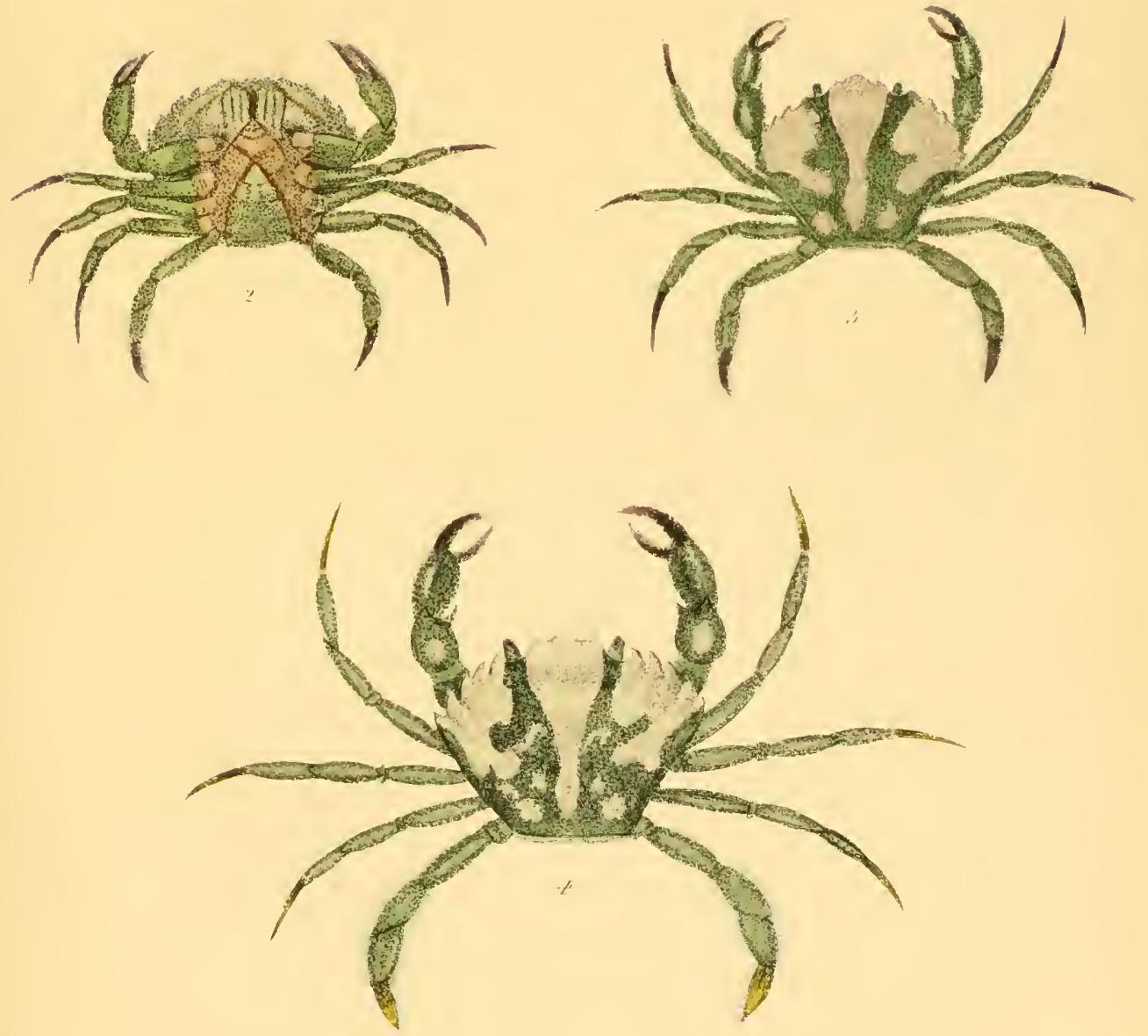

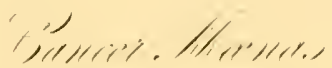



The motions of the Cancer manas are lively, quick, and active. But it does not swim. In the natural state, it constantly endeavours to retreat, shumning the presence of man as an inveterate enemy. None of our native species is alike littoral. The shore is almost as much the place of its abode as the sea. Wherever rock, and weeds, and sand abound, it is commonly present, ever seeking shelter in the fissures, or under the shelves, so that the body may be protected by some covering.

Heat and hunger are the great incentives to action throughout the tribe. Like insects, these creatures are wonderfully susceptible of cold. A very moderate degree of refrigeration will render the Cancer manas almost torpid, even in summer.

But it is naturally the most restless animal imaginable, and continually prepared to escape from confinement. Specimens in captivity must be therefore kept in vessels deeper than the stretch of their limbs, otherwise they will contrive to crawl over the ledge. Nevertheless, they are easily preserved; adverting to change their element frequently, -always a few hours after having fed.

The Cancer manas feeds voraciously. No animal matter is rejected. What is most convenient and acceptable to all its congenera also, is mussel, which may be kept fresh a long time, though that seems no great recommendation. This creature is not nice in the quality of its sustenance. It feeds as promiscuously as any other, whether the substance be fresh or putrid; nor, in time of scarcity, are some of the algæ and fuci refused. I have never seen any animal matter rejected, fish or flesh,-living or dead,-and the quantity devoured is enormous. But after a voracious meal, nothing is generally sought the succeeding day; and specimens can abstain entirely from food for several days, without sensible injury; during which time, they remain perfectly tranquil.

Should a mussel shell, or other bivalve, be split asunder, and the half given to a specimen of the Cancer monas, it holds the valve in one claw, and with the other picks out the contents, conveying the morsel to its mouth as people employ their hands. The shell at length emptied, is as clean as if cleansed artificially. 
The external integument is an indurated shelly covering, composed of numerous separate pieces, connected by a kind of cartilaginous substance, and all the limbs are composed of articulations. Perhaps this external integument is strengthened by successive invisible interual secretions, for younger animals are easily crushed, whereas it is difficult to make any impression on old ones. But it is so far inorganic that it seems to undergo no visible alteration during the time it serves the animal invested. However, this is a subject which has never undergone sufficient scrutiny.

The Cancer manas occurs of all different dimensions, from young of the smallest size to the mature adult. But I am not aware that any single specimen has undergone sensible increment under observation of the naturalist. If he inspects such a specimen month after month he will probably find it no larger at the end than at the beginning, farther than some slight relaxation of the cartilages, if that actually takes place. Therefore, without the important event, to which we shall speedily advert, it would remain always the same.

Yet nature may not be idle in the intervals. Secretions may be advancing, though unseen, preparatory with what is indispensable for the concomitant subject's preservation, and for admitting with age the increment of an animal whose integunents are inflexible.

At certain seasons of the year all the limbs are full of flesh, as is most evident in the claws, such as of the Cancer pagurus, where they are of considerable size. But there, as well as in the Cancer manas, while the time approaches, that progressive increment shall render the capacity of the subsisting shell insufficient for its contents, the limbs seem to be deserted by the flesh. A soft integument is forming on the inner surface of the carapace, interposing between it and the internal parts, wherein these parts are about to be included. By a wonderful and inexplicable operation of nature a complete new integument, ultimately crustaceous, is generated within the subsisting shell, with the whole linbs folded over the breast, so that the least possible portion of the internal space, soon to become an absolute vacuity, is occupied.

Next, when all is mature, the subsisting shell opens or gapes hori- 
zontally, between the hind pair of limbs, by the yielding of the ligament forming the hinge of the thorax and carapace, which admits the separation of these two portions, and allows escape from within of the confined animal, clothed in its new integuments.

The gaping edges or lips of the opening then close by their own elasticity, while the old shell, emptied of its contents, appears to the spectator as entire as ever.

An absolute change has ensued, yet without any relation to the process of metamorphosis, in the proper acceptation of that character.

The spectator beholds a new animal before him, distinguished by all the parts of the individual with which he was previously so familiar. It is alike perfect, the colours fresher and more vivid, either exactly the same in quantity and proportion as originally, or perhaps under some rariety and modification. But the creature is somewhat larger in this its new garment than in the preceding shell,-nothing can be more admirable.

After a brief interval of tranquillity this new animal moves, and rests, and feeds as the old one; I should rather say as when invested by the old integument, for it is only the covering, not the actual crentur. itself, which is regenerater.

It is not enough, horrever, that the change is effected once. It must be repeated again and again,-as often as additional increment requires additional space for the contents.

I cannot affirm at what period exuviation commences, or when it ceases, how often the shell is generated, or whether throughout the continuance of life. At a very early age it becomes indispensable, and it is frequent. But later shells seem to subsist very long, as is evident by the quantity of animal and vegetable parasites investing them, doubthess the growtl of years.

To follow the course of this remarkable process is extremely interesting, and I acknowledge, that, being wholly unexpected, the first time of its occurrence I witnessed it with great surprise.

I had preserved a reddish middle sized specimen for several months, which became very tame and familiar, Plate XXXIV. fig. 5. The heat 
of a sultry summer's day induced me to put it outside the window of my study, in a capacious vessel of sea-water, where it remained during the night, for all marine animals are benefited by the coolness of the atmosphere. Next morning, when thinking little of the matter, I prepared to replenish the vessel, a crab, lying on its back, struck my view, and beside it one of rather larger dimensions, its very image. I hastily concluded that a stranger had been introduced,-not at all an unlikely incidentas here was a ready receptacle for any subject that might have arrived.

But exuviation had ensued in the night: the latter was the animal, clothed in its new garb, and close beside it the former, now an empty shell.

Similar exuviations have repeatedly taken place. Yet the effect is always so singular that I never behold it without astonishment.

Specimens about to exuviate are usually dull, heavy, and inactive, for a day or two preceding the change. I know not whether correctly, but I have been led to conclude, that, for the most part, this incident belongs to the night, or early morning, whence, being very transient besides, it is rarely witnessed.

For a long time, having constantly found the old shell quite entire, all the accessories and the minutest parts in their places, and all the others in correspondence, bristles, antennæ, eyes, exactly similar, I concluded, not umnaturally, that they must have been encased in each other. I could not conceive how by any other means, than the new growing within the old, the conformity could be so precise,- - thence, that on exuviation, each was withdrawn as from a sheath or socket.

My conjectures, however, have not been verified, and, I apprebend, that I was indulging too many fallacies.

The new animal, as I shall call it, escapes from the hind part of the old shell, which gapes the whole length between the two hind legs, and beyond them.-Plate XXXV. figs. 1, 2, 3, 4. Hence, the new organs protrude, if I be not mistaken, in the same order as they stand in the old shell, the hind legs first, and the claws being liberated the last. One fact is indisputable, in the new shell being always larger than the old. Many persons affirm, also, that it is soft, and that the crab, in its natural 
haunts, now conceals itself until it hardens. Apprehensive of injuring the new animal by pressure, I have always avoided that test, from my desire of preserving the subject. Nor have I remarked any disposition for concealment, farther than temporary tranquillity. No exuviation is preceded by sensible enlargement of the animal. Therefore a change of the shell is indispensable. If not equally indurated as the old one, the new shell hardens speedily. Being soft would probably facilitate its escape, on relaxation of the cartilages of that which it quits.

There is no positive prognostic announcing approaching exuviation, nor any rule for determining its intervals, or its frequency. These depend on circumstances peculiar to the individual subject. It is evidently concomitant on increment, therefore commencing at the earliest age.

I took a minute specimen at Blackness Castle, on September 9. 1814. It cast its shell on the 27 th of the same month, and again on the 13th of October. This new one was replaced by another on the 29th. Therefore the intervals were about a fortnight. The animal was found dead on December 31st, without farther exuviation.

I took another young specimen on June 29th of a subsequent year. Its colour was pure green, with three white patches towards the anterior surface of the shell, Plate XXXIV. fig. 1. Similar patehes are not uncommon on the Cancer manas; I have seen specimens half the size of this last marked by them.

The limbs of that just specified extended 13 lines. It was very active, and fed voraciously. The shell was cast on August 16th, when the white patches of the new one were less conspicnous. Exuviation succeeded again on the 18th of October, and a third time on the 9th of Jamuary, when the shell appeared as in fig. 2, with one patch only. The limbs now expanded about two inches. The animal's rapacity was undiminished; it sprung upon its prey, but could not discover it if at any distance. The shell became gradually more dingy, and in two months, or ten weeks from the last exuviation, the white patch was totally obliterated. This specimen rejected food on March 20th, and cast its shell, for the fourth time, in the night of the $22 \mathrm{~d}$. Its enlargement was now very conspicuous, the limbs expanding above two inches 
and a half. The old shell separated was quite pale; the new one dark green, without any white whatever. It is represented, fig. 3, as appearing on April 13, having undergone no alteration from the date of exuviation on March 22. The creature again seemed dull on May 31st, which was followed by another exuviation, being the fifth, during the night of the first of June. In the new integument it appeared very considerably enlarged in all its parts, the colour of the shell dark green, whereon were some darker specks; after the lapse of a fortnight the cast shell attained a lighter reddish tinge than the colonr of brick.

The creature had become very tame. It continued feeding readily on every kind of animal substance offered; even half an Aphrodita, a very rough morsel, was devoured, and only some of the scales rejected. It always came to the side of its glass prison, as if expecting a supply from any one in the vicinity. During the day it shewed itself desirous of reposing under any covering, and strained hard to get a large flat shell into such a position as would afford protection. Night was the season of greatest activity, which was succeeded by quiescence towards morning. Then it would remain long crouching down in the ressel, though always ready to be aroused by the presence of food.

From various circumstances, it is obvious, that, although the animal undergoes an extraordinary process in changing the integument, that the impressions, in as far as they would be received in the old integument, shew the habits acquired are not lost, but remain permanently. Something like memory or election is demonstrated.

After the preceding specimen, which was a male, had been above a year in my possession, another of little disparity in size, a female, was introduced into the vessel along with it.

All the animals of this species, large and small, of whatever age or sex, in as far as I have observed, wage the fiercest war against each other, whether from their contentious dispositions, or to satisfy their cannibal appetites. Therefore, to guard against accidents, I took the precaution of gorging both these creatures with food. But here it might have been rpared, for they were completely reconciled from the first moment; and shewed, by unequivocal symptoms, how agreeable a companion was 
to each other. From extreme restlessness the male became quite tranquil, and an actual embrace speedily followed.

These creatures dwelt together amicably, and fed readily,- and this continued for some time. I was in great hopes they would have bred, whereby various obscurities regarding their progeny might have been dispelled.

But the male, unfortunately, died soon afterwards, just fourteen months after having been acquired.

I regretted this as an untoward incident, for several reasons. I knew the animal's progress, its age could be nearly determined, and I was familiar with its habits and treatment. But it is so with all living creatures,-only intervals of observation can be enjoyed. Many must be studied to discover the properties of one.

Here the periods of exuviation had been distinctly noted, proving, as in other instances, that the intervals are irregular.

The female above referred to, a fine but peculiar specimen, was taken on July 22. A great proportion of white being intermixed with the predominant green of its shell, it remained to be seen whether it would gradually disappear on successive exuviation, as that of the former animal. The body was just one inch broad, and expansion of the limbs two inches and three quarters, when first delineated on July 27 . Plate XXXV. fig. 1.

I had not to wait long.

Exuviation of this specimen followed on the night of the first of August. Except in size, the new shell exactly resembled the old; the markings in every respect were similar. The animal was now very vigorous; but it was ravenous in proportion. Though dwelling in perfect harmony with its companion, the male above mentioned, it would deprive him of his provender by forcible assanlt, to be carried off and devoured at leasure.

Their nnion was unproductive. Its mode is in so far remarkable, that the apron of each is folded back on the cartilaginous hinge.

This female, after rejecting food during three days, cast its shell a second time in the night of October 25 , and came in so much larger 
with its new integument, that it was surprising how the body could bave been contained in the old one, which now remained quite entire. It is represented as empty, Plate XXXV. fig. 2, back ; fig. 3, breast.

In the distribution of colours, the new shell bore an intimate resemblance to the shell that had been forsaken; but the dimensions were so much enlarged, that I scarcely recollect any other instance of such disparity.-Plate XXXIV. fig. 4.-The shell, figs. 2, 3, had subsisted eighty-five days. After that represented, fig. 4, had subsisted 165 days, the under surface had acquired a reddish tinge. Ignorant of the ultimate size which the Cancer menas might reach, I indulged little prospect of farther exuriation. However, after the long interval of 210 days, this female cast its shell again in the night of May 24, when the new subject appeared considerably larger than before, but not so much in proportion as on the preceding clange.-Plate XXXVI. figs. 1, 2. The shell was renovated in beautiful purity, the same variegation of white and green being interspersed. But, witlin ten days, it had acquired a reddish tinge throughout.

It is remarkable that all the cast shells of this species should undergo a speedy change of colour, whaterer may have been its composition or distribution while clothing the living creature. Between nine and ten montlis after the change as above, the whole under surface of the new shell was reddish, the inner edge of the forceps blue. The white of the upper surface became more lingy ; it was overspread by the red : and as the alteration advanced, both were delineated in the close of April, that is, when the shell had subsisted eleven months from the last cliange.-Plate XXXVI. figs. 1, 2. Therefore, the subject was not delineated until eleven months had elapsed after exuviation.

Meanwhile, the animal remained tame, and continued feeding plentifully. On one occasion, previous to its present state, as in Plate XXXVI., and while still clothed in the shell, Plate XXXV. figs. 2, 3,-for we must always recollect that the change is not of the animal, but only of its integument,-it unaccountably left its own capacious ressel, and getting into another with two hermit crabs, devoured.most part of one of them. 
I. $I$.

IX. MTYTI

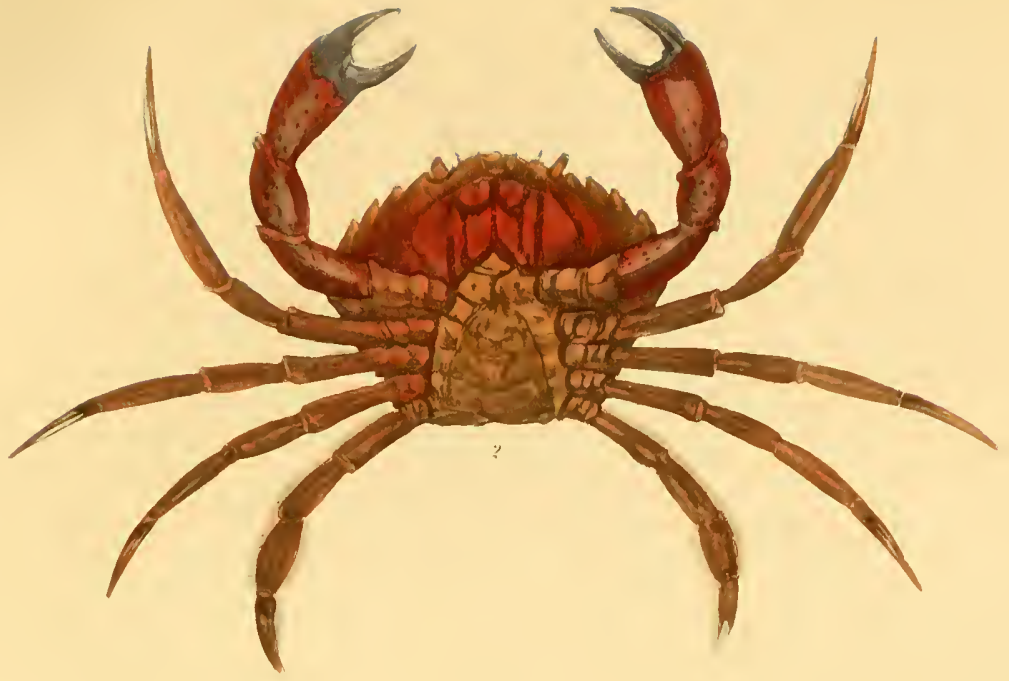

3
$e^{5}$
1
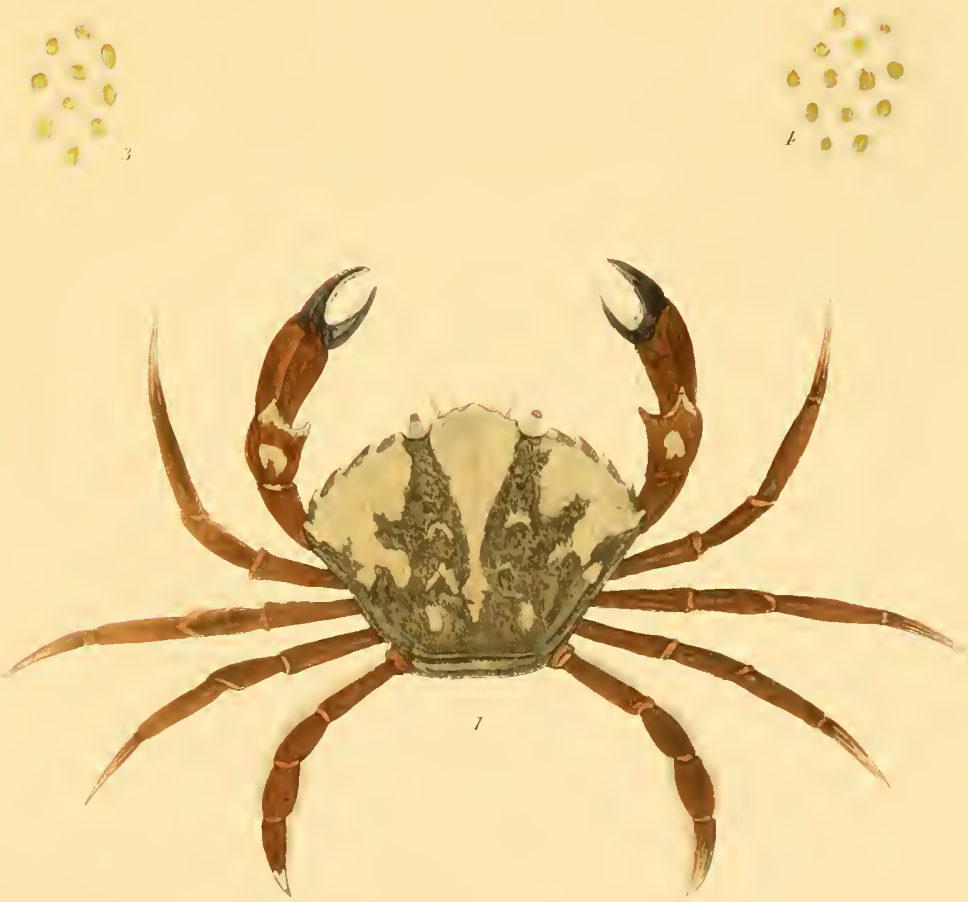

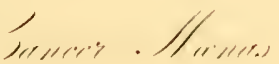



It had, itself, in the next place, a narrow escape, laving been found almost lifeless from impurity of the water, it could with difficulty be preservel.

These were the chief incidents occurring after acquisition of the female. It was taken on July 22; and in the night of the first of Augnst it cast its shell. On the tenth, the male was introduced to its vessel. Their union ensmed almost immediately. On the 17th, the male rejected food, and it had east its shell on the 19th.

Next day I found it expedient to separate these animals.

The survivance of the male was short; it died within a fortnight.

A whole year now passed withont anything of importance oceurring in respect to the surviving female. But in March, or about eighteen months subsequent to the preceding dates, it became rery restless, and fed sparingly: and, on the morning of the 14th of that month, I was surprised to see a ruantity of detached spawn, in thousands of loose orange coloured ova, scattered thronghont its ressel. Its tranquillity was then restored.

The production of spawn, at the distance of eighteen months from the time that the pair liad been together, was certainly most mexpected; and apparently adverse to the course of Natme. It was highly improJable that ora lad required so loug an interval to gain maturity: so. that, if they did not, these were the prodnce of an unimpregnated female. I transferred some of them to different ressels, wherein they remained entire for several days, exposing an internal yellow muclens, within an albuminons looking spherule.

From July 30, the animal rejected food, and persisted in abstinence for a fortnight, when it weakened and died, after having been about two years and a month in my possession.

It is seen from the preceding observations, that the original colour's may be either speedily altered, or obliterated, or that they may be permanently renewed.

It is not easy to account either for the uniformity, or for the change of colomr. There is nothing to sanction anticipation of the fact. But, 
alter the change takes place, I have never witnessed any return to the original colours.

The specimen, Plate XXXIV. fig. 5, hat a white limb; I kept it curefully to discover what would ensue on exuviation, for theory here was useless. The animal cast its shell, and the same limb came in white is before.

This fact is very perplexing,-whence is the colour derived? It would be a strong argument for maintaining that the new shell is generated in the oll, as within a sheath. Therefore we must not lose sight of it.

Reproduction of defective parts. -The Cancer manas being so conmon, so easily obtained and preserved, it is peculiarly adapted for the investigations of the inquisitive into the varions processes operated by the energies of Nature.

Herein, I believe, many vulgar errors may be corrected ; some originating in fallacious principles; others from precipitate conclusions, inherited from the days of ignorance.

It is commonly admitted, that new limbs are produced to replace those whereof such Crustaceans, as the species under consideration, have been wholly or partially deprived by violence; that regeneration exactly compensates privation; and that, whether a leg or a claw be torn off, another will be generated from the vacant stump of the member.

No doubt the general principle is true. But Nature's modus opemandi, the circumstances and the precise process of repairing the defect, do not correspond with the vulgar sentiments, which are alike unfounded, in aseribing the loss of the Lobster's claws to thunder.

Such errors probably arise from the casual inequality appearing anong the different members of various species of the Cancer, and in failing to discriminate those species of the Astacus, wherein there is a natural disparity in the size of the claws ab origine.

Perhaps if might be better to amalgamate all that can be said on the subject with subsequent discussion, were it not that naturalists, occupied by special pursuits, commonly desire special illustrations of their special subjects. 
The Canecr monas comprises a roracions, fierce, and contentious race, involved in perpetual warfare, whereof many mutilations of those escaping with life are borne as undoubted evidence of peril. Hence, among miscellaneous collections, are found specimens variously impaired; and if the whole are confined in the same vessel, those incessant conflicts, tending to universal extermination, after further aggravations, will leave one only as the victor.

Eutire genera wonld disappoar, did not the energies of Nature heal their otherwise deadly womils.

Amidst such energies, some are always directed to the restoration of perfection; whence, although the precursor be itself defective, its successor is perfect, as will be discovered on exuviation. But it must be observed, that all suljects are liable to accidental imperfections of parts, or in dimensions.

A specimen, which was defective of the right claw, having cast its shell, it came in with the wanting claw now perfect ; but this new organ was somewhat smaller than its fellow.-Plate XXXVII. figs. 3, 4. On another exuviation, the claws came in nearly equal.

A specimen, Plate XXXVII. fig. 5, which laad been mutilated of four limbs, and half the forceps of the left claw, cast this shell on October 8, and came in entire with the whole complement of limbs, together with the wanting pincer, now white.-Fig. 6.

$\Lambda$ small specimen having been left somewliat incautionsly in the ressel of one rather larger and stronger, was mutilated of the right claw and three limbs of the same side, and of a limb on the left side. Notwithstanding this extraordinary privation, it cast its shell, the new animal, to my surprise, coming in with all the limlss in perfection. -Plate XXXVII. fig. 7, cast sholl, back ; fig. 8, breast ; fig. 9, new perfect animal.

As is well known, low papille rising from the remaining stump announce regeneration in fleshy reproductions. This is a fact so familiar, and I may say of such uniform occurrence, that, without adverting to the circumstances, I conjectured that papille were actually rising here, from the rudiments of the defective organs. But let us remember that 
the stump is shell, not Hlesh, unless it may be some small residuary fragments, -and that, in this state, the stump may be called inorganic. Thus the whole remains unaltered, until a perfected animal is revealed to view by the first exuviation.-Fig. 9 .

Let us quit this subject meantime, for another no less interesting to him who is absorbed in wonder by the steady and uniform government of the universe.

Perpetuation.-Until the latest period, nothing was known of what merited the earliest observation, the continuance of this portion of the animal world.

Considerable obscurity still reigns over the propagation of the Crustaceans, or the numerous animals associated under this general name. The species of all seem to be perpetnated by ova, whereof the embryo of many thus escaping, has still to undergo such important change or modification as may be compared to real metamorphosis.

But there are others wherein the interest seems comprehended in some slight development of additional parts.

The sex of the Crab, male or female, which, in as firr as I am aware, camnot be distinguisher by age, size, colour or proportions, is denoted in this section of the race by the appearance of the thorax, breast-plate or apron, which in both sexes is triangular. That of the male is longer and narrower compared with the dimensions of the specimen, while that of the female is larger and broader.

These creatures begin to breed at a very early period, and continue very long prolific. They multiply in extraordinary numbers, and at all sensons of the year. I have seen the Cunrer manas laden with roe in the depth of winter.

This roe or spawn originates within the shell or carapace, where it may be found in a soft and immature condition. While advancing farther it issnes by one or two orifices under the apron, which is elevated by its progressive discharge, and spreads innumerable clusters of ova to the very edges.

When the speeimen, Plate XXXIV. fig. 5 . reached the end of October, the discharging spawn continued raising the apron during ten weeks. 

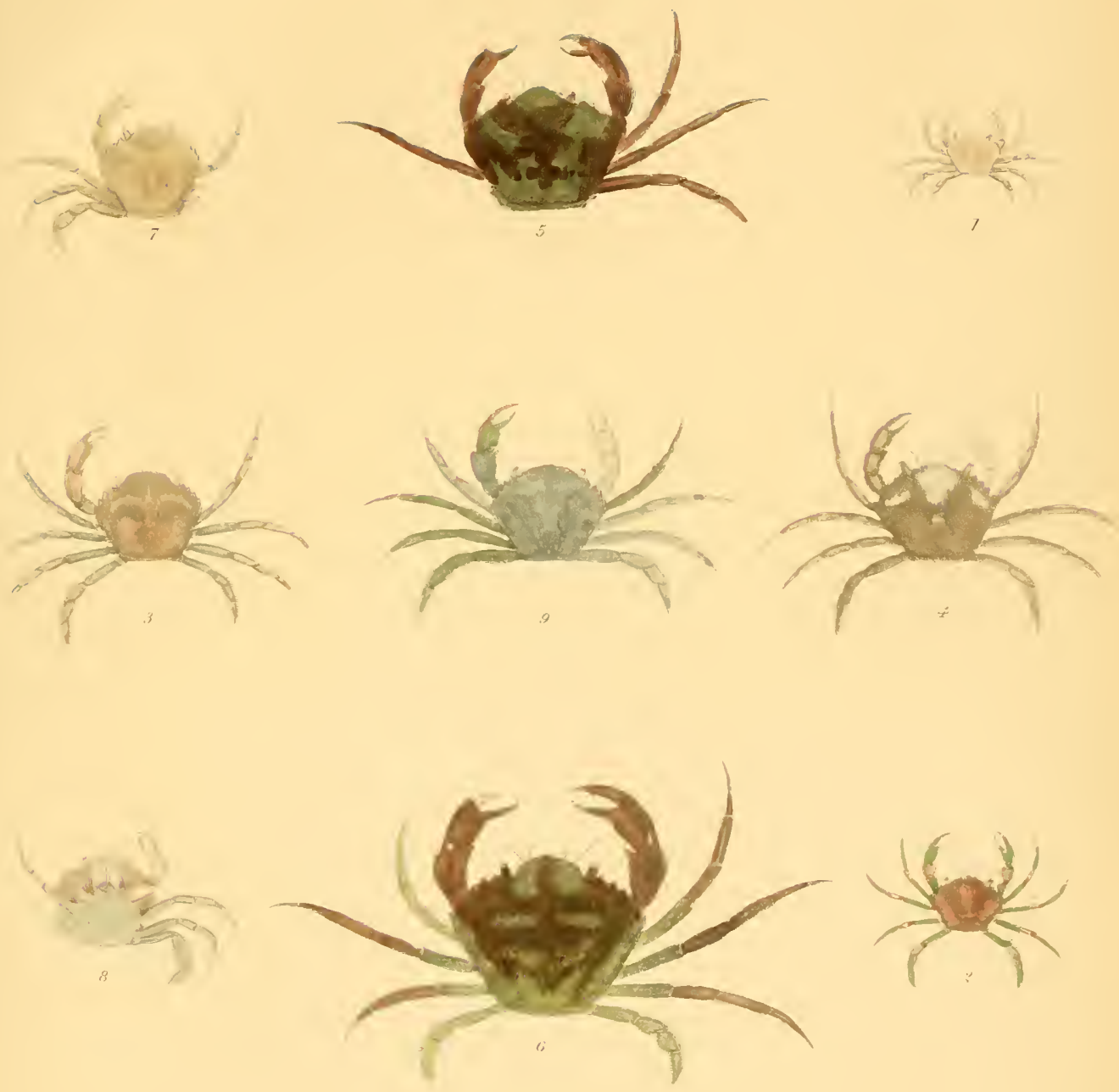

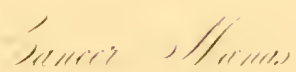




$$
\begin{gathered}
\text { HA } \\
\text { CA }
\end{gathered}
$$


When somewhat advanced, the roe of all the crabs that I have seen consists of a dense mass of ova, or a compact thick cake, gencrally vivid red, which gradually loses its solidity along with its colour. The parts of the one are relaxed, the intensity of the other fades. In detail the roe is discovered to consist of chusters resembling bunches of grapes or currants, as illustrated by various examples in this volume. Here it was composed of minute spherical ova or capsules, attached by short pedicles to a stalk, fig. 6 , and many such stalks affixed to one of larger dimensions constituted a cluster. The gradual increment of the whole is so great as to augment the mass, which protrudes from below the edges of the apron, and raises it above the rest of the shell.

Myriads of ova were dropping from the mass on the eighth and ninth of January, as the Canrer monas does not deposit its spawn, like many animals, on extraneous substances. While still adhering in its place, the skin of the capsule grows thimmer and thinner, it partially exposes the contents, and finally bursts, fig. 7 , to discharge the foetus, figs. $8,9,10,11$.

Many of the young were hatched on the 12th of January; their farther multiplication followed for some time. At this early stage they are extremely minute, nor bearing the slightest resemblance to the form of the parent, neither, unless having watched their progress incessantly, could I have credited their origin. All are of light grey colour ; the body rather globular, with a flattened tail, somewhat resembling that of a lobster, consisting of six or seren evident articulations, and a forked extremity. The feet are indistinctly discernible. A long spine, wanting in some, rises from the back of others.

Un fortunately these young animals are too delicate to remain the subject of permanent observation. Similar facts to those above specified have been repeatedly witnessed on other occasions; but I have been always disappointed in the occurrence of those metamorphoses which would have shewn their advances to perfection.

Such remarks, however, are not to discourage other naturalists, who will ever find the Cancer menas a convenient and suitable subject for elucidating the properties of its genus. 


\section{Plate XXXIV.}

FIG. I. Cancer moenas, the Shore or Harbon Crab. Young specimen.

2. The same, haring cast its shell, now shewing only one white spot instead of three patches previously there.

3. The same, having again east its shell, which has come in uniformly green, the white spot being obliterated, and the shell now considerably larger.

4. Cancer manas, reddish-brown specimen, with a white limb.

5. Portion of its roe or spawn, consisting of full and empty capsules, enlarged.

6. Empty capsule detached, having discharged the fotus.

$7,8,9,10,11$. Young prodnced from the roe of fig. 5 .

\section{Plate XXXV.}

FIG. 1. Cancer manas, fomale, taken on July 22 ; delineated July 27.

2. The preceding, fig. 1, east its shell on the first of August, but the new subject was not then delineated. Inother exuviation ensned on 25th October, leaving the empty shell, of which this figure represents the breast, and the next figure the back.

3. Back of fig. 2.

4. New subject produced by exuviation of figs. 2,3 , on the 25 th of Oetober.

\section{Plite XXXVI.}

Fig. 1. Exuviation of the last figure, Plate XXXY. fig. 4, having taken place on 24th May, 210 days after that of 25th October, this subject, fig. 1, was produced. Back.

$\therefore$. Breast of the same.

These figures were not delineated until eleven months had elapsed from the date of exuriation on May 24.

3. Ova or capsules.

4. Ova or capsules.

\section{Plate XXXVII.}

FIG. 1. Cancer manas. Toung specimen, white, with red eyes.

2. Young specimen, body redlish-brown, limbs greenish.

3. Specimen defective of one claw, the right. 


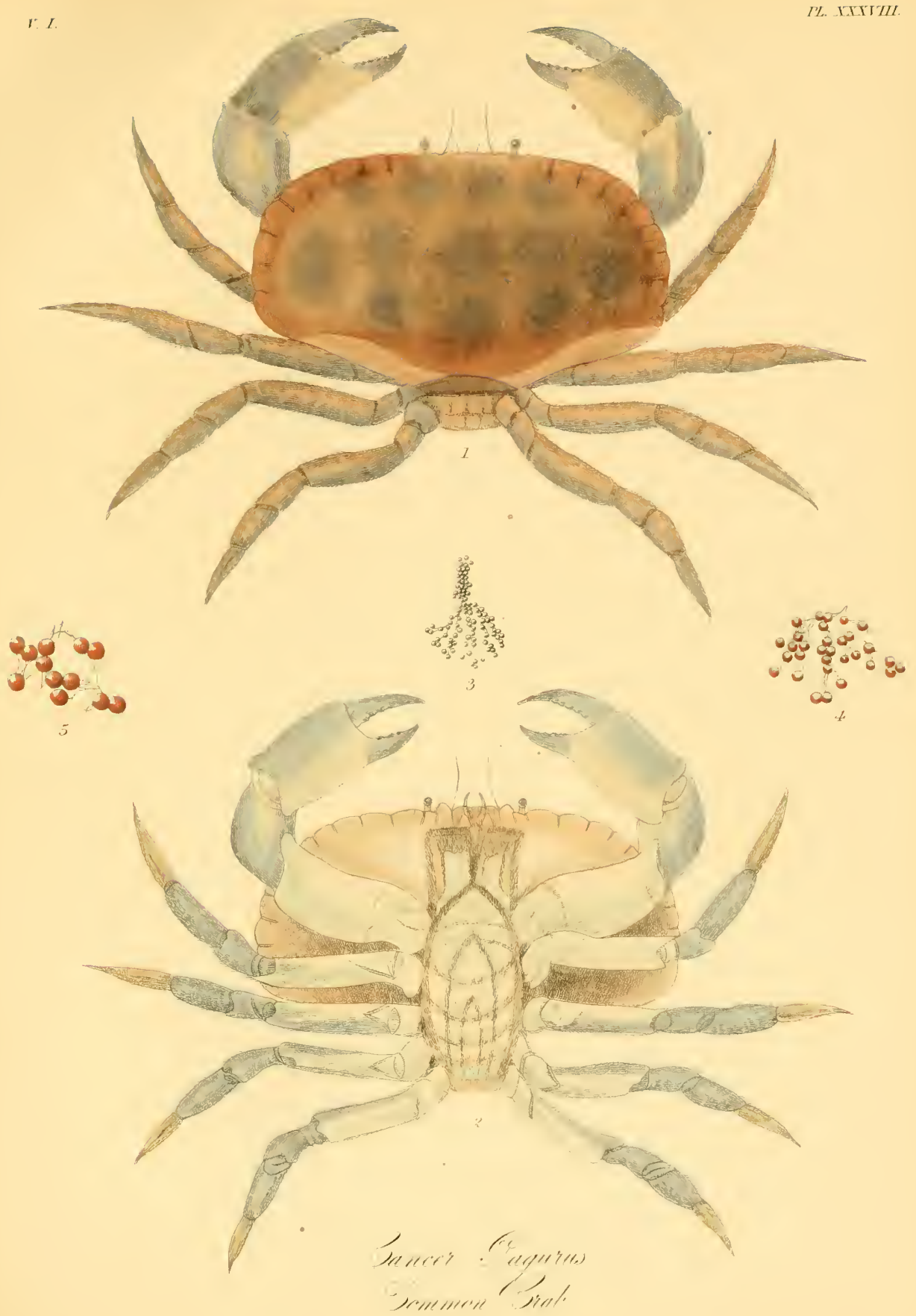





\section{Plate XXXVII.}

F1G. 4. The same, having cast the shell, now come in with the defective claw entire.

5. Specimen mutilated of four limbs, and a pincer of the left claw.

6. The same, after exuviation, all the defective parts having come in entire.

7. A specimen having been mutilated of one claw and four limbs, cast the shell, which is represented by this figure. Back.

8. The same, cast shell. Breast.

9. The specimen affording the preceding, back and breast, figs. 7, s, now reproduced entire, with all the parts.

\section{A.-§ 2. Cancer Pagurus-The Common Crab.-Plates XXXVIII., XXXIX., XL., XLI.,-LXX.}

This is an animal so well and so universally known as scarcely to require description. Yet rery few are acquainted with its real nature, or are conversant with any material points of its history.

The former species is most familiar in its earlier stages, the present only in its latest growth, that is, when in maturity. The former species also is disregarded almost everywhere, it seldom serves for subsistence ; but the latter is profusely consumed as food by all ranks and classes of people, and in certain places only the more delicate parts preserved, while the rest are thrown away, abundance rendering them of no value, as already signified.

The common crab is one of the largest of the Scotish Crustacea ; nor is it inferior in other parts of Britain. Its dimensions seem entirely dependent on age and the place it inlabits, attaining; according to report, the unwieldy size of twelve inches between the limbs across the back of the shell, and weighing a number of pounds Bnt here if, instead of twelve, specimens measure only six or seven inches, they are deemed full size, and if eight, they may be accounted large.

The dimensions of such rapacions animals must always depend on the profusion of subsistence. But in calculating these dimensions, 
peculiarities are involved, especially the change of the shell, whereby they are entirely regulated.

The common crab is both the largest bodied and the strongest of its genus pertaining to Scotland. I have heard some vague accounts of another, described as exceeding its size, but, considering the prevalent exaggeration of facts not to be immediately verified, and especially relative to marine products, I do not feel much disposed to rely on such assertions. Nevertheless the limbs of the Cancer homidus, as we shall see, certainly expand farther.

This species, the Cancer pagurus, is more of uninterrupted oval form in proportion than any of the others; the claws stronger, perhaps, and the limbs shorter ; the apron, also, is narrower than that of the rest of its family here described, the Cancer manas, Cuncer' or Portumus liridus, and the Cancer or Portunus pusillus. Nine prominent flutings, commencing with each eye in front, border the shell. The eyes are sustained on peduncles considerably apart, rather low and small, and between them a pair of litrger and a pair of smaller antennæ. Three of the flutings are on the margin of the shell, opposite to these organs. The surface of the shell, finely granulated, is of a reddish bromn colour, and the tips of both claws jet black, a strong and decisive feature.Plate XXXVIII. fig. 1, upper surface ; fig. 2, under surface.

When ronsed by lunger, the Cancer pagurus is fierce and rapacious. Regardless of superiority in size or in strength, it springs on whatever it desires to render a prey ; and feeds greedily on all animal substances, whether living or dead, fresh or putric. Everything is seized and devoured, and the stomach being very capacious, considerable quantities are consumed at a time. Nothing is rejected, and the repast is repeated frequently. In common with its tribe, however, it is patient of abstinence, ceasing to feed before exuriation, and sometimes after it. I could not ascertain that a small specimen, received through the favour of Dr Duguid, a learned naturalist, from Kirkwall, fed for a complete montl or longer. In the course of another month it devoured a shrimp.

But this species, apparently strong, is alike delicate as others; 

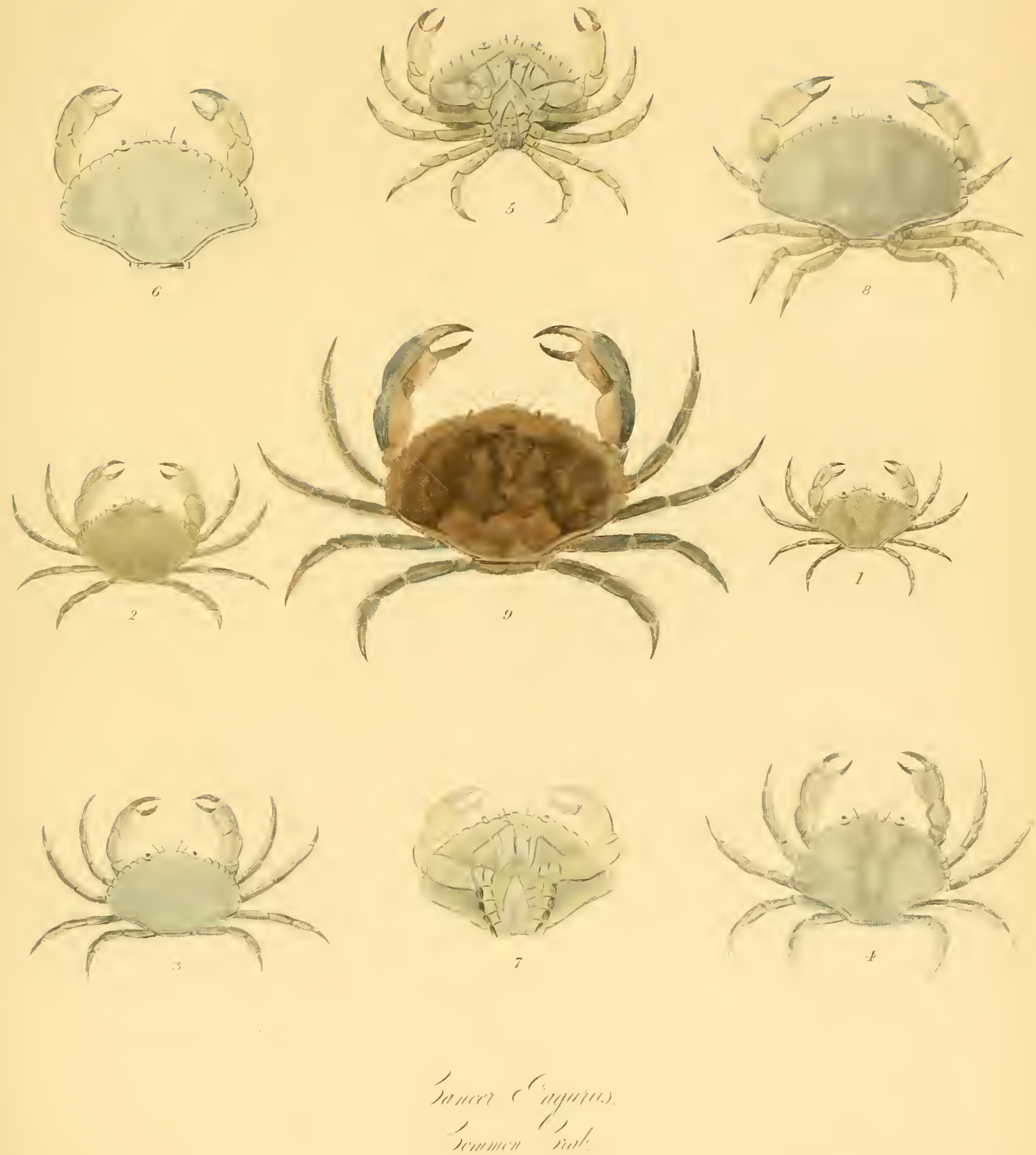

whence, the vessel containing specimens designed for permanent observation, must be carefully emptied and replenished within a few hours after feeding; or the specimens should be transferred to different vessels, which is safer,-repeating replenishment next morning, or sooner. Frequent inspection of all snch captives is indispensable.

Individuals of the Common Crab, when alone, become very tame and tranquil ; indeed, they seem to be among the tamest and most tranquil of the tribe;--whence, for a long time, I was induced to think them of very pacific nature. But four small ones having been committed to the same vessel, I was then undeceived by discovering that one of them had been devoured by a companion, two of the four being larger than itself. Ou the same day, I found the smallest of the three survivors in the fings of the largest, which was more powerful, nor could I rescue it without the loss of several of its limbs.

This mutilated subject being shifted to another vessel, it was with some surprise that I saw it immediately begin to feed on portions of mussel which I supplied.

Now, it proved to have undergone an extraordinary mutilation. Seven of its ten external organs were actually gone; for only the two claws and the posterior right limb remained. Nevertheless, these were entire, and next day the animal seemed quite well,-consuming the remainder of the mussel beside it. The mutilation occurred on October 20th, and delineation followed on the 3d of November.-Plate XLI. fig. 1 , back ; 2 , breast.

This incident afforded ample evidence, that notwithstanding the pacific disposition of the species, presumed from apparent tranquillity, the weak were not to be trusted in the society of the stronger.

Ninety-four days after mutilation, the victim cast its shell. The new animal came in very pale, almost white, and what was more remarkable, with the whole complement of ten limbs entire. Those corresponding to the seven which had been deficient, seemed to me somewhat under the natural size. The posterior limb on the left side, corresponding to that mutilated, was smaller than its fellow on the right, 
whose original had escaped. This renovated creature was delineated the day after exuviation.-Plate XLI. fig. 3. It died in April.

The history of the assailant of the mutilated animal, which had committed such injuries, is afterwards given in detail.

Two small specimens having been together, I observed, on October 30 , that the larger, which was nearly white, had mutilated its lesser companion, not only of both claws, but of six limbs in addition, leaving only the first on the right side, and the second on the left, Plate XLI. fig. 1. Thus, eight of the ten external organs were deficient, while the remaining two seemed to be injured. Nevertheless, the animal fed when offered a fragment of mussel, though incapable of turning itself if supine. Three days afterwards it was quite voracious.

I preserved this mangled creature very carefully, contemplating the solution of several points still enigmatical, should it survive exuviation. Matters advanced propitiously enough for some time; the animal fed on the $23 \mathrm{~d}$ of December, but it died during the night of the $24 \mathrm{th}$.

Yet this did not seem in consequence of its wounds, from the evil effects of which it had certainly recovered. But the period of exuviation was at hand, and the apparent immaturity of certain parts preventing their liberation, while others wore completely ready, and actually protruding for escape,- - the death of the creature ensued.

What I could see on this occasion, led me to conclude that all the limbs of the new animal, while in the original shell, lay folded across its breast.

It was of some consequence to determine the precise fact, not only as elucidating the truth, but as confuting the prevalent opinion of new limbs shooting from the old in one case, and being derived from so many sheaths in another. I have already shewn the improbability of papilla originating from mutilated stumps to announce reproduction. In such enquiries, however, there is scarcely any direct means of verification to be adopted, farther than patiently following the course of Nature, and awaiting the issue of observation.

Thus, the assailant of the preceding specimen, that had unluckily perished, had been preserved for some time previously. It was then 
very pale ; and five or six weeks after coming into my possession, it was delineated white, on November 3.-Plate XXXIX. fig. 1.

Such specimens are rare. I have never seen any, unless of small dimensions. However, they survive as readily as others, and possibly live as long; but whether attaining full size, without the wanted modification of colour, is doubtful. No one informs me of having seen a large Common Crab white. The aspect of such specimens, in their earlier stage, is different from that of the ordinary appearance, as may be seen from fig. 9, which is introduced here for the purpose of contrast.

The specimen, fig. 1, had been taken on the 29th of September; it mutilated its companion on the 20th of October, without any symptom of itself having suffered. Rejecting food on the Sth of November, it cast its shell on the 9 th ; when the new animal came in, larger than before, and still paler, being now almost white, fig. 2. Its next exuviation was on April 30th, when the new shell coming in again somewhat larger, was still pure white, of soft and delicate aspect.-Fig. 3.

It is surprising to behold a creature of ample size, with which we are familiar, presented in miniature among many of its kind of darker hue, but by exception clear and polished, and white as the drifted snow. The difference at first sight is unaccountable, - so great and irreconcileable, that the spectator will pause in allowing their kindred.

The shell now subsisted from April 30, until September 12, when exuviation produced another considerably larger than previonsly, of the purest white, so clear and transparent, that the place of the interanea, or the organs confined within, shone through its refined substance. The old one remaned quite entire, that is without gaping, or any evident separation of the line of union between the hind pair of limbs, whence the new shell had issued. All the different parts besides remained as usual in their own proper position. Delineation of this subject was postponed until November 10 , or about two months; whereon it may be remarked, that although no sensible enlargement of the animal ensues, some slight natural or accidental alteration is usually perceptible. It is generally of trifling importance.-Fig. 4.

In regard to colour, I viewed the preceding facts as satisfactory 
evidence, that the shell of the Cancer pagurus may be repeatedly generated with scarcely any deviation from its original quality.

The first drawing, it will be observed, had been executed on the $3 \mathrm{~d}$ of November, fig. 1 ; and the last on November 10, or with the lapse of above a year.-Fig. 4 .

But the animal continued still growing, and it cast its shell for the fourth time on the 29th of March following, in the second year of its captivity, or above 500 days after the period of the first delineation. Yet no colouring matter was visibly incorporated with it.

The under surface of the empty shell, cast on March 29, was admirably and faithfully delineated after the new animal had left it.Fig. 5.

But a singular fact was betrayed on this last exuviation. The new specimen, as I must still call it, now produced from figs. 4, 5, was defective of the whole eight limbs. It had a strange appearance without them. Only the two claws, both tipped with black were present, the other eight were totally deficient. The rest of the other parts, all except the tips, were beautifully white.

I did not at first observe this extraordinary deficiency, the creature was so very tame and tranquil ; it rested on the breast, but being accidentally reversed it exposed the truth. The drawiugs now made, fig. 6 , back, fig. 7 , breast, may be compared with those preceding.

In a few days the mutilated animal fed copionsly, and continued to do so. It seemed quite well, and remained very tame. Its only peculiarity was falling frequently on its back, from inability to balance itself, for want of so many limbs.

I preserved this creature with uncommon care, partly from indulging anticipations of futurity, partly from curiosity, to determine whether my various conjectures above alluded to were sound or erroneous.

Animal life is so fleeting, exterual form so easily impaired, I was continually on the watch.

Yet these animals are well adapted for experiment, being fed and preserved with such facility.

After the defective shell investing the living creature, figs. 6,7 , had 

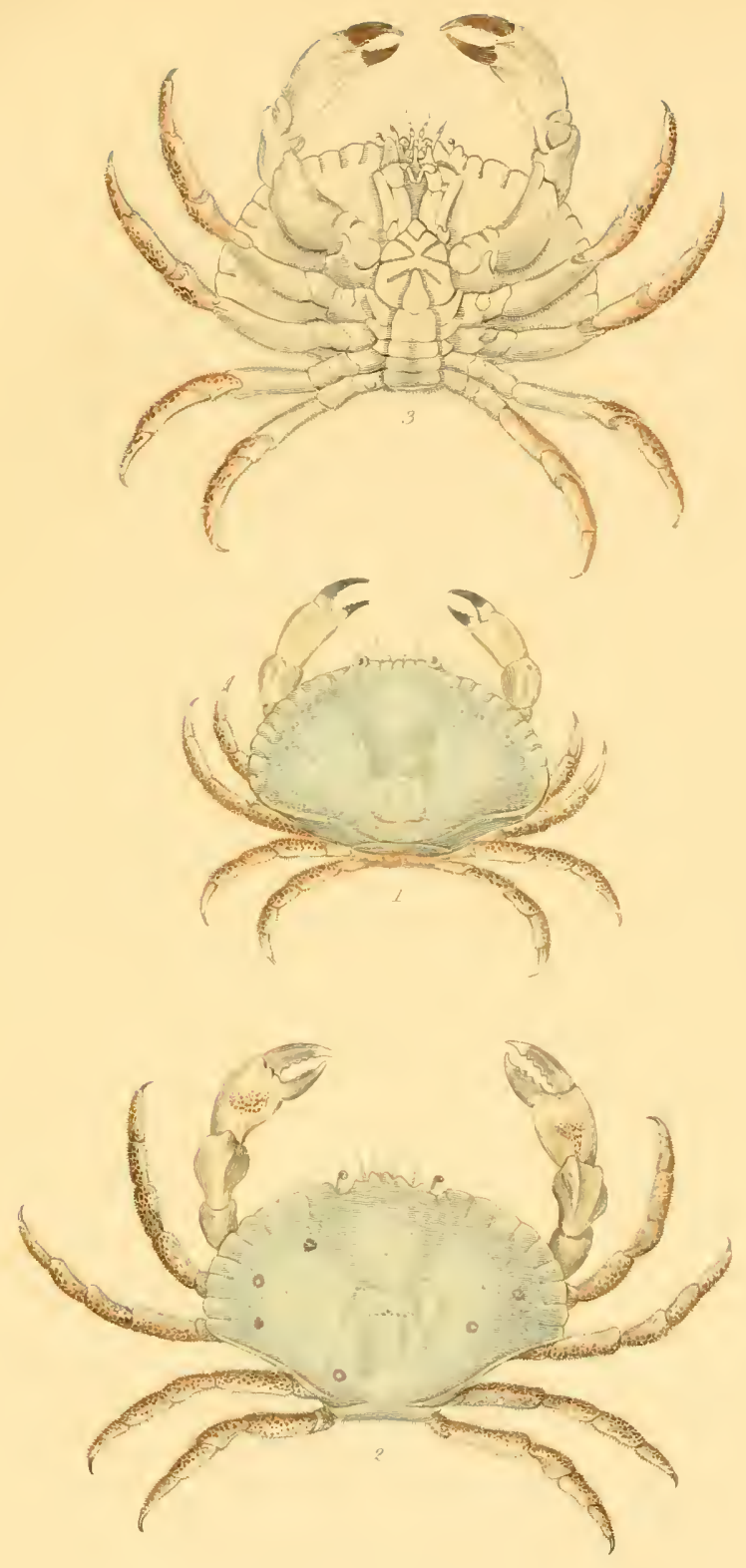

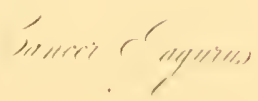



subsisted eighty-six days exuviation followed once more, on the $23 \mathrm{~d}$ of June.

What was now disclosed? A new animal, considerably larger than the old, of the purest and most delicate white, with the whole limbs entire, symmetrical, and in beautiful perfection.

I gazed on the object,--I could not behold it without renewed admiration of Nature's energies in producing her appointed works, in all their predetermined harmonious perfection.-Plate XXXIX., fig. 8.

This exuviation plainly proved, in confirmation of other examples, that no protrusion announcing the generation of defective organs issues from the stumps of the shell remaining on mutilation. Therefore regenerations are not by means of additions.

Yet there are some perplexing facts. If each of the new limbs be not withdrawn from a sheath, as from an old limb, according to common belief, how are the whole arranged with the body in the subsisting shell before exuviation? Can it be otherwise than folding over the breast?-In my opinion it cannot. Certainly no portion of the originating organ protrudes from the stump of the defective member. Besides, how could the bulging shell of the new claws be drawn through the narrow channels, and contracted joints of the old? On the whole, therefore, there seems no other satisfictory explanation than by admitting the concentration of the new animal and its organs within the original shell.

But how or from whence are the new integuments derived; how are they interposed so as to include the flesh of the limbs, or to contain the internal parts? I believe that skin is allowed to be derived from fleshy parts, and although the bulk of the stomach is such that it might afford some lesser secretion to invest the internal organization, the substance of the limbs seems to have wasted almost entirely away. Content with relating obvious facts, I must leave the solution of such abstruse questions to greater physiologists.

Whatever is the mode by which it is operated, if we admit that the external parts of the creature nasciturus, that about to be produced, are generated, we are relieved of all embarrassment in accounting for the re- 
production of defective members. Each member is formed entire, therefore comprehending all subordinate parts. Thus, should a pincer of either claw be defeetive, it will be generated and produced on exuviation along with the whole claw ; should the lind pair of limbs be wanting, they are generated in the dormant subject lying in the old shell, and will be produced as parts of the new subject in the new integument. But no new additions will be generated to restore the symmetry of the original parts.

The cast shell contains nothing, it is an absolute vacuity.

Although the integument enclosing the stomach may be possibly derived from some internal coating of the carapace, or some secretion may originate from that source, I do not see how the like can be expected from the old limbs, or, if it could, how it would fulfil a similar office. Neither is it evident that the shell of the limbs is derived from their own contents, though certainly most probable. The new animal is always larger than the old, which rather confirms the opinion maintaining that the original integument is soft and compressible before hardening as a shell.

I have said much of form, but hittle of colour, a subject not devoid of interest. The colour of the common crab seems to be always a shade of reddish-brown when in perfection of the adult. That of younger specimens is somerwhat rariegated, as may be seen of the different figures in the plates. All are probably advancing progressively to the ordinary colour. I know well that little confidence is to be reposed in colour, and how much it is undervalued by naturalists. Nor am I aware that it ever denotes peculiar permanent properties.

It may be affirmed that, until attrining the final hue, the shell is continually undergoing some modification. Thus the specimens, Plate XLI. figs. 5, 6, 7, all of nearly the same size, were delineated within a month of each other. The specimen, fig. 5, was originally brownish, very faint. On casting the shell it appeared pure white, with a purplish tinge. Its next exuviation produced a pure white shell, which was followed by another in five or six weeks, darkening very little until the animal clied two or three months later. The specimen, fig. 6, tended first to brownish, then 
to purple, with bluish patches. The specimen, fig. 7, originally brown, came in purplish on exuviation. The specimen, Plate XXXIX. fig. 9, was different from the whole of these.

But returning to the mutilated specimen, so anxiously preserved, which had recovered all the defective parts on June 23d, after having been deprived of them for eighty-six days. The next shell with the perfect animal subsisted from the $23 \mathrm{~d}$ of June to the $3 \mathrm{~d}$ of October, or 102 days, when it was succeeded by one of the purest, and, as before, of the most beautiful white above; however the limbs were not equally so.Plate XL. fig. 1.

Now the animal underwent no change either in appearance or habits, further than what is always concomitant on exuviation. It was tame, tranquil, fed readily, and proved healthy.

The shell introduced to view by the change of the $3 d$ of October, perfect in all its parts, subsisted until the 10th of April. A new exuviation produced another, large in proportion, alike symmetrical and perfect, still of a fine white, but with rather more colouring and bristling on the limbs. The second year of its captivity was now advancing, and its habits continued unchanged. It was extremely tranquil, very tame and familiar, always approaching the side of the vessel as any one came near, and holding up its black tipped claws as if in expectation of food. Farther, it allowed me to lift it in my hand, without the smallest resistance, when shifting its dwelling became expedient. At this time it was proved, from the successive exuviations, that the permanent symmetry of the animal was restored from the extraordinary defects of four-fifths of its important organs.

About a month after the last exuviation, the vessel containing this specimen, when standing on a table, covered by another glass vessel, was accidentally overturned on the floor of an apartment, and both shivered to fragments. The animal was stunned; yet $I$ entertained hopes of its impunity from real danger. It fed subsequently; nevertheless serious injury had been sustained, for I found it dead on the 16th of May.

I could not help regretting the loss of what had been so long the subject of so much care, and fiom which I had derived such information. 
It was an interesting creature, as if a little dumb companion, having nevertheless had always something to impart.

The preceding specimen survived just about two years and eight months. It had borme eight shells, and had undergone seven exuviations. All while under observation.-Plate XL. figs. 2, 3.

Perpetuation.-The common crab is one of the most fertile of its tribe. Indeed, were it otherwise, the extinction of the species might be expected with some reason, from the incessant persecution it is exposed to.

The quantity of roe borne by the female is incredible, and the multitude of the offspring far exceeds any probable computation. Did all attain maturity, and propagate in their turn, there would not be sufficient space unoccupied in given bounds for the existence of other animals.

The common crab begins to breed at a very early period of its life, during the greater portion of which it probably continues. An ample profusion of roe elevates the apron while the growing parent is yet of very moderate dimensions, which in its origin is very pale, almost white, or faintly yellow.-Plate XLI. fig. S.

The season commences with the earlier months of the year, the roe advancing in March and April, also in May or June, as well as more irregularly at other times; that just referred to appeared in October.

As the roe matures it is converted to fine vivid vermilion. That of a specimen, seven inches broad, was in such quantity as to raise the apron four inches in the middle of March. The ova or capsules were in millions, still very small, and requiring some time for attaining maturity.

In this state it exhibits a solid mass, which on extrication is found to be composed of numerous clusters of capsules or ova, that aggregated individually, that might occupy so many hollow cylinders.Plate XLI. fig. 9. A cluster, under the microscope, resembles a bunch of beautiful ripe fruit, not unlike red currants. The clusters are less luxuriant than the roe of several other species described here, the capsules being more dispersed, nor alike concentrated, as will be seen of the two following species.-Plate XXXVIII. figs. 3, 4, 5.

Neither is the roe so easily obtained. The female common crab being unmarketable while in roe, the fishermen avoid taking them ; and 

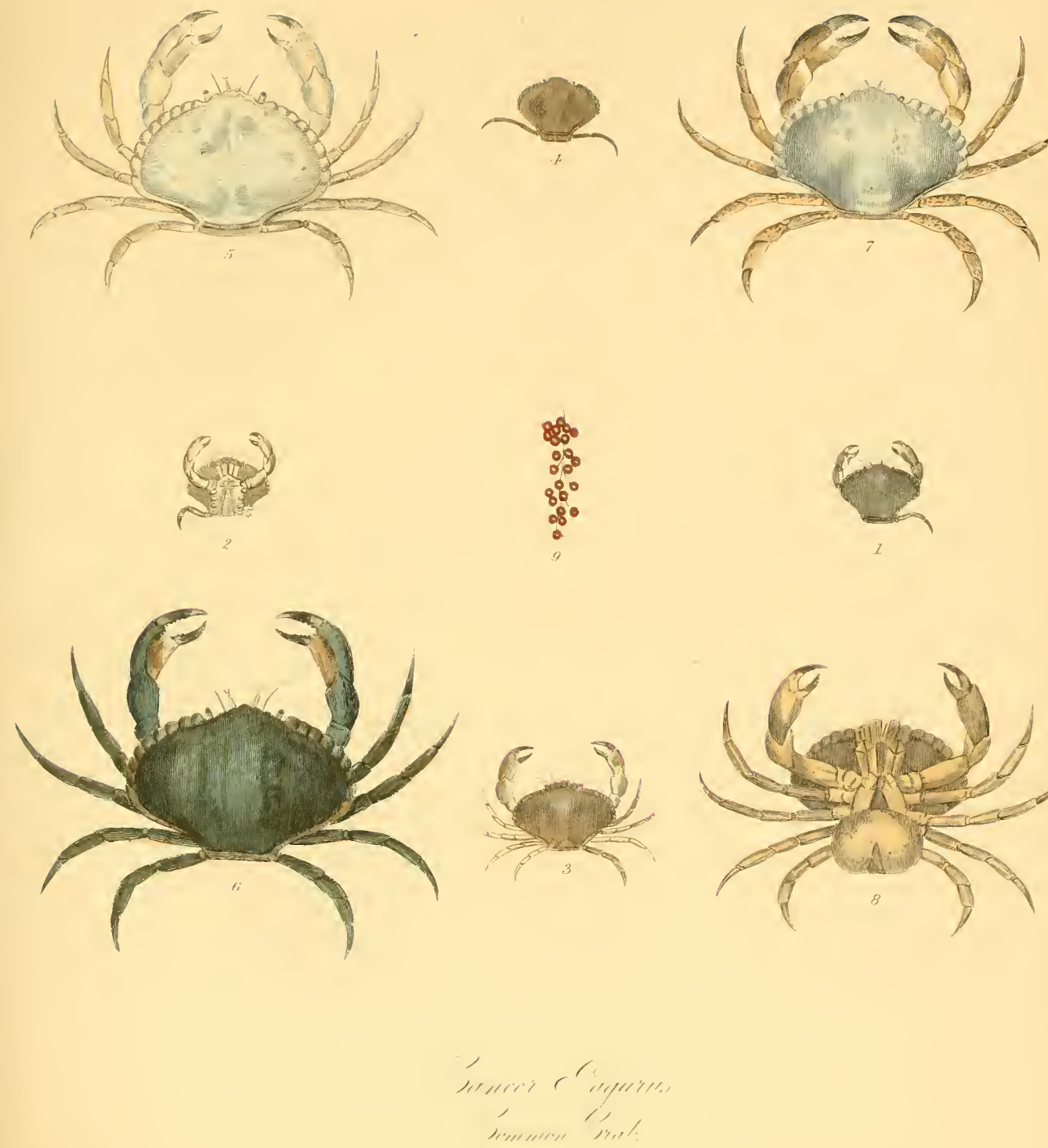

if specimens are causally brought ashore, they are always so maltreated, that I cannot affirm I have ever witnessed their survivance for anylength of time, to bring the roe to maturity. Therefore, it is chiefly from younger individuals that we can look for satisfactory results.

As the ovarium swells, the anxiety of the parent for its preservation from injury, becomes very evident. When elevating the apron or breastplate, it is kept free of external pressure, by the creature continually standing on the limbs, and rising higher and higher to avoid contact with other substances below.

Hence, it will be observed, that the capsules are not deposited, but burst like the former, while attached to the parent, for escape of the young. These are of the wonted form, resemble the preceding, nor are distinguished by any peculiarities.

The crab-fishery seems to be neither a lucrative nor a favourite employment in Scotlind; and, although many are occupied in it, ehiefly on a small scale, it appears to be always deserted when other branches of such marine pursuits occur.

\section{Plate XXxvili.}

Fig. 1. Cancer pagurus, the Common Crab, back.

2. The same, breast.

3. Cluster of ova, natural size.

4. Portion of the same enlarged.

5. Portion more enlarged.

Plate XXXIX. History of a white specimen.

Fig. 1. Cancer pagurus, young, taken 29th September.

2. The same, after its first exuriation in eaptivity, on November 9.

3. The same, after exuviation on April 30, following November 9 .

4. The same, after a third exuviation, on September 12. Back.

5. The same, Breast.

6. The same, after a fourth exuviation on Marel 29, following Nov. 12, when the whole eight legs proved deficient. Back.

7. The same, shewing the deficiency. Breast.

8. The same, after a fifth exuviation on June 23, when all the parts were restored entire. Back 
Plate XL.

FIG. 1. The same, after a sixth exuviation on October 3. Back.

2. The same, after a seventlı exuviation on 10tls April, after October 3. Back.

3. Breast.

\section{Plate XLI.}

Fig. 1. Cancer pagurus, small spceimen, mutilated of seven limbs on October 20. Back.

2. The same. Breast.

3. The same, after exuviation in 102 days, all the defective limbs having come in entire.

4. Cancer pagurus, which perished after mutilation.

5. 6, 7, 8. Cancer pagurus, young. The last full of spawn.

A specimen somewhat older is represented Plate XXXIX. fig. 9.

9. Cancer pagurus, roe.

Plate LXX. Supplemental.-Miscellaneous Crustaceans.

FIG. 1. Cancer pagurus, monstrous claw.

\$ 3. Cancer (portunus) Lrvidus-The Flying Crab.-Plate XLII., LXX.

The two preceding subjects afford a mass of valuable illustrations in the history of this section of the Crustacean race. I have united them in the same paragraph, wherein I mean to include also the present and the following articles, because none of the whole are distinguished by such important peculiarities, as to render a separate place for each essential. On the contrary, as we shall see, they are united by the strongest ties, as cxlibited in various definite features.

All that comes from the hand of the Creator is orderly, and consistent with the harmonies of nature. The Supreme Intelligence has assigned to everything its own proper place and position in the frame of the universe, whether it precedes, whether it follows that which is of its 

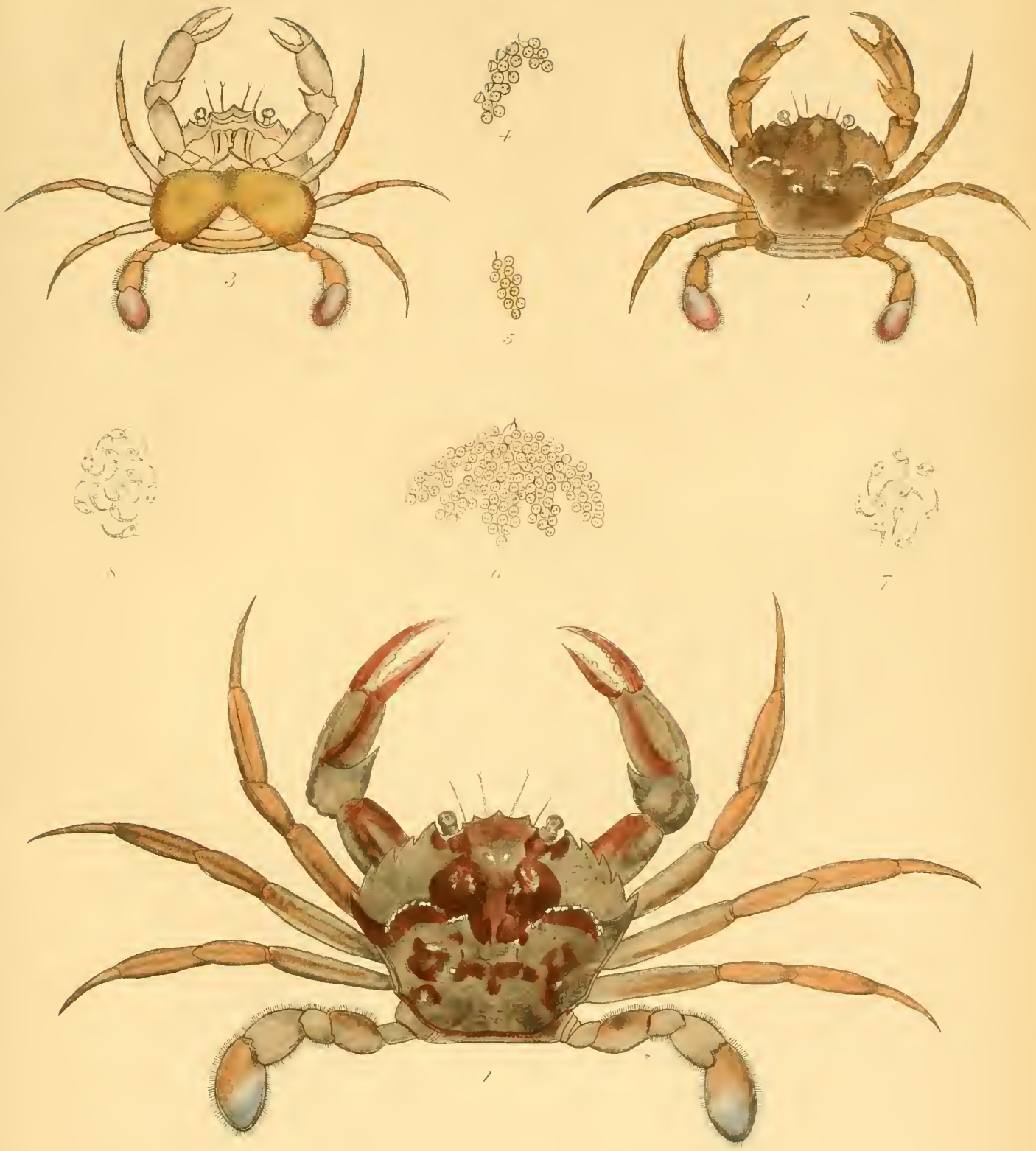

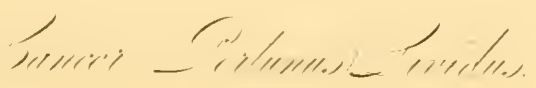



nearest kindred. It is we, however, who spread confusion, who know not the origin of order, or whether what we behold is designed to be temporary or permanent.

Tet how grateful ought not we to be to the Author of symmetry and perfection, those two qualities binding the world together, for the faculties whereby we are enabled to discover the grand basis of universal harmony in a common bond of union. We, who are so liable to be overwhelmed by sickness and sorrow,-whom personal infirmity bows to the earth, are nevertheless permitted to contemplate the marvellous products of Heaven,- - to conjecture their ends and purposes, and thence to determine in our own mind the bonndless porrer of Omnipotence. How is our gratitude for such ineffable favour to be shewn? how shall we bear record amidst the action, the infinity of time and space, elevating each succeeding thought and reflection to the will of the Divine Author?

Let us pray the Father of mereies to permit our swelling breasts to heave with adoration of his indulgent favour to ourselves, and the olyjects of our preference.

Nothing can be more desirable than to complete the plan we are now following, in the classification of such animals as bear a reciprocal resemblance, and their subdivision into smaller sections, when allied by common features; for, by this means, they may be easily recognised, and their position adjusted.

Yet it has never been distinctly laid down where or how the commencement of a genus introduces the student to its discussion. Therefore we must still submit to considerable inconvenience, rectifying it progressively where opportunity admits. We must summon the aid of all auxiliaries, rejecting the fashion of some observers, in precipitately concluding that their own comments are not only the latest, but the best.

The Portunus lividus is a very beautiful and symmetrical animal, decked in lively colours; and is to be viewed as among the finest specimens of the Cancer tribe of moderate dimensions.

Recollecting the various diversity of form and arrangement belonging to each different animal, there is little to restrain its separation from 
the neighbouring genera, to which it may not be inconveniently attached as an appendage.

The shell, when nearly full grown, may be circumscribed by an ellipse of two inches by an inch and three quarters, the feet expanding seven inches. Nearly the same proportions prevail universally in those of all dimensions. The eyes and antennæ much resemble those of the preceding Crabs. The former, sustained on stout peduncles, fold laterally from the root into cavities on the edge of the shell, the two forked antennx, within two of setaceous form, are in constant motion. The exterior edge of the shell, behind each eye, is serrated by five teeth, and three others are on the marginal portion in front between the eyes. A large spine rises from the second joint of each claw, besides which are some smaller spines. The extremities of the posterior limbs are of an oval form, the external articulation as if divided also by one of flatter shape interposed,--whereby the animal is enabled to spring vigorously through the water, and is thence denominated the Flying Crab by fishermen.

The flattened portion is finely and completely fringed.

The shell of this animal is stained by various colours, red, blue, and white, modified on the back in numerous shades, forms, and intensities. In fine and beautiful constrast, the under surface is universally of pure and delicate white. Two crescents of minute white specks, much resembling the form aud appearance of a pair of spectacles, are always seated on the upper surface of fine specimens. The animal is seldom seen of uniform colour; it is variegated. The symmetry of the whole shell, and its various parts, are admirable.-Plate XLII. fig. 1.

This is a lively creature ; it springs suddenly on its prey, though not so fiercely as the Cancer manas. A great quantity of food is devoured at once, and the animal is erer realy to feed, crouching down in quiescence after a voracious repast, wherein all other animal substances are acceptable.

Perliaps, from its conformation, the Portunus licidus may resort to deeper water. It remains always completely immersed in confinement, never testifying the desire betrayed by other specimens, of quitting its element occasionally, or indifference at continuing a short time dry. 
Perhaps, from this reason, it scarcely ever proves as tame as the rest. But I have often remarked that those specimens seldom exposed to view are wilder than those never in concealment.

This is one of the most prolific of the tribe. It breeds at various seasons of the year. In April and May, in particular, the female is laden with roe, which $I$ have also seen in profusion late in November.

No distinction, whereof I am aware, either in form or colour, is peculiar to either sex, unless the remarkable dimensions of the females swelling apron. So wise a provision of nature for protection of the young is manifested by the wonderful care of Omnipotence. The apron is sometimes elevated so much by this preparation for preservation of the race, as to form a right angle with the under surface.

These are most beautiful and wonderful arrangements, whether from the symmetry, colour, or position of such enormous quantities of roe as are brought to maturity. Now the animal appears somewhat distorted, until the restoration of its form ensues by dispersion of the spawn.Plate XLII. fig. 2, back ; fig. 3, front.

The profusion of roe in one, as well as its progressive increase, were extraordinary, insomuch that, although the apron was elevated perpendicularly, and I am figuring the specimen reversed, I say that, although rising to form a right angle with the front on the 8th of November, the mass still continued enlarging, with the apron turned back, nearly on a level with the upper surface. It did not lose its paleness, however ; and being invested by a thin mouldy film, the specimen died on the 27th.

This female was of a very dull eolour, tencling at last to brownishgreen, of which I once saw another iustance in April.-Plate XLVI. fig. 1.

A consiclerable time before maturity the spawn appears a fine yellow or orange conglomerated mass of spherical ovi ; but the colour fades with its adrances, and the component parts of the mass relax, when they resemble luxuriant clusters of fruit; portions are represented in different stages.-Plate XLII. figs. 4, 5. A cluster of 117 mature capsules, delineated on May 21st, is seen in fig. 6. Thousands of young were discharged in three days from the ample ovarium affording this beatiful 
cluster, but in two days longer the parent died, as if unable to relieve itself from such an oppressive load. Some mucor, besides, was afterwards discovered on part of the roe.

The density of the mass refines gradually with time as it relaxes in clusters, and the capsular integument is extenuated, so as to expose the included young. Next it bursts, to allow the escape of its mature contents.

The multitude of young discharged from a prolific parent is very great, the spawn still adhering to the shell as in preceding examples. Also, the contents totally void of all resemblance to the features of their kind, are very minute, not exceeding half a line in length, the anterior part large, the rest slender. Some have a clorsal spine, like the thorn of a briar, which, however, is for the most part wanting, but all have two red eyes, and the body is speckled under the microscope.-Figs. 7, S.

The young animals are extremely lelicate, and very short-lived; it seems impossible, notwithstanding every precaution, to preserve them during any metamorphosis that may lead to their ultimate form. One fact, worthy of notice, common indeed to all this section of the Cancer tribe, is exemplified here: while an excessive profusion of roe impedes the action of the female, instinct induces her to rise higher and higher on the limbs, as if on tiptoe, to keep it always safe from pressure ; this is obviously the more essential, as the roe is never deposited.

But on some occasions the parent seems desirons of relieving itself of certain portions of the spawn, whether to lessen the inconvenience of such a burden, or from its approaching decay, and this it can easily do by means of its pincers.

A vast quantity of loose minute white globules covered the bottom of a vessel containing females on the Sth of March. None proved to be prolific. Nor has it done so when occurring in the same manner on other occasions, though carefully treated. Even where the mass of roe is prolific, numerous single expsules are detached by the parent, and I apprehend that entire clusters are also separated.

At all times clusters of roe may be severed with scissors, for observation, without the parent suffering any injury. The whole attains maturity particnlarly in May. The two groups of young represented, 

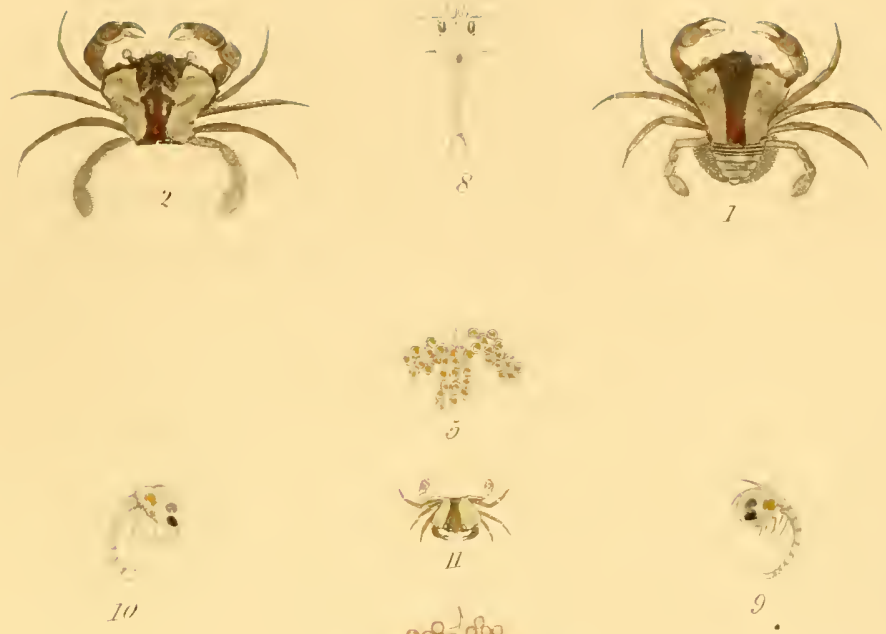
0.808 fin
00006 of
$0 \%$
6
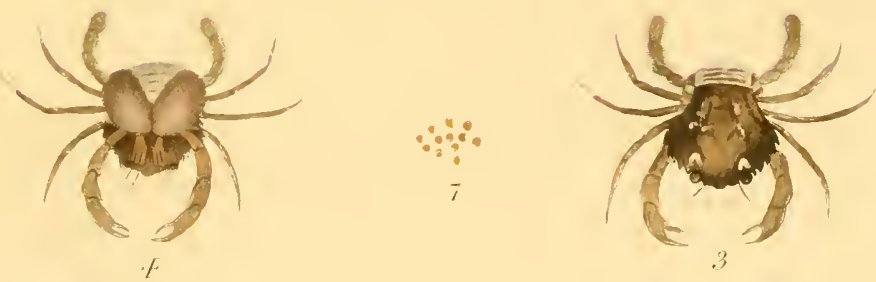

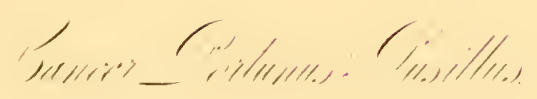



figs. 7,8 , were delineated on the 20 th of that month. Many thousands were hatched from the roe of a prolific female on September 25th, and others continued escaping until October 15 th, when the remaining capsules had disappeared.

This animal seems less contentious than some of the race, though the males are always prepared for warfare. The females, however, dwell together in peace.

The moderate dimensions, and easy preservation of specimens, adapt them particularly for the study of the naturalist.

\section{Plate XliI.}

F1G. 1. Cancer (portunus) lividus, male; baek.

2. Prolific female; back.

3. Same, under surfaee, shewing the spawn.

4. Cluster of full and empty eapsules; enlarged.

5. Cluster of eapsules; enlarged.

6. Cluster of 117 eapsules, nearly mature; enlarged.

7. Young from the eapsules; enlarged.

8. Young from the capsules; enlarged.

Plate LXX. Supplemental.-Miscellaneous Crustaceans.

Fig. 1. Portunus lividus, apron of the male.

2. Apron of the female, external surface.

3. Ovariun of the female, nearly mature. Retaining organs, $a, b$.

4. Detaehed ova.

\$. Cancer (portunus) Pusillus-The Sand Crab.-Plates XliII., XLIV.

According to the plan now proposed, I would rather design to hold the Cancer pagurus, or Common Crab, as the principal subject here, and the subordinate paragraphs as accessories. Whatever inconvenience this may be attended with, it will be at least productive of simplification. 
In the discussion we have already treated of three species, where the hind limbs are so fashioned as to prove auxiliaries in swimming. In fact, the last now remaining, is a beautiful image, in miniature, of that which precedes it. This will enable us to avail ourselves of considerable abbreviation, though neither that, nor subdivision, may be sufficient. Form and habits are for this the most effectual guides to assign them their proper place in the Systema Natura.

The Cancer pusillus is one of the smaller Crabs belonging to this section of the Crustaceans. The body broadens about an inch betreen the margins next the limbs, or across the shell, where the limbs of larger specimens are about two inches asunder.

The form of the shell is often somewhat rudely trapezoidal, the breadth in front being double the breadth behind, which is the distance that the bind pair of limbs stand apart. The margin, from the eyes to a distance on each side, is indented by five obtuse teeth, and there are three in front; the eyes and antemne may be compared to those of the preceding species. But, it must be observed, that as the back of the Common Crab is smooth, and swells regularly, here it is indented by symmetrical depressions in various specimens. Also, the hiud limbs are broad, flattened, and finely fringed, the second árticulation as if subdivided, all as in the Portunns liridus, to which animal it bears an intimate resemblance.

It would be difficult to describe the great variety of colour, its intensity and distribution, prevalent amoug the different specimens of these pretty little animals. They are generally either light or dark, plain and uniform, or mottled. A broad triangular figure, a wedge-shaped belt or stripe, frequently crosses the back from the front of the margin, leaving the remainder of the surface light on each side of the limbs, dividing it as if into three compartments. Whaterer preclominates above, the limbs are always marbled.

Neither intensity nor distribution of colour seem to be governed by any obvious rule, whether uniformly dark, or beautifully variegated and very light.

This creature feeds very voraciously on fish, which facilitates its 
preservation; it springs on the prey, and there is good reason for believing that the weaker of the species are not spared in ease of necessity. Exuviation probably snceeds here at shorter intervals than with the others described, yet so irregularly, as to preclude all definite conclusions relative to its frequency, or the permanence of the shell.

A brown belt ran down the middle of a small beautiful specimen, dividing the white portion, which spread to each side of the margin. This it preserved a month after being taken, Plate XLIII. fig. 2 ; when exuviation introduced a new one, marked exactly as before. But this new one subsisted no longer than seventeen days. Here the animal came in very little larger than its precursor. It had been extremely shy in its previons shells; it was now more familiar, and darted through the water.

Mutilated specimens, reproducing the shell, appear with all the mutilated parts restored on exuviation. In the end of October, a specimen, whose limbs expanded two inches, had lost its claws. It had difficulty in feeding without them, for the forceps prove the chief auxiliary on such occasions. However, it subsequently contrived, by means of the remaining limbs, to bring the food up to the mouth.

In eight weeks it cast the shell, when a new one came in, quite entire, larger than previously. But I thonght the claws rather under what should have been their full dimensions. The new shell was of a brownish colour, little variegated, and the limbs marbled, Plate XLIV. fig. 1 ; shell delineated after having been cast by the new tenant.

These animals, like the others, seem to commence breeding at a very early age, and the period of their multiplication occupies a considerable portion of the year ; they are no less prolific, for a single parent is the progenitor of thousands of young.

On June 22, a specimen striped dark brown down the middle of the back, with lighter sides, bore immense quantities of beautiful scarlet roe, raising the apron very high. It proved extremely restless, and apparently impatient of confinement, nevertheless feeding readily.

On July 1, the roe still angmenting, distorted the animal's shape, by projecting the elevated apron backward; but its beautiful ruddy hue 
was gone, and paleness announcing the arrival of maturity, Plate XLIII. fig. 1. Numerous young having burst their capsules, were at this time seen in the vessel, and they were hourly angmenting.

These ereatures appeared of light grey colour, with black eyes, a large body, a dorsal spine, and a long tail. A yellow substanee occupied the body, perhaps some residuum ; or the shell might be stained by colouring matter. At this early stage they sprung through the water.

A multitude of young continued escaping from the capsules, until the whole were discharged; and on the thirteenth of the month, the animal had recovered its symmetrical proportion.

Thus the roe was dispersed in about a fortnight.

Within three weeks from the first appearance of the young, while examining different living animals in the same vessel containing the subject of these observations, I was again betrayed into such an error as detailed in the outset of this section. Exuviation had unexpectedly taken place, and I was once more surprised as by the sight of a stranger animal, Plate XLIII. fig. 2 ; The new shell was much clearer and much purer than the old; the light portion on each side of the dark stripe extending to the margin, more vivid than previously. This shell was not sensibly larger than before, but the colour infinitely finer.

It will be observed that this specimen had bome an ovarium, which was exhausted before exuviation. In as far as I have been able to discover, such an important change never takes place under other conditions, but the proximity of the two incidents are unknown: they are never cotemporary. As the whole integuments separate without the smallest reserve, it is plain that exuriation preceding an exhausted ovarium, might entail destruction on the brood, whereas indemnity attends its postponement.

A small female mutilated of all but three of the legs, had been in my possession two months. In the middle of November, the roe, bright scarlet, was now approaching fast to maturity. I was anxious to preserve the animal for the result of exuriation, and to ascertain whether this event would precede dispersion of roe. Spite of so great a mutilation, it seemed to feed, but it had been so severely wounded, that it 

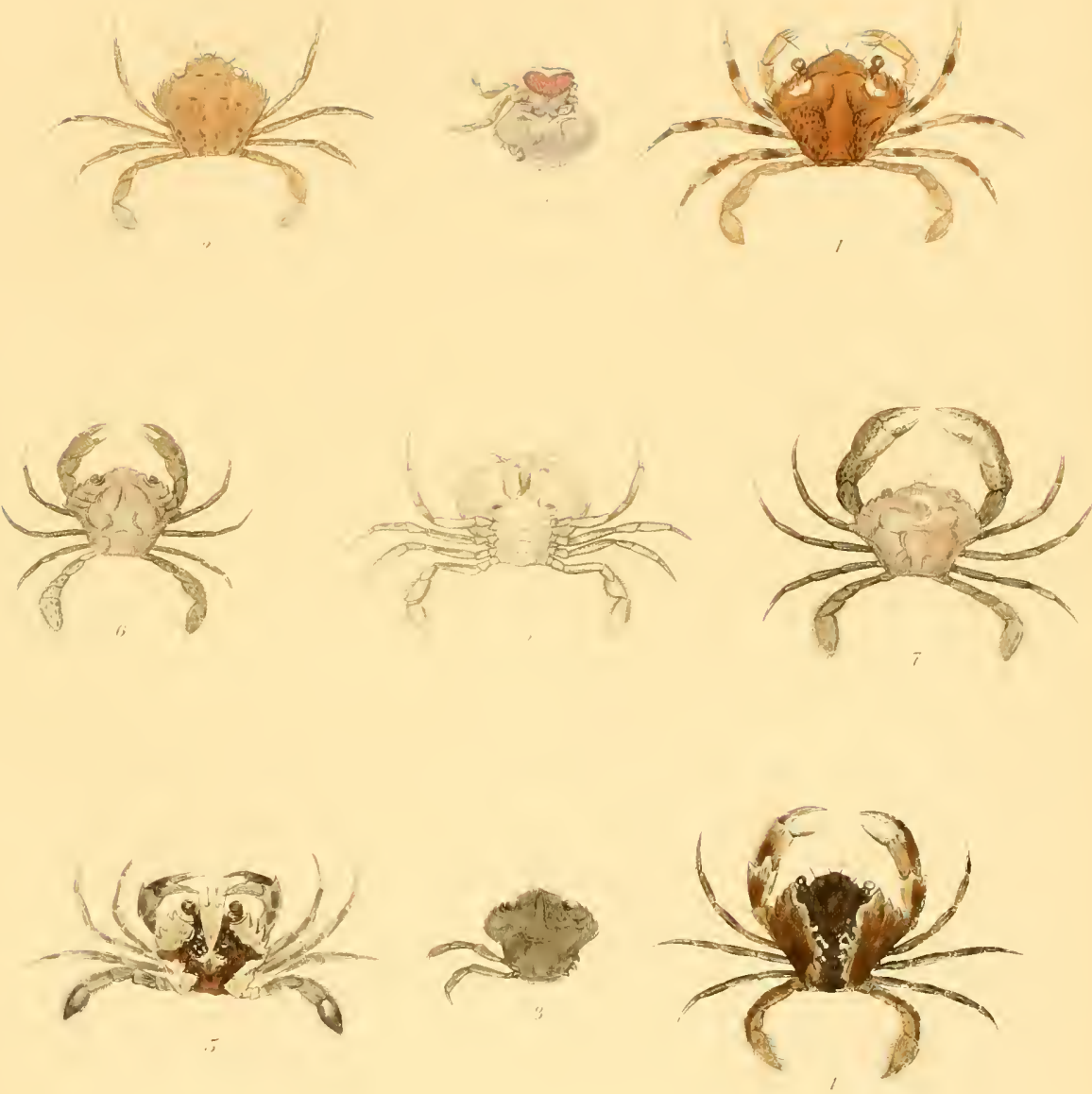

died in the close of November, without exuviation, Plate XLIV. fig. S, back ; fig. 9, breast, shewing the roe.

The shell is sometimes cast very suddenly; wherein all naturalists seem to be taken by surprise.

A small speeimen, obtained on April 8 , whose limbs did not expand an inch and a half, cast its shell unexpectedly, there being no indications of exuviation half an hour before the event. When observed, the new shell was scarcely free of the old.

At the same date, the quantity of spawn on another specimen was immense; the ova reddish, with an orange tinge, overspread half the under surface, extending to the very margin of the shell above the animal's feet, and investing all their roots.-Plate XLIII. fig. 3, upper surface ; fig. 4, under surface.

The chief breeding season of the Portumus pusillus comprehends April and May. NIany specimens are then laden with the vivid vermilion roe, fig. 6 , which fades on advancing nearer to maturity, fig. 5 . At that time detached capsules are also found in their vessels, fig. 7 . Some breed much later in the year, as in October and November, when they are also full of roe. The young, figs. $8,9,10$, were very active on escaping from the capsule.

The specimen, Plate XLIII. figs. 1, 2, which had been freed of the sparm on July 13th, and afterwards east its shell on August 6th, was invested by a white zoophyte in the subsequent month of February; the colour of the shell, whence this later product rose, had faded, yet the animal fed readily, though the zoophyte, which proved a Vorticella, with numerous branches and bells, remained. It died in March, without any other obvious cause, when a cluster of at least an liundred capsules was exhausted before exuriation.

In as far as I have been able to discover, this important change never takes place under other conditions. But, I repeat, the proximity of the two incidents is unknown. As the whole integuments separate without reserve, it is plain that other exuviation, preceding an exhausted ovarium, would expose the brood to destruction, whereas experience shews safety attends its postponement. 
When observed, I say, the new shell of 8th April was scarcely free, iudeed I had reason to doubt whether the animal had sufficient strengtl for effecting the change.

The Portunus pusillus is not alike common as many others. It seems to frequent only particular districts. It is preserved with equal facility as any of the rest ; and the observer may be assured of always deriving much amusement from it.

The intervals of some leading incidents being abbreviated, tends greatly to his convenience.

\section{Plate XLIII.}

Fig. I. Cancer (Portunus) pusillus, prolific female; back.

2. The same, laving diseharged the roe, and then undergone exuviation, now seen in the new shell; back.

3. Prolific female; back.

4. Breast of the same laden with a profusion of roe.

5. Cluster of roe approaching maturity.

6. Cluster of roe in an earlier stage.

7. Detached eapsules.

8. Young from the ova of figs. 1, 2 ; enlarged.

9. Young from the roe of another specimen, dorsal spine conspicuous.

10. Another.

11. Young specimen, whose shell, on exuviation, subsisted only seventeen days.

\section{Plate XliV.}

Fig. 1. Cancer (Portunus) pusillus, produced on exuviation of Plate XLIIl. fig. 2.

2. Specinen mutilated of both claws, cast shell, producing an entire specimen.

3. The breast of the same, east shell.

4. Specimen of unusually dark colour.

5. Lighter specimen, finely variegated.

6. Feruale of uniform colour.

7. Male of uniform colour.

8. Mutilated specimen; back.

9. The same; breast. 
§ 5. Cancer (Pinnotheres) veterom.-Plate XLV. figs. 10, 11, 12, 13.

As we have distinguished the Crustaceans by an indurated integument, it might be inferred the quality of the covering of the whole presents much similarity. This, however, would be erroneous, for beginning with what is as hard as a uut shell, we should soon arrive at what may be compared, in softness and flexibility, to mechanical manufacture. Some are tenacious withont brittleness.

But the only example occurring to me of great deviations from the ordinary principle are in two species; first, the female of the Cancer horridus, on which we shall pass no further observation at present; secondly, the Pinnotheres veterum, which merits a few special remarks.

The history of this latter animal has embarrassed naturalists, nor can I hope to contribute much to its elucidation, owing to the extreme rarity of the species.

It is one of the smaller animals inhabiting the Scotish seas, and it seems to be most irregularly distributed in the British islands. Dwelling at all times apparently in society of another, the most unlikely of any associate, the Mytilus modiolus, their history is generally interwoven together. I think it is Dr Leach who says he found only three specimens in the Mytilus modiolus, or horse mussel, whereof he opened no less than one hundred specimens in quest of them. Mr W. Thompson, however, and Mr T. V. Thomson were more suceessful on the coast of Ireland, as the former observes, that, on opening eighteen mussels, he found fourteen of the Pinnotheres, all females, and he quotes the latter, Mr T. V. Thomson in remarking, that, by the dredge, on any bank of old Modioli or Pima, where the Pinnotheres has been observed, almost every shell will be found to contain one full grown female, some two, and others three, independent of young ones, and males oceupying them in common with the females. -W. Thomson, Ap. ; Annals and Magazine of Natural History, Vol. X. p. 274.

Although fine specimens of the Mytilns modiolus abound in various parts of Scotland, I cannot discover that the frequency of the Pinnotheres corresponds in any respect, or has been thus recovered. It does 
not appear that this animal rambles at large like others of the restless fraternity ; on the contrary, it always becomes an inmate of some of the bivalve shells, dwelling there in peace along with the proper owner.

On one oceasion, I found a specimen with the body thick, nearly circular, half an inch in diameter, the two claws and eight limbs rather slender, and about as long in proportion as those of the preceding species. Two red eyes in front, considerably apart, are scarcely elevated above the margin. Between two of them two small forked antennæ also project, resembling those of the kind referred to ; the colour of the whole animal is reddish.

A long time elapsed before I conld be sensible that the specimen fed, though supplied with various animal substances. But I thought it nibbled some of the green fucus. In six or seven months, however, it fed readily upon mussel.

This specimen proved a female. On the first of July angmenting spawn was elevating the aprou, which is remarkably large, and visibly consists of seven segments. In a fortnight it protected a quantity of fine vermilion capsules. Some of these, detached on the 15 th, were seen to be quite spherical, and very large.

While the spawn still adhered to the parent, numerous young, now swimming actively through the water, had escaped on the 26th. To the eye they are very minute, and of yellowish colour. All lay motionless in two days at the bottom of the ressel.

Red internal spawn afterwards seemed to shine through the integuments of the animal early in August.

This creature was very timid, inactive, and extremely susceptible of the influence of atmospherical changes. On the slightest shock the limbs contracted; it would lay supine and motionless, as if dead, or counterfeiting deatl, for an extraordinary time.

Some alteration in the aspect of the animal followed liberation of a quantity of the spawn, as shewn by the figures.

The creature survived fourteen months. When dead the integument, both back and brenst, proved compact, flexible, and tough. 

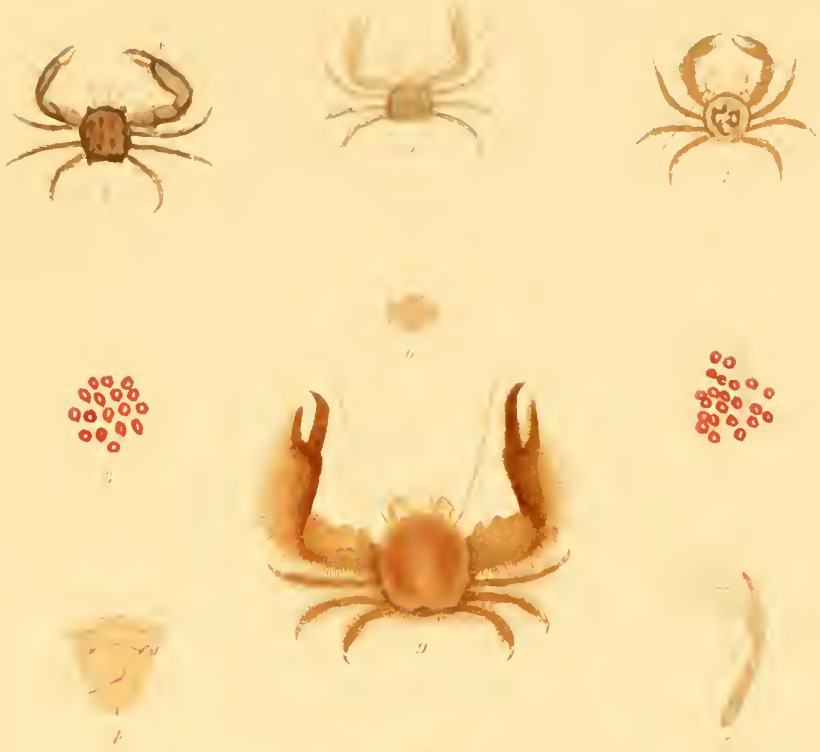

80.0

$80 \% 80$
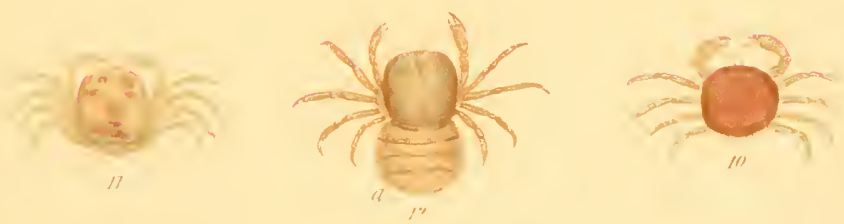

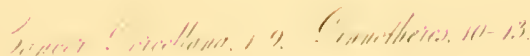



Plate XLV.

Fig. 10. Cancer (Pinnotheres) veterum, prolific female.

11. The same, having discharged the roe.

12. The same when dead, apron, $\alpha$, unfolded.

13. Antenux, enlarged, $a$.

B. The preceding Decapodes, or Ten-footed Brachyuri,-though not arranged in the same continued, uninterrupted line,-are nevertheless connected by many affinities, especially the absence of angular shells, the presence of short antemne, and other features.

But there are also some Decapocle Brachyuri with long antenne, with all the feet complete, or the hind pair abortive, which may be adverted to in passing.

From the abortive hind feet, however, there are naturalists who, with sufficient plausibility, reject the following two species from the Decrpodes, considering them as furnished with only six real limbs besides the claws.

\section{\$ (1.) Cancer (porceldana) loxgicornis-The Ventilating Crab.- Plate XLV. figs. 1, 2, 3, 4, 5, 6, 7, 8.}

This is the smallest of the Scotish Crabs that hals come under my view. It is of orbicular form ; the body of many is perfectly so, about four lines, or the thirt of an inch in cliameter: the expansion of the limbs also, is about an inch and a half ; the hind pair of different structure from the rest, are not always visible. Nothing peculiar characterises the others, unless the great size and inequality of the claws of certain specimens. Nevertheless this, with some minor features, renders it doubtful whether there are not actually two species to be thus distinguished.

A. Claws nearly equal ; Spinous; Limbs Spinous.

B. Claws unequal, one double the size of the other.

The eyes project in front like those of the Pagurus. Nothing peculiar appears in the two internal short antennæ. The exterual antennæ are long, being equal to three diameters of the body. 
There is extraordinary development and action of the pedipalpi; two projecting organs near the mouth, usually very small in other species, from which a distinctive and most appropriate name may be derived, as the Funning or Ventilating Crab,-which will never be thought of, however, by those studying only the form of dried specimens.

The pedipalpi, as I conclude them, prolonged in six articulations, originate nearly in a horizontal line with the claws, and they extend considerably beyond the margin of the shell. A fringe elothes the inner edge of the four upper articulations with long hairs, though not very profusely; these organs reciprocally curve towards each other with an alternate see-saw action, as if occupied in ventilation, which is particularly evident in the afternoon.

The animals are externally plain or variegated, much diversity of colour being prevalent among them. The body is uniformly brown, light, or mottled, the limbs often resembling tortoise-shell.

Such creatures are very trauquil, concealing themselves wherever they have an opportunity.

They rarely feed, but sometimes consume mussel.

The breeding season is in May and September, spawn then elevating the apron of the female.

This apron is very large, and of remarkable formation ; the last or internal segment resembling a quincunx compounded of several pieces.

Early spawn is very compact. It afterwards relaxes in clusters. Many of the detached capsules seemed to me larger than those of other species. Specimens die suddenly. During my inspection of one in apparent health, it fell back, and never moved again.

These animals are recovered in great numbers from deep water. I have not observed that any were taken near the shore. Certainly they were found in greater profusion formerly than of late.

Plate Xlv.

Fig. 1. Cancer (porcellana) longicornis, male; back.

2. Female, breast.

3. Another specimen.

4. Apron, enlarged.

5. One of the pedipalpi, or ventilators, enlarged. 


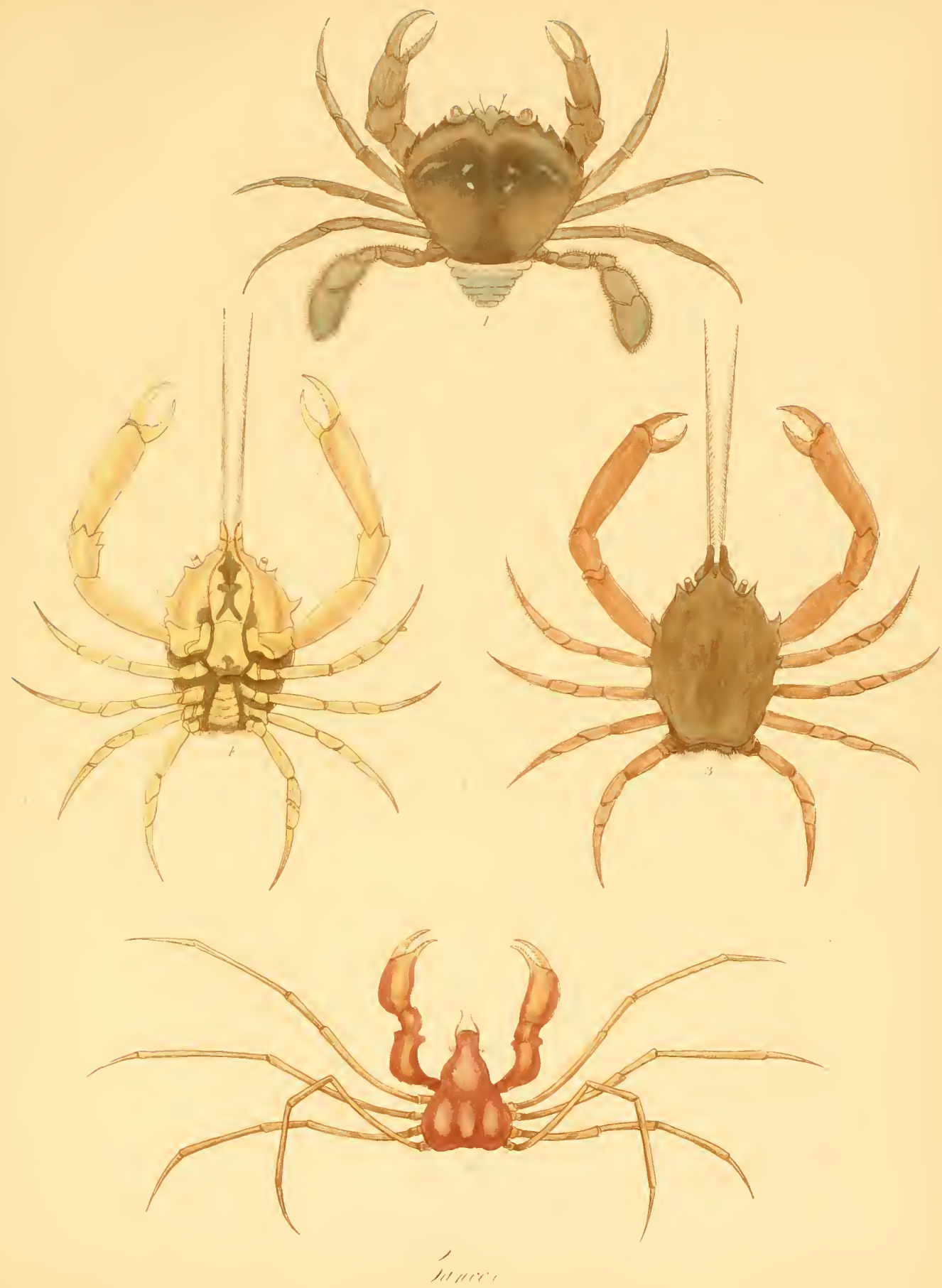



Plate XLV.

FiG. 6. Mass of roe.

7. Cluster of capsules or ova, enlarged.

8. Detached capsules or ova, enlarged.

§ (2.) Cancer (porcellana) Platycheles.-Rough-footed Crab.

Shell nearly cirenlar, about three quarters of an inch in diameter, somewhat convex. Claws large and strong. These, together with the margin of the shell, are thickly beset with bristles. The external antennæ are very long; the internal proportionally short. Colour universally reddish-brown.

None of several specimens have ever fed, though offered various substances. They seem to be very paeific, and are evidently extremely delicate, the slightest impurity of their element uniformly proving fatal. Nevertheless, under suitable treatment, several specimens have survived some months in confinement.

Plate XLV.

F1G. 9. Cancer (porcellana) platycheles.

\section{C.-Cancer (Cortstes) Cassiveladnts.-Plate XLVI. figs. 1, 2 .}

The body of the preceding animal is of a circular form, the limbs short and stout, and the antenna very long. The antennæ of the present subject are also very long, straight, pointed, and fringed along the interior. The body, or carapace, extends in a long oval about an inch and a half in breadth, with five spines on each side of the shell. The feet originate from the narrow portion of the shell, the elaws are long and slender, and the tail curves over the posterior part.

This creature dwells in deep water, but it is very rarely seen in any of the districts that I have frequented.

In drying, the redness of the shell is converted to cream colour.

\section{Plate XlVi.}

Fig. 1. Cancer (corystes) Cassivelaunus, back.

2. Same, breast. 
Amidst the numerous animals comprehended under the common character of Crustaceans, the general form of so many is so different from that of others, as by comparison to afford the best guide to their position in the Systema Nature, and the discrimination of their genera.

I have not been so fortunate as to obtain and preserve a sufficient number of specimens and varieties, as to shew the essential distinctions among them, or to determine either the transitions or analogies. Some, indeed, I have had in profusion; but, on the other hand, a single specimen has constituted my whole stock, throughont, which the research of twenty or of thirty years or longer has not angmented.

In several instances, therefore, the only auxiliary that I can offer is correct representation from the life. Where opportunity has granted more, I bave eagerly availed myself of it ; but, I candidly acknowledge, that $I$ have been always more solicitous about obtaining facts, and nultiplying species, than founding systems, which latter are less within the province of the practical naturalist.

Hence, perhaps, do many restrict their whole labours to the history of a single genus, or perhaps to that of a single species.

Among the more noted forms of the body, a large section of the Cancer tribe is exhibited as entirely triangular or sub-triangular, in various modifications.

I know not with what justice, but it has appeared to me that these are always somewhat more delicate than the others, a fact to be determined or confuted only by numerous subsequent observations.

The disproportionate parts certainly render the preservation of entire subjects more precarious.

\section{D.-1. Cancer (inachus) Donsettensis.-Plate XlVI. fig. 4.}

When the general appearance and character of a subject are so prominent, that to mistake it for any other is impossible, I cannot see that enumeration of trivial peculiarities is of the slightest importance.

The form and dimensions of this species, which is scarce, are well expressed in its representation, Plate XLVI. fig. 4.

Specimens have survived during many months. They dwell together in peace. 


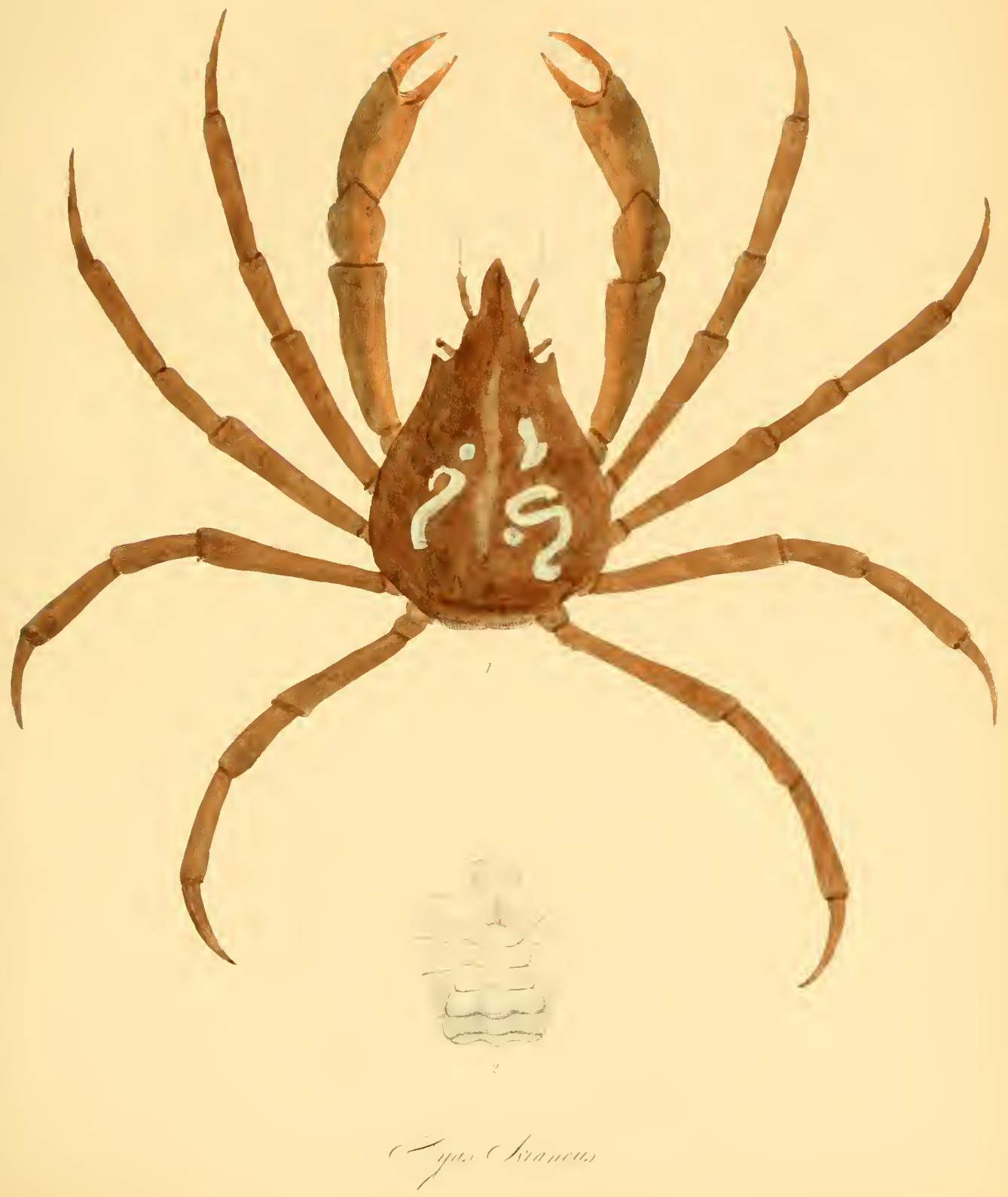





\section{D.-2. Hyas araneus.-Plate XLVII.}

Dr Leach quotes from authors by whom this subject is named Cancer maia, Inachus, and Hyas by himself, whereof he says there are two British species, Hyas arencus and Hyas coarctatus. It is to the former that the attention of the reader is now directed.

Excepting the Cancer horridus, the Lithodes maia of the last named author, the subject of the present paragraph is the largest of the triangular crabs inhabiting Scotland.

The Cancer or Iyys araneus appears under much variety of aspect, so great, indeed, that were there varieties, I should almost dloubt whether the two represented in the following plates, shall be identified with those of preceding anthors. But such varieties may be ineidental to age, or sex, or position : and, as already signified more than once, the ductility of matter, especially of organic matter, affords listinctions often requiring search by a miscroseopic eye.

Length of the body, towards three inches; extreme breadth, under two. Expansion of the limbs, which are long, rather slender, and armed with nails, six or seven. Two eyes, each borne on a peduncle, incline from the sides of a solid rostrum.-Plate XLVII. fig. 1 ; XLVIII. fig. 1. The apron, thorax, or abdomen of both sexes is large, of an irregular quadrangular form in the male, Plate XLVII. fig 2 ; and that of the female, somewhat resembling an irregular hollow spherical segment. -Plate XLVIII. fig. 2.

Many thousand ova have elevated the apron as early as the middle of February, and thence forward to the middle of July. At the latter season, the animals are full of roe, protruding from under the edges of the apron. In far advance, this substance consists of fine luxuriant reddish-orange clusters, each capsule attached to a principal stalk by its own pedicle, and each of these stalks to one of still superior dimensions, so that the aggregate forms a cluster.

This is an extremely languid and inactive animal, far from interesting to view, for many hold its appearance to be very repulsive.

Deep water seems the proper dwelling of full-grown specimens; 
but many of moderate dimesions lurk in the clefts of the rocks, and conceal themselves under large stones nearer the shore.

Perhaps it is chiefly owing to the inert disposition of the creature, that its shell appears so often totally invested by marine algæ, fuci, zoophytes, and some testacea. All these crowded together in profise combination, completely disguise its real form. Of two specimens, like those represented, the back of one was wholly invested by a coating of smooth compact sponge, the sixteenth of an inch thick; and that of the other by at least forty serpulæ.

Full-grown, clean, fine specimens of the Hyas araneus are not common.

Plate Xlit.

Fig. 1. (Cancer (hyas) araneus, male.

2. Apron.

\section{Plate XlViII.}

Fig. 1. Cancer (hyas) araneus, female. Apron, a.

2. Cluster of roe.

D.-3. Cancer (intas) coarctatus.-Plate XliX.

The nature of some creatures appears to us so extraordinary, and so different from what we might conjecture it should be, that no improbable surmise might sanction credulity in their having been transferred from the scene of their original creation, to a milder or a more rigid climate now occupied by them.

The languor and inactivity of certain genera in this tribe of animals is most extraordinary. They seem as if born to live in torpor. Scarcely ever in sensible motion, if accidentally roused by some artificial stimulus, it is only to relapse into more profound repose, for certainly this is their greatest enjoyment, their strongest propensity, perlaps the immediate result of atmospherical influence. Their state now, is probably an effect approximating torpidity. But what can be so powerful and irresistible as torpidity? It is the most overwhelming of all repose, that which neither resolution nor inclination can impair; that which leads immediately from life to death without apparent suffering. 


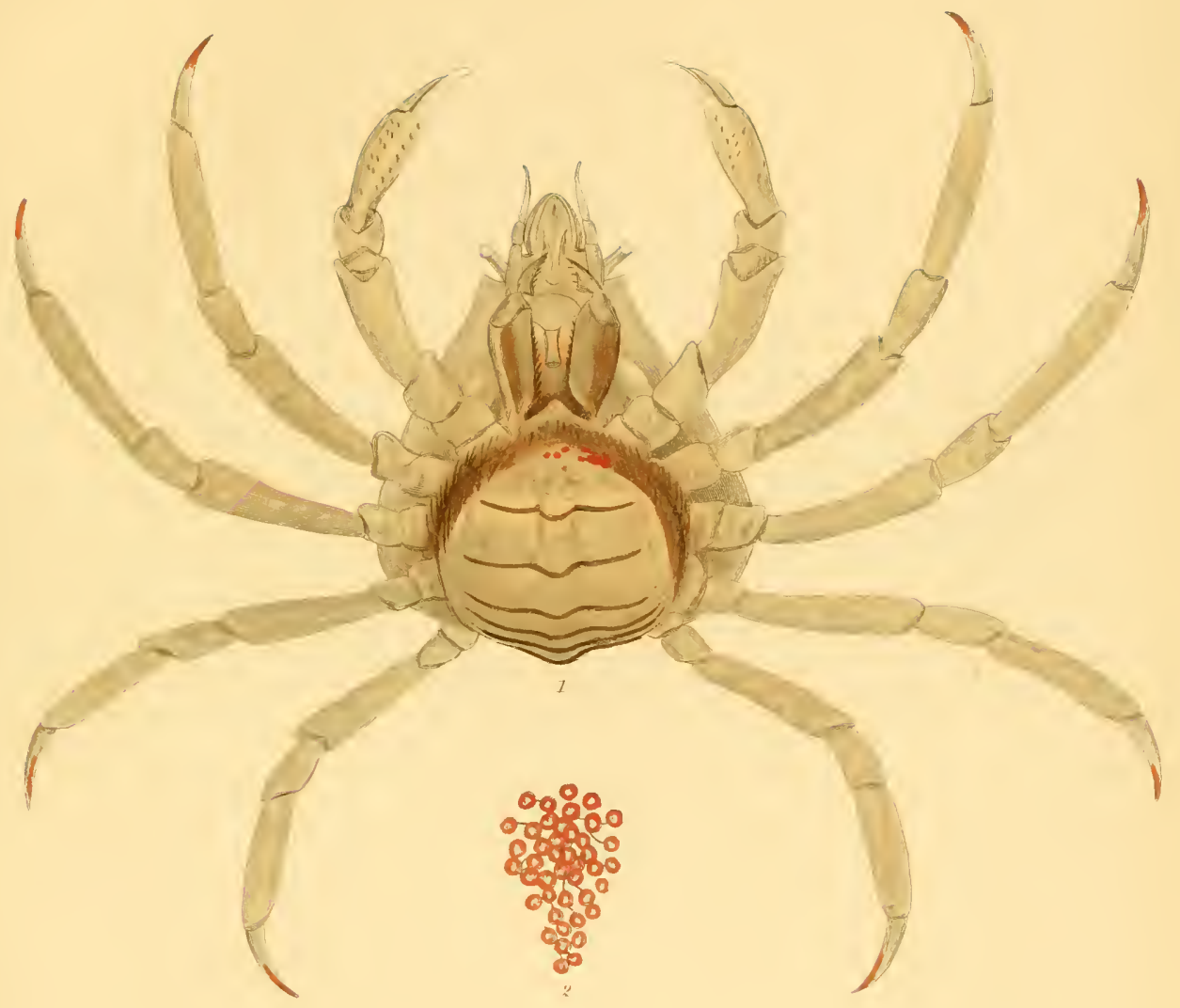

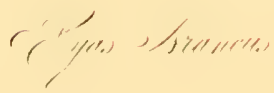



Peculiar incidents are concomitant on prolonged repose: it admits encroachments on the state of the living animal, incompatible with vital sensations ; and, first of all, it allows numerous parasites to found a nidus amidst living matter, and themselves to live at the expense of life; now the whole, together with the limbs and other accessories large and small, becomes invested by foreign matter, completely disguising,-even distorting the true form and appearance of the specimen and all its parts, from those the most familiar with them.

But this is greatly promoted by the situation of both the subject and the parasite. Thus, some escape it entircly, and the shell remains as free and clean of all parasite substances and foreign matter, and of as vivid colour, as if carefully cleansed of accidental impurities.

Such specimens, however, are not numerous, their condition probably involving more peculiarities than we are commonly aware of.

One is represented, Plate XLVIII. fig. 1, the lengtl of the body about an inch and a half, its breadth about an inch. Claws rather long and slender, as are the limbs, which, armed with nails, expand five inches between the opposite extremities. The rostrum is cleft, and the eyes seated on peduncles, standing at a large angle to the axis of the hody; which is owing to contraction of the breadth : the shell of some is more irregularly triangular than that of any of either of the preceding. Its colour is univer'sally tile red.

The apron of the male tends to an irregular quadrangular form ; that of the female, of larger dimensions, is directed to protection of the spawn, which is a close compact mass in its earlier stages. Then it is vivid red, but becomes pale as adrancing towards maturity, for the skin of the capsules growing thinner with age, its consistence relaxes, and in July, when in great perfection, clusters, like bunches of currants, may be separated; but they are intricate, nor ensily divided, so as to be distinctly seen and represented.-Plate XLIX. figs. 4, 5.

Some years ago a fine small specimen, Plate XLIX. fig. 6, was washed on board a steam vessel plying between Orkney and Shetland, during a storm; on reaching me this creature fed voraciously on most animal substances. 
A Pycnogonum, fig. 6, long enjoying indemnity in the jar to which it was committed, still escaped, but a crab of a different kind perished. Yet the perceptions of the stranger specimen, in regard to the presence of food, were remarkably obtuse. Though sensible of its vicinity it experienced much difficulty of coming in contact.

The shell of the stranger specimen was quite clean on its arrival, but the leaves of fuci having been thrown into the vessel, for protection and shelter, the crab had rent them in fragments, and clothed itself in rags. The latter is effected by means of the spinous processes rising from the shell, and here the ruddy integuments appear to be invested with the ragged fragments.

In four months, when a new and much larger shell came in on exuviation, the old shell was broken dorn, and partly devoured; the new one remained quite clean and symmetrical.

Some time afterwards the use of green shreds of the fucus was resumed ; at length they were finally abandoned.

This specimen survived seven months from the beginning.

Plate Xlis.

Fic. 1. Cancer (hyas) coarctatus, adult female.

2. Apron of the female.

3. Apron of the male.

4. Cluster of ova, enlarged.

5. Another.

6. Specimen washed on board of a vessel.

§ (4.) Cancer phalangium, Macropodi phalangidu; Leach.-The

Spider Crab.-Plate L.

Several of the genus comprehending this animal, are separated by distinctions so slight, that their narrow resemblance readily misleads the unwitting observer. Certain distortions, frequent about the rostrum and antemnæ, perhaps tend to promote the confusion.

Probably the subject represented here is the real Spider Crab, to which a place may be assigned in the older nomenclature of the Systema, as the Cancer phatangium. 

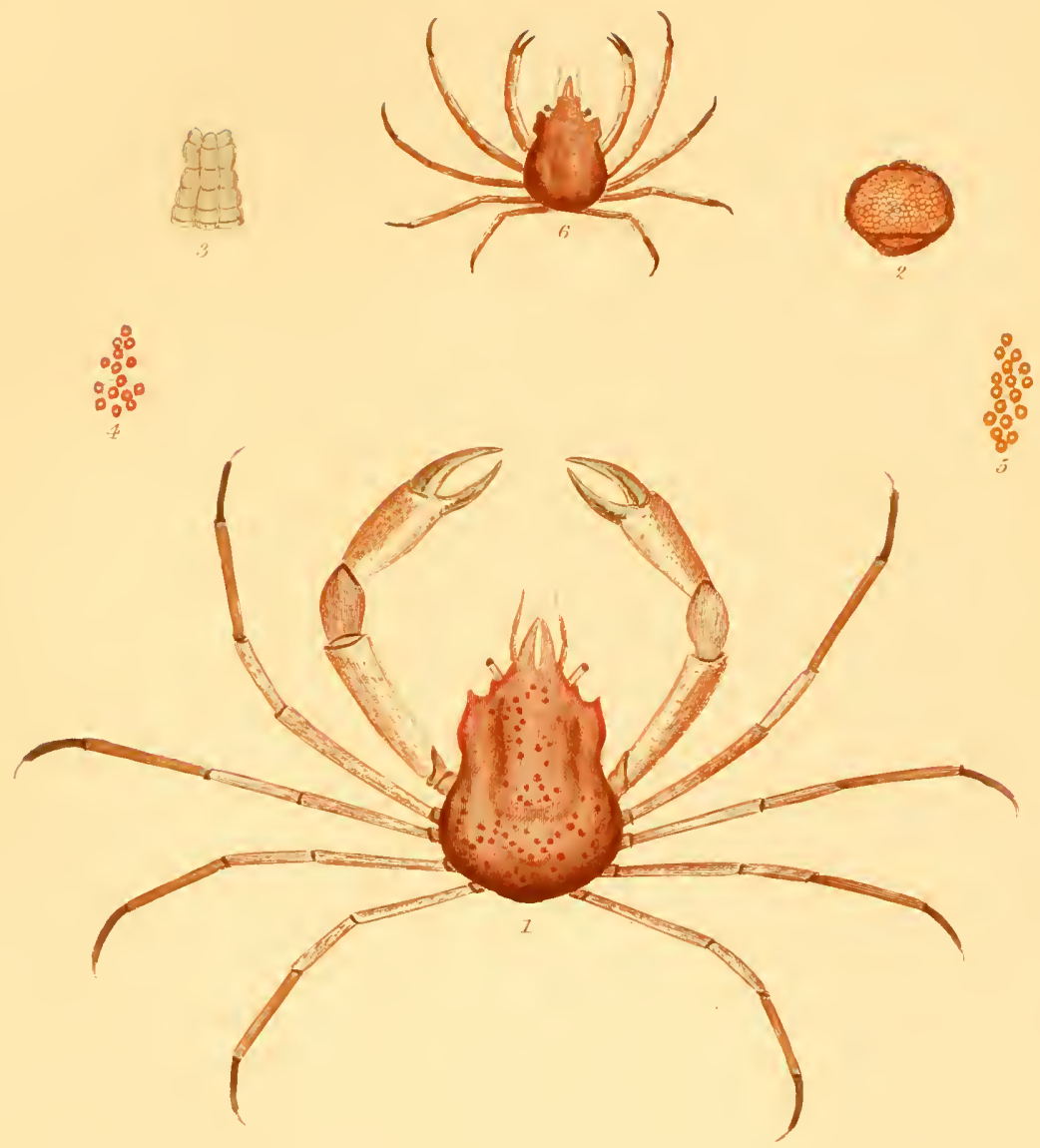

Yyen tersideteres 
Y.
CAMII INTE WIA USA 
Its form, as that of the preceding species, though of inferior size, is subtriangular, extending seven or eight lines from the base to the apex, or extremity of the rostrum, and somewhat less across the base ; the claws of larger specimens stretch towards two inches, and the limbs expand about six between their opposite extremities.

A distinctive character seen among the species consists in the form of the articulation of the claw adjoining the forceps being short, and rudely ovoidal in one, and in another its outline or ogee convex above, and concave lower down. The two hind limbs are provided with nails. The form and position of the eyes or antenna will be understood from simple inspection of the figures.-Plate L. figs. 1, 2.

Many specimens are totally covered by straggling short bristles, especially scattered on the limbs, and sometimes the claws, as in fig. 2, are quite hairy. I am not completely aware of the import of these features. The eolour of the finest specimens is wax yellow, some are dingy white. Here the animal receires no embellishment.

The whole parts are slender, delicate, and apparently very weak, and incapable of resistance. In fact they are readily detached, to which they are particularly exposed by their disproportionate length; the aspect of imbecility justly denotes their true character, for mutilated specimens are extremely common. The animal, besides, advances with a wavering and unstealy gait. At rest it sinks on the base amidst the bented limbs, while the claws fold very awkwardly below them.

The apron of the male is nearly quadrangular, that of the female approaches the segment of a hollow sphere. An external view of it, as covering the roe, is offered in fig. 3 ; the roe itself is exposed by fig. 4 .

This roe is in less profusion here than in any of the preceding crabs. The capsules composing it adrance in March and April, its progress being according to the season ; that of March is represented, fig. 5, and some capsules, more enlarged, fig. 6 , wherein the eyes of the included young are visible. The number of these in some specimens did not exceed an hundred. The young, hatched from capsules in the first week of March, resembled such as above described from other crabs.

The senses of the Spider Crab are alike obtuse, as explained of pre- 
ceding species. It feeds on fish, or on mussel, which must be brought almost in contact with the mouth, or otherwise it may pass undiscovered. When fed, the specimen first securing a morsel is assailed by its companions in their endeavours to carry it off. All are otherwise extremely pacific.

I know not how to interpret certain passages regarding "the Spider Crab in a state of ecclesis or moulting," as related in the Ammals and Magazine of Natural History, Vol. VIII.

There the observer says, - " A few days since a Spider Crab was sent to me alive, taken in the act of changing its coat. The operation was singular. The upper and lower shell being parted, the legs were withdrawn from their old cases, and served as a lever to detach the under shell from the upper. Some exertion of the legs was necessary to raise the upper shell. This had been accomplished, but it was not entirely detached from the borly when brought to me. The body was quite soft, and the hard skin of about the consistence of parchment. In fact the change was almost completed."

The exuviation of the specimen, Plate L. fig. 2. took place on the 18th of September, when the animal, as there represented, appeared considerably larger than previously. It seemed to have escaped from the hind part of the shell, which was quite entire elserwhere. This old shell was very thin, the hairyness of the claws and bristles on the rest alike conspicuous.

With sufficient attention to preserve the purity of the water, these animals will survive months in confinement.

Plate L.

F1G. 1. Cancer phalangium, the Spider Crab.

2. Another specimen.

3. Apron of the female corering immature spawn.

4. Spawn.

5. Spawn in Marcl, enlarged.

6. Purtion of spawn, more enlarged. 

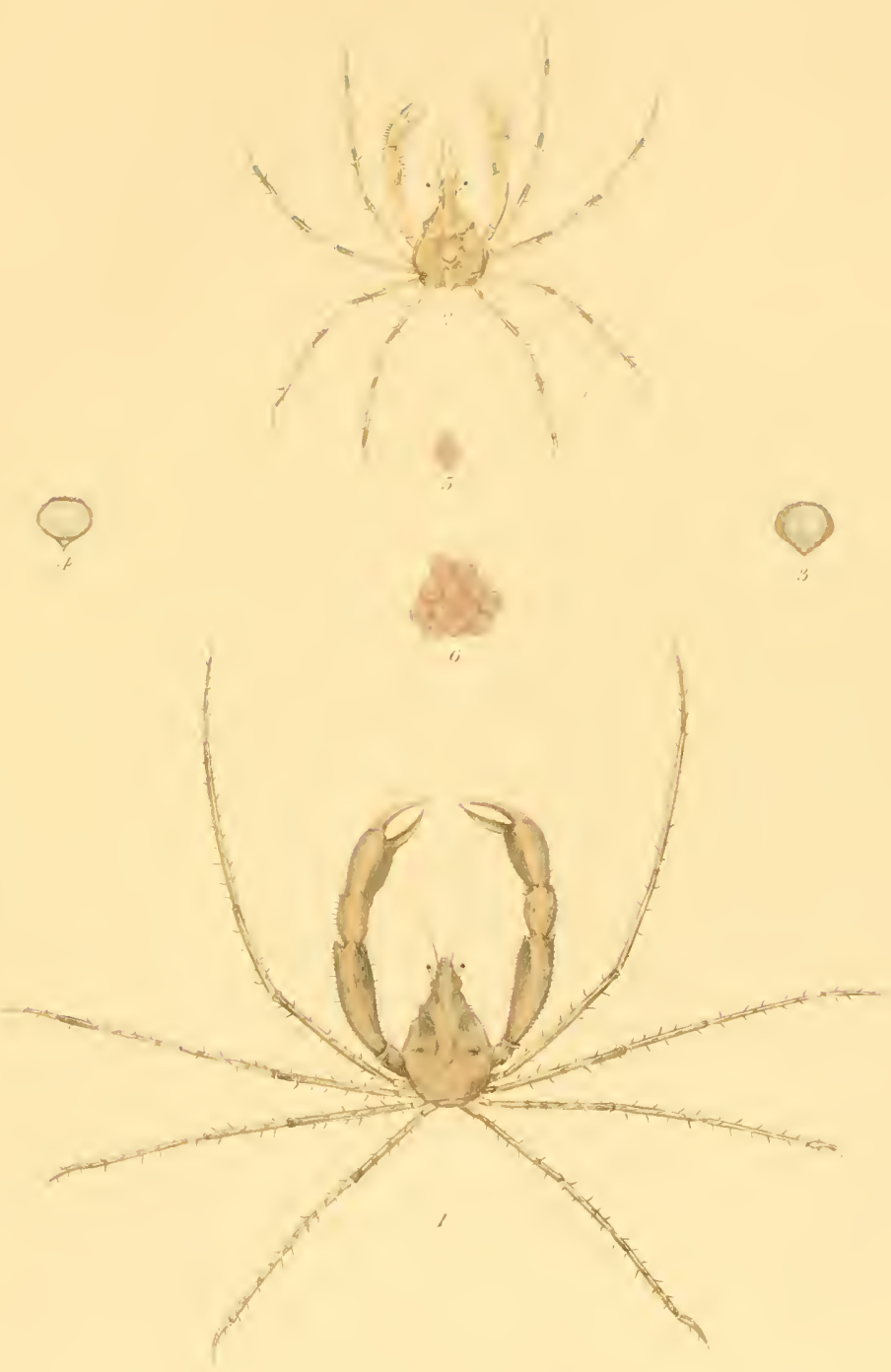

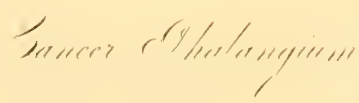




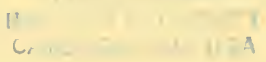


§ 5. Cancer horridus, Mata lithodes.-The Prickly Crab.Plates LI., LII.

The appearance of the Prickly Crab, or at least of its important parts, will be best understood from its name. Dr Leach has prefixed half a dozen synonyms to his description of the animal ; but as we do not intend to overload this treatise with nomenclature, they may remain where he has left them.

Were the size of a living ereature to be computed by the space which its parts can actually cover, this would be distinguished as the largest of the crabs belonging to the Scotish seas, and its appearance is certainly the most singular. The length of the shell of the finest specimens, from the base to the extremity of the rostrum, is about six inches, and the extreme breadth four and a half, being wholly of a triangular shape.

The limbs expand no less than twenty-two inches between the opposite extremities, the longest being the second pair, but they are not proportionally strong.

Only six limbs are prominently visible; the hind pair, much the smaller, are concealed under the edge of the shell from their origin. Great disparity subsists between the size of the two claws, the largest extending seven inches from the root. The rostrum terminates in a solid fork, while the antennæ stretch above two inches.

This species is totally covered by large and strong prickles, like thorns, some extending above an inch, which, were not the animal of very pacific nature, might prove it a most formidable enemy, yet it seems quite the reverse.

Here the apron of the female is very large, and of peculiar texture, flexible, and of consistence somewhat resembling sheepskin leather, yiekling to pressure of the finger.

A singular cavity penetrates the shell, which is adapted for receiving the swelling spawn. This, during the month of January, is composed, in its earlier state, of a vast congeries of slender threads. The apron of the female resembles a portion of wood or other solid substance, curiously sculptured in regular and irregular figures. 
Colour of the whole animal, different shades of fine yellow.

A learned naturalist told me he had seen twelve of these creatures taken from the stomach of a cod. It is not common.

\section{Plate LI.}

Fig. 1. Caneer horridus, the Prickly Crab. Back.

2. Rostrum, natural size.

3. Antennæ.

4. Apron or thorax, reduced.

5. Cavity in the shell for accommodating the growing spawn.

Plate LII.

FIG. 1. Cancer horridus, under surface, reduced.

\section{PA R T I I.}

A.-DECAPODES, TEN-LIMBED, LONG-TAILED, CRUSTACEANS,-MACROURI.

We have been as yet occupied only with that section of the Crustacean animals comprehending the short-tailed crabs or Brachyuri, properly so denominated. All are of aquatic nature; and although there are some terrestrial Crustaceans in this country, I do not intend to enter on their history at present.

Such Crustacenns are composed, as we have seen, of one large shell, vernacularly designed the carapace, and a number of slightly articulated segments, proportionally small, and rapidly decreasing, which, compared to lowrer parts in the organization of some other animals, all terminate in a portion applied to the under surface or breast, and is denominated indifferently the thorax, the plastron, or the apron.

If the whole thorax be relieved of its currature, and extended as if in a straight line, it appears still very short from the preceding examples.

Another numerous family of the Crustacean tribe, is denominated Macrouri or long-tailed, comprehending the Astacus or Lobster, and its congenera. 
$1 / 1$
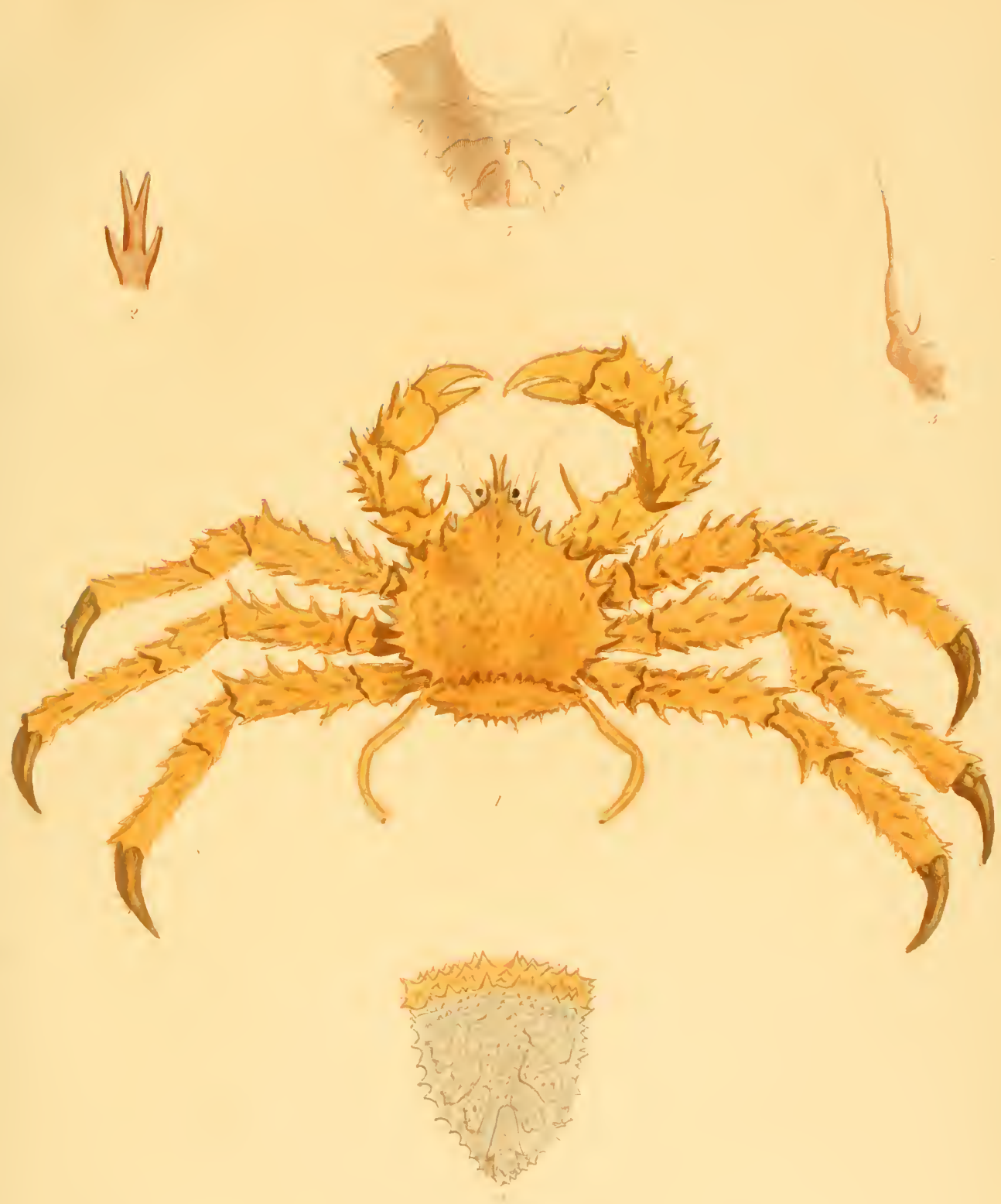

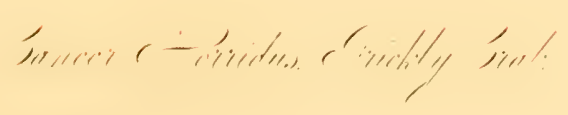


and 
Here the whole body seems at first sight to be constructed after a different model, and, together with the tail, divided after a different fashion from that shewn by the Brachyuri.

The first segment of the body, the carapace, still constitutes a shell of very unequal proportions to the rest of the segments. All the parts are distinctly divided, and usually bordered by a fringe. Antennæ, of remarkable length, are also present.

The transition from the Cancer to the Astacus is so great that we naturally enquire what is the medium of connexion. But I can find none others equal to the Cancer Bcmhardus or Hermit Crab, and the Galathea or Bastard Lobster.

A brief paragraph may be devoted to each.

\section{§ 1. Cancer Bernitardus, the Hermit Crab or Soldier.-Plate LIII., LIV.}

This is one of the creatures whose presence is most familiar to persons frequenting the sen shore. Its singular habits, so unlike those of the other tenants of the deep, never fail to attract attention, while at the same time very much tend to perplex the spectator.

Let him take advantage of the recess of the tide, at the proper season and situation, he will be struck with beholding a number of turbinated shells traversing the sand, as if of their omn accord, in all directions, but after a fashion evidently different from what would be followed by the proper owners of the tenements.

The nature of motion resulting from organic structure, every animal unrestrained is distinguished by pecularities here.

Many are of extremely small dimensions, some much larger, all wandering about after their individual objects, though none are discovered to be guided by any common impulse. Among them must be distinguished, but most unequally distributed, shells quite entire, defaced, or defective. If the progress of these wandering suljects be disturbed, its course is generally interrupted, and each of the shells is found on examination to be occupied by a Hermit Crab.

To comprehend the form of this animal it is necessary to deprive it of its babitation. Then it is seen to be formed of two distinct portions, 
neither of them strictly resembling either the Cancer or the Astacus. The upper part is crustaceous, being invested by a shell, the under part bare, soft, and roid of segments, quite of fleshy consistence.-Plate LIII. fig. 1 ; LIV., both as in their shell ; Plate LIII. fig. 6 ; LIV. fig. 1. two specimens, both withont the shell.

Two eyes in front are sustained on peduncles: rising within the roots of these are two shorter forked antemne, besides two very long and slender antennæ, whose structure resembles that of a lobster, while in form the internal antenne may be compared to those of the crab.

Nominally, there are ten limbs, which, in the first place, exhibit a great disparity between the size of the two elaws. The first and second pair of legs are long and strong; the third and fourth short and abortive. A projection crosses the extremity of the tail.

Total length of the adult, six inches.

Among the varions shades and variegations of colonrs of different specimens, red predominates.

In some it is vivid almost throughout. The limbs of smaller subjects are fine marbled, like tortoiseshell.

Though, to shew the form and proportions, the claws be represented here, they are, in fict, generally folded under the animal.

This species feeds readily on animal substances. One claw holds the shell of a bivalve, while the other pieks out the contents.

It is very lively, and very voracious. Several specimens may be kept together with indemnity, for the nature of the hermit crab is pacific. With strict attention to the purity of its element, a subject may be preserved for a considerable time.

This species is well adapted for experiment and observation.

The process of exuviation is almays interesting, because a new creation seens to attend it. But it is here somewhat different from that above described, in partaking of another nature. One-half of the integuments, namely, the upper portion or crustaceous parts, are all that separates, for there is no possible exuviation by changing the skin of the lower or fleshy portion.

If it does separate, the change is insensible. The former comes off 

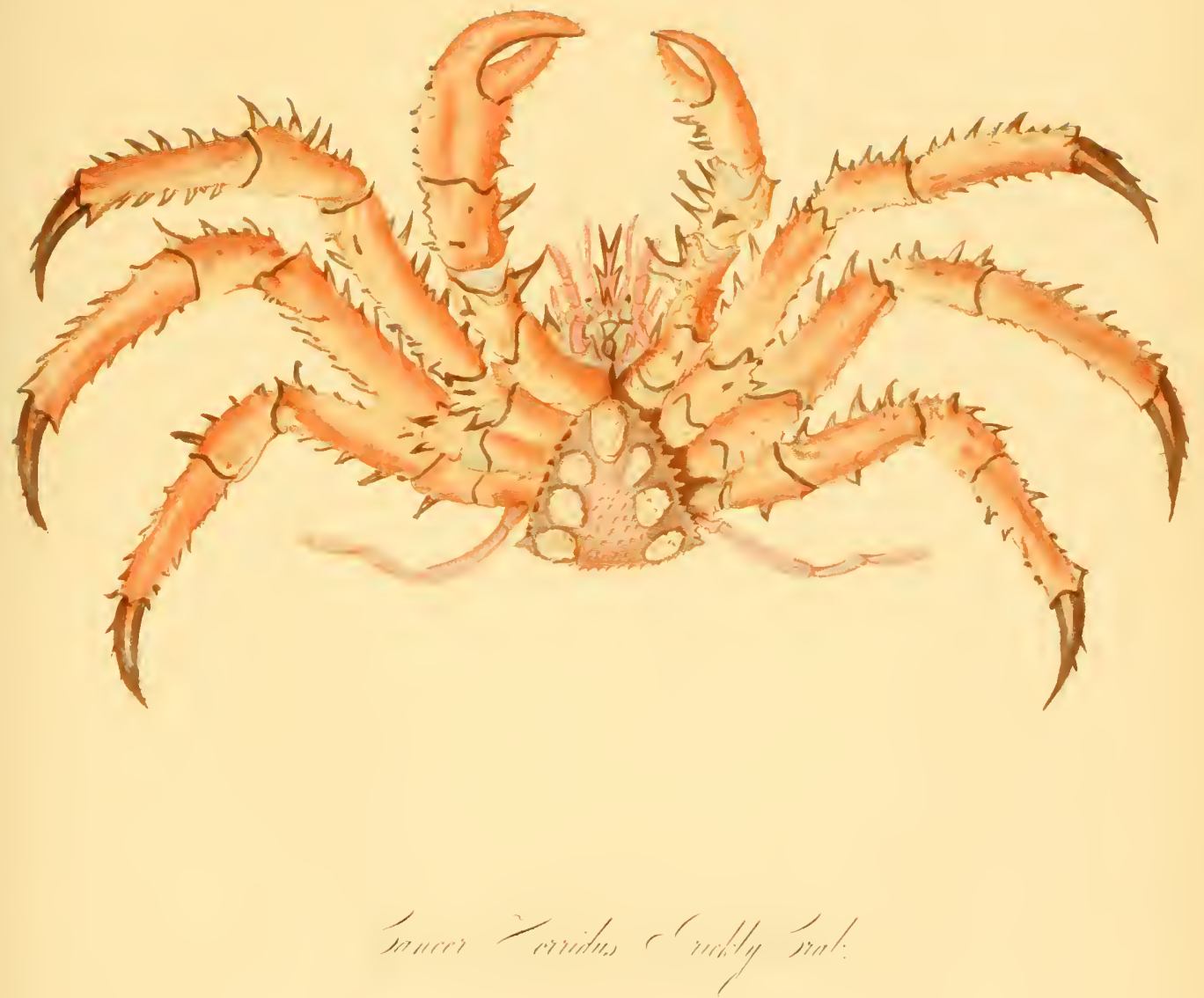

quite entire, the antennæ resembling two slender needles, and the covering of the eyes perfectly tramsparent.

The means of the process, and the nature of the new generation, seem more obscure and difficult to be understood or explained than in the Cancer tribe.

I do not know that this incident has any dependence on the seasons, having witnessel it in Jamnary, Narch, and November.

If the animal, umprovided, can find a vacant shell adapted for protecting the fleshy parts, its species seems indifferent; neither does each require such a safeguard, where secure from exposure to injury. A large specimen of a testaceous Limax, confined in the same ressel with one of them, having died, the crab devomred the flesh, and elothed its tail with the empty shell.

In the natural state, this artificial covering must be changed, so as to accommodate the growing occupant, which instinctively knows at an early stage what is the most suitable for its purpose. However, there is no necessity here that, more than any other article of real apparel elsewhere, should be nicely fitted.

A small specimen having occupied the empty shell of an Echinus, seemed, while travelling along, to be provided with an immense turban.

When we view an animal which must shelter its bare and naked parts, and whereof four deformed limbs always seem shapeless and distorted, and roid of any visible protection, we are prone to conclude that the wonted beneficence of nature is withheld.

The measures adopted for protecting all the tenants of the earth are not indeed alike explicit to mankind ; many are totally secret, unknown, and altogether unintelligible; yet that there is some powerful safeguard, cammot be denied, for withont it how conld the race be preserved from generation to generation?

The provisions of nature are all regular and effective: hence the Hermit Crab begins to breed at a very early age, even before attaining the size of the small prolific specimen :-Plate LIII. fig. 6 . Here will be found some deviation from the nature of the Cancer; for it adheres not to the shell, but to the flesh of the left side of the parent, totally unpro- 
tected. It is true, however, that certain organs, though diminutive, and apt to be overlooked, are always present as auxiliaries for its security. Yet as it does appear that, together with the side, it is totally unprotected, we may conjecture that the shell occupied by the parent is truly designed as a substitute for an integument, within which this most important portion of the animal substance can be withdrawn. While still immature, the spawn is a dense mass of beautiful purple ova, afterwards fading, as it relaxes and ripens towards maturity.-Plate LIII. figs. 3, 4 ; cluster enlarged, fig. 5 .

This spawn consists of several hundred ova or capsules; but they are not alike numerous as those of most of the preceding animals. The numbers may partly depend on the age of the parent. Small quantities are borne by small specimens; those resembling fig. 6 , whose limbs do not expand an inch; nor do the numbers of capsules belonging to many large specimens exceed an hundred. The capsular integuments are gradually refined, so as to expose the included foetus rolled up, with the head and tail in contact. Is it advances, two large black eyes, like crescents, appear externally in front, and an internal red spot about the middle of the body. At length, escaping their prison, the young animals appear as in figs. 5, 7, 8.

But, in conformity with the general normal crustacean shape, these young animals bear no resemblance to the parent, which must be gained on passing through the various metamorphoses appointed by nature.

Now, it would seem much more like a lobster than a crab. It is at first very light and transparent-the upper portion disproportionately large compared with the rest of the body. Only four limbs are visible, while a few segments indicate the lower or fleslyy half, terminating in a broadened extremity of about eleven irregular bristles.

At this time the creature swims with a jerking action. But never surviving beyond a few days, the observer attempting to follow its progress permanently, will be disappointed.

$\Lambda$ pril is the chief breeding season, when the spawn appears in perfection, adhering constantly to the female; for it is never deposited on foreign substances, whether the parent be large or small. 


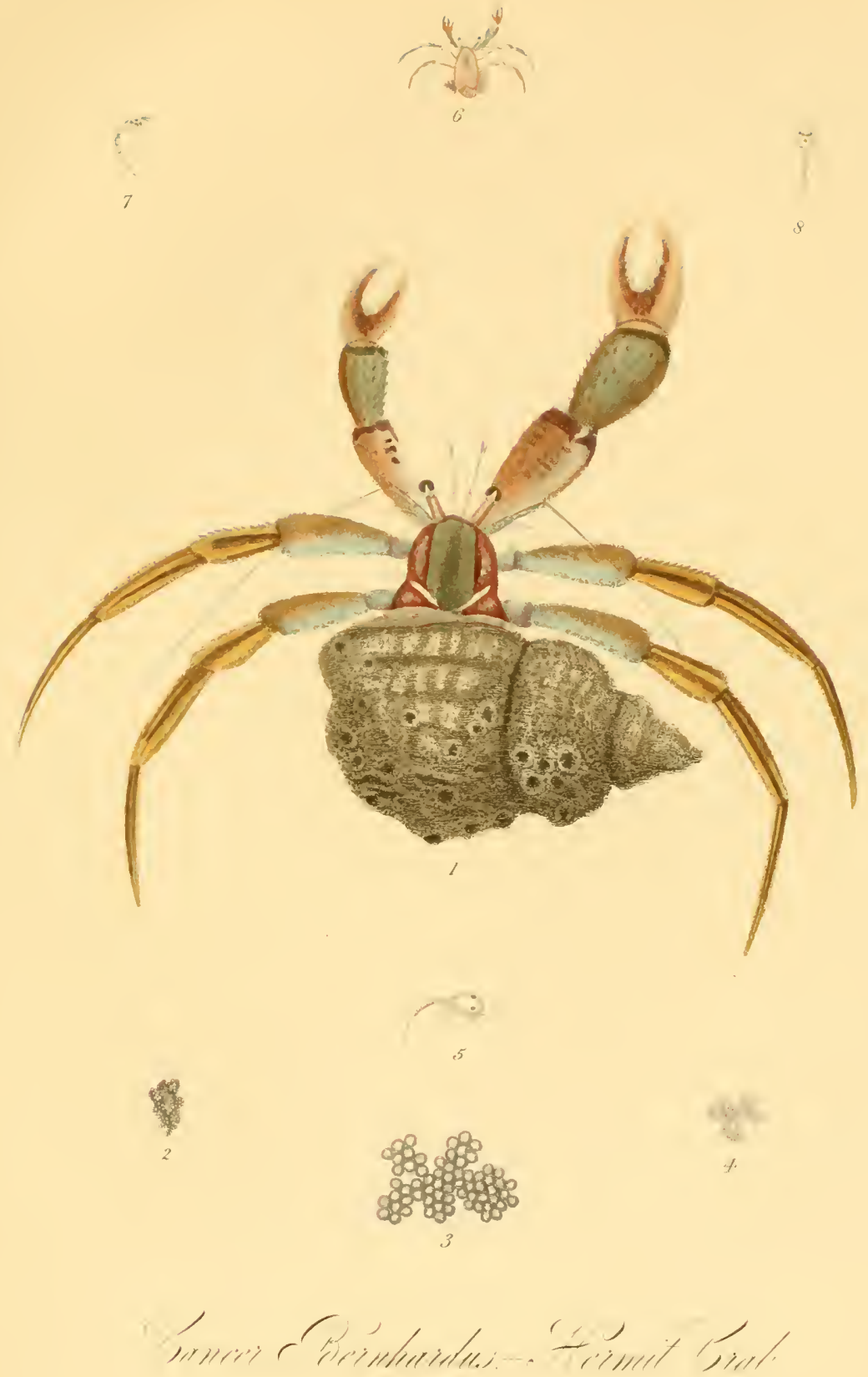


$110-110-7 X+Y$

CG 
Multitudes of the young will burst their capsules while under observation.

\section{Plate LiII.}

FiG. 1. Cancer Bernhardus, the Hermit Crab, occupying a shell.

2. Spawn in an early stage.

3. Spawn in an advanced stage.

4. Spawn in an intermediate stage.

5. Young animal hatched from the spawn.

6. Young prolific female.

7. Young animal from the spawn of fig. 6 .

8. Another.

\section{PIATE LIV.}

Fig. 1. Cancer Bornhardus, Hermit Crab, out of the shell.

2. Small specimen, with a shell.

\section{§ 2. Galatied Spinigera-The Thorny Bastard Lobster.-Plate LV.}

If the preceding animal, with four abortive limbs, be an intermediate link betreen the Cancer and the Astacus, the subject of this paragraph, having only two abortive limbs, and eight of perfect formation, in complete development, should bring us a step nearer the Lobster family, its complement being the same in respect to number as that of the Crab.

Though some species of the Cialathea dwell in the Scotish seas, sufficient opportunity has not enaluled me to investigate their nature so profoundly as required by the interests of science,-and this partly from the rarity of the finest specimens, partly from the brief survivance of some individuals to which my attention was devoted.

A few of the Galathca spinigera only, have therefore come under review, but enough to shew that it is one of the most beautiful, curious, and symmetrical of the tribe.

The general form of this animal bears much resemblance to that of the Astacus marinus or common Lobster, but the proportions and colours are somewhat different. It extends eight inches from the tips of the antennx to a luxuriant fringe bordering the margin of the unfolded tail. 
During health and strength, however, the wonted position of the organs is never so relaxed as to expose either the true form or dimensions of the parts. As the thorax of the Crab clasps close to the breast, so does the curvature of the Lobster's tail affect its real appearance, by concealing the abdominal portion. Hence the body of the animal at rest assumes an oval shape, as represented, Plate LV. fig. 1 .

The claws extend five inches; and of equal length to them are the external antenne; all seated on the sides of a sharp, pointed rostrum. Between the external and internal antenna are two prominent eyes, sustained on short peduncles. Five fins, or flattened pieces, finely fringed, compose the horizontal tail, one being in the middle with two on each side. It will be observed, that while the tail of the Crab terminates in a single triangular segment, that of the Lobster is composed of five portions, fig. 2. Numerous spines are dispersed over this animal, particularly on the claws and limbs, and on the margin of the shell. Also the clars of some specimens are profusely invested by some small tufts of brown hair, which are abundant on certain parts, and even reach the sockets of the eyes. The claws of the large specimen represented here were very hairy. Much of the hair rather resembled short bristles. But this external feature is disgnised by the colour; for the shell on cleansing proved to be red.

Specimens are of extremely different aspect, owing to the variety and interspersion of colour. Red is always predominant, with irregular, cross, vivid, blue stripes, interspersed both on back and breast. The inner portion of the eye, or that next the head, is blue. Young specimens are often variegated red, and pure white. The blue colour seems of latest acquisition. This creature feeds on mussel and other animal sulustances; but owing no doubt to the rude treatment received at the hands of the fishermen, it is seldom obtained in a condition so vigorous as to feed ; and indeed as many are presented dead as alive to the collector. Not being purposely the objects of research, it is only by chance that, when entangled in fishing-nets, they can be brought ashore.

Their motion is singular and vehement, for they spring backwards by the action of the unfolded tail. 
Y.I.

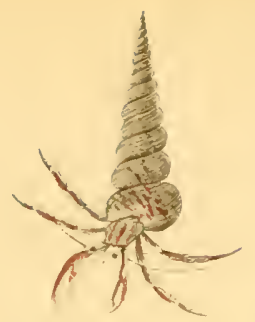

PL.LIV.

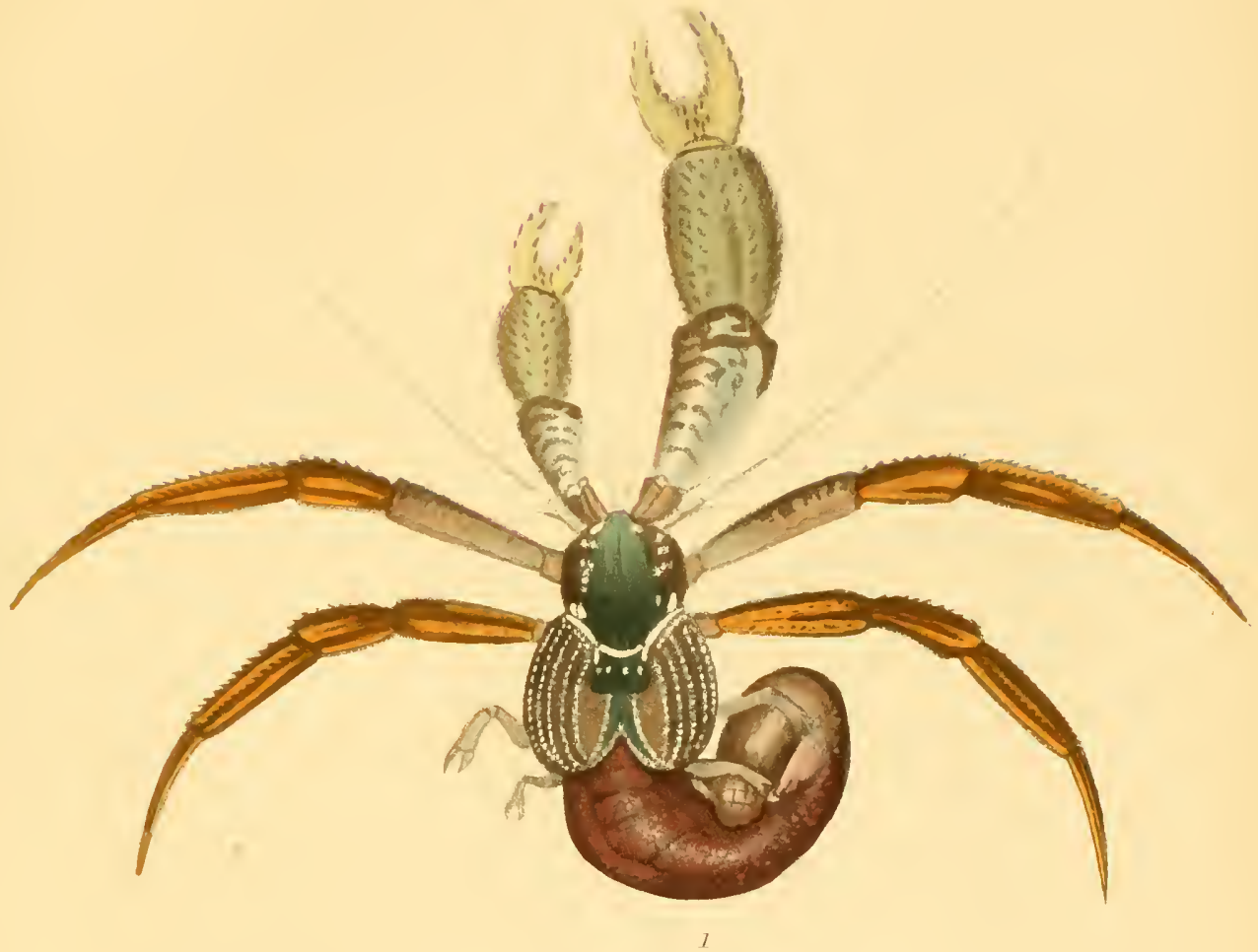

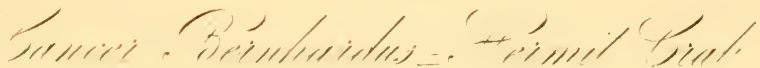



It is not easy to determine the differences of small specimens, becanse such animals alter greatly, and gain accessions with age. Some of the younger are represented in the relative plate, and anong them possibly figs. 5, 6, shew the earlier stages of the Galathea rugosa.

This animal's breeding season commences while it is very little advanced, as shewn by its dimensions. Among several smaller specimems obtained in the beginning of October, was one whose limbs expanded scarcely three quarters of an inch. It died, when the tail unfolding; exposed a cake of spawn, adhering within, of an oval form, two lines in length, and half a line in breadth.

The propagation of the Galathea bears a general correspondence to that of both the Crab and the Lobster.

'The spawn of both these animals occupies the imner portion of the tail, which, in the former, becomes the thorax or apron protecting it. The roe of the Lobster is affixed across the upper interior of the articulations; but in none of the Lobster tribe is it disposed in sueh distinet, beautiful, regular, and symmetrical fruit-like branches or clusters, as in some of the Crabs.

The spawn of the Galathen is not nearly in equal profusion to that of any of the Crabs that I have seen : it is either of a rich florict red, or a fine yellowish-orange colour. The season of its maturity comprehends May and June ; and, in common with those already described, the young escape from it while still affixed to the parent.

A small specimen,-one scarcely extending two inches from the tips of its almost invisible antenna, was taken about the first of May. The curvature of the tail protected a quantity of the finest red roe.

On the morning of the eighteenth, between two and three hundred young appeared in its vessel, without any of the capsules having been detached.

In transparency, these young animals much resemble the young of the Crangon or Shrimp ; but the body had a reddish-yellow stain, which I at first conjectured to be the residue of the yolk of the ovum; however, some external stains rather proved it the original colonr of the shell. This young animal is minute like the rest, abont half a line in length, or 
searcely as much, the tail quite flat, with visible articulations, whereof the last consists of two horizontal fans, with five hairs or bristles on the margin of ench. Only six limbs now appear, which are also provided with hairs or bristles, and whose constant quivering produces a vortex in the water by their rapid vibration. I could not discover the antennæ, perhaps from their extreme tenuity; nor can I pretend to describe the numerous and complicated organs, whose extremity being that of the head, forked conspicuously. Two large oval eyes, each set in a fluted or chamneled frame, somewhat like that of a picture, project from each side. The young are void of any similitude to the parent; and, unfortunately for the observer desirons of following their progress, the third day always terminates their existence.

In preceding passages, it is said that the exuviation of the Cancer is probably more frequent among younger specimens, which rather seems a general mule. Yet it may only indicate more rapid increment, in proportion to the total bulk of the subject, compared with the frequency of that process in others.

A very small mutilated specimen of the Galathea rugosa had been some time in my possession: on the night of February 14, it cast its shell, which separated entire in a single piece. This shell measured only eleven-sixteenths of an inch from the tip of the claws to the extremity of the tail, shewing, at the same time, what had been overlooked, that the animal had been mutilated of the left claw, and a limb in its vicinity. But the new shell came in complete; nor were any of the members at all defective. The limbs, however, were very pale,-the body a little darker, and speckled red. On the 11th of March this creature was delineated. Another exuviation followed on the 27th of the same month, but I was not sensible of any enlargement, either now or on the previons occasion. This was reserved for a third exuriation, on the 4 th of May, when the size was evidently augmented, and a yellow stripe ran partly down the new shell. In regard to the old shell, it was very entire, and very transparent. Still a fourth exuviation followed on the morning, when the transparency of the old shell now separating, did not appear inferior to that of the former, but no enlarge- 
I.I.
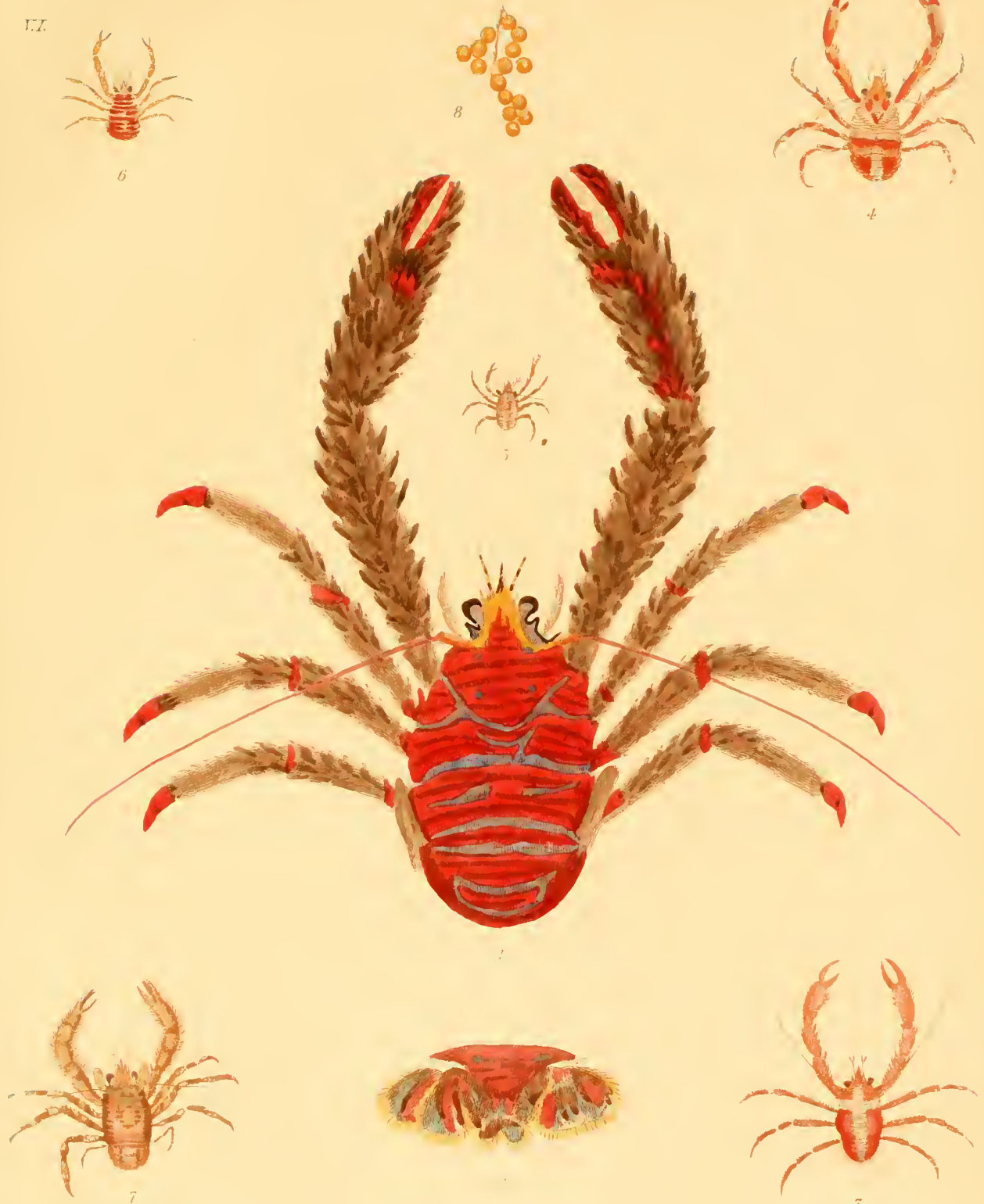

5

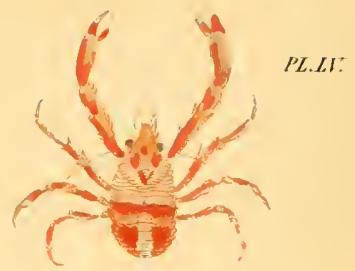

L.LI:

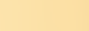



ment of the size was sensible. I found the specimen dead on the last lay of the month, without any obvious cause, though for some time the colour had faded. Here the intervals of exuviation were short, none of them exceeding forty days. When of such transparence as exhibited in these examples, the integument of all specimens must be of incalculable tenuity.

Without any positive evidence of the fact, varions circumstances have induced me to conjecture that this species may be migratory.

Plate LV.

FIG. 1. Galathea spinigera, Bastard Thorny Lobster; vernacularly the Tommy Harper.

2. Extremity of the extended tail.

3. Young specimen.

4. Young specimen.

5. Young specimen, a female, which survived five or six weeks,Galathea rugosa?

6. Young specimen.-Galathea rugosa?

7. Young specimen, very hairy.

8. Spawn, enlarged.

B.-DECAPODES, TEN-LIMBED, LONG-TALED, CRUSTACEANS-MACROLRI. ASTACUS, THE LOBSTER.

THE two preceding animals will suitably illustrate the transition of the form of the Crab to some other than previously discussed in the preceding pages. Its most immediate ally will be found in the Lobster. The form of this genus differs considerably, as is well known, from that of the Crab, and its properties prevent it from being confounded with the ereatures belonging to other tribes.

\$1. Astacus Norvegicus, Linnaus, Norwegian Lobster.-Nephrops, Leach. Plates LVI., LVII., LXX. figs. $6,7,8$.

From the Cancer we endeavour to advance by intermediate stages, wherein are found great modifications, to the Astacus. Perhaps, instead 
of the Astacus marinus, other genera dwell either in this or in foreign countries, whereby the transition might be more naturally and effectually shewn, but satisfactory illustrations will be probably found in the two we have just named, the Astacus Norvegicus and Astucus marinus. With the last we are most familiar, it is readily and easily obtained by many, who prefer beholding every object itself to confiding in the correctness of description. Perhaps this is always the best method of acquiring knowledge.

No better example of human ignorance can arrest our progress than contemplating the formation of the animal before us; to describe its various parts is scarcely within the power of language, and to explain the use for which the Governor of the Universe designs them, surpasses the narrow and coutracted sphere of our widest range of learning.

This is a beautiful, lively, and active creature, common in some places, scarce in others, and affording some room to conjecture that it may be migratory. Certainly it is sometimes very difficult to be obtained, nor ought the words of a distinguished Northern naturalist to be overlooked,-—"Hunc semel in mari vidi versus superficiem aquæ, antennis brachiisque longioribus mire ludificantem."-Falnicius, Fauna Groenlandica, No. 219.

The largest specimens in this country extend thirteen inches from the tip of the antenuæ to the marginal extremity of the caudal fringe, whereof the body, as invested by its shell or carapace, occupies six inches to the point of the rostrum. The large claws, and the long antennæ, are of about half the extent of the whole animal, that is, between six and seven inches.

First, the carapace or principal shell, commencing with the rostrum, is guarded by five rows of spines ; three narrow indefinite segments, then four strong and distinct ones, when the whole terminates with the caudal segment, as composed of its five fringed members.

It would be difficult to frame a minute description of the animal, for which some general observations must suffice. The two claws commonly exhibit disparity in length and strength; various rows of thoms or teeth, all tipped with white, run longitudinally along the interior sur- 


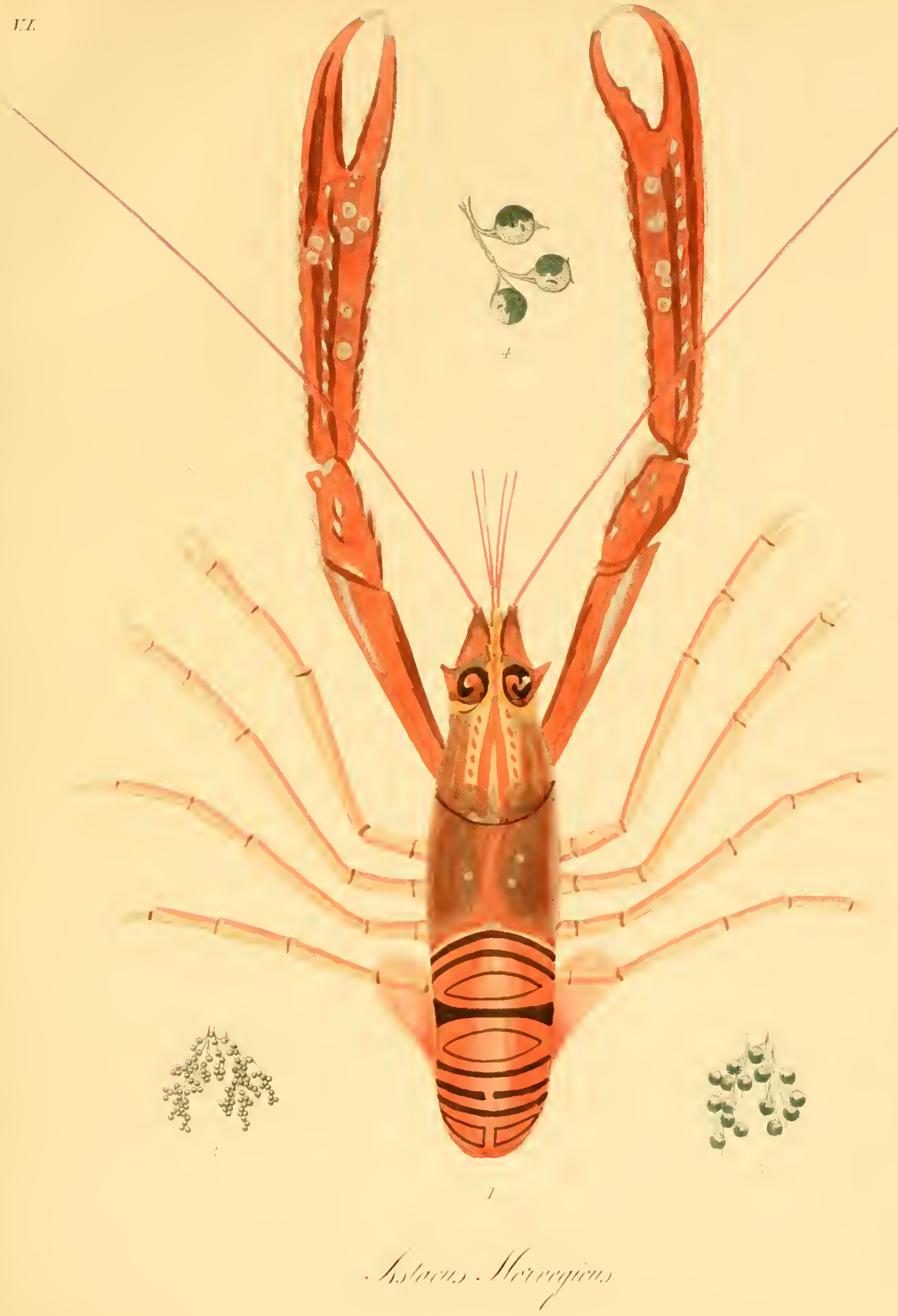



face. Two pair of the limbs next them are each provided with forceps, which are wanting in the rest. Several thin finny processes, of irregular structure, auxiliary to the animal's motions, also in securing the roe, and for other purposes, belong to the interior of the part between the limbs and the last segment. As two pair pertain to each segment, there are ten pair in all,-_each consisting of an oval plate, completely fringed, unless at the root, where the united plates are connected with the animal. But the reader, to understand these obscurities, must rather resort to inspection of the parts than endeavour to discover their structure and use by explanation.

Two long external antennæ originate from beneath the anterior extremity, and between them two others, shorter and forked.

All consist of numerous vivid, red, cylindrical segments, with interannulations. The shorter antenna are of curions structure, and beautifully annulated ; the interior of the shorter limb of the fork is fringed by pencils, and some straggling hairs near the upper part. No pencils appear on the other limb of the fork.

A large black reniform eye, of very peculiar aspect, apparently derived from a shelly plate sustaining the one side, rises on each of the sides of the rostrum.

Many parts of this creature are very finely fringed, the fringe consisting of the most luxuriant and beatiful feathers, as exposed by the microscope. The same structure pervades those of the head, those of the abdomen, and those of the caudal extremity ; the pediments sustaining the long antenux are fringed by above sixty such feathers. None of these ornamental borders are displayed, unless by the animal during life.

The tail itself consists of a central portion, with two moveable foliaceous plates on each side, thus making up the whole complement of five portions. A lateral fold or joint, with a spine on each side, distinguishes the external plate at a third of the length of each from the fringe.

Owing to the length of the body this appears a slender animal, and in fact it is so. A specimen extending thirteen inches was only fourteen lines thick. All the parts of those much smaller in size will be found in nearly the same proportion as here specified. The body of one extended 
four inches and three quarters from the point of the rostrum to the caudal fringe ; its large antenna and claws were of about equal length, or the claws somewhat shorter.

It is to be observed, that the curvature of the tail is never relaxed during life; and if a delineation, proposed for the extending animal, is commenced while it lives, this must be completed after death, - a general rule, affected only by peeuliar incidents.

Females are full of spawn in April, which is exposed in the same arrangement as in the common lobster ; now the tail is extended, for the inner surface is limed with masses of spawn, adhering to the strong fleshy bars connecting the two margins. The ovarium is of a very faint, dull, greenish colour, sometimes appearing almost bluish. The ovum itself is quite spherical, with a speckled shining integument; at the period, of which I now speak, the eyes of the included young are visible.

The Norwegian Lobster, frequenting the Scotish seas, is commonly taken unintentionally in the nets of fishermen.

Plate LVI.

Fig. 1. Astacus Norvegicus.

2. Spawn.

3. Portion of spawn, enlarged.

4. Three capsules, more enlarged.

\section{Plate LViI.}

Fic. 5. Astacus Norvegicus, prolific female, under surface.

\section{Plate LXX.}

Fia. 6. Astacus Norvegicus, upper portion, shewing the fringes ; the antennæ curtailed.

7. Another specimen, shewing the fringes; $a, a$, fringe; $b, b$, curtailed antennæ.

S. Caudal extrenity of the same.

The Norwegian Lobster is called the Cray fish by the fishermen, but none other is so denominated by them. 


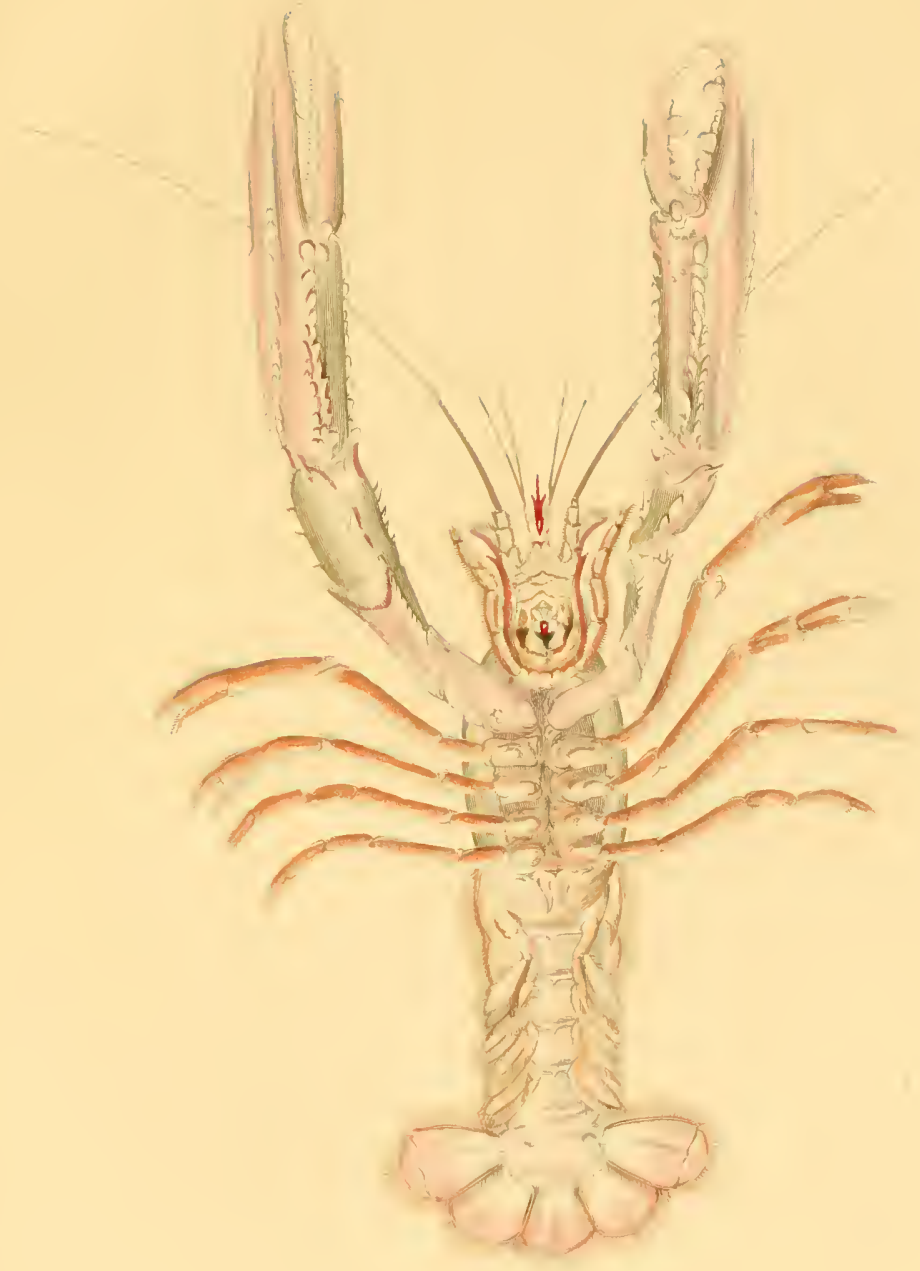

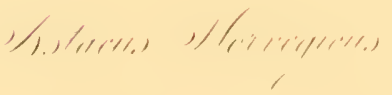



I am not aware that the Fresh water Cray-fish is naturally an inhabitant of Scotland; but a brood was introduced, thirty-five or forty years ago from England, by the proprietor of New Posso, in the county of Peebles, which, together with the progeny, has been extirpated for at least twenty-five or thirty years.

It is from the ova of the cray-fish that a learned naturalist, Rathke, hath demonstrated the progressive development of the embryo. Amidst many attempts to accomplish the like from a number of the other crustaceans, I have been uniformly unsuccessful. It is true that the general form and position of the subject included is sufficiently exposed, but the integuments are never refined enough to shew the regularity, the true arrangement, or modification of the metamorphosing parts.

The genuine cray-fish is said to dwell chiefly in muddy streams, whereof, from the mountainous nature of the comntry, we have very few in Scotland.

\section{§ 2. Astacus marinus-The Common Lobster.-Plate LVIII. LIX.}

No animal is more familiar than the Common Lobster: its form and habits, together with the womnds it is prone to inflict on unguarded curiosity, are sufficient to imprint its recollection on the memory. At the same time, there is scarcely any other of its kind whose history is less known.

It is everywhere songht as an epicurean delicacy, and sometimes purchased for high and unreasonable prices. Besides, from the absolute alteration of colour nuder culinary operations, the animal is viewed as a curiosity.

The Lobster attains considerable dimensions in Scotland; and, where it can escape the wonted persecutions of mankind it certainly lives many years.

In the middle of December, I procured a fine specimen of a living female, laden with a profusion of roe. It extended twenty-two inches in length, from the tips of the antennae to the caudal fringe. Of this, the carapace or body-segment, which is the criterion of dimensions in a 
commercial sense, extended above six inches, the large claws nearly eight, and the antemne towards ten.

The tail is composed of seven segments.

Another female, also laden with a profusion of roe, extended twelve in hes from the extrenity of the rostrum, the length of the claws being seven inches.

The proper colour of the Lolster is understood to be pure black, which is converted to red by boiling. Few, however, are pure or jet black, and many parts of the under surface especially, are mottled in various specimens, which even appears on the immer surface of the claws.

Capsules, in thousands, invest the inner surface of the tail, often appearing as a great mass, being affixed in five or six portions, both to the bands by which it is crossed, or their appendages, and the margin of the tail. These ova are minute, spherical, black, opaque, and united in bunches like small black currants. On boiling some from a specimen in the end of January, the colour was converted to red, exposing the black eyes of the included embryo very conspicuously through the integument. It is difficult to define the real dimensions of Lobsters; great disparity of size certainly prevails among them. Some, if not all the large, are arried both from Scotland and other northern kingdoms, where none are reckoned marketable, to London.

I was indelsted to Mr Gillespie Graham, an eminent Scotish architect, for inspection of part of a gigantic claw found near the Isle of Skye above thirty years ago. This, the first or exterior joint, with the forceps of the left claw, measured nine inches in length, four across where broadest, and two and a half through where thickest. According to ordinary proportions, the whole organ nust have been between eighteen and twenty-four inches in length, conserquently, the entire animal at least three or four feet long.

The Lobster fishing is conducted on a considerable scale among some of the Western Islands of Scotland, for the supply of the London market.

It is said that few are taken under nine inches length of the shell, nor will the agents for the fishery, superintending the produce, receive 


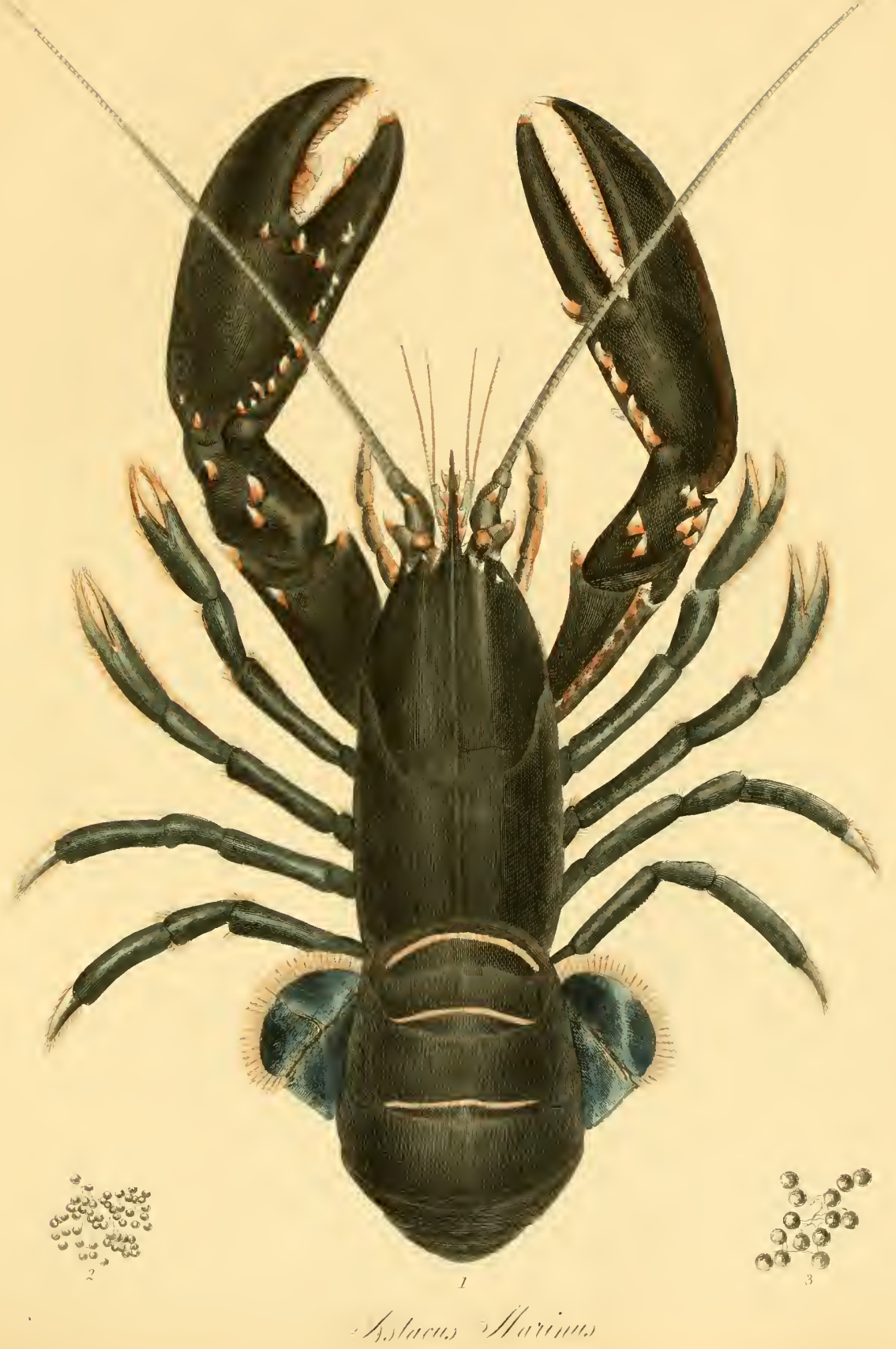


those under eight. The fishery is carried on by boats and nets at different stations. Six or seven dozen Lobsters may be captured during the night, by a single boat, in favourable weather; and it is said that 60,000 have been taken in the course of a year, by the boats belonging to the Islands of Lewis and Harris.

\section{Plate LVIII.}

Fic. 1. Astacus marinus, the Common Lobster, back.

2. Cluster of spawn.

3. Portion of the same, enlarged.

Plate LIX.

FIG. 1. Astacus marinus, the Common Lobster, prolific female, under surface.

§ 3. Crangon-The Shrimp.-Plates LX., LXI.

Those leamed authors professing themselves the most sedulous for arranging the Systema Natura, have associated very few animals with the Lobster tribe, subdividing those of analogons form and nature into other groups, whereof the Shrimp is comprehended as one. Nice distinctions are not my special object so much as pointing out the kindred, uniting numbers together in concentrated families, whereby I would chiefly confine myself to the general configuration falling within the sphere of observation. It is more convenient that naturalists should select such subjects as they can command most readily, or such as they think they can discuss most satisfactorily; but it is mortifying that, of the present animal, like the preceding, very familiar by name, the two authors in highest repute for their writings on Carcinology, should not have thought it worthy a syllable: whereas it is certainly as interesting as any other parts of their history, and the more especially as their labours would have been much more effectual than mine.

The shrimp, in this country, is commonly of small size, and may be compared in form and aspect to a diminutive lobster.

The largest specimens extend four inches and a half from the tips 
of the long antennæ to the caudal fringe; these antennæe are about an inch and a half in length: the smaller antenne between them are forked.

Two spherical black eyes, without any sensible peduncle, are seated on the back of the hear.

The large claws are terminated by one-half of a forceps, and a hook opposite to it: the caudal segment terminates in five members, whereof that in the centre tapers nearly to a point; the others are finely fringed.

The natural colour is dark grey, approaching black; but it is extremely variable, often becoming very pale, and sometimes almost white: the integuments are likewise so thin and transparent as to expose both the form and the colour of the food in the stomach of the animal.

This is a very lively creature, growing quite tame on short confinement, and always approaching the visitor of its vessel's side; it is absoIutely caruivorous, all animal substances being acceptable to it.

The shrimp, while supine, frequently seizes fragments, and preserving the same position, swims away with them, around and around the interior of the vessel, all the time devouring its prey.

An extraordinary change of colour is concomitant on feeding.

The shell is often cast; but no definite external symptom seems either to amounce or to regulate exuviation. The true form of the parts is to be best ascertained from the slough, which includes the long antemne: or, if there be a fissure in any part of the skin, it is in the membrane of the lowest part of the carapace or bory-shell, where connected with the next segment. The slough is very pale grey, and appears somewhat gelatinous when raised from the water: in a few days it becomes as white as paper. It is not improbable that this is the season of imbecility, enabling the stronger to devour the weaker, while so imperfectly protected. Specimens have fed the day before exuviation.

The occurrence of this incident is extremely irregular. A specimen, some time in my possession, was delineated on June 17th,-Plate LX. fig. 1 : on the morning of July $2 d$, it cast its shell, and this was repeated on the 31st of the same month. The slongh, now separating, is represented Plate LXI. fig. 2. A few days afterwards, the animal leapt out of the water and perished-the ordinary fate of the species. 


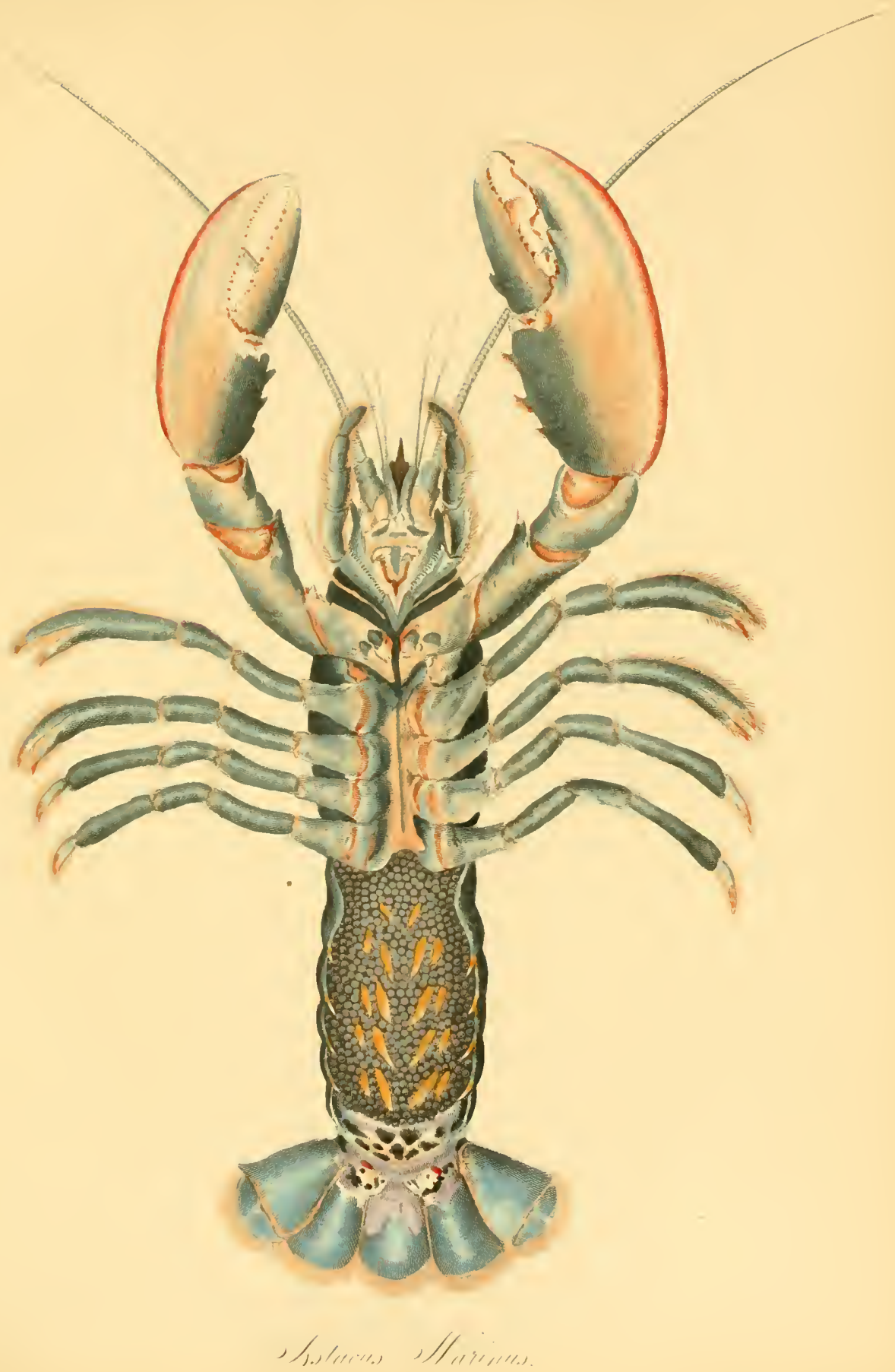




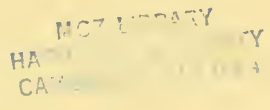


The female contains a great quantity of roe, occupying most of the surface of the abdomen, and consisting of large grey capsules, which reach maturity chiefly in June and July. On June 2d, many from above an hundred specimens then proved prohific, Plate LX. fig. 2. On July 15th, above an hundred specimens being again obtained, many females among them also proved prolific.

Their propagation, however, is not confined to summer. The embryo is long of attaining maturity ; it escapes from the capsule while still adhering to the body of the parent.

Now, the young animal is very minute, not extending above the third of a line, white to the eye, and grey under the microscope, quite unlike the parent in every thing. At first only two claws and six limbs are developed. Four prongs, each bearing several bristles, issue from the front of the head, on the sides of which the eyes are implanted. Five segments follow the carapace; a sixth, with the tail, terminates the animal.

The young swim actively, and congregate at the side of the vessel exposed to the light. Their delicacy is unfortunately such that they cannot be preserved so long as to shew the progress and completion of metamorphosis.

The natural and favourite abode of the shrimp is smooth sandy shallows, near the sea-shore, where it burrows among the wet sand, to remain on recess of the tide.

It is neither difficult to be got nor to be kept.

In captivity it speedily becomes very tame and familiar, and its peculiar habits are sufficiently amusing to the spectator. Yet it is of precarious preservation; nor is it to be trusted at any time in a shallow ressel. On the slightest alarm, it makes surprising springs, and almost invariably perishes by leaping out of the water. Specimens have survived many months in my possession.

\section{Plate LX.}

F1G. 1. Crangon vulgaris, The Common Shrimp, back.

2. Prolific female, under surface. 
Plate LX.

Fig. 3. Claw, enlarged.

4. Detached ova, enlarged.

5. Young from the capsule, enlarged.

6. Head of the same enlarged.

7. Tail of the same enlarged.

\section{Plate LXI.}

F'1G. 2. Cast shell-slough of Plate LX. fig. 1.

Vote.-Many subjects, congenera of the Crangon, dwell in the Scotish seas. I regret extremely that when some of the most curious and beautiful occurred, a number of years ago, I had not then the means of preserving sufficient materials for their history. It is long since I have been deprived of suitable opportunities for resuming that branch of zoological research. A few drawings, indeed, remain, but I would avoid converting them to their original purpose, unless corroborated by repeated observations. Therefore I shall restrict myself to very little more on the subject, as an appendix to the preceding paragraph.

\section{§ 4. Pandalds annulicornis-The Ring-horn Shrimp.-Leach.- Plate LXI. figs. 1, 3, 4, 5.}

Though this is not identified at present with the genus Crangon, the difference was not acknowledged by former naturalists.

The animal extends five inches from the tips of the antenne to the extremity of the tail.

The whole body is finely variegated red and white; and the annulations of the antennæ are red and white altermately. Females have been full of roe in small spherical white capsules, spreading over the abdomen, in February, March, and April. The eyes of the young herein appear very conspicuous, on approaching maturity; some have been produced in the middle of February. 

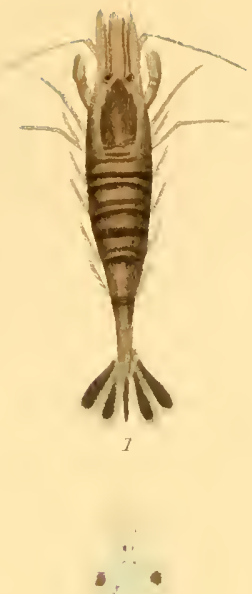

is

13

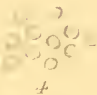

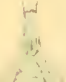
sis

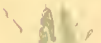

hy

( )
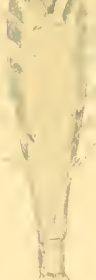

$+8)_{1}$

Ji,

r II!IIII! 

Exuviation ensues at all seasons, the shell or slough separating quite entire. Like the former, it is perfectly transparent, and has much of a gelatinous aspect when raised from the water.

\section{Plate LXi.}

Fig. 1. Pandalus annulicornis-Ring-horn Shrimp-adult, back.

2. Cast shell of Crangon.

3. Another specimen of Pandalus.

4. Cast shell.

The preceding remarks must suffice for the meantime, though the reader would find many others very interesting on a more comprehensive survey.

One of the genus Hippolytus, so named by Dr Leach, is represented Plate LXI. fig. 5 . 


\section{CHAPTER IV.}

\section{MISCELLANEOUS CRUSTACEANS.PLATE LXII.}

THE leading features in the history of the principal member of the Crustacean race, the Crab and the Lobster, have been sufficiently illustrated by the preceding discussion.

Nevertheless, many subordinate genera remain, whose nature requires elucidation. Some of these are most obscure and ill understood, and present a series of curious and interesting facts for explanation. Therefore, descending but little into minutia, I would propose to engross their names in a miscellaneous chapter, from which any particular subject may be selected for special commentary.

I an sensible that the whole will require acurate revision, correction, and amendment, wherein I must claim the indulgence of the reader.

Let me remark, besides, that, in the course of protracted observations, numerous subjects new or unintelligible, fall under notice,-that many are mutilated or imperfect, - and many indistinctly seen, concerning the nature and form of which only conjectures can be offered, it is very likely that any account of them compiled from defective materials, will scarcely convey conviction along with it; but combining the substance obtained by several observers, it is possible that, if not arriving at the truth, we shall be in less hazard of deviating far from it.

We shall not attempt to follow any regular order here. 
1: 7

I'L. LXI
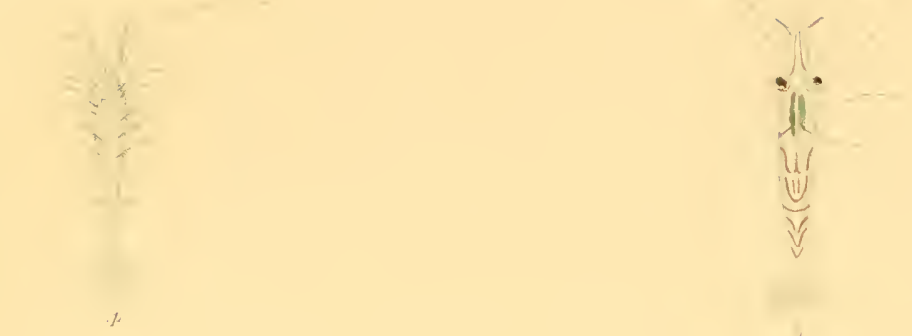

$\frac{1}{5}$

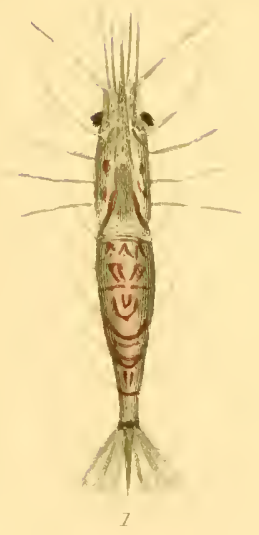

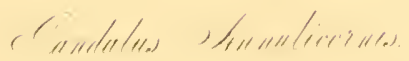





\section{$\oint 1$. Cancerilla tubulata.-Plate LXII. figs. 1-5.}

Various reasons might be given, perhaps, and those sufficiently convincing, for adding this animal to the list of Entomostraca, which, under its present state, is rather indefinite.

A youmg Ophiura, a kind of Star-fish, as above shewn, its slender rays expanding about nine lines, was taken in the beginning of Mar; Plate LXII. fig. 1. A very minute foreign object was observed affixed to it a fortnight later, at the root of one of the rays, but so much intercepted, and so indistinctly seen, that its precise form could not be determined. The ray, however, having fallen to pieces on the 25th of the month, as incident to these animals, left the disc entire, where the object was exposed as a prominence, fig. 2, and, on reversing the dise, it appearerl under the microscope, as in fig. $3, \alpha$. While clinging to the mutilated disc, more of it was discovered than previonsly.

This minute object proving a parasite, detached itself, when I concluded it to be one of the Crustaceans, and probably allied to the Cancer family.

The shell, rather a clumsy oval, was of dull yellow colour, bearing a red cross on the centre of the back, and a red speck in front: its form rudely triangular, the margin tolerably even, with two antemne apart from each other, rough, with hairs or bristles. No eyes were visible, probably from the position, nor conld I find above six legs, which were armer with claws. The animal fell on its back, and the legs were in considerable action.

Two short cylinders, each crowned with a globular enlargement, formed appendages to the body, when about twelve distinct vivid blue ova could be enumerated in each of the spheres. On June 2, these were so far matured, that the form of the included foetus was perceptibly irregular, as exposed through the integument. In two, a red speck like an eye was observed. The whole parasite might have been inscribed within a cirele a line in diameter.

The parent was dead on the 5th of July, and the internal parts having decayed, only the shell, with its red cross, remained. 
Fortunately, the young, which had been hatched a day or two previously, survived; they were extremely minute, provided with six legs, and had a red speck on the surface of the shell, towards the anterior.Plate LXII. fig. 5.

My convenience was neither such, nor the position of the animal so farourable, as to admit minute and accurate inspection of all the parts, whence the preceding must be taken only as a general view of the subject. Besides, my reluctance to advert to a single specimen is notorious. I should avoid doing so, but from the chance that some one better informed, may be able to supply what I am compelled to leave deficient.

It is extremely probable that what was exposed, will prove that this creature may belong to the Cancer tribe, and that it may be classed as an unknown genus, closely allied to the Entomostraca, especially as indicated by the globular ovarian appendages. The red speck may be an eye, and the feathered antennæ, if they be truly such, may assist us in assigning the animal its true position.

I have never seen any instance wherein the nicroscope proved so useful an auxiliary.

No other specimen has occurred.

Plate LXII.

F1G. 1. Young Ophiura.

2. Disc of the same.-Cancerilla, $\alpha$.

3. Dise of the same.-Cancerilla, $a$,

4. Cancerilla detached from the Ophiura, enlarged.

5. Young Cancerilla from the ovarium of fig. 4 .

\section{§ 2. Astaricilla.-Plate LXII. figs. $15,16,17$.}

The subject of this paragraph being originally weak, mutilated, and imperfect, must be considered as involving many difficulties opposing correct observation. I say nothing of diminutive size if all the parts be present, thongh that is also an embarrassment; but where the organs are actually wanting, it is obvious that our endeavours to supply the deficiency may lead us very far astray, unless for one individual. I have 

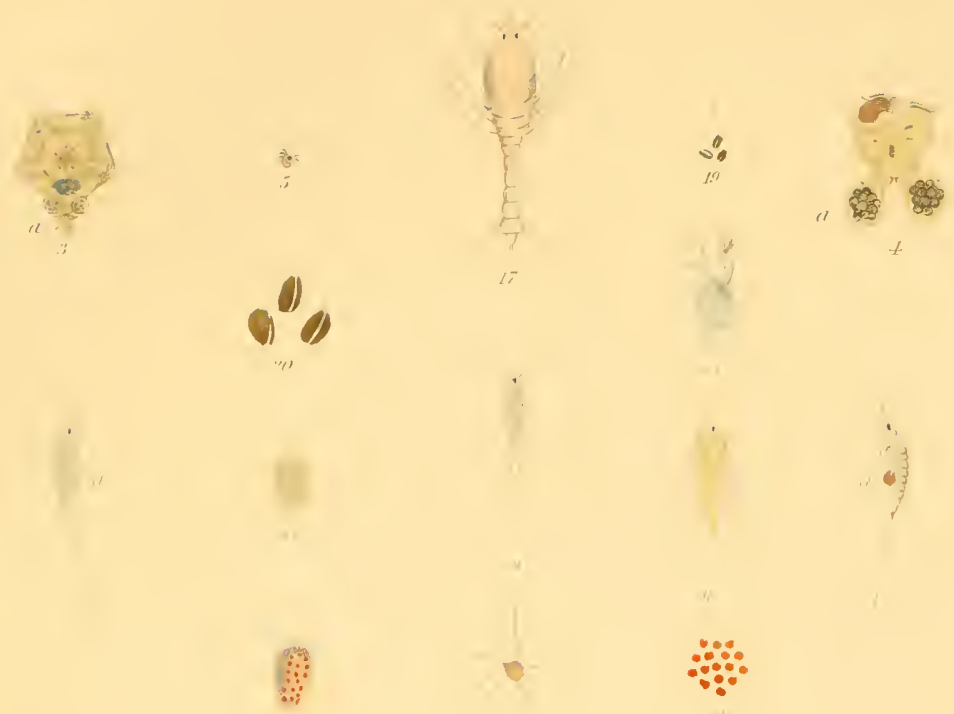
$\because \because$
$\because \because \because$

$\because$

\section{1}

紊

a
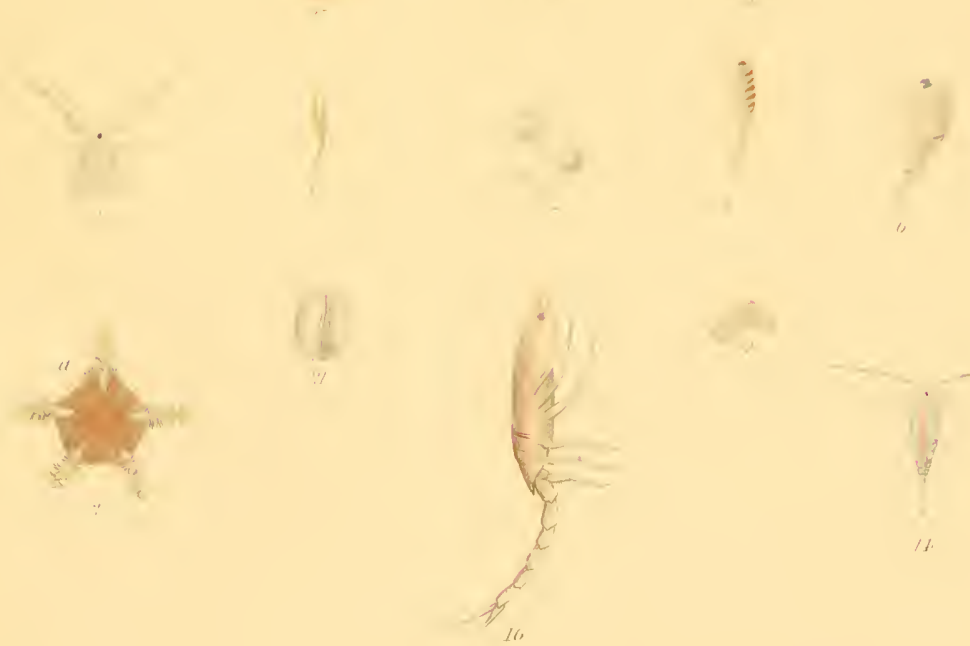

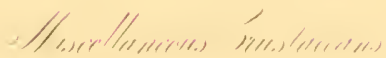



never seen or heard of any specimen ; but, whether it may not be identified with the Cancer scorpioides of the late Mr Montague, who also describes a mutilated specimen, I cannot presume to determine.

This specimen occurred among the muddy residue from a quantity of marine collections.

The form bears a considerable resemblance to the general appearance of a lobster ; yet I cannot pretend to definc precisely the number and structure of the organs of which it is composed : figs. 15 and $16 \mathrm{scem}$ to me sufficiently expressive,-the former, natural size, the latter, magnified, of the animal. Total length six lines. The body composed of about six segments, the first infinitely the largest, and much resembling a lobster shell ; the tail romnd, solid, and consisting of seven articulations, the last with a small fork. The animal lay constantly on its side ; but, if rising to stand, which was seldom, it carried the tail erect, at right angles to the body, or sometimes recurved and folded in, as usual with the lobster.

When the creature was stimulated, it rose and sprung up among the water, as if to reach the surface: otherwise it scarcely ever inclined to move; colour universally brownish or dingy white.-Plate LXII. figs. 15,16 .

I could discover nothing more from the original, hitherto the exclusive subject of reference, than above described; but, in about three weeks, I was induced to conjecture the presence of an advancing ovarium in the vicinity of the abdomen, though I conld not discern it distinctly. On the 26tli of March, however, my conjecture was partly confirmed by finding a number of the young.

It is from these and the adult that we are to understand the real structure of the animal, not forgetting that possibly it may undergo certain modifications from subsequent metamorphosis.

The young were pure white to the naked eye, not extending half a line. When subjected to the microscope, they exhibited what was defective or imperfect in the parent. Thus, tlic antenum were forked unequally, the smaller prong being an offset at a third of the whole length above the root; a forked offset also issued from each side of the penult 
segment, and the last segment itself terminated in a fork. The resemblance of the young to the parent was such, that whatever metamorphoses succeed, they take place at an early stage.-Fig. 17, the young Asteracilla, magnified.

The young gradually augmented in number, ultimately amounting to about thirty.

From what could be seen, there were obviously four pair of limbs, the first at some distance above the rest, besides some false feathered limbs.

This creature was found on the $2 \mathrm{~d}$ of March, among the residue of miscellaneous collections from the sea.

\section{Plate LXII.}

FIG. 15. Asteracilla caudatoc.

16. The same, enlarged.

17. Young Asteracilla, magnified.

\section{§ 3. Astacilla longiconnis.-Plate LXIII. figs. 1, 2, 3, 4 .}

This is an animal distinguished by such singular appearance and habits, that neither can escape the notice of the least observing. As if confined within a long cloak, the limbs are employed to secure its stability; two monstrous horns load the head, and in reposing, as it grasps the slenderest twig with its six hind feet, while all the body is bent back above the point of fixture, it actually seems broken backed.

The Astacilla, whose generic name it has been proposed to convert to Arcturus, extends two inches from the tip of the antennæ to the extremity of the tail.

The body is subcylindrical, composed of eight unequal segments, from which four pair of jointed limbs originate, and, at a considerable interval lower down, other three pair of plain limbs armed with claws. These three pair spring from a segment equalling half the length of the whole animal, which terminates in a caudal segment of foliaceous structure below, besides the two large antennæ of five articulations each, and two short feathered antennular organs under them; there is an eye on 
each side of the head. The usual colour of the animal is dingy white throughout.

The four pair of upper members resemble a rich furred ruff, in fine specimens; but, in poor specimens, the fringe clothing them is little more than perceptible,-if these are to be accounted limbs, the whole complement, including the six posterior members, is fourteen, which may have led some observers to consider the Astacilla a species of Oniscus.

Its motions are very singular, aggravated, perhaps, by apparent extraordinary disproportions. The position frequently assumed, and long retained, is adhering by the hind legs to any foreign substance, with the head downwards. I have never seen any specimen attempt to swim, to which, indeed, its general form is quite adverse.

\section{Plate LXIII.}

Figs. 1, 2. Astacilla, natural size, fig. 10, enlarged.

The exuviation of a specimen took place during the first week of October, when the shell was detached in trro portions, the posterior comprehending the six hind limbs.

The season of propagation extends from March to December. The union of two fine large specimens seemed to ensue on the 12 th of this latter month: ova appeared June 14th, on the thornx and abdomen of another specimen. But the presence of a diminutive white zoophyte injured the roe, which proved abortive of progeny.

As the position of the spawn is not exposed to view it certainly remains attached to the parent, while the young quit the capsules, and are seen running about the vessel.

A full grown specimen having reached me on March 21, a suitable vessel received it. Herein I was much surprised next day to find above sixty young, which had been recently produced. All were pure white; they exceeded a line in length; their black eyes were rather oval; and they entirely resembled the form of the parent.

Some circumstances are perplexing, especially regarding the number, for it may be questioned whether some had not been concealed, or attached unobserved. 
A different specimen, of ample dimensions, which had been in my possession, though always refusing to feed, from the beginning of May, was then breeding unobserved. On the 21st of the month its remarkable appearance struck me while inspecting the vessel. It always stood erect on a piece of sponge, the body at right angles to the six hind feet. The long antennæ now stretched forward as usual with the species, but each appeared as thick or thicker than the body itself ; and on a transient glance, I thought them invested by a coating of fur; however, this unaccountable fact was easily explained by the application of a lens. A numerons brood had been produced in the night, whereof the whole, without exception, had seated themselves on the antemnæ; yet the parent neither testified impatience of their presence, nor seemed to suffer any uneasiness nnder the burden. All were very pale or dingy white, none of them extending a line.

The young grew very rapidly. But as they continued constantly affixing themselves, it certainly proved an annoyance, which was ultimately fatal.

This animal dwells in the deep sea : fine specimens are rare.

\section{Plate LXiII.}

Fig. 1. Astacilla (arcturus) longicornis, fringed apparatus.

2. Another specimen.

3. Anterior portion, fringed organs, $a$.

4. The same enlarged, fringe, $a$.

§ 4. Oniscus balthicus (Ideotea mariva).-Plate LXIII. figs. 5, 6, 7, 8, 9.

A genus of animals was constituted under the name of Oniscus by the older naturalists, which perhaps engrosses the whole subjects of this and the following paragraph ; they are both pelagic and littoral. Later naturalists have incorporated the two together under the generic name Ideotea.

Length of the Oniscus balthicus from the tips of the antennx to the posterior extremity twenty-one lines. The body is divided into nine seginents, whereof the first constitutes the head. In front are two 
larger and two smaller antennæ, besides two eyes, also situated in front. The last segment terminates in an obtuse projection, and covers some follicles at the extremity below. Of the four antennæ the two external are half an inch long, rather stout, and pointed, consisting of five articulations ; an internal pair, nearly in the middle between them, are shorter. There are fourteen limbs disposed as seven pair, each provided with a recurving claw; fig. 8, a, limb; fig. 8, b. Colour dingy yellow, or brownish-yellow, with three or four white specks down the centre of the back; or it is altogether of variegated, and some are mottled.

This creature feeds voraciously, seizing and carrying off prey in its fore limbs. It also devours the smaller crustacea and mussel very readily. It swims swiftly, and when at rest it generally clings to some substance admitting of its position supine.

Exuviation ensues at different seasons; the shell has been always cast in two portions. Perhaps the limbs are arranged in two divisions, separated by a slight excess of the usual interval.

The variegated specimens are beantiful animals, especially when first appearing in their new shells.

I have been induced to conclude that the number of segments is only seven, though nine may appear from some delusion.

\section{Plate LXIII.}

Fic. 5. Oniscus (Ideotea) balthicus.

6. Last segment of the same, enlarged.

7. Cast shell, anterior portion, enlarged.

8. Variegated specimen; fig. $8, a$, limb; fig. $8, b$, antennæ.

9. Greenish specimen.

\section{§ 5. ONISCUS (IdeOteA) ENTOMon.-Plate LXIII. fig. 10, $a$.}

Several anthors name this subject, but few seem to have had it alive. The Baron de Geer, who treats at large of various crustaceous animals, observes, that, never having seen a living specimen, he can say nothing of its habits; Tom. 7, p. 523. 
It is a creature very easily recognised, however, from the form of its body, and of the larger or external antennæ.

The finest specimens extend above eighteen lines from the tip of the antennæe to the lower extremity. The body subcylindrical, is composed of nine segments, whereof the first and last are the head and tail, the latter much excceding the length of any of the others. Four antennæ, two larger and two smaller, are borne on the head, the larger or exterior pair consisting of five articulations, with a large black eye seated at the root of each. Fourteen feet, armed with claws, are disposed in seven pair along the body, whereon some bristles are to be seen. Colour greenish.

This is an active creature, it darts swiftly through the water, sometimes tumbling amidst it. When swimming, the larger antennæe are closed, and advanced in front.

It feeds readily and greedily on animal substances, devouring them also as they are carried along between the fore legs.

\section{Plate LXIII.}

F1G. 10. Oniscus (Ideotea) entomon, enlarged; fig. 10, $a$, relative proportion between the body and larger antenna.

§ 6. Asellus Medus.E.-Plate LXII. figs. 6, 7 .

Two parasites, which I can describe but imperfectly, frequent the Medusa; though whether to prey on it, or merely for rest and protection, I have been unable to ascertain.

Their appearance is very different from any of the preceding animals; and unless in the presence of two eyes, both bear much resemblance to the Cyclopean race among the Entomostraca.

Length about half an inch; thorax large and thick, occupying half the whole extent, the lower part of the body tapering abruptly downwards, while small in proportion.

Two short spinous black tipt antennæ, and other two are below, somewhat apart from them, of about the same length. Two large oval eyes 

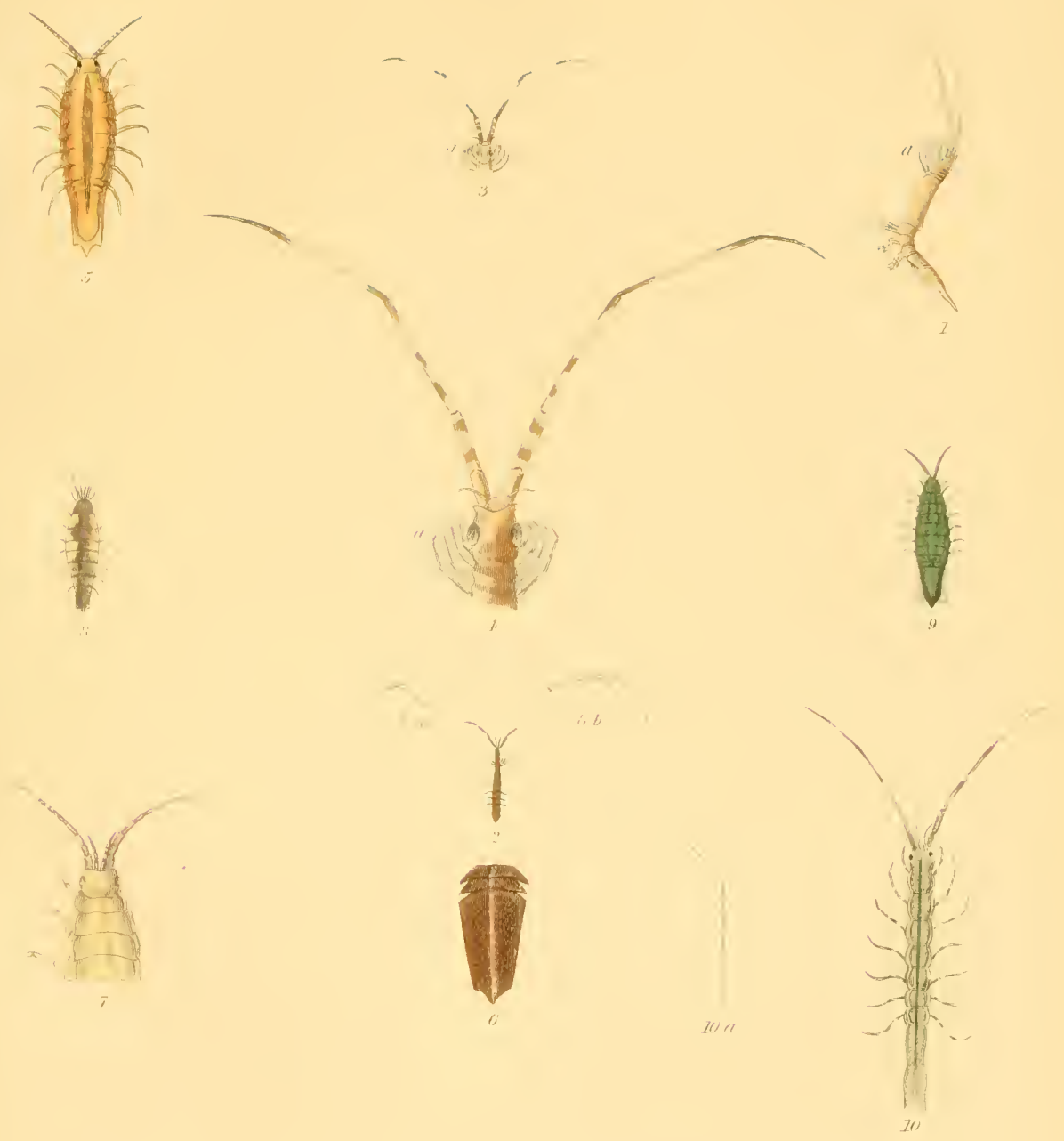

15. 

are seated in front of the head. The caudal extremity terminates in two large leaves, each with two triangular, flat, finny prolongations, and a similar prolongation with the like projections on each side of the two leaves. Besides some appendages below, there are ten limbs provided with claws. Colour grey; sometimes almost white.

This animal dwells as a parasite on the outside and inside of the umbrella of some of the larger Meduse: it often lies supine on its back, curving and elosing up like the terrestrial Oniscus. It also swims swiftly through the water, where a portion of its shell projects dry and glossy above the surface.

Twelve or fifteen of these animals being removed from nine Medusa on the 18th of September, several of them appeared to be prolific. The spawn adhered in a cluster high on the abdomen, but specimens remain so closely and pertinaciously in their curvatures, as scarcely to allow distinct inspection.

A prolific specimen having been committed to a separate vessel on September 19, about fifty young were found there. They were very minute and lively, white to the eye, and grey by the microscope. Their limbs amounted to ten, all of the same charncter, being provided with claws. The tail folded in like that of a Lobster.

The young animal, rolling itself up, remains on its back like the parent, a striking feature in the habits of the adult, which continues in this position on any part of the Meclusæ without falling off, as might be expected, from having no external means of adhesion.

It was impossible to obtain a view of either the eyes or the caudal extremity of the young. Probably a certain metamorphosis is undergone, whereby the lower organs are developed.

Another brood, of about sixty, appeared on Septernber 29, from is prolific specimen in a different vessel, all pure white like the preceding.

\section{Plate LXII.}

Fic. 6. Asellus in edusc, adult.

7. Young, enlarged. 


\section{B.-Aseluds Medus.E.-Plate LXII. fig. 8.}

Some years ago, I had occasion to make the following entry in my journal, regarding another parasite on the Medusa, which no subsequent opportunity has enabled me to repeat:- " Length, half an inch; antennæ, four, long and slender; two green eyes; limbs, five pair, besides a false pair ; tail terminating in pieces. It swims swiftly, and its habits somewhat resemble those of the fresh-water Crustaceans. Occurs in September."

\section{C.-Crclops stagnorum.-Plate LXII. figs. 9, 10, 11, 12, 13.}

From certain points of general resemblance between the preceding animals, and some of the Entomostraca, they ought not to stand very far apart perhaps. The latter are a very numerous race, both marine and fresh-water, many of which having attracted the notice of skilful observers, renders it unnecessary to treat of that special subject in detail. It is chiefly of late that they have become the objects of very minute scrutiny. This will be seen from the works of the Baron de Geer, of Otho Frederick Miuller, and particularly, from the copions and very valuable treatise of $\mathrm{Hr}$ Baird, a British naturalist, who, in addition to his own excellent observations, concentrates all the preceding information of others.

The animals associated as the Cyclopean race, or under the denomination of Nonoculus, derive their character from Nature having provided them with only a single eye, instead of two or more bestowed on so many of the inferior tribes. Sometimes, indeed, two may be present, so approximated, as to induce the cursory observer to believe that there is only one.

The nature of vision, its powers, or imperfection, is extremely obscure, especially among the tenants of the waters; some exhibit a single speck, others two, four, or more, or even a profusion which are precipitately denominated eyes, without any evidence that they are truly auxiliaries of vision. But we may safely conclude, that their power and their functions are alike equivocal.

The subject of this paragraph having been noticed by others, I 
shall briefly remark that it is a minute animal, under a line in length, from the tips of the antennx to the extremity of two terminating caudal forking hairs. The body is composed of about nine segments, the first, with the head, the largest. Of four antennæ, two in front are much larger than the others. A single black eye is interposed between their roots. Seven pair of limbs, and some organic parts, which aid the animal in swimming, run along the under portion.

Prolific females bore a cluster of twenty or thirty spherical ova or capsules, attached as an ovarium to the thorax and abdomen of two specimens; with such clusters the ovarium of one appeared at a slight interval from the body on November 24, being perhaps contained in a sac ; that of the other was in immediate approximation. The cluster is of an ovoidal form, and yellowish colour.

This animal inhabits fresh-water pools : it is not common.

\section{Plate LXII.}

Fig. 9. Cyclops stagnorum, enlarged, back.

10. Head magnified.

11. Prolific female; ovarium enlarged.

12. Another, enlarged.

13. Ovarium magnified.

\section{D.--Crclops Punctatus.-Plate LXII. fig. 14.}

The Cyclopean race might be partitioned into several sections, which is unnecessary here, from the brevity and the nature of these incidental observations. The monographers of the race have amply shewn how it is to be distributed. The varieties, which are not numerons, dwell both in the fresh-waters and in the sea. Belonging to the latter is the Cyclops punctatus, a minute animal, extending only about a line and a half. The body consists of several segments. Two very long slender antennæ, composed of numerous articulations, and bearing several bristles, originate from the head; and interposed between the roots 
situated on the centre of the head, is a small dark eye. The tail, consisting of several articulations, terminates in a fork of two pencils.

This animal moves swiftly by jerks through the water.

One specimen has occurred, whose colour, when dead, was converted to white.

\section{Plate I.XII.}

FIG. 14. Cyclops punctatus.

\section{E.-Cyclors fasciatus.-Belted Cyclops.-Plate LXX. fig. 9.}

I speak with some hesitation of this creature, which in form is somewhat oniscoidal. It is about a line in length, and rather of flattened figure; springs through the water, and is orange to the eye. Towards the posterior extremity it is distinctly begirt by three belts.

It was very common a number of years ago, but $I$ have not seen it of late.

Plate LXX.

Fig. 9. Cyclops fasciatus.

§ 7. NYMPHON GRACILIS-Plate LXIV. figs. 1, 2, 3, 4, 5, 6 .

The resemblance of some animals, such as the Hyas araneus, and Cancer phalangium, to the spider, is perhaps much less impressive than that of the Nymphon, whence certain naturalists have explicitly distinguished it as the Spider Crab. Undoubtedly this must be considered a very singular looking creature, of a strangely disproportioned form in the reciprocal dimensions of its organs, and still more extraordinary in the attitudes assumed, so unlike those of all other animals familiar to ns. A slender body, not lialf an inch long, nor half a line thick, with an organ resembling fangs or forceps in front, is sustained on four pair of long, feeble, slender limbs, expanding above two inches and a half between their opposite extremities. On the upper surface are four eyes. Colour universally dingy yellow, sometimes almost white.-Plate LXIV. fig. 1. 


This is a languid and inactive animal, of the most tranquil disposition.

Among several specimens collected on the 21st of February, was a prolific female, fig. 2 . I believe that fig. 1 , taken in another year, was a female also. But that now referred to as fig. 2 was distinguished by a great cake of spawn, not less than towards half an inch in diameter, and half a line thick. This being attached to the under surface, added still more to the singularity of the appearance.-Plate LXIV. fig. 2, Nymphom gracilis, $a, a, a, a$, limbs ; $b, b$, cake of spawn.

The animal was now sustaining itself on its limbs. It rested likewise after the fashion of the Cancer phalangium, with the body sunk amidst the whole, only in the present case the cake of roe was below, and the limbs bent back quite upright, as if to shun some inconvenience. Fig. 3, limbs, $a, a$; cake of roe, $b, b$. The cake had somewhat of a villous aspect. Forty-eight hours after assuming the strange position now described, the creature lay supine, as if dead, with all the limbs extended.

But the new attitudes enabled me to discover that the roughish looking surface of what I concluded a cake of pure roe or spawn was, in fact, a congeries of numerous young, some separating from the parent, others free.

At this period they are white, of various dimensions, and in various states, but undergoing scarcely any sensible metamorphosis, unless in the development of additioual limbs.

Of these some had four, and some had six, according as younger or older, for a few hours might produce the difference. The expansion of the limbs was from about half a line to the sixteenth of an inch between their opposite tips.-Fig. 4, enlarged. In these young animals with six limbs, the pair of the complement still defective, appeared merely two stumps.

The parent having lain some time supine, as above described, revived, and reared itself upon its legs during the subsequent day.

The production of many young still continued, either single, or by the separation of clusters, consisting of several entangled together. 
On March 4th, the parent still testified symptoms of animation, the limbs partly contracted over the adhering clusters, or unfolding on the under the surface.

Thus, in conformity with the nature of all the other Crustaceans which we have hitherto discussed, the young of the Nymphon still adheres to the parent, after exclusion from the spawn attached to its body.

Possibly the spawn is sustained in its place by auxiliary organs.

The animal dwells in the sea. It is not rare.

\section{Plate LXIV.}

F1G. 1. Nymphon gracilis, adult.

2. Prolific female ; limbs extended, $a, a, a, a$; supposed cake of spawn, $b, b$.

3. Position assumer by the specimen, fig. 2 ; limbs, $a$; supposed spawn, $b, b$.

4. Young Nymphon hatehed from the spawn, enlarged.

5. The same, more enlarged.

\section{§ 8. Prcnogondm littorale-The Whale Louse. \\ Plate LXIV. figs. $6,7,8,9$.}

The appearance of this animal is in striking contrast with that of the former ; the one being light, weak, and slender, the other coarse, heavy, and strong.

It consists of a body composed of four segments, the first prolonged as a rostrum, at the base of which are seated four small black eyes in quadrangular arrangement. The aperture of the mouth is in the extremity of the rostrum, for this is one of the suetorial Crustaceans ; but no specimen has ever fed visibly, though offered many different substances. Four pair of articulated ungulated limbs support the body, the posterior extremity of which is obtuse. The claws are firmly affixed, to secure the whole, where practicable.

This is the most languid and inactive of all creatures. It is scarcely ever seen to move, even to the bending of a limb; nor does it betray any propensities whatever that I have seen. 


There is a great disparity in the size of specimens, some being twice the dimensions, and their appearance very different from the aspect of others.

Three specimens, none of them large, were taken ; a flat, round cake, about a quarter of an inch in diameter, and nearly an eighth of an inch thick, adhered to the under surface of one of them.-Plate LXIV. fig. 6 ; of which the animal is seen enlarged, fig. 7 . This, from its appearance, I conjectured to consist of spawn, therefore it was transferred to a different vessel, where it remained several weeks. At length, being divested of the cake, I could not discover the presence of any portion of an ovarium.

The animal survived nine months.

\section{PLATE LXIV.}

FIG. 6. Pycnogonum littorale-The Whale Louse.

7. The same, enlarged.

8. Another specimen.

9. Rostrum of the same, shewing the position of the black eyes, enlarged.

Note.-Pycnogonum.-A promising young naturalist, Mr Henry 1). S. Goodsir, enumerated several species of this genus among his earlier observations. Being appointed Conservator of the Museum established by the Ediuburgh Royal College of Surgeons, he availed himself of all opportunities of investigating the history of some of the lower animals for several years, which he did with much success. His amiable disposition rendered him a universal favourite, and his talents always seemed to me of the highest order. At length, being named uaturalist and surgeon to the expedition under Sir Joln Franklin, to explore the Polar seas, he accompanied it on its departure from Britain.

\section{\$ 9. Aseldus vulgaris.-Plate LXV. figs. 1, 2, 3, 4, 5, 6 .}

It is surprising, in viewing the British Famna on a comprehensive scale, how few of the Crustaceans, even of very moderate dimensions, are to be found in the fresh-wraters, though a sufficient number in forn 
and variety abound in the sea. Some species, indeed, are profusely distributed, though others are comparatively rare. The dwelling of certain animals is sometimes such, as to induce us to involve a contradiction in calling them common, when, in fact, they prove quite the reverse.

It is extremely doubtful whether, according to modern arrangements, the proper position is assigned to this animal. Formerly the common Asellus followed the Crustaceans, in accordance with the Linnean system; but the object of that system, now abandoned, was to facilitate the acquirements of the student, by the utmost order and simplicity.

Although the species about to be described is said to be common by various authors, as its name indicates, $I$ have found it extremely rare.

There is one place, however, in the immediate vicinity of the City of Edinburgh, a pond at Red Braes, where it abounds in remarkable profusion; therefore this must be a situation most congenial to its nature, which will always regulate, restrain, or promote the numbers of an animal. Being surrounded by trees, whose decaying leaves cover the bottom of the pond, neither food nor shelter is wanting. If I have seen it elsewhere, it has been only in solitary specimens.

To the naked eye this is a coarse, and rather an ugly object, if any product of the creation can be truly deemed such from the hands of the Creator, for that is a point whereon I entertain many scruples.-Familiarity, besides, reconciling us to all things.

The curious structure of the Asellus, unintelligible by our imperfect organs, is illustrated in an admirable mamner by the microscope, always a ready auxiliary in revealing the secrets of nature. This is shewn very impressively by Plate LXV. figs. 1, 2; the first the natural size, the second an enlarged view of the animal, sufficiently descriptive of its appearance. In Scotland it is called the Slater.

Among a group of Aselli many occur under a great disparity of organic dimensions. None exceed six lines in length, by little above half a line in breadth, then declining to those most diminutive.

This creature is of flattened form, with two eyes, four antennæ, fourteen limbs, and a forking style from each side of the last segment, all constitutiug the external organs. 
The body is formed of seven transverse plates, distinctly separate, with curving ends, as sufficiently exposed by inspection from above; besides which are the first segment, with the eyes and the antennæ, and the last of different formation from any of the rest, much larger, and bearing the styles. Numerous short bristles invest the margin and many parts of the body.

The whole aspect of the creature is very peculiar, and very different from any other in these volumes, though much correspondence may be traced between the number, proportion, and distribution of the parts among the whole. This animal feeds upon vegetable matter exclusively, and, unless the next, it is the only one of the crustacean race with which I am acquainted that does so. The leaves of the beech in decay are preferred, and in such parts of the pond as these are most abundant there the Asellus is most numerous. The animal does not swim, it runs freely and expeditiously over the decaying leaves, but the smoothness of glass is so adverse to the structure of its limbs that it cannot ascend a cyclinder without the assistance of some other substance.

The breeding season extends through several months of the year. The ovarium, in common with that of the other subjects of this section, spreads over the lower part of the thorax and abdomen, consisting of about forty ova, contained perhaps in a sac, or confined by a delicate integument.

That of a specimen, being white, was far advanced on March 20th. When mature it is yellowish. Many of the young, very minute, and almost white, which had been recently hatched, were running abont the vessel, over and under the leaves, on the $22 \mathrm{~d}$ of May. They had sensibly grown on July 10th, and were then darker than previously. The young animal is about half a line long, and transparent under the microscope. On July 15th I endeavoured to secure a specimen ascending the side of the vessel, which bore a quantity of spawn on the breast and abdomen, it escaped, however, to retreat among the refuse below ; but, by means of a long glass tube, it was caught next morning.

This animal, being prolific, was well adipted for elucidating some investigation regarding the ova. Two watch glasses, of unequal convex- 
ity were therefore selected, of such dimensions as necessarily leaving a cavity where there was sufficient room for the specimen crawling between the convex surface of the one, and the concavity of the other.

Thus the animal being safely lodged here, the vacuity was easily brought under the focus of the microscope, exposing the ova to view, while the subject itself could not turn over and conceal them from the observer. Here I found an external ovarium, consisting of abont forty yellowish ova; besides which a very fer minute in the vicinity seemed to have been detached.

The animal was then liberated.

None of the ova were hatched during some days devoted to inspection. In a week, that is on July 22, the parent was free of the whole, but I could not find any of the young. No opportunity has since occurred of repenting the experiment.

One season each of three specimens had a cluster of white ova on the thorax, in the middle of September.

The posterior extremity of the young is proportionately more obtuse than iu the parent. Further, unless it be immediately or speedily consequent on production from the ova, they do not seem to undergo any conspicuous metamorphosis.

Exuviation is less frequent here than of many other crustaceans. The integument, however, separates in two portions, which are nearly white.

This is an extremely pacific, tranquil creature, always seeking shelter.

Specimens have survived many months in confinement.

\section{Plate lit.}

Fig. 1. Asellus vulgaris.

2. The same, enlarged.

3. Group.

4. Ovarium, enlarged.

5. Detached ova, enlarged.

6. Young from the ovum, enlarged. 
§ 10. Limnoria terebrans.-Plate LXV. figs. 7, 8, 9, 10, 11, 12, $13,14,15$.

A Chain Pier, of considerable dimensions, was erected on the southern shore of the estuary of the Forth, about two miles from Edinburgl, in the year 1S21. This strncture proved of great public utility. The previous inconvenience of the regular ferries along the const, the habitual intemperance of the boatmen, and the total deficiency of authoritative regulations, still too general from the feeble police of Scotland, rendered them alike dangerous and disagreeable. Providentially few serious accidents occurred amidst perpetual painful tumult, disorder, and alarm. Every improvement corrective of these grave annoyances became of the highest importance.

Besides, an enormous expense to the nation was incurred from injudicious and incessant repair on Leith harbour, within a mile of this new structure, the Chain Pier. Above $£ 240,000$ of dobt had been contracted by the managers of that harbour for repairs and alterations, chiefly about the years 1836 and 1840 .

No expecticnt could have proved more beneficial, or could have succeeded better at first, than the structure now specified. But, it seems incident to Scotlaud, that almost every important plan for public or private benefit, is followed by immediate failure.

Neverthcless, without imputing blame to individuals, so little do mankind know or study the operations of Nature, so weak and shallow their penetration of futurity, that this strong and castly structure, which bids defiance to the tempest, was attacked by a diminutive insect, whose ravages threatened its speedy ruin.

Having a favourable opportunity, my attention was directed to this diminutive animal, originally in the year 1826 , when I was enabled to prosecute some enquiries with comparative facility, from Mr Scott of Trinity, the omner of the structure ; Captain Donaldson Boswall of the Royal Navy ; Mr Dall, Superintendant of Gorernment stores, and others taking an interest in the subject. 
But a zealous and skilful naturalist, Dr Coldstream, having subsequently published an account of his own observations on the subject, I shall here confine myself to a ferr personal notices.

Though new to most naturalists, from its attacks on the Cliain Pier at Newhaven, I was informed in the year 1827, that the flood-gates of the Wet Docks at Leith were infested by the Limnoria eleven years previously; - probably, becanse a copious influx of fresh-water from the interior of the country was discharged within them. Its ravages had been also witnessed by the late Mr Robert Stevenson, an eminent engineer, on the wooden structures employed by him in ereeting the Bell Rock Lighthouse, seventy or eighty miles from Trinity Chain Pier.

As the nature of the animal in question savours much of that of the two preceding, perhaps it might liave been conveniently incorporated with them, under suitable distinctions, in the Oniscoid genus, instead of instituting a new one for its reception, where, I believe, it yet stands single. This was done, however, by the late Dr Leach, a uaturalist profoundly rersed in the history of the Crustaccans.

In appearance and in motion, this creature resembles a diminutive specimen of the 1 phrorlita squamata.

The body is linear and flattened, the back slightly convex. It is composed of seven segments, besides the head, bearing four antenne and two eyes; and the last segment with two styles like the Asellns. But these segments are so indented and sublivided as to appear fourteen in all. Fourteen limbs are arranged below in seven pair. The form of the head is rounded, with much sinnilarity to that of a cat, having a large black eye on each side, composed of about seven specks, one being in the centre. The antemie are nearly of equal dimensions, each pair apparently consisting of four and five articulations respectively, thickly beset with hairs, and terminating in bristly pencils.

The segments of the body are deeply divided, the whole being covered with hairs. Four follicles eonstitute the under part of the posterior extrenity.

Much diversity of size prevails anong these minute animals, which, full grown, seem to be about a line and a half in length, and half a line in breacth. 
An ovarium, consisting of about eight white capsules, has appeared on the thorax.

$\Lambda$ s the preceding animal, the Asellus, feeds exclusively on decaying leaves, so does the sustenance of the Limnoria terebrans seem to be derived entirely from the wooden piles which it is destroying.

Its ravages consist of innumerable channels or galleries, perforating the wood, until its substance is so much reduced as to fall to pieces, or be washed away by the waves.

Various expedients have been suggested and adopted for counteracting the evil, though hitherto without the slightest success; but one important experiment, and that which should promise most, has been yet overlooked. It is well known that all the insect tribes are most fastidious in the choice of their food. Multitudes are continually perishing when the sustenance most appropriate is unattainable. Therefore, were the Chain Pier, the pillars, abutments, or other parts, constructed of piles or prisms comprising several different species of wood, that alone which was grateful to the animals would be the subject of their attacks. Whence, by allowing a considerable interval, the kind eseaping entirely, or the least injured, would be discovered by inspection.

It is not improbable that the enigma would be solved by a single experiment.

\section{Plate LXV.}

Fia. 7. Limnoria terebrans, back.

8. Under surface.

9. Head.

10. Head, shewing the eyes and antennæ.

11. One of the antenna more enlarged.

12. Limb.

13. Eye.

14. Cluster of ova.

15. Ovarium more enlarged.

All the preceding figures are enlarged. 
§ 11. Cypris pilos 1 -Plates LXII. figs. 19, 20, 21, 22, 23, 24, 25.

The reader will preserve in remembrance that we have arrived at a very miscellaneous portion of our work, wherein we cannot profess to preserve any of that order and arrangement which is so beneficial in others.

The animal which forms the subject of this brief parngraph, is usually associated with the modern tribe, engrossing so many species under the name of Entomostraca.

To view it externally, many would pronounce it merely one of the diminutive bivalve Testacea.

Perhaps it nna be defined an insect inhabitating a bivalve shell ; it illustrates one of the facts whereon we have bestowed considerable attention, and which affords very satisfactory evidence that dimensions are no obstacle to exuviation.

The genus Cypris includes sereral species, some of which, from their diminutive size, might be thought to resemble each other. Indeed, I am acquainted with scarcely any species which might not be inscribed in a circle a line in diameter: some are not half as large. The subject of this paragraph appears ovoidal to the eye, consisting of a double-ralved sholl like many of the Testacea, Plate LXII. fig. 19; the valves somewhat resembling those of the mussel. But its colour is green, and it is covered with short hair--Plate LXII. fig. 20, Cypris enlarged; fig. 21, shell more enlarged ; fig. 22, form of the valves. This must be accepted for more specific detail.

It is difficult to understand the precise form of its organs, being included in a shell, the edges of which are very little relaxed.

But it seems to me that the animal loses both the integument and the valves, which are all reprodnced.-Fig. 23, exuria enlarged.

The Cypris dwells in still, fresh waters, swimming freely, and with a kind of smooth action, much resembling that of the Hydrachnæ. It is carnirorons, feeds roracionsly on mussel, numbers congregating around the prey.

In Scotland, the Cypris breeds in September and October, depositing very minute orange-coloured ova, chiefly on vegetable substances; or if in coufinement, on the sides of its prison.-Fig. 24. But the favourite re- 
ceptacle rather seems to be the empty valve of one of the species.-Fig. 25.

Of three such valves, one contained eighteen ova, another twenty, the third twenty-four. Probably, these were produced by three different animals.

Spawn had appeared on September 15, and on October 5, some of the young were hatched. They were very minute. The microscope detected nothing.

Plate LXII.

FiG. 19. Cypris pilosa?

20. The same, enlarged.

21. Einpty shells moro enlarged.

22. Empty specimen.

23. Exuvia.

24. Ova, enlarged.

25. Ova deposited in the empty valve of a shell.

Considerable variety of the tribe Entomostraca may be found in Scotland, such as the Cypris lavis, which dwells along with the preceding, and is of smaller size. $\Lambda$ specimen spawned in autumn.

\section{Plate LXX.}

FIG. 10. Cypris lavis.

11. Spawn magnified.

\section{Crpris Forthensis.-Plate LXX.}

A very minute species of the Cypris inhabits the estuary of the Forth, which I have obtained several times.-Plate LXX. figs. 12, 13, 14,15 . This is of a very faint, dull, reddish-bromn, the shells opaque, somewhat resembling those of a mussel, and several exposing one or more black internal specks. The animal springs through the water, and crowds of it congregate on the sides of the vessel towards the light.

\section{Plate LXX.}

FIG. 12. Cypris Forthensis, group.

13. Another group.

14. Group enlarged, the shells elosed.

15. Specimen protruding parts of the animal, enlarged. 


\title{
CHAPTER V.
}

\author{
PARASITES.-PLATES LVI., LVII.
}

MANkind, inflated by pride and folly, vainly suppose that, beeause the beneficence of Ileaven las bestowed on them senses to observe, and reason to judge, they ean determine the cause and the use of every thing presented to their riew.

How great is their error! they onght rather to bow themselves in the humility of ignorance.

Their total existence is divided into periods of pleasure and pain. But although we may plead the Divine farour, so eminent for protecting the tenants of the globe, how shall we account for the subsistence of torment? Could it be that sensibilities and suseeptibilities are inseparable from animated matter?

\section{§ 1. Caligus curtus.-Plate LXVI. fig. 1, enlarged.}

This is one of those plagues which Nature, for hidden purposes, permits to exist for the annoyance of living creatures, - a persecuting, small, but deadly enemy to those ten thousand times larger than itself.

Perhaps I should premise, that although the general outline of the Caligus is sufficiently exposed by a simple lens, it is scarcely practicable to ascertain the detail of the parts of the living specimen by any auxiliary. These being chiefly visible from below, this great diffieulty originates from position, tenuity, proportions, and confusion of the principal organs, 

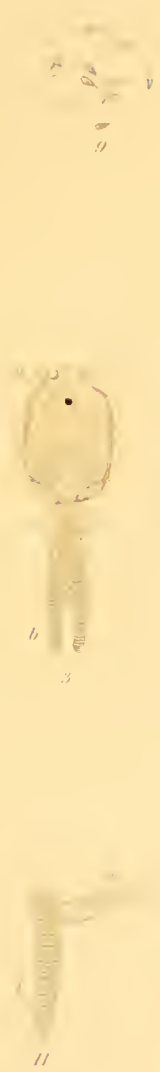
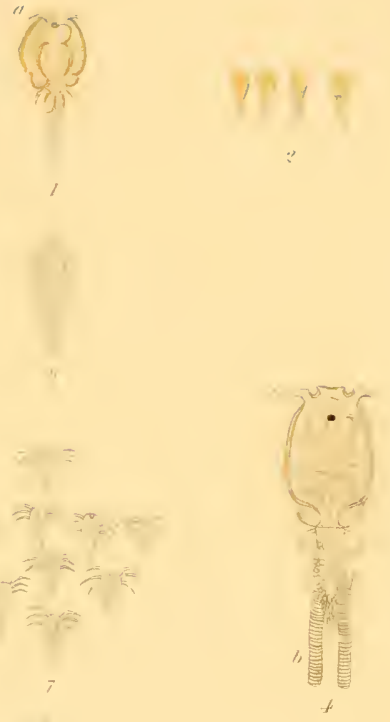

$\frac{7}{111}$
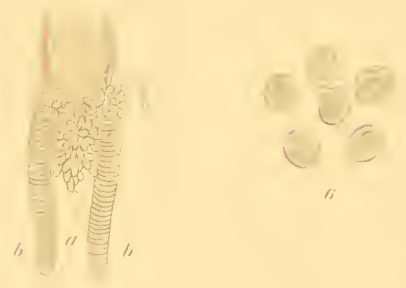

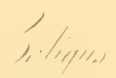


HAT MC? LIST RY 
and their homogeneous colouring. All these embarrassments are aggravated by the living state,-that alone from which $I$ am willing to derive information.

There are few subjects to which this animal may be compared: it would most resemble a diminutive instrument of sport, the battledore, provided the single hand were divided into two tubular appendages, a little apart.

Thus, it consists of a thin convex shield or body, from the anterior edge of which originate two antenux, and from the posterior margin issue two cylindrical tubes. Two black eyes, apparently merging in one, are on the upper surface, near the anterior edge, and under it, the short tubular proboscis. Eight limbs also issue from the under surface of the shield, by which, or by means of part of them, the animal affixes itself firmly and pertiuaciously to its prey.

It is extremely difficult to discover the number, the form, the position of these organs, but they are what most naturalists agree to be the complement of this species. The total extent of fine specimens may be about seven lines, but there is a great disparity of size among them.

\section{Plate LXVI.}

FIG. 1. Caligus curtus, enlarged.

2. Specimens nearly of natural size.

3. Upper surface of a specimen, enlarged; $a$, position of the antennæ : $b$, cylindrical tubes.

It may be from the homogeneous colour obscuring distinct vision that descriptions by differeut authors are discordant. Regarding one of which Muiller treats, he says, Oculi et antema hujus specicbus difficulter deteguntur ; and he seems to assign the position of the former to the edge of the anterior portion.-Eutomostraca, p. 128. Baster speaks of black eyes; whereon Mïller remarks,-Eir oculorum caligine genus nonen sortitum est.P. 129.

This parasite affixes itself by means of the limbs on the under surface, to spots from which it camnot be dislodged without considerable force; therefore it must be a terrible persecutor. 
The total length of the finest individual specimens may approach six or seven lines, the breadth of the shield or npper portion being towards two. The whole is divided into three distinct sections : first, the shield or body, somewhat orbicular, thin and slightly concave, apparently composed of several shelly plates, faintly indicated, and with a clear margin; secondly, a much smaller portion, by some called the abdomen, and next the tubular appendages. On the edge of the front are two antennular organs, which, exterually, seem fringed, and behind these are the two narrow oval black eyes, which, even under a moderate magnifier, seem confluent, though actually separate; thence inducing various observers to class this subject with the Monoculi ; three pair of the limbs belonging to the under surface issne from the abdomen; a fourth is perhaps armed with a kind of horny spines; colour of the whole animal lighter or darker wax-yellow.

This creature darts quickly throngh the water, or up the side of the glass, considerably above the surface, where, incapable of returning, it adheres and perishes.

Various fishes, especially the cod, are infested by the Caligus, from which, having no means of liberation, they gradually pine away, languish and die.

But, as if in just retribution, the Caligus itself is infested by a minute white leech, in vast multitudes, little exceeding a line in length. While occupied with the Caliyus in 1824, I observed this parasite, which has been since more distinctly described and named Udonella, by an industrious naturalist, Dr Jolnnston. I camnot affirm, however, that the two may be identified as a single species.

At certain seasons of the year, the female Caligus bears two cylindrical tubular appendages, appearing deeply indented throughout by numerous external cireles.

Howrever, these appendages are but temporary, not permanent, though the delicacy of the animal, preventing its survivance more than a few days, precludes observation alike of their origin and of their obliteration.

Having isolated a specimen bearing such appendages, in a watch- 

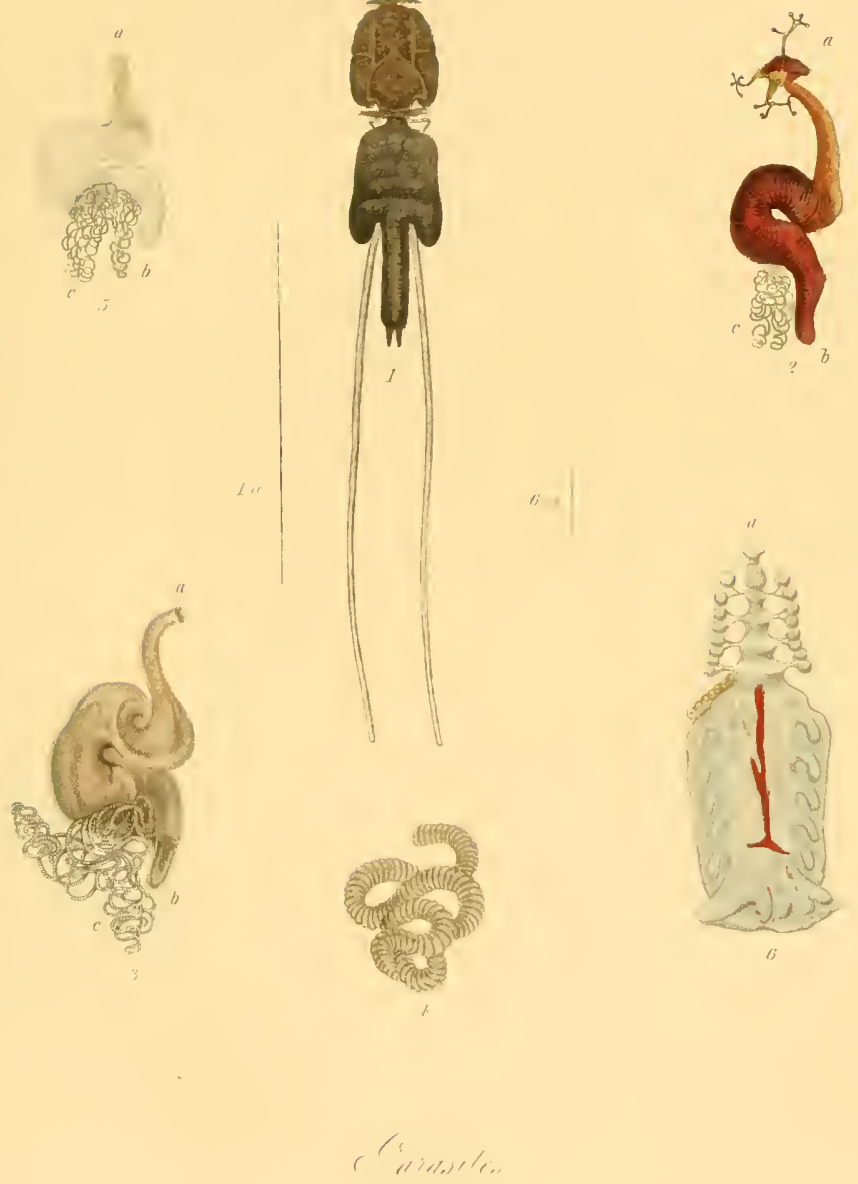

glass, on November 25th, I next day found many embryos, each in its amniou or involucrum, quiescent. Intermingled with these were numerous white specks, in active motion, which, under the microscope, proved voung Caligi, very minute, provided with six limbs, nor shewing any resemblance whatever to the parent.

Nothing could be more transparent than the amnion involving the embryos, some of which soon burst their prison.-Fig. 6, enlarged ; young, fig. 7, magnified.

Now, the illusion representing the cylindrical appendages as $i n-$ dented, was dispellerl; for the supposerl circles, forming so many anuulations, had originater from the embryos, in their integuments, being piled like so many pieces in a rouleau of coinage, horizontally above each other.

Among a number of the adult Caligi examined on November 30 th, many specimens wanted the ovarian cylinders, while the discharge of embryos in their integnments continued from those that had them.

At least trenty specimens rere found among Caligi collected on the 5th; all wanting the tubes.

At this time they were infester by the Udonella.

From the form of the Caligus, displayed on bursting its integument, compared with that of the adult, the animal undergoes an evident metamorphosis in its course to maturity.

The surface of the shell is frequently speckled red, and many become ruddy or purple, as the animal dies. Some of the young, on escap ing from the amnion, seem to be speckled.

Several facts regarding these minute animals are unintelligible, and athers very indistinctly understood. Indeed, I am at a loss to comprehend the real nature of almost the whole external objects affixed to the figures represented in the plate.

A minute zoophyte, fig. 10, had found a nidus among them.

\section{§ 2. Caligus salmonis.-Plate LXVII. fig. 1.}

As the preceding parasite infests the Cod, so does the present subject infest the Salmon. To free itself of this obnoxious enemy, the Salmon is said to quit the sea and ascend rivers; but whether truly so, I cannot cer- 
tify from my own knowledge. Possibly fresh-water, which is speedily fatal to most marine animals, does not spare the Caligus.

The Caligus of the Salmon is somewhat larger than that of the Cod, the shield rudely and obtusely quadrangular, with faint indications of compartments. Thus the parts of the shell are more solid, and the ovarian tubes very long.

Total length of the animal two inches, whereof the body occupies half an inch, by two lines in brealth. The ovarian tubes an inch and a half. Colour of this subject, dark brown.

Plate LXVII.

FıG. 1. Caligus salmonis, slightly enlarged.

\section{§ 3. Caligus.-Plate LXVI. fig. S.}

This animal, which I had reason to consider a Caligus, was attached by a long ligament to the anterior part of fig. 3 . I had never seen it before nor siuce, and being moch smaller than the figure in the plate, which is enlarged, I conjectured it might be one of the young in an intermerliate stage, advancing to metamorphosis. Nothing followed, however, to conroborate this conjecture, and I should have omitted the subject entirely, had I not observed it alluded to as a distinct species in the recent valuable work of $\mathrm{Mr}$ Adams.

Plate LXVi.

FiG. 1. Caligus curtus? enlarged.

2. Four specimens somewhat under the natural size.

3. Female Caligus, antennular organs, $a$ ? ovarian tubes, $b$; upper surface, enlarged.

4. The same, under surface. Here the feet are indistinctly seen, enlarged.

5. Lower portion of another female, more enlarged. Leech, $a$ : ovarian tubes, $b$.

6. Embryos in their integument, enlarged.

7. Young Caligi free of their integument, enlarged.

8. Caligus, originally attached to fig. 3, enlarged.

9. Capsules of unknown nature, full and empty, enlargerl.

10. Zoophyte growing on a living Caligus, enlarged.

11. Leech, $a$; seated on an ovarian tube, $b$, enlarged. 


\section{LERN EA.-Plate LXVII.}

The preceding animals are not the only instruments of torment tolerated by Nature, for the annoyance and destruction of living creatures. There are other still more terrible and more irresistible enemies preying upon them, against which they do not seem to have any possible means of defending themselves: for they attack different parts of the body, where they are quite inaccessible to any organs of the sufferer.

\section{LERNeA BRANCHALIS.-Plate LXVII.}

This is a parasite of the most irresistible and destructive kind by which any living being can be infested, and it assumes a position where it is not only safe from all endeavours to shake it off, but it can scarcely be dislodged by means of sharp instruments, when the fleshy part to which it adheres is separated.-Plate LXVII. figs. 2, 3, 4, 5. Its singular shape precludes the powers of description; it can be understood best only from inspection of the original, and next from the figures here presented, especially Plate LXVII. fig. 2, which slightly exceeds the natural size.

The whole exterior is of a hard, horny substance ; but, in fact, whatever be the substance, it resolves into a strong vascular body comprising the Lernaa, which is continually replenished with the blood of its victim.

From an enlargement of the npper extremity, three organs issue, which are provided with subordinate cruciform or branching parts, fig. 2, a, inserter in the fleshy parts of the Corl, or other fish, about the gills, the rest of the body substituted for the intestinal parts of other parasites, being a strong and elastic tubular skin or integument.

Capacious ovarian tubes, $c$, are connected with the under part of the animal; but I have not been sensible that they were occupied by spawn during any periods of my inspection.

The whole is of a hard horny, almost shelly substance, but the three organs of fixture obviously belonging to the highest portion, the remainder is merely to be compared to a hollow intestine.

We cannot discover any motion of the animal, or how the head, 
with its inflexible deadly organs, is advanced into the fleshy parts of the prey. It rather appears to be stationary; and it requires to be very carefully withdrawn, for in the course of extrication, the upper portion, with the arming apparatus, is usually broke off, though the lower part remains full of blood. On emptying the latter, however, which may be done by pressure, its elastic figure, quite transparent, is discovered.

\section{Piate LXVII.}

FIG. 1. Lernaca branchialis.

2. Entire specimen, apparatus of the head, $a$; lower extremity, $b$; ovarian tubes, $c$.

3. Another specimen, having lost the extremity, $\alpha$, in the course of extrication. Lower extremity, $b$; ovarian tubes, $c$.

4. Ovarian tubes, enlarged.

5. Empty speeimen.

\section{§ 4. BotryLLorer.-Plate LXVII, fig. 6, enlarged ; natural length, $a$.}

I speak provisionally of the precise place and the parts of this subject, having been unable to satisfy myself, from a single specimen, of the most important facts, namely, whether it is Crustacean, and whether a Parasite. It was found among the residne of general marine collections several years ago, nor have $I$ ever seen any resemblance to it before or since.

Length, three-eighths of an inch; greatest breadth of the body about half as much.

The subject consists of two parts, probably as distinct in use as in form. The chief portion or body consists of a rudely quadrangular flattened substance, wherein were very obscure indications of something, like several pairs of limbs, on each side of an internal vessel; the shoulder is prolonged, in a general tapering form, to what is probably the extremity of a snout, from the sides of which originate about four pair of grape looking organs, with several others along the shoulder. But the whole was so imperfectly seen that I cannot venture to say any thing very positive regarding it. The drawing, however, was executed by a 
skilful artist. The anterior part of the amimal moved from side to side. It survived several days.

\section{Plate LXVII.}

FiG. 6. Botryllofer.

\section{\$ 5. Pegasillus hirsutus.-Plate LXII. fig. 18.}

This subject I consider pretty much in the same predicament as the preceding. Originally I thought it a Crustacean parasite, but it did not maintain that character to sufficient conviction.

A week after a quantity of miscellaneons matter had been eollected from the sea, in the end of February, a vast legion of Monoculi rose towards the surface of the water. Many of the subjects of the present paragraph were interspersed among them.

These were absolutely microseopic objects; length not exceeding the sixth of a line, the body tapering slightly downwards; a pencil of bristles hung from each shoulder, at least once and a half as long as the body. Four black speeks in a line, slightly curved, appeared across the forehead.

Colour of the whole animal white.

This erenture has a quick, active, searching, motion, frequently bristling itself up.

I could not refer it to any establisher genus, nor ean I affirm it to be a perfect animal, or in progress to metamorphosis.

\section{Plate LXII.}

F1G. 18. Pegasillus hirsutus, enlarged. 


\section{CHAPTER VI.}

TIE IIYDRACHNA, OR WATER SPIDER.-PLATES LXVIII, LXIX.

THE genus Hydrachna comprehends a race of small carnivorous animals, exclusively aquatic, bearing considerable resemblance to the Crustacean tribe, which we have just quitted. They also exhibit certain prominent habits, in common with those of terrestrial Spiders.

But there are varions distinctions in form and proportions, in general organization, and animal propensities, altogether affording such a modification of distinctive features, as to constitute sufficient elements of a separate genus, whereof $I$ shall at present endeavour to avoid all prolix discussion.

Some of its characters are quite obvious, others much less so.-Thus, although equally ravenous, fierce, and cruel, with the boldest, I am yet unaequainted with any species among the Hydrachnæ, lurking in quiescence for concealment, during the approach of prey, or of constructing a snare for the unwary victim.

Nevertheless, independently of the figure, there is much correspondence in many things between the Crab, the Spider, and the Hydrachna. The beholder cannot but be impressed with their general similarity of shape, and with the same ferocious disposition, as belonging to predatory animals, and demonstrated in the employment of destructive organs to attain their purpose.

Having had very favourable opportunities for observation, a number of years ago, though subsequently interrupted, I ceased for a long time 


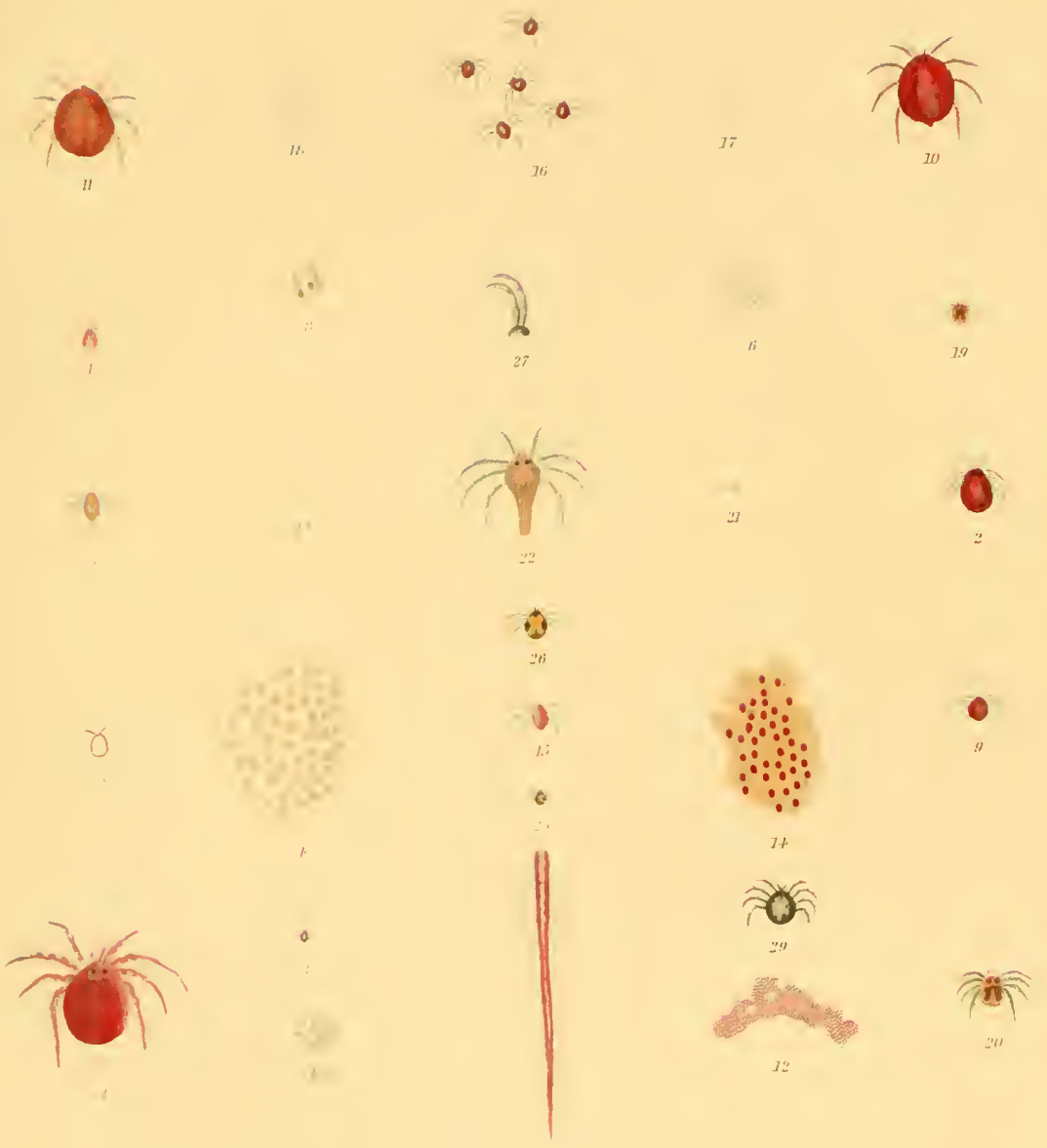




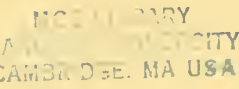


to prosecute farther enquiries into the subject. But, I acknowledge that I did so with the less reluctance, after perusing the work specially devoted to it by the leamed and industrious Otho Frederic Müller, whose writings, universally useful, must be always most highly prized by those who ean form a due estiniate of their intrinsie value.

The extensive knowledge displayed by Miiller was derived from that best of sources, practical acquaintance with each individual species constituting a genus, and that very often while many of them were yet in the living state. Müller, like Linnæus, seized on a few of the most prominent features, those not difficult to be recognized ; but, if any thing shall be regretted of Müller, it is his anxiety for describing numbers so great as to have left neither time nor opportunity for preserving his subjects alive.

Modern authors, however, perhaps less skilful, but more eager for change, have ventured to dismember certain genera, or have left only an inferior section to represent the whole. They have vainly endeavoured to erect so many new systems from among the fragments. But mere deseription of the body, including anatomical details, by entering on such minutia as none but some of the more modern naturalists wonld have thought of, is insufficiently adapted for general information. Besides, much remains for explanation ; for, the lower we descend for charicters, as the source of deductions, the less important features are obtruded to view.

The Hydrachne, to be literally interpreted Water Spiders, are very beautiful animals, of delicate and symmetrical form, decorated with vivid colours, agrecably interspersed. Their lively courses amidst their transpirrent dwelling, the limpid element, combined with the diversity of their appearance, render them amusing and full of interest.

Müller, who is still to be held the leading anthority on the subject, claracterizes this genus generally, as engrossing animals distinguisherf by eight feet, two articulated palpi, and two, four, or six eyes.

The figures amexed to these observations, explain more amply that the shape of the body is globular, ovoidal, or simple, with a prolongation 
behind ; that the head and body are united in one, forming a single organization, of what other authors subdivide as three, that is, head, thorax, and abdomen. Earlier distinctions were founded on the figure of the body, the presence, number, and position of the eyes, and other judicions characters, such as may be readily recognized and sufficiently adapterl for scientific arrangement. For these, some modern naturalists desire the substitution of certain minutix, sometimes of very difficult detection and equivocal determination; which may be possibly alike decisive when discovered, such as the form and position of the mandibles, the place of the mouth, the intervals and proportions between the joints and the limbs, and other matters. But these must be sought by naturalists habituated to similar investigations, nor do they contemplate the preservation of the subject itself entire, in freedom, or with the knowledge of its luabits.

Hydrachne dwell exclusively in fresh water; they are found in marshes, ponds, lakes, slow and tardy eurrents, where a wider and more ample space adnit their pursuing a deviating course thronghout the brighter portion of the finer days of summer. The observer who stations hiniself at a certain point of the brink, towarls the margin, is assured of heing visited by each suceessively in its course. Let him advance, he may anticipate that in passing onwards he shall be visited by another: next, by a third, a fourth, and by many in succession. All are guided evidently by a common impulse, as having a particular object in view. Thus, they expose themselves to capture; for the naturalist, loy merely sinking a white sancer obliquely in that direction from whence they visibly journey, and raising the opposite edge leisurely, intercepts their nearer approach in farther retreat, and secures them.

Such may be a nseful lesson. The habits of those wild animals, most valuable to the hunter, are thus rendered the means of their capture. Should Hydrachma be alarmed, they always descend, seeking safety in deeper and deeper water, the wonted resource of aquatic animals to escape; some there are, however, who under similar circumstances always endeavour to rise upwards.

Certain species, undoubtedly, prefer considerable depths; a few may 
be called rather littoral, which frequent the margin and the shelter of the coverts cast by shade, or otherwise, over the places they inhabit, and run along in search of such minute particles as are to be found near the bottom.

Many swim with evident exertion, advancing slowly and heavily amidst their element, from the disproportionate powers and dimensions of . their slender hairy limbs as natatory organs, compared with the size and density of the body. Their speed is precisely in the ratio of the prevalent temperature. Ilence they are most active in summer.

Hydrachne, like all other insects, are extremely sensitive of the influence of heat or cold. During the genial season of the year, they are full of life and action ; but retreating to their haunts below, on the approach of winter, they probably remain torpid until the return of spring.

They are subject, besides, to a kind of torpor or lethargy, also like insects, during the finer parts of the season. Specimens become suddenly motionless, without any obvious external cause ; and after remaining as dead at the bottom of their vessel, gradually revive to activity.

Some years ago, while occupied with the effect of freezing mixtures, I subjected several Hydrachne to them, during the heat of summer. When the preparation had sunk to thirty-eight degrees, six fell to the bottom, and there remained motionless. On this occasion the cold was resisted longest by the species denominated Papillator of Muiller. In other experiments during winter, two Hydrachno became languid when the water fell to thirty-six degrees; and when the heat was reduced to thirty-two degrees only one or two could move their legs. Next day the wonted activity of all was resumed.

Possibly the habits of this animal are modified by situation. In the close of July I took four from a small pool lying in the course from the high road to Canty Bay, in East Lothian, opposite to the Bass islet. All were of the species Cruenta, plump and vigorous. Unlike the ordinary labits of their kind, they burrowed in the mud, and frequently ascended from the bottom of the vessel, totally disguised by what had adhered to 
them. Among others taken subsequently from the same place was one evidently in a fit, which remained so for some time, lying motionless while removed to a different vessel. Next, the feet beginning to move, it revived, and swam away. Another died after remaining long in a fit, copiously discharging a reddish-brown liquid.

Some anologies will be found quite as decided between the nature of this and the Cancer tribe, rigorously circumscribed as such.

Hydrachnæ, so active throughout the day, seem to pass the night in profound repose. Early in the evening the numerous tenants of a jar of water are all seen motionless, resting on the neighbouring plants, or sustaining themselves by contact with the side of the glass. There the limbs are much contracted, and nearly in the same attitude as if clinging to a plant.

The common equisetum, or horse-tail, is useful as a place of repose for the night, besides which, it is nibbled by these creatures during the day. Its presence may be still farther beneficial, as a place of protection from their mutual hostilities. $\Lambda$ t night, therefore, the general quiescence proves a considerable difference from the nocturnal habits of most aquatic, and especially most marine animals, rendering it the season of their widest excursions, and their fiercest encounters.

The repose of the Hydrachna is also influenced by the absence of light, for it is uninterrupted while an apartment continues dark, but all are aroused to action by its admission. Then their chief enjoyment is sporting in the smmshine, and in their renovated element.

Hydrachne are among the most rapacious of living animals, bold, fierce, and cruel, the natural and inveterate enemies of all their congenera: they are no less hostile to each other, against which is waged a perpetual war of extermination. Neither do they hesitate on attacking such animals as are suitable to their appetites, though double the size of the assailant.

One species, let us provisionally denominate it IHydrachna ferox. from its nature, dwelt in a small pond, in common with another species not dissimilar, though perhaps of somewhat inferior dimensions, the back stained with a yellow cross.-Plate LXIX., figs 1, 2, natural size and 


\section{$i$ \\ I.}
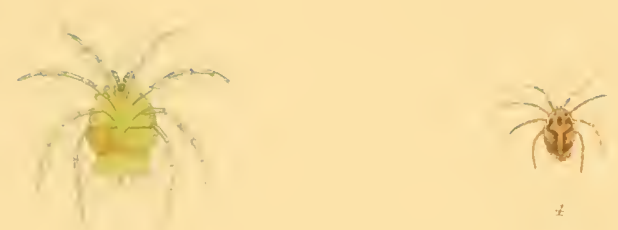

ก

n
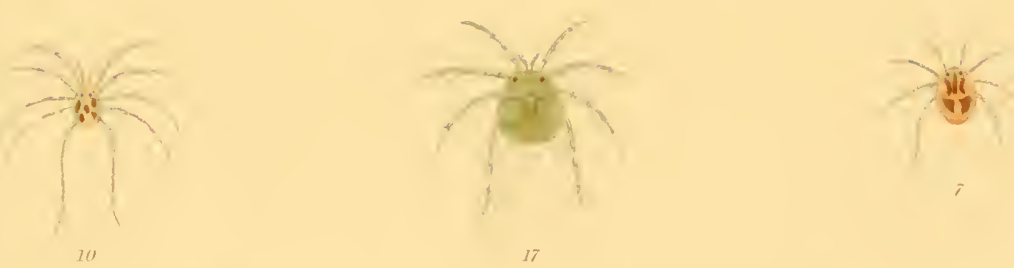

- ces
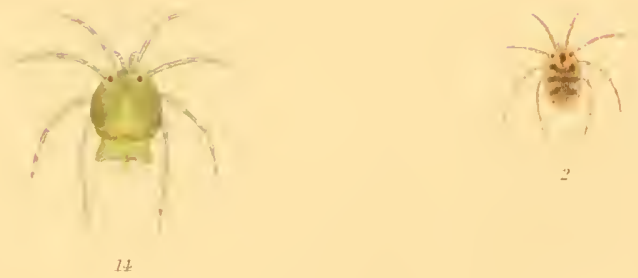

Jentimelien 
H. IVETEITY

CAMZNIDGE. MA USA 
enlarged. The natural prey of this latter is the Hydrachna spinifer:Figs. 3, 4, 5.

On the margin of this pond lay the fragments of a decaying boat, containing a quantity of macerating leaves fallen from the neighbouring plantations among ten or twelve gallons of water, where had also generated numerous broods of the lower animals-the boat baving remained two or three years in the same spot undisturbed.

The water was replete with multitudes of the Entomostraca in particular, in considerable variety, and among them the finest specimens of the Daphnia, or Water Flea, which is one of the largest of the tribe, nor much inferior to the smaller Hydrachne.

I was accustomed to resort thither for supplies of microscopic objects, both in general and promiscuous collections, and as selected objects from among many, being the most valuable to be obtained in the neighbourhood. On one occasion I found that a phial of miscellaneous matter had included above sixty Daphnix, and six specimens of the Hydraehna ferou; these being put aside for the night, without farther expectation of what the morning might disclose. I observed, on the return of light, with some surprise, that each Hydrachna had seized a Daphnia-hurrying it along, though hardly to be retained from strength and dimensions within its ferocious grasp; and on the following morning, that not one of the sixty, unless a few minute specimens, survived-the shells of the rest, all lying at the bottom of the phial, voided of their contents, testified the fate of their reeent tenants.

Again, ten of the same, the first species of the Hydrachna above named, having been accidentally committed to a jar, with above a hundred Daphnix, none of the latter had escaped next day.

As it was impossible that the assailants required such a quantity of food, it became evident that the victims were the objects of a mere wanton thirst for destruction-a most mischievous feature in the history of these minute carnivorous animals.

It was discovered, besides, that among a number of the Entomostraca introduced along with the Hydrachna, one was speedily seized, and borne 
away by each, when its existence quickly terminated; the stronger, meantime, either pursuing an uninterrupted course, resting on some neighbouring substance, or lying supine at the bottom, while more leisurely devouring its prey.

Young Hydrachnæ also ferociously seize the animals, thongh larger than themselves; thence, where a few minute Daphnia escaped at first, as in the preceding case, they too were quickly devoted to destruction.

Thus, Hydrachne do not spare each other; so that whether impelled by hunger or excited by animosity, numerous colonies of both themselves and the Daphnia are gradually exterminated, with exception of a single specimen remaining, the ultimate victor of both.

A small specimen fixed itself on the Hydrachna extendens, a contmon scarlet flattened kind, already referred to as larger, and named by Muiller; nor could the victim by any means dislodge the assailant. It lay as if stumned and about to perish, until relieved of its enemy. This red species is one of the quieter and more pacific. From frequenting sandy places, and moving heavily, it is liable to pursuit.-Sometimes the animals of one species are attacked and devoured by the Hydrachna of another, not a third of the size.

These mutual attacks are accompanied by all the ferocity of the fiercest animals of prey, and they are effected by means of their offensive organs reciprocally. Great devastation is the consequence. The formidable fangs of a beautiful black and yellow species, with bluish legs, are seen from a specimen of the character of Plate LXIX., fig. 27 ; also from the Hydrachna, figs. 25, 26, which was taken in May, in 'Braid Hills pond.

Hydrachnæ continue plump and sleek, from feeding on those dying in their vicinity. The colour of some named here, the extendens, for example, remained vivid, and the body in good condition, while surviving others: and if one of the dead was pierced, the substance escaping tinged a considerable quantity of water red.

The disposition of these little animals, so strongly displayed in more violent sensations, is greatly modified. From four specimens of them 
dwelling in harmony during captivity, I was induced to name the creature Hydraclena placida, a character so opposite to that which has been described.-Plate LXVIII., enlarged, fig. 29.*

Hydrachne sometimes subsist spontaneously on other animal substances. When feeding profusely, they are full, plump, and smooth, of velvet appearance, and remain so after death. Owing to the extreme difficulty of obtaining correct delineations of such active and restless animals, it is probable that most of the figures preserved have been those of specimens after life had fled. All the illustrations presented here, however, were taken from animals during vigorous animation. Nevertheless, the characters of many are most equivocal.

The Hydrachne breed at different periods of the year, and, in common with the smaller insects, chiefly during summer. Conspicuous indications of sex were noted long ago by Miiller, and more recently also by M. Dugés. But there are species wherein the difference is extremely slight, though no resemblance between the male and female exists in others.

During the union of a species of the Spinifer, the pair remained motionless at the bottom of their vessel. Spawn appears in April, and during the subseqnent month, and the maturity of the young has been also postponed as late as the beginning of November.

Certain species of Hydrachne are extremcly prolific. Some of thuse above enumerated, such as the Hydrachna crtendens, affixed more than six hundred ova to the side of a glass jar, where its history could be favourably and distinctly followed. The quantity and fashion of the deposit depends much on the species; it is generally in patches, and the same spot being resorted to repeatedly by the parent, it occasionally attains considerable dimensions.

The patches consist of twelve, twenty, an hundred and fifty, or a greater number of ova, for the most part symmetrically arranged in a single stratum, on leaves, wood, stone, or whatever else may have been

* Body, tending to globular, about half a line in diameter. Eyes, two on the anterior surface, black, considerably apart. Limbs with scanty bairs. Colour greyish-brown, lighter on the middle of the back. Taken in a small pond on Braid Hills. 
in the vicinity. Sometimes the quantity and aceumulations are wonderful. On raising a branch of privet, which dipped amidst the water of a pond, I found the leaves actually weighed down by the quantity of spawn investing them.

One of the sides of a leaf bore from sixteen to twenty patches, each consisting of at least fifty ova, and both sides of others had forty or fifty patehes, equally exuberant.

A twig with a few leaves was consigned to a jar of water, from which at least ten thousand young were hatched by the 4th of August: and next day the multitude proved infinite. All these I concluded to have sprung from the species Ferox or Spinifer.

Besides the places of usual resort, the under surface of stones sunk in the water is frequently invested by thousands of ova, though it would be diffienlt to comprehend how the parents can either reach or quit their site.

Simple inspection of such leaves, as above deseribed, is very delusive; a transient view would persuade the observer that what he sees is very remote from the truth.

The aggregate production of young animals is a very interesting subject, in shewing the ratio of multiplication. But no specific computation has determined the quantity of spawn from any single speeimen of the Iydracha. Patehes from individual speeimens of the Ferox, have consisted of four, eight, nine, twelve, eighteen ova each, respectively. These patehes are from half a line to a line or more in diameter, alike indefinite in number, form, and contents.

But they are always a beautiful object under the microscope.

In general the embryo seems to attain maturity in fourteen days. Wore are sometimes required, for here, as may be readily concluded; there is also frequent irregularity.

Patches, consisting of from twelve to fifty ova, appeared on the 29th and 30th of Angust, on the sides of a vessel containing specimens of the Hydrachna critenta-Plate LXVII. figs. 1, 2. One about the eighth of an inch in diameter, received some aceessions subsequently, and broke up about the 25th of September.-Plate LXVIII. fig. 9. I then rated 
the period requisite for gaining maturity at about twenty-eight days : but the young are so minute individually, that, although the spawn had been obviously dissolving, I could not at first discover them ; mere specks to the eye, they could be with difficulty selected for olsservation.

Under the microscope such nascent Hydrachna are discovered to have only six limbs, the whole complement is of later acquisition. Their two black eyes, somewhat apart from the frout, are sufficiently conspicuous.-Plate LXVIII., fig. 7 .

All but one of the young of seven ova from the Hydrachna feror, affixed to a glass on the 6th of September, Plate LXVII. fig. 8 , were hatched on the $22 \mathrm{~d}$ of that month.

But although gross irregularities embarrass the history of the genus, other observations shewed that the young might be matured in fourteen days.

On the 23d of July, I committed five large and turgid females of the Hydrachna ferox to vessels ; spawn appeared next day, of pale-yellow albuminous matter, in three patches, containing three, twelve, twentytwo ova, respectively. Other five, introduced on the 25th of July, produced spots, the first containing thirty ova, the second eighty-seven. Some of the former were hatched on August Sth, thus making the perior for reitching maturity extend to fourteen or fifteen days.

A number of Hydrachne having been transferred to a ressel on August 11th, a patch of eight ova appeared next day, and on the day following, other two of eight and twelve ova respectively.

In the latter, the eyes of the embryos were visible on the 20th, and on the $27 \mathrm{th}$, three had forsaken their prison; thus attaining maturity in fourteen days. Some remained twenty hours longer, moving and shifting their position within their capsules.

Additional observations shewed, that, in August, fourteen days were just about enough for the young attaining maturity from the date of production by the parent.

The advance of the embryo is distinctly exposed within the integument as maturity approaches.

A ruddy tinge distingushes most of them, and some are stained 
scarlet or vermilion, derived perhaps from the contents of the abdomen. Hence, where the parent is unknown, it is difficult to determine the particular species occupying the spawn.

The decaying leaf of an Iris bore a patch of several hundred ova on the 15th of September. Its colour brightened in proportion as the embryos approached maturity.-Plate LXVIII. fig. 14. Some had escaped on October 26th and 27th, but many remained on the $2 \mathrm{~d}$ November, when one of beautiful vermilion quitted its capsule during microscopical observation. This young animal must consequently have remained there at least forty-eight days.-Plate LXVIII. fig. 15. Thus the period between production and maturity is infinitely varied and most irregular, whether from being dependent on the species, as is probable, regulated by the temperature of the atmosphere, or influenced by both.

If the spawn be in a watch glass, the young rush out of the water on escaping from the capsule, and run very actively on the bare glass itself.

II. Dugés remarks, that such mascent Hydrachnæ run on the surface of the water, and on the sides of the vessel, believing also, that before attaining perfection, they may, as parasites, infest such insects as frequent the water.:

Hydrachne descend amidst their element on the approach of cold ; and they seem to seek shelter among mud, or the roots of plants, throughout winter, or until aroused by the reviving influence of Spring.

In certain years they abound, in others they are rare, and some seasons seem to favour the multiplication of particular species; possibly atmospheric influence has as much effect on the spawn as on the parents themselves.

In May 1802, hundreds in great variety could be taken in a recent artificial pond, whereof the superficies did not exceed a quarter of an

* Much information will be derived from the perusal of two memoirs on the genus Acarus, by the aeute naturalist here referred to. He there partitions the genus Hydrachna of the Linnæan system into several subdivisions, chiefly derived from external characters, and explains the metamorphosis of the young in their progress to perfection.-Annales des sciences Naturelles, Sec. Ser., tom. I. Paris 1834, in 8 ro. 

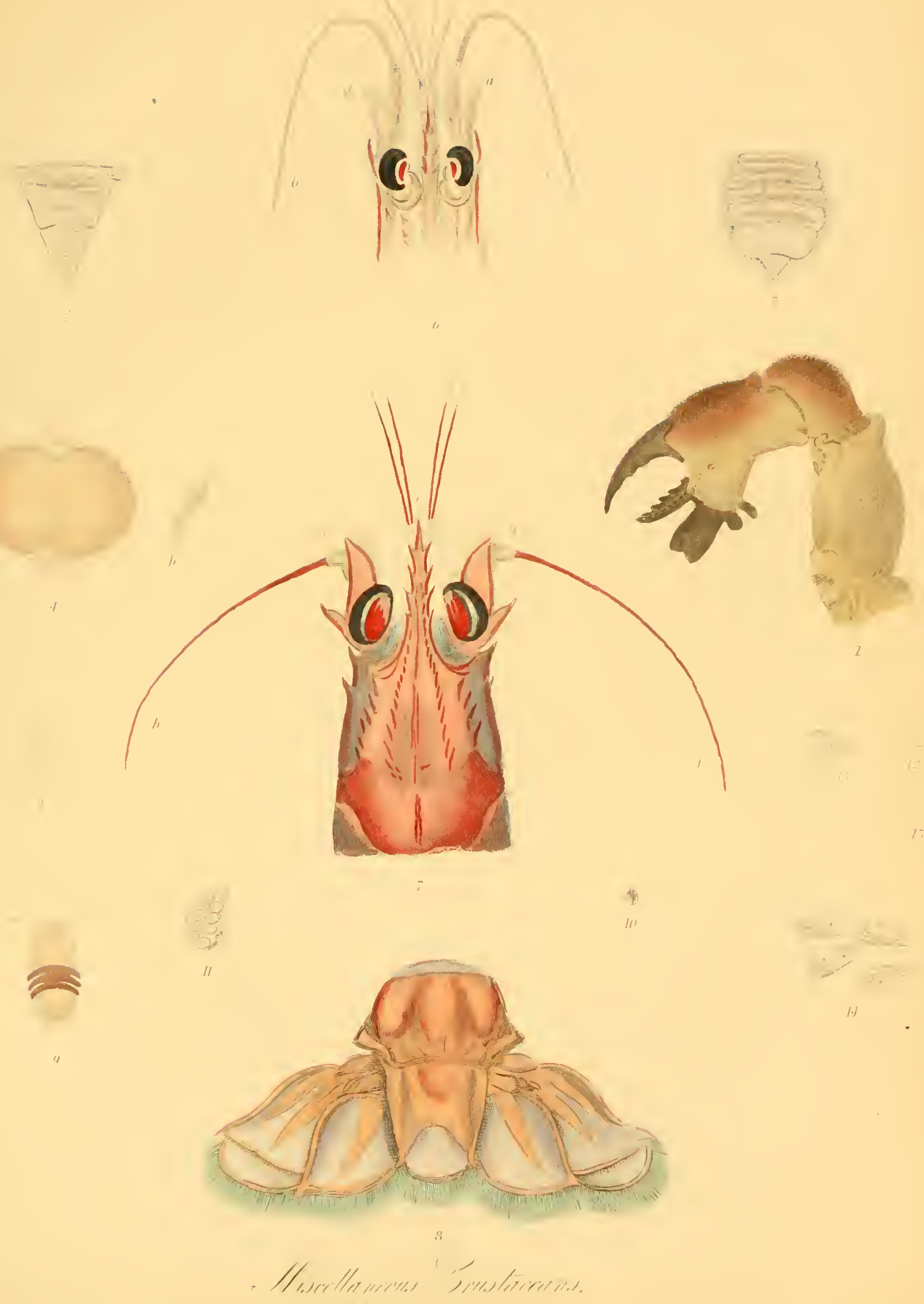


$$
r_{c}+1+x
$$


acre. But the pond being stocked with perch about that time, the Hydrachnæ became rare subsequently.

They were also very numerous afterwards. I remarked the like in 1809.

About that time, some, of many falling into my possession, survived above a year.

The history of only a few specimens has been preserved along with this brief narrative, for the purpose of illustrating the general and varied features of a very singular race of living beings.

\section{Plate LixVIII.}

Fig. 1. Hydrachina cruenta.

2. The same, enlarged.

3. Another specimen, natural size.

4. The same, enlarged.

5. Limb, enlarged.

6. Spawn, enlarged.

7. Young from the same, enlarged.

8. Spawn of Hydrachna ferox, enlarget.

9. Hydrachence extendens.

10. The same, enlarged, back.

11. The same, enlarged, belly.

12. Spawn, natural size.

13. The same, enlarged.

14. Other spawn of the same, enlarged.

15. Yonng from fig. I4, enlarged.

16. Group of young from fig. 12, enlarged.

17. Empty spawn, the young having been discharged.

18. Portion of the same, enlarged.

19. Hydrachna geographica.

20. The same, enlarged.

21. Hydrachna caudata.

22. The same, enlarged.

23. Spawn of Hydrachna sparsa.

24. The same, enlarged.

25. Hydrachna punctata.

26. The same, enlarged. 


\section{Plate LXVIII.}

27. Fangs of the same, enlarged.

28. Hydrachna placida.

29. The same, enlarged.

\section{Plate LXIX.}

Fic. 1. Iydrachna ferox.

2. The same, enlarged.

3. Hydrachna spinifer.

4. The same, cnlarged.

5. Another specimen.

6. Hydrachna maculata.

7. The same, enlarged.

8. Hydrachna sparsa.

9. The same, enlarged.

10. Iydrachina varia, enlarged.

11. Hydrachna crassipes.

12. The same, enlarged.

13. Hydrachna albator, small.

14. The same enlarged, back.

15. The same, enlarged, belly.

16. Hydrachna albator, female.

17. The same, enlarged.

Now, let us panse awhile to inthlge a brief retrospect of the preceding observations. The have accomplished a general survey of a large proportion of the animated unirerse, for none other was in riew. Our progress has been slow and desultory; no rigid injunction prescribed the reverse of either,-nor was expedition or regularity enjoined. Thus we have not ventured to take a general nor a specific view of what may have been the leading incidents of that stupendous event,-the Creation. But the enlarged and magnanimous mind cammot fail to discover that a boundless blank, chilling and cheerless, must have overspread the Universe, for which the Divine Power has substituted an host of families of 
living beings, each abiding by its own nature. Doulttless peace and tranquillity occupied the regions of Paradise when originally diverted from solitude, though possibly for periods but short and fleeting,-if we siy so, it is done in profound ignorance, in all humility, for we canuot presume to affirm what might be the earliest of it, and what the latest, or whit the progress.

Neither the smaller nor the largest are called of the greater impurtance, nor do we know the influence either of light or of darkness.

Yet we may presume that only what was actually done proverl pleasing to the Ormipotent Being,-_or good in his sight. Firther, without arrogance, we may conjecture, that harmony alone predominated when the gates of Paradise were first nulocked,-that the lion and the lamb reposed together in peace.

If the earliest periods were so spent in harmony, by what were these succeeded? Did the sum still sink trancuilly beneath the horizon; did darkness overspread the earth? That could be displayed when his beans nshered in the morning of the second day, or of the third? When the preceding evening fell, did peace still prevail; or now, when sunshine procluims the truth, has the flesh of the lamb been piereed by the fangs: of the lion ; - were its innocent limbs besmeared by the bloody stains and remmants of its gore? Too much reason there is to believe, that the vices of animatecl nature, still revelling to our degradation, were already let loose, but that, through the Divine furour, we have gained the means of obliterating their revolting impression, or effacing their sanguintry conseruences.

The Powers of the Creator orer the creation adapt each created being to the peculiar place it shall occupy in the Universe.

We commenced our survey with strange and unusual objects, those of which an innumerable part of mankind have never heard, and which few have ever seen. But we found life vigorous in the Holothuria throughout a remarkable clistribution; nor was its distribution impaired, as we turned to the Asterias and Echinus.

Pursuing our irregular course, we reached other beings, whose or- 
gams, discharging the same functions, seemed to be multiplied an hundredfold.

But, multiplied or rednced, Divine farour still applied the whole to the purposes for which they were intended.

In advancing, we think we behold certain important organs misplaced. The mouth, the most prominent in front, or seated in the neck, or in the belly, - we behold one, or two, or a multitude of eyes, on the upper surface, or clusters on either side of the anterior portion,- - we see the limbs reduced or multiplied, the feelers probing the nature of what is presented to them.

Is not this the will of the Creator, who finds reason to modify or transpose the instrument of feeling, of sense and sensibility?

Were it omitted, all these might become nugatory and inefficient. But here is the magnitude of His power displined, and all for the benefit of the humbler works of the creation. It is needless, however, to descend to minutie,-let us abide by the magnitude of the incident, not of the object, for incidents are great and overpowering, while objects are trivial and diminutive; - we are seeking what is to occupy and enlarge the mind, not for what is to dazzle the eye, or to swell on the ear,-we retreat within ourselves, seeking a peaceful solitude in the reflection on the porrer and benignity of the Omuipotent. 


\section{ANALYTICAL INDEX}

TO VOL. I. OF

\section{THE POWERS OF THE CREATOR.}

CHAPTER I._ECHINODERMATA. • . . • . PAGE 17

Holothuria-difficulty of fixing its proper position in the Systema

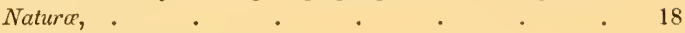

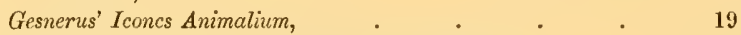

Specimen of the Scotica, Inharens, and Phantapus, . $\quad 20$

Holothurio dwell in the sea, . . . . ib.

Their true nature cannot be discovercd in a distempered state, . ib.

\$ 1. Holothuria pentactes, . . . . . . 21

General appearance of the Holothuria, . . . . 22

Holothuria pentactes, its size, members, \&c., . . . ib.

When detached generally float as long oroids, . . . 23

Suckers can be wholly retracted and sunk in the flesh, . ib.

Tentacula, in a quiescent state, retracted witbin the body, . 24

Absorbs water copiously, . . . . . . ib.

Colour various, . . . . . . . . ib.

None recovered from the sea fit for immediate study, . 25

Mr Henry Goadby's Lecture, . . . . . . ib.

Bohadsch, Mitller, Tiedemann, Delle Chiaie, . . 26

Holothuria pentactes dissected by Mr Goadby, . . . ih.

Respiratory Tree-Mr Goadby, Dr Knox, . . . $\quad 27$

Naturalists do not agree as to the nervous system-Delle Chiaie,

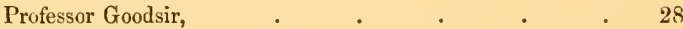

Natural form and habits-Mr Daniel White M'Culloch, . 29

Their safety depends on coolness, . . . . $\quad$. 30

Not so stationary as other species, . . . . . ib.

Tendency to rupture, . . . . . . . ib.

Mr Adams, Sir Edward Belcher, . . . . . . 31

Prolapse of the intestinal organs alike frequent, . . ib.

Food not ascertained, . . . . . . 32

Extreme timidity of the Holothuria, . . . . . ib. 
CIIAP'TER I.-continued.

Found about the mouth of the Forth, . . PAGE 32

Usual colour different shades of brown or purple, . . . ib.

Found floating like balls of various shapes, _ . . 33

Ampuda Poliana, . . . . . . . ib.

Mr Merrilees of Lerwick, . $\quad$. $\quad$. $\quad$ ib.

Plates I., II., III., IV., V., VI., VII., VIII., explained 34

$\$ 2$. Holothunia fusus,-The Spindle Sea Cucumber or Sweepwater, 35

Specimen from the north-eastern part of the Forth, . . ib.

Size, form, and peculiarities, $\quad$ o $\quad$ o $\quad$. 36

After sunset shoots out eight luxuriant, arborescent tentacular organs, 37

The tentacula seem a vegetable product, . $\quad$. 39

The beautiful arborescent apparatus becomes a wide shallow. funnel at night, . . . . . . . ib.

On the slightest shock, or intrusion of light, the whole apparatus is quickly withdrawn, . $\quad . \quad$. $\quad . \quad$. 40

The Tentacula distended by a fluid, . . . ib.

Use of the tentacula uncertain-probably designed for an alimentary purpose, . . . . . . 41

The intestine always full of a soft brown or yellowish matter, . 42

Quantity of animal matter iu a Holothuria equivalent to what is in a rat or weasel, . . . . . . . . 43

Delle Chiaie, . $\quad$. $\quad$. $4 \quad$. 44

Food of the Holothuria still problematical, . . . ib.

Borly covered by flexile, extensile papillæ-not with a tube, 46

When quiescent, the skin resembles sbagreen; prolonged, the body is invested by a woollen-like coat, . . . i ib.

The suckers overspread the whole skin-when disengaged each has an independent action, . . . . . ib.

Advances head foremost - the fore and hind suckers alternately re-

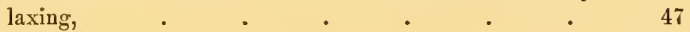

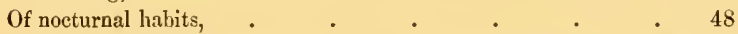

Holothuria pencillus must be expunged from the Systema Naturce, 49

After entire mutilation new tentacula produced, . $\quad 51$

Propagation, . . . . . . . ib.

None of the spawn proved fertile, . . . . 54

The whole organic mass separated from the body, death in consequence, 55

Such mutilation ascribed to accidental causes, . . $\quad 56$

Holothuria fusus found about Orkney and Shetland, and the estuary of the Forth, . . . . . . $\quad .57$

Professor Goodsir, . . . . . . .

Species of the Holothuria multiplied beyond the truth, . $\quad 58$

of various colours, . . . . . . . . il. 
CIIAPTER I._continued.

Holothuria fusus readily covers itself with extraneous matter, PAGE 59 Doubtful if any individual of the species is exempted from mutilation, 61 Some of Delle Chiaie's specimens survived loss of intestines fifteen days, ib. If the intestines are evacuated by the anterior extremity regeneration commouly replaces them; if by the posterior, death invariably ensues,

The nature of what is called Trepang, or Beche de Mer, so perplexing to naturalists, perhaps determined, . . . ib.

Propagation, . $\quad . \quad 6 \quad$. $\quad . \quad 63$

Bohadsch, Tyermaux, Bennet, Beale, . . . ib.

Scottish Holothurix free of offensive odour-Bosc, _ . $\quad 64$

Most farourable abode of the Holothuria fusus is in deep water, $\quad 65$

Plates VIII., IX., X., XI., XII., explaincd, . 66

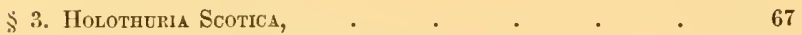

IIistory of the Holothuria imperfcetly understood, . . . ib.

Difficulty of identifying the different species, . . $\quad 68$

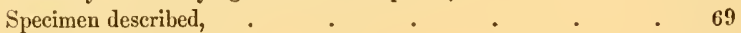

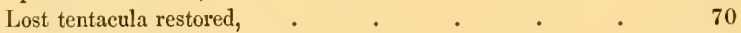

Habits the sarne as the fusus, . . . . . 71

Two other specimens, white, . $\quad$. $\quad . \quad 4 \quad 72$

Plates XII., XIII., explained, . . . . . ib.

§ 4. Holothuria Bodotri

Professor Forbes on Echinodermata, . . . . ib.

Nore irregular shape than the preceding species, . . $\quad 73$

Form and organs described, . . . . . . ib.

Tentacula aud antennulie not so luxuriant as the fusus, . il.

Little difference in its habits, . . . . . ib.

Some spccimens pure white, others yellowish brown, . 74

Dwells in the Forth, from Inch Keith to Mar Bank, . . ib.

Divides itself into two or more parts spontaneously-each regener-

ating the defective organs, . . . . ib.

Mode of progression solved, . . . . . . ib.

No precise rule governs the time of division, . $\quad$. $\quad 75$

Before division the animal assumes the figure of a sand-glass, $\quad 77$

Renovated tentacula of the purest white, . . . 78

Food of the animal yet undiscovered, . . . . ib.

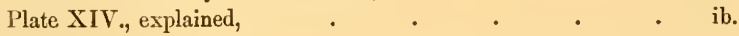

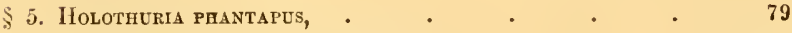

Most remarkable of the whole species, . . . . . ib. 
CHAPTER 1.-continued.

The difference in form and parts described, . PAGE 80

One of the largest specimens about four inches and a half long, $\quad 82$

When laid open, six strong, muscular bands run down the whole length, 83

Plate XV., Holothuria phantapus, . . . ib.

Holothuria elegans of Mï̈ller, . . . . . 84

Holothuria evidently a local creature, . . . . ib.

Large and fleshy species said to serve as food at Naples, . ib.

Few naturalists hare studied from living specimens, $\quad 85$

Holothuria,-summary of details, . . . . ib.

Little known of their habits in their native state, . . . 86

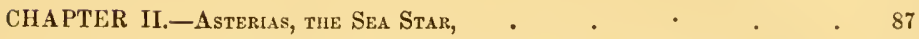

All inhabit the sea-no similar animal found in fresh water, ib.

Considerable variety in their organization, . . . . ib.

In the water they lave a swift, gliding motion, as if nearly buoyant, 88

Deprived of water they soon fall from the sides of the glass to the bottom, ib.

Crawl into fissures for protection when the tide ebbs, . . 88

Swarm throughout the Scottish seas in great rariety, . ib.

They are voracious and carnivorous, . . . . ib.

Their alleged destruction of oysters improbable, . . . ib.

Not the ray's of the star-fish which its prey may dread, but its mouth, 90

Their habits, . . . . . . ib.

Grow to a large size, . $\quad$. $\quad$. $\quad$. $\quad$. $\quad$. 91

Number of organs not uniform in these animals, . . ib.

All are cold, rigid, and disagreeable to the touch, . . ib.

Subject to frightful mutilations, . . . . ib.

If death does not ensue, the lost organs are replaced, . $\quad$ ib.

The aspect of individuals vary much, both in form and colour, ib.

Presents many beautiful patterns for imitation in the arts, . $\quad 92$

Surface subject to continual alteration, . . . ib.

Mode of perpetuation obscure-roe generated in spring and adrances

to maturity in summer, . $\quad . \quad$. $\quad$. $\quad 92$

Ovaria determined by the species, . . . . . 93

The embryo animal originally circular, . . . . ib.

Star-fish live many ycars-may be divided into two sections :-
I. The Asterias. II. The Ophiura, . . . ib.

SECTION I.-§ 1. Asterias glacialis.-Northern Sea Star, Cross-fish, 93

Abundant in the Scottish seas, . . . . . ib.

Form and organs, . . . . . . . . 94 
CHAPTER II.-continued.

Most large, powerful, and ravenous of its kind, _ PAGE 94

Purple secms the natural colour, . . . . . ib.

Inactive, it is contracted and apparently helpless, . . ib.

Food, . . . . . . . . . . . 95

Ovarium, . . . . . . . . . 96

Spawn long of attaining maturity, . . . . . ib.

Extremely subject to mutilation of the rays, . . . ib.

I'late XVI., explained, . . . . . . ib.

\$ 2. Asterias rubens,-Reddish-yellow Sea-star, . . . 97

Extremely variable in colour, . . . . ib.

Resembles the previous specimen, . . . . ib.

One specimen fifteen incbes between the extremities of the rays, ib.

Form, organs, ovarium, \&c., . . . . . . ib.

Subject to mutilatiou of the rays, . $\quad$. $\quad$. $\quad$. 99

Reproductive energies powerful, . . . . 100

Mutilation not incident to size or age, . . . . . ib.

Same facts apply to both tbe glacialis and rubens, . 101

Plates XVI., XVII., XVIII., XIX., explained, $\quad 102$

\$ 3. Asterias (cribella) oculata.-This animal is readily recognised, ib.

Its appearance and organs described, . . . ib.

Food, . . . . . . 103

The young bear no resemblance to the adult, . . ib.

Shelters itself under rocks and stones, . . . . . ib.

Plate XX, explained, . . . . . . 104

\$ 4. Asterias aranclaca, . . . . . . . . ib.

Size, organs, colour, \&c., . . . . . . . . . ib.

Propagation, . . . . . . . . 105

Not common, . . . . . . . . ib.

Plate XXI., explained, . . . . . . ib.

§ 5. Asterias endeCA,-Nine-rayed Star-fish, . . 106

One of the larger and more beautiful inhabiting the Scottish seas, ib.

Description, . . . . . . . . . . ib.

Ora, . . . . . . . . . ib.

Not common, . . . . . . 107

Plates XIX., XXII., XXIII., explained, . . . . 108

\$ 6. Asterias (Solaster) papposa, . . . . ib. 
CHAPTER II.-continued.

One of the largest, singular, and beautiful dwelling in the Scottish seas, 108

So remarkable as almost to defy description, . . . ib.

Its peculiar characteristics, . . . . 109

Glandular specks not supposed to be organs of vision, . . 110

Feeds voraciously on mussel and even their own species, . 111

The sucker resembles the proboscis of an elephant, . . 112

All very tenacious of life, . . . . . . ib.

Ovarium, . . . . . . . . ib.

The oraria advance from April until July, . . . ib.

Named Kelle, or Te Kelle, by the Scottish fishermen, . 113

Plates XXIV., XXV., XXVI., explained, . . . ib.

SECTION II.-Ophidra bracteata,-Plate-mail Star-fish, . ' . ib.

Ophiura prominently distinguished from other star-fish, . 114

Chief distinctions described, . . . . . . ib.

The form probably undergoes considerable modification with age, ih.

Size and vigour depend upon locality and sustenance, . $\quad$ ib.

Some live in deep water, \&c., . $\quad . \quad$. $\quad . \quad 115$

Extremely numerous, $\quad . \quad$. $\quad . \quad$. $\quad$ ib.

\$ 1. Appearance, form, and organs described, . . . . ib.

Feeds voraciously on mussel, . . . . . . ib.

Sometimes has a disagreeable odour after feeding, . . . ib.

Mutilation of the rays particularly incident, . . . . ib.

Propagation, . $\quad . \quad$. $\quad . \quad$. 116

Ovoid capsules compose the spawn, . . . . . . ib.

Specimens of six inches have been replete with ova, . $\quad$ ib.

Plate XXVII., explained, . . . . . . ib.

$\$ 2$. Ophitra vulgaris, $\quad$. $\quad$. $\quad . \quad$. $\quad 117$

Most common and numerous of any species, . . . ib.

Distinguished by the profusion and distribution of colours, ib.

Best specimens found in the northern seas of Scotlaud, . ib.

Disc small in proportion to the animal, . . . ib.

Undergo great changes in attaining the adult state, . . ib.

The riys particularly liable to mutilation, . . . . ib.

Plate XXVIII, explained, . . . . . . .

\$. Ophiura Punctata, . . . . . . . 118

The largest species belonging to the Scottish seas, . . ib.

The finest specimens expand to more than eight inches, . ib. 
CHAPTER II.-continued.

Description, . . . . PAGE 11 i

Plate XXIX., explained, . . . . . . . o ib.

Miseellaneous observations, . . . . . ib.

Conatula barbata, . . . . . . 120

This animal nearly allied to the Ophiura, . . . ib.

Form, organs, and habits, . . . . ib,

Liable to great mutilation, . . . . . . ib.

Food unknown, . . . . . . . 121

Not so rare in Orkncy as elsewhere in Scotland, . . ib.

Plate XXX., explained, . . . . . . . ib.

Echinus, the Sea Urchin, . . . . . ib.

Observations of reputable authors imperfect, . . . ib.

Insufficiency of Artists, \&e., . . . . . 122

§ 1. Echinus SpIlara, . . . . . . 123

Size, organs, peeuliarities, and habits, . . . . ib.

Spines of use in prehension or seizure, . _ . . $\quad 126$

Can travel on its back by means of the spines and suckers, . ib.

Carries everytbing useful or useless on its back, . . . ib.

The spines are deeiduous, but reproduetion restores them, . ib.

Divested of the spines the shell resembles an orange, . 127

Colour darkens with age, . . . . . . 128

Shell about the sixteenth of an ineh thick, . . . ib.

Planked like the hull of a vessel, . . . . ib.

Orifiee above surrounded internally with the ovarium, . ib.

If uninjured is not of diffieult preservation, . . . 129

Natural propensity to destroy, . . . . . ib.

Reputed to have been used as food by the ancients, . . ib.

Said to lave been formerly brought to the Edinburgh Market for

the sake of the roe, . . . . ib.

One species denominated Eclinus edulis, . . . . . ib.

Animal deseribed, . . . . . . . 130

Pedicellaria corer the Eehinus in thousands, . . . 131

The head separates from the stalk, . . . . 132

Not separate and independent parasites, . . . . . ib.

Plates XXXI., XXXII., explained, . . . ib.

\$ 2. Echinus (Spantangus PUrpureus), . . . 133 Another kind of Eehinus, . . . . . ib.

Very different in form, and less familiar to naturalists, . ib.

Called Man's face, and Monkey face, by the Scottish fishermen, ib.

Belongs to deep water, and is often permanently buried in the sand, ib. 


\section{CHAPTER II.-continued.}

Perhaps the largest Scottish shell animal, the crustaceous race excepted, . . . . . . PAGE 133

Rudely resembles a flattened heart, .. . . ib.

Two specimens each five inches in lengtl, . . . . ib.

Description, . . . . . . . ib.

Usually sunk in the sand, of which it swallows an enormous quantity, 135

Plate XXXII., explained, . . . . . . ib.

\$3. Spataxgus (flavescens), -Nireus, . . . . . ib.

Fine delicate-looking animal, somewhat lieart-shaped, . ib.

Largest specimens two inches and a-half in length, . . . ib.

Three or four kinds sufficiently definite, . . . 136

Form, organs, \&c., . . . . . . . . ib.

Burrows in the sand at various depths,-rather a scarce animal, ib.

Plate XXXIII., explained, . . . . . . 137

Miscellaneous remarks regarding the term Eclinodermata, ib.

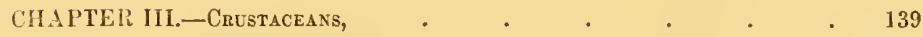

Sublivision resting on analogy essential, . . . . . ib.

The observer ought to preserve an accurate record of facts, . ii.

Crustacea form an immense class, . . . $\quad 140$

Great rariety, and as yet imperfectly known, . . ib.

The shelly covering leads to singular physical consequences, ib.

It is frequently renovated, . . . . . . 141

Shells of living crustaceans of various colours, . . ib.

Some naturalists have viewed the animals as near akin to inseets, ib.

Shell composed of numerous parts or segments, . . ib.

Crustaceans provided with a number of limbs, by which the genera is founded, . . . . . . . 142

The Decapodes, or those with ten limbs, the most familiar, . ib.

Iotion of the crustaceans is chiefly walking or running, . ib.

Harbour generally among rocks and stones, . . . ib.

The senses, especially of sight and smelling, very obtuse, . ib.

Gencrally carnivorous, . . . . . . 143

A few gencra confine themselves to land vegetable products, ib.

Some of them of a most contentious nature, . . . ib.

The Actinia a deadly enemy, . . . . . ib.

Frequent change of water essential to the preservation of specimens, 144

In the living animal the claws are open and the tail closed-the

reverse is the case when death ensues, . . . ib. 


\section{CHAPTER III.-continued.}

The Cancer monas kill and devour one another, . . PAGE 145

Crabs and Lobsters eagerly sought after as food, . . ib.

Imported from Norway to the London market; and some of the Western Isles are said to yield 60,000 annually, . . 146

None but rocky coasts are frequented by Lobsters and Crabs, ib.

The common Crab and Lobster ouly used for food in Scotland,not so in the Adriatic, . . . . . ib.

Some genera so peaceable and inactive, that many specimens are overgrown with marine regetables, . . . ib.

Progeny of a single Crab, sparel for two seasons, would probably satisfy 10,000 people, . . . . . 147

The sexes distinguished by the shell, . . . . ib.

The roe adheres to the shell of the female until the foetus bursts the egg, 148

A few tribes of Crustacea discharge the ova through long tubes, ib.

Most Crustacea undergo great changes in their progress to maturity, ib.

An error to imagine that animals protected by a hard integument undergo no alteration with the loss of life, . . . $\quad 149$

Habits of the crustaceans extremely diversified, . . ib.

Death simulated to escape danger, . . . ib.

The integument of some is horny or coriaceous, ․ 150

The crustacean tribes treated of divided into three portions, ib.

PART I. A.-Decapodes, ten-limeed, short-tailed Crabs,-Brachyuri, ib.

§ 1. CANCER MIENAs,-The Shore or Harbour Crab, . . ib.

Its form and organs, . . . . . . 151

Crustacean class compared to insects, . . . . ib.

Dr Milne Edwards, . $\quad$ - . . . 152

Principal divisions not more than two in the erab, . . ib.

Green the prevailing colour, . . . . ib.

Habits and disposition, . . . . . 153

Food, . . . . . . . . ib.

External integument an indurated shelly covering, . . 154

Occurs of all difierent dimensions, . . . . ib.

At certain seasons the limbs full of flesh, . . . ib.

Acquires a new shell when the old is insufficient, . . ib.

The change effected again and again, . . . . 155

Specimens about to exuviate usually dull, heavy, and inactive, 156

The animal escapes from the hind part of the shell, . . ib.

Specimen from Blackness Castle-its exuviation, . . 157

Became very tame-something like memory demonstrated, . 158

Exuriation verified by another specimen, . . . 159

Female spawned after eighteen months, . . . 161 


\section{CHAPTER III.-continued.}

Reproduction of defective parts, . . . PAGE 162

Perpetuation, • . $\quad$. $\quad . \quad$. 164

Plates XXXIV., XXXV., XXXVI., XXXVII., explained, 166

A.—§ 2. Cancer Pagurus, -The Common Crab, . . 167

This species most familiar when in maturity, . . . . ib.

Dimensions depend on subsistence, $\quad$. $\quad$. . . ib.

The Common Crab the largest and strongest in Scotland, . 168

Form and organs of Cancer pagurus described, . . ib.

Fierce and rapacious-its food, . . . . ib.

Dr Duguid, Kirkwall, . . . . . .

Extraordinary exuriation-lost limbs restored, . . 169

Death from the immaturity of certain parts at exuviation, $\quad 170$

Limbs of the new animal, while in the original shell, folded across

its breast, . . . . . . ib.

No one has seen a large Common Crab white, . . . $\quad .171$

Shell, though repeatedly regenerated, of the same colour, . 172

Specimen, on exuviation, defective of eight limbs, . . ib.

Next change the limbs wholly restored, . . . 173

New animal and its organs must be concentrated within the original shell, . . . . . . .

Colour reddish-brown, $\quad$. $\quad$. $\quad$. $\quad$. $\quad 174$

Permanent symmetry, by successive exuviations, restored from dedefects of four-fifths of its important organs, . . 175

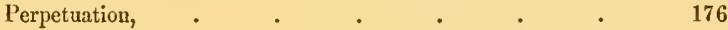

The Crab-fishery neither a lucrative nor favourite employment, 177

Plates XXXVIII., XXXIX., XL., XLI., LXX., explained, 178

§ 3. Cancer (portunus) lividus, -The Flying Crab, . . ib.

Beautiful and symmetrical animal, decked in lively colours, . 179

Its organs and form described, . . . . . 180

Shell stained by various colours, red, blue, and white, _ ib.

Food, . . . . . . ib.

One of the most prolific of the tribe, . . . . . 181

None of the roe productive, $\quad$. $\quad . \quad 4 \quad . \quad 182$

This animal less contentious than some of the others, . . 183

Plates XLII., LXX., described, . • . .

\$ 4. Cancer (portunus) pusillus,-The Sand Crab, . . ib.

One of the smaller species-its form, colour, \&c., . . 184

Food, . . . . . . . . 185 
CHAPTER III.-continued.

Reproduction of the shell, . . . . PAGE 185

Numerous young burst their capsules, . . . . . 186

Exuviation sometimes very suddenly, . . . . $\quad 187$

Chief breeding seasons, April and May, . . . ib.

This species somewhat rare, _ _ _ _ . 188

Plates XLIII., XLIV., explained, . . . . . ib.

§ 5. Cancer (Pinnotheres) veterum, $\quad$. $\quad 189$

One of the smaller animals inhabiting the Scotish seas, . it.

Associates with the Mytilus modiolus, . . . ib.

Dr Leach, Mr W. Thompson, and Mr T. V. Thompson, ib.

Enters some bivalve shell and dwells in peace with the owner, 190

Size, appearance, and organs, . . . . . ib.

Propagation of young, . . . . . . . . ib.

Plate XLV. explained, . . , . 191

\$ (1.) Cancer (porcellana) LONGicornis, - The Ventilating Crab, ib. Smallest of the Scotish crabs, . . . . ib. Its form, organs, de., . . . . . . . . Extraordinary development, the pedipalpi, . . . 192 This species very tranquil,. . . . . . . ib. Food, perpetuation, \&c., . . . . . . ib. Plate XLV. explained, . . . . . . ib.

§ (2.) Cancer (porcellaxa) Platycheles,-Rough-footed Crab, . 193 Form, organs, food, \&c., . . . . . . . ib. None of the specimens ever fed, . . . . . ib. Plate XLV. explained, . . . . . . ib.

C .-Cancer (corystes) Cassivelaunus, . . . . . ib. Form, \&c., described, . . . . . ib. Dwells in deep water, and rarely seen, . . . . ib. Plate XLVI, explained, . . . . . . . . ib. General remarks on Crustaceans _ . . . . 194

D.-1. Cancer (1nachus) Dorsettensis, . . . ib. Form so marked as not to require description, . . ib. Specimens dwell together in peace, . . . . ib.

D.-2. Hyas araneUs, - . . . . 195 Dr Leach-two British species, Hyas araneus and Hyas coarctatus, ib. 
CHAPTER III.-continued.

Variety of aspect great-size, form, \&c., . . . PAGE 195

Ora, . . . . . . . . ib.

Extremely languid-deep water its proper dwelling, . ib.

Shell often totally invested by marine algæ, . . 196

Plates XLVII., XLVIII., explained, . . . ib.

D.-3. Cancer (hyas) coarctatus, . . . . . ib.

Torpidity irresistible, . . . . . ib.

Specimen described, . $\quad . \quad$. $\quad . \quad$. $\quad 197$

Small one washed on board a steam-ressel between Orkney and

Shetland, . $\quad . \quad$. $\quad . \quad$. $\quad . \quad 198$

Plate XLIX. explained, . . . . . . ib.

§ (4.) Cancer phalangium, Macropodia phalangidm; Leach,-The

Spider Crab, . . . . . . ib.

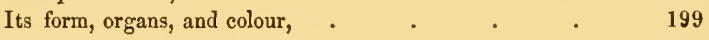

Weak and incapable of resistance, . . . . . ib.

Perpetuation, . . . . . . . . ib.

Senses alike obtuse as in other species, . . . . ib.

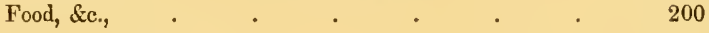

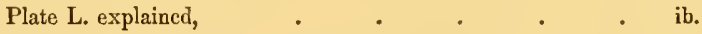

§ (5.) Cancer horridus, Maia lithodes-The Prickly Crab, . 201

Dr Leacb, . • • . • . . ib.

Size, appearance, and organs, . $\quad$. $\quad$. $\quad$. $\quad$ ib.

Spawn cavity, . . . . . . . ib.

Colour, . . . . . . 202

Plates LI., LII., explained, ib.

PART II, A.-Decapodes, ten-limbed, long-tailed, Crustaceans,-Macrouri, ib.

The Macrouri comprehend the Astacus, or Lobster, and its congenera, ib.

Difference between the Cancer and Astacus great, . 203

\$ 1. Cancer Bernhardus,-The Hermit Crab or Soldier, . . ib.

General remarks, . . . . . ib.

Form, organs, size, and colour, . . . . . . ib.

Food-lively and voracious, . . . . . 204

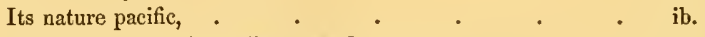

Process of exuviation different, and more obscure, . ib.

Breeds at an early age, and somewhat differently from the Cancer, 205

The young bear no resemblance to the parent, . . 206 
CHAPTER III.-continued.

April the chief brecding season, . . . PAGE 206

Plates LIII., LIV., explained, _ . . . 207

§ 2. Galatge" spinigera,-The Thorny Bastard Lobster, . ib.

One of the most beautiful, curious, and symmetrical of the tribe, ib.

Form, size, organs, \&c., described, . . . . 208

Motion singular and velement, . . . . ib.

Propagation, . . . . . . . . 209

Exuviation, $\quad . \quad$. $\quad . \quad$. $\quad . \quad$. 210

This species presumed to be migratory, . . . ib.

Plate LV. explained, . $\quad$. . . ib.

B.-Decapodes, ten-himbed, long-talled, Crustaceans,-Macrouri,

Astacus, the Lobster, . . . . 211

The form of this genus differs considerably from that of the Crab, ib.

$\S$ 1. Astacus Norvegicus, Linncus, Norwegian Lobster, ib.

Beautiful, lively, and active creature,-perhaps migratory, 212

Fabricius, Fauna Groenlandica, . . . . ib.

The animal described, . . . . . . $\quad$ ib.

The ovarium, $\quad$. $\quad . \quad$. $\quad$. 214

Plate LVI., LVII., LXX., explained, . . . . ib.

Called the Cray fish by fishermen, . . . . ih.

Fresh water Cray fish not natural to Scotland, . . 215

From the ova Rathke traced the progress of the embryo, . ih.

Said to dwell chiefly in muddy streams, . . ib.

§ 2. Astacus marinus, - The Common Lobster, . . . ib.

Thongh familiar its history little known, . . ib.

History and description of specimens, . . . ib.

Ova, . . . . . . . . . 216

Mr Gillespie Graham,-gigantic claw, . . . . ib.

Lobster fishing in the Western Isles for the London market, ib.

Plates LVIII., LIX., explained, . . . 217

§ 3. Crangon,-The Shrimp, . . . . . .

Learned authors say little of the Shrimp, . . . ib.

Size, form, \&c., . . . . . . .

Lively creature, and rery tame, . . . . . 218

Carnivorous, . . . . . ib.

The shell often cast, but without any preliminary indication, ib. 
CHAPTER III.-continued.

Propagation, PAGE 219

Its natural abode smooth, sandy shallows, near the sea shore, ib. Plate LX., LXI., explained, $\quad 219,220$ Note,-appendix to preceding paragraph, . . 220

\$4. Pandalus annulicornis, - The Ring-horn Shrimp,-Leach, . ib.

Not identified with the genus Crangon, . . . ib.

Description, . . . . . . ib.

Exuviation ensues at all seasons, . . . . $\quad 221$

One of the genus named Ilippolytus by Dr Leach, . . ib.

Plate LXI. explained, . . . . . . ib.

CHapteR IV.-Mrscellaneots Crustaceans, . • . $\quad 222$

Many subordinate genera to the Crab and Lobster, . ib.

§ 1. Cancerilla tubulata, . . . . . . 223

Account of a parasite attached to a young Ophiura, and named as above, . . . . . . . ib.

Plate LXII. explained, ․ . . . 224

\$ 2. Astaricilla, . $\quad$. $\quad$. . . . . ib.

Mr Montagu describes a mutilated specimen, . . $\quad 225$

Form, organs, length, \&c., . . . . . . ib.

Ovarium, young, \&c., . . . . . . ib.

Plate LXII. explained, 226

\$3. Astagilla longicornis, . . . . . ib.

Distinguished by singular appearance and habits, . . ib.

Form and organs described, . . . . . ib.

Considered by some a species of Oniscus, . . . . 227

Its motions rery singular, . . . . ib.

Plate LXIII, explained, . . . . . . ib.

Exuviation took place in October, . . . . ib.

Propagation from March to December, . . . ib.

Progress described, . . . . . . . 228

Animal dwells in deep water, . . . . . ib.

Plate LXIII. explained, . . . . . $\quad \mathrm{jb}$.

§ 4. ONisces balthicus (IDEotfa Marina), . . . ib.

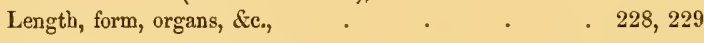


CHAPTER IV.-continued.

Feeds voraciously, and swims swiftly, . . PAGE 229

Exuriation at different seasons, . . . . ib.

Plate LXIII. explained, . . . . . . ib.

\$5. Oniscus (IDEotea) entomon, . . . . . ib.

Baron de Geer had never seen a living specimen, . . ib.

Animal deseribed, length, form, organs, \&c., . . . $\quad 230$

Darts swiftly through the water, . . . . ib.

Feeds greedily on animal substances, . . . . . ib.

Plate LXIII., explained, . . . . . . ib.

\$ 6. Asellus MEDUS正, . . . . . . ib.

Two parasites frequent the Medusa, resembling the Cyclopean race among the Entomostraca, . . . . ib.

Length, organs, \&c., . . . . . . ib.

Dwells as a parasite on the Medusa-swims swiftly, . 231

Spawn, . . . . . .

Plate LXII. explained, . . . . .

B.-Asellus Meduse, . . . . . . . 232

Form and habits described, . . . . . ib.

C.-Cyclots stagnorem, . . . . . . ib.

Observations of Baron de Geer, Müller, and Baird, . ib.

Cyclopean race characterised by one eye only, . . ib.

Animal described, . . . . . . 233

Ova, . . . . . . . ib.

Inhabits fresh-water pools, . . . . . ib.

Plate LXII. described, . . . . . . ib.

D.-Cyclops punctatus, . - . . . . ib.

Cyclopean race dwell both in the fresh-waters and in the sea, ib.

Punctatus a minute animal, \&c., . . . . ib.

Moves swiftly by jerks through the water, . . . 234

Plate LXII. explained, . . . . . ib.

E.-Crclors fasciatus,-Belted Cyclops, . . . ib.

Its form, \&c., described, . . . . ib.

Plate LXX. described, . . . . . . ib.

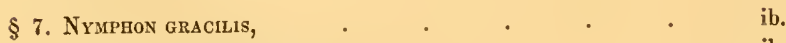

Styled the Spider Crab, . . . . . . ib. 
CHAPTER IV.-continued.

Its slender form described, . . . . PAGE 234

Languid, and of a tranquil disposition, . . $\quad 235$

Prolific female, . . . . . . ib.

The young and their organs, . . . . ib.

The animal dwells in the sea, . . . . . 236

Plate LXIV. explained, . . . . . . ib.

\$ 8. Pycxogonum littorale, - The Whale Louse, . . ib.

Unlike the preceding, this animal is coarse and strong, . ib.

Its form, \&c., described, . . . . ib.

Most languid of all creatures, and without propensities, . ib.

Great disparity of size, . . . . $\quad 237$

Plate LXIV. explained, . . . . . . . . ib.

Note,-Pycnogonum,-Mr Henry D. S. Goodsir, . ib.

\$ 9. Asellus vulgaris, . . . . . . . . ib.

Doubtful if this animal has been assigned its proper position in the Systema Natura, . . . . . . $\quad 238$

Though rare, it abounds in a pond at Red Braes, near Edinburgh, ib.

Coarse, repulsive animal, called the Slater in Scotland, . ib.

Its form, . . . . . . . . . ib.

Does not swim, but runs, . . . . . . . . $\quad$ ib.

Propagation, . $\quad$. $\quad$. $\quad$. $\quad . \quad$ ib.

Exuriation less frequent than amongst other Crustaceans, . 240

Extremely pacific and tranquil, . . . . ib.

Plate LXV. explained, . . . . . . ib.

\$ 10. Linnoria terebrans, . . . . . 241

Attention directed to this insect in 1826 by its ravages on the Chain Pier, . . . . . . ib.

Dr Coldstream's observations, . $\quad$ - $\quad$ - 242

Dr Leach instituted a new genus for its reception, . ib.

Its form, organs, \&c., described, . . . . . ib.

Much diversity of size prevails, . . . . . ib.

Orarium, . . . . . . . . . . ib.

Food-the wooden piles, . . . . . . ib.

Various remedies found unavailing, . . . . 243

Plate LXV. explained, . . . . . . . ib.

\$ 11. Cypris rilosa, . . . . . . . . ib.

Usually associated with the species named Entomostraca, 244

Genus Cypris includes several species, . . . . ib. 
CHAPTER IV.-continued.

Form, size, \&c., described, . . . . PAGE 244

Its shell reproduced, . . . . . . ib.

Dwells in still, fresh waters, . . . . . ib.

Breeds in September and October, . . . . ib.

Plates LXII., LXX., explained, . . . . 245

Crpris Forthensis, . . . . . . ib.

Inhabits the Forth, . . . . . . o ib.

Colour and action, . . . . . . . ib.

Plate LXX. explained, . . . . . . ib.

CHAPTER V.-PARAsites, . . . . . . . . 246

Man incapable of determining the cause and use of everything, ib.

§ 1. Caligus curtus, . . . . . . . .

This one of the plagues which nature permits, . . ib.

Form and organs described, . $\quad$. $\quad$. $\quad$. 247

Plate LXVI. explained, - . . . . . ib.

Descriptions of authors-Mïller, Baster-discordant, . ib.

Organs farther described, . . . . . . 248

Fish, especially the Cod, infested by it, . . ib.

Itself infested by a minute white leech, . . . . ib.

Embryos, . . . . . . . . 249

Undergoes a change in its progress to maturity, . . ib.

Shell frequently speckled red, . . . . . . ib.

\$2. Caligus salmonis, . . . . . . . . .

This parasite said to infest the Salmon, . . ib.

Size, form, \&e., . . . . . . . $\quad$. 250

Plate LXVII. . $\quad$. $\quad$. . .

\$ 3. Caligus, . . . . . . . . ib.

Mentioned as a distinet species in the work of $\mathbf{M r}$ Adams, ih.

Plate LXVI. explained, . . . . . . ib.

LERNAA . . . . . 251

LERNAA BRANChIALIS, . . . . . . ib.

A most destructive parasite, . . . . . ib.

Description, . . . . . . ib.

Plate LXXVI. explained, . . . . . $\quad 252$

\$ 4. Botryllofer, . . . . . . . ib.

Doubtful whether a Crustacean and a parasite, . . ib. 
CIIAPTER V.-continued.

Deseription,

Plate LXVII, explained,

$\S 5$. Pegasillus hirsutus,

Did not quite maintain the eharaeter of a Crustacean parasite,

History and description,

Plate LXII., explained,

ib.

ib.

ib.

ib.

CIIAPTER VI.-The Hydracha, or Water Spider, . ～. . . 254

The genus Hydrachna deseribed, . . . . ib.

Miiller, Linneus, . . . . . . . 255

Animals distinguished by eight feet, . . . . ib.

Dwell chiefly in fresh water, . . . . 256

Sensitive of heat or cold, . . . . . $\quad 257$

Habits possibly modified by situation, . . . ib.

Pass the night in profound repose, . . . . 258

Most rapacious, bold, and cruel, . . . . . ib.

Hydrachna ferox, . . . . . . ib.

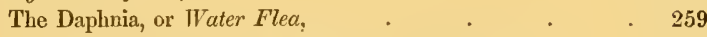

Number of Daphnize destroyed by the Iydrachna ferox, . ib.

Hydrachna extcndens of Nüller, . . . . 260

IIydrachna placida deseribed, . . . . . 261

Food of the Hydrachne, . . . . ib.

Breed at different periods of the year-Miiller, M. Dugés, . ib.

Spawn deposited on leaves, wood, or stone, . . ib.

Embryo attain maturity in fourteen days, . . . $\quad 262$

M. Dugés, Annalcs des Sciences Naturelles, . . 264

Plate LXVIII., I,XIX., explained, 265, 266

Conclusion, . $\quad . \quad 2 \quad . \quad 266$ 



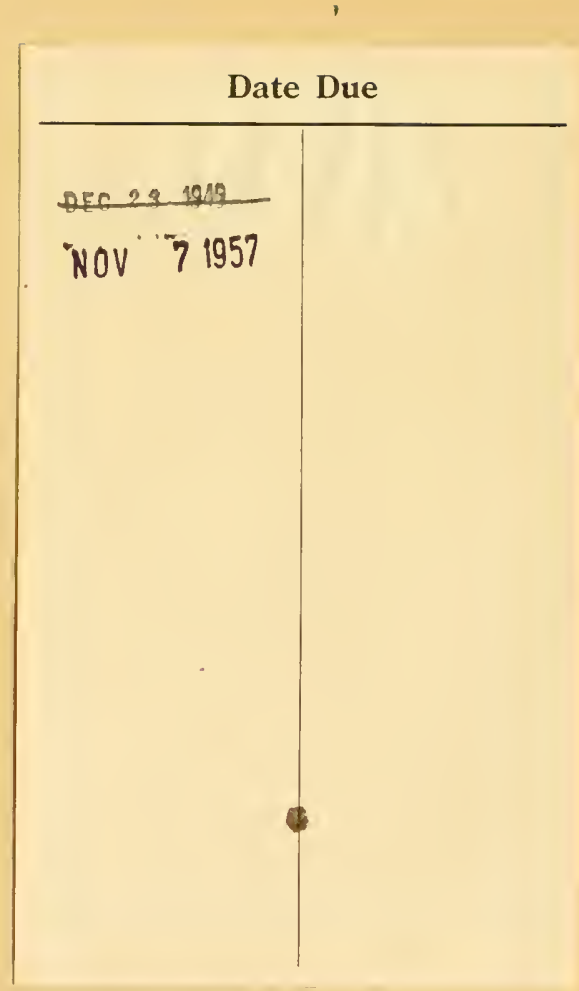


